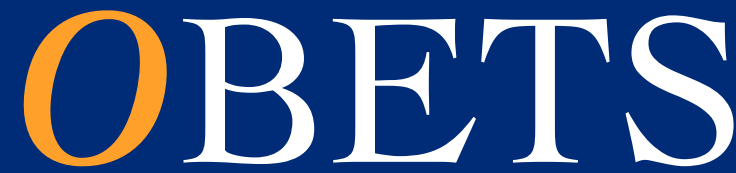

Revista de Ciencias Sociales

$$
\text { vol.9 } \cdot n^{\circ 2}
$$

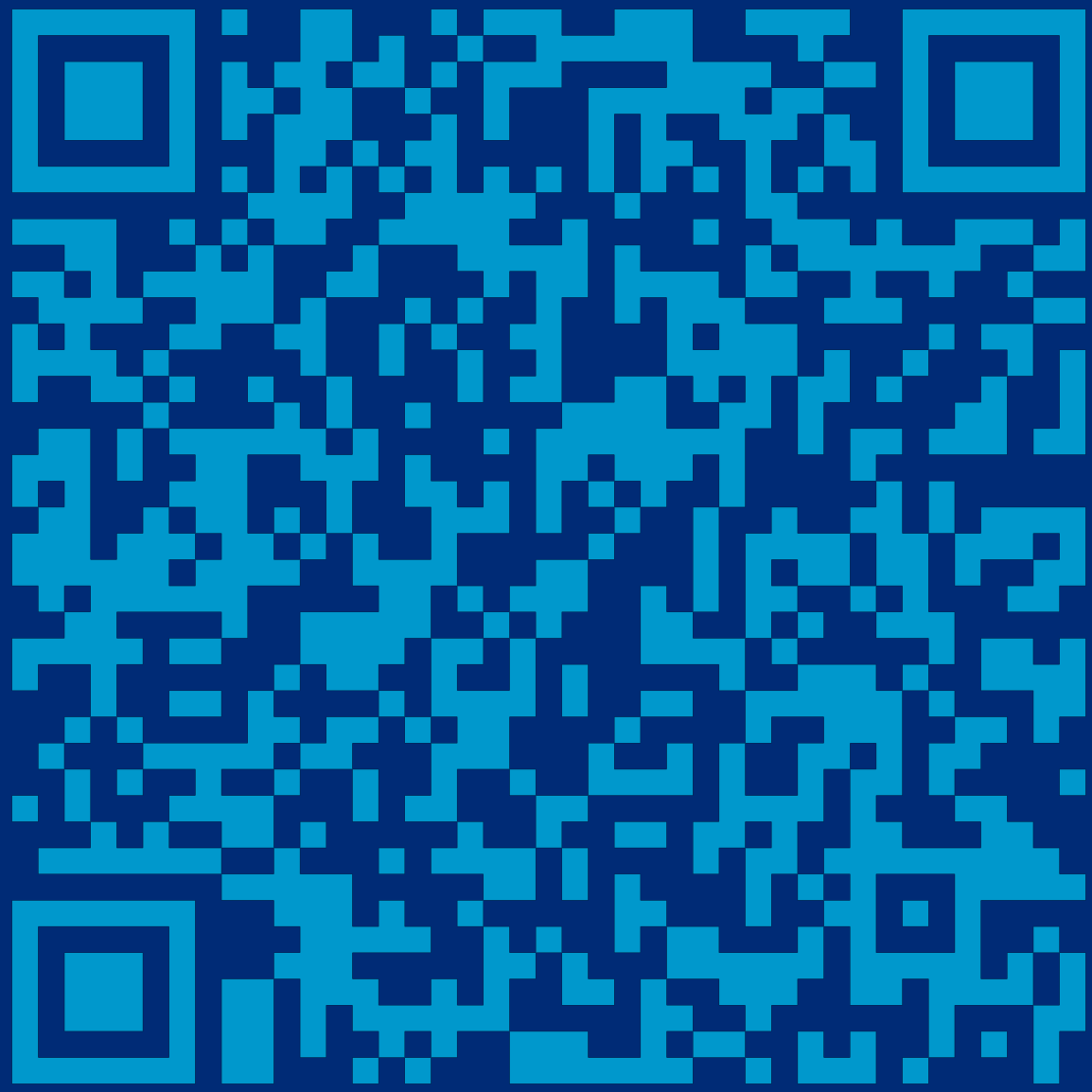

\title{
Julio-diciembre 2014
}

Instituto Interuniversitario de Desarrollo Social y Paz Universidad de Alicante 

OBETS

Revista de Ciencias Sociales 



\section{OBETS}

REVISTA DE CIENCIAS SOCIALES

PUBLICACIONES DE LA UNIVERSIDAD DE ALICANTE 
Publicaciones de la Universidad de Alicante

Campus de San Vicente s/n

03690 San Vicente del Raspeig

Publicaciones@ua.es

http://publicaciones.ua.es

Teléfono: 965903480

Fax: 965909445

(C) de la presente edición: los autores

OBETS. Revista de Ciencias Sociales.

Editada por IUDESP.

Instituto Interuniversitario de Desarrollo Social y Paz.

Universidad de Alicante.

Periodicidad: Semestral

http://web.ua.es/revista-obets

Email: revistaobets@ua.es

ISSN: 1989-1385

Depósito legal: A-885-2008

DOI: 10.14198/OBETS

Diseño de portada: candela ink. / O. Santacreu

Composición:

Patricia Barbero

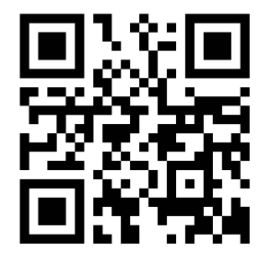

Los contenidos están bajo una licencia Creative Commons Reconocimiento 3.0 España.

Los contenidos pueden copiarse, distribuirse o comunicarse públicamente, bajo las siguientes condiciones generales: Reconocimiento. Debe reconocerse los créditos de la obra de la manera especificada por el autor o el licenciador (pero no de una manera que sugiera que tiene su apoyo o apoyan el uso que hace de su obra). Los términos de la licencia disponibles on-line en: http://creativecommons.org/licenses/by/3.0/es/ 
OBETS, Revista de Ciencias Sociales es una revista de investigación de periodicidad semestral editada por el Observatorio Europeo de Tendencias Sociales (OBETS), grupo de investigación integrado en la sede de la Universidad de Alicante (España) del Instituto Interuniversitario de Desarrollo Social y Paz (IUDESP). Dirigida a profesionales, investigadores/as, estudiantes, profesorado y público general interesado en la investigación académica en el campo de las Ciencias Sociales, comenzó a editarse en 2008.

La revista tiene como objetivo la difusión de estudios de naturaleza académica que contribuyan al mejor conocimiento de la sociedad contemporánea. En este sentido está abierta a la publicación de resultados de investigación empírica, metodológica o teórica de ámbito nacional e internacional. La revista abarca un amplio abanico de temas inscritos en el ámbito de la Sociología y Ciencias Sociales, como estudios de opinión pública, metodología, demografía, estructura y cambio social, ciencia política, teoría sociológica, antropología o psicología social. Los trabajos se publican en español, inglés, italiano, portugués o valenciano/catalán.

La revista está integrada en RUA, Repositorio Institucional de la Universidad de Alicante y cumple con el estándar de metadatos Dublin Core (http://www.dublincore.org) y con el protocolo OAI-PMH (Open Archives Initiative-Protocol for Metadata Harvesting: http://www.openarchives.org) para la transmisión de contenidos en Internet. Cuenta también con el DOI 10.14198/OBETS. A través de su página web y del RUA la revista ofrece opciones de acceso a contenido por títulos, autores, palabras claves o fecha.

A fin de alcanzar el mayor nivel de calidad posible en los trabajos publicados, todos los artículos se someten al arbitraje por pares académicos, considerando tanto la novedad de los resultados como el rigor metodológico en los diseños de investigación y análisis. El equipo editorial de OBETS. Revista de Ciencias Sociales no se hace responsable, en ningún caso, de la credibilidad y autenticidad de los trabajos. Del mismo modo, las opiniones y hechos expresados en cada artículo son de exclusiva responsabilidad de sus autores/as y OBETS. Revista de Ciencias Sociales no se identifica necesariamente con ellos. 
Incluida en:

\begin{tabular}{|c|c|}
\hline SCOPUS & $\begin{array}{l}\text { Base de datos bibliográfica de resúmenes y citas de artículos } \\
\text { de revistas científicas editada por Elsevier (revista aceptada } \\
\text { para inclusión en Scopus el 02/07/2014) }\end{array}$ \\
\hline DICE & $\begin{array}{l}\text { Base de datos para la difusión y calidad editorial de las } \\
\text { revistas españolas de humanidades y ciencias sociales y } \\
\text { jurídicas }\end{array}$ \\
\hline ISOC & $\begin{array}{l}\text { ISOC - Base de datos del Centro de Información y } \\
\text { Documentación Científica (CINDOC) del CSIC }\end{array}$ \\
\hline CIRC & Clasificación Integrada de Revistas Científicas \\
\hline RESH & $\begin{array}{l}\text { Sistema de valoración integrada de revistas españolas de } \\
\text { Humanidades y Ciencias Sociales }\end{array}$ \\
\hline LATINDEX & $\begin{array}{l}\text { LATINDEX-Catálogo. Sistema regional de información en } \\
\text { línea para revistas científicas de América Latina, el Caribe, } \\
\text { España y Portugal }\end{array}$ \\
\hline DOAJ & $\begin{array}{l}\text { DOAJ - Directory of Open Access Journals } \\
\text { SPARC Europe SPARC Europe Seal for Open Access Journals }\end{array}$ \\
\hline E-REVIST@S & $\begin{array}{l}\text { Plataforma Open Access de Revistas Científicas } \\
\text { Electrónicas Españolas y Latinoamericanas (CSIC) }\end{array}$ \\
\hline DIALNET & $\begin{array}{l}\text { Portal de difusión de la producción científica iberoamericana } \\
\text { impulsado por la Universidad de La Rioja }\end{array}$ \\
\hline MIAR & MIAR: Matriu d'informació per a l'avaluació de revistes \\
\hline CiteFactor & CiteFactor: Academic Scientific Journals \\
\hline SJIF & SJIF Scientific Journal Impact Factor \\
\hline ULRICH'S & ULRICH'S Periodicals Directory \\
\hline RECOLECTA & $\begin{array}{l}\text { RECOLECTA: Recolector de Ciencia Abierta de la FECYT } \\
\text { y del Plan Estratégico REBIUN 2007-2010 }\end{array}$ \\
\hline SCIRUS & SCIRUS - Buscador de información científica \\
\hline SHERPA/RoMEO & $\begin{array}{l}\text { Políticas de copyright de las editoriales y autoarchivo. } \\
\text { University of Nottingham. }\end{array}$ \\
\hline DULCINEA & $\begin{array}{l}\text { Dulcinea - Proyecto coordinado por el Ministerio de } \\
\text { Educación y Ciencia para identificar y analizar las } \\
\text { políticas editoriales de las revistas científicas españolas }\end{array}$ \\
\hline
\end{tabular}




\section{EQUIPO EDITORIAL}

\section{Consejo de redacción}

\section{Dirección:}

Oscar Antonio Santacreu Fernández - IUDESP. Universidad de Alicante, España

Secretaría técnica:

Antonio Francisco Alaminos Fernández - Universidad Jaume I de Castellón, España

Vocales:

- Mercedes Alcañiz Moscardó - Universitat Jaume I de Castellón, España

- Cristino Barroso - Universidad de La Laguna, España

- Mario Alejandro Guillén García - Programa Interdisciplinario de Población y

Desarrollo Local Sustentable (PYDLOS), Universidad de Cuenca, Ecuador

- Nina Rother - BAMF. Alemania

- Natalia Ix-Chel Vázquez González - Facultad de Ciencias Políticas y

Administración Pública. Universidad Autónoma del Estado de México, México

\section{Comité científico}

- Alberto Acosta Espinosa - Facultad Latinoamericana de Ciencias Sociales (FLACSO), Ecuador

- Antonio Alaminos Chica - IUDESP. Universidad de Alicante, España

- José Beltrán Llavador - Dpto. Sociología y Antropología Social, Universidad de Valencia, España

- Gianfranco Bettin - Università degli Studi di Firenze, Italia

- Fermín Bouza Álvarez - Universidad Complutense de Madrid, España

- José Manuel Canales Aliende - Dpto. de Estudios Jurídicos del Estado, Universidad de Alicante, España

- Vidal Díaz de Rada - Universidad Pública de Navarra, España

- Guillermina Díaz Pérez - Universidad Autónoma del Estado de México

- Mariano Fernández Enguita - Universidad Complutense de Madrid, España

- Margarita Latiesa Rodríguez - Universidad de Granada, España

- María Asunción Martínez Román - Dpto. Trabajo Social y Servicios Sociales. Universidad de Alicante, España

- Beatriz Padilla - Instituto Universitário de Lisboa (ISCTE-IUL), Lisboa, Portugal

- Andrea Pirni - University of Genova, Italia

- Ettore Recchi - Università degli Studi 'G. d'Annunzio' Chieti e Pescara, Italia

- M'hammed Sabour - University of Eastern Finland, Finlandia

- Pedro Sánchez Vera - Universidad de Murcia, España

- Sylvie Strudel - Université Panthéon-Assas, Paris, Francia

- José María Tortosa Blasco - IUDESP. Universidad de Alicante, España

- Anna Triandafyllidou - European University Institute, Florencia, Italia; ELIAMEP, Atenas, Grecia 


\section{ESTADÍSTICAS 2014}

Durante el año 2014 se han recibido un total de 35 artículos y 6 reseñas de libros. Durante el mismo año se ha concluido la evaluación externa (revisión por pares de forma anónima) de 32 artículos (91\%) estando el resto en proceso de evaluación (9\%).

De los 32 artículos evaluados, 14 han sido aceptados (44\%), de los cuales la totalidad fueron remitidos a sus autores/as a fin de incorporar las modificaciones propuestas por las evaluaciones. Cada artículo ha sido revisado por una mediana de 2 revisores/as. Cada revisor/a ha evaluado una media de 1 trabajo.

En 2014 el tiempo medio de espera de los artículos aceptados (desde su recepción hasta su aceptación definitiva) ha sido de 88 días, y el tiempo medio entre aceptación y publicación ha sido de 43 días. Para las críticas de libros, estos tiempos han sido de 81 y 117 días respectivamente.

Tabla 1. Resumen estadísticas 2014

\begin{tabular}{l|c|c|c|c}
\hline \multirow{2}{*}{ Artículos } & \multicolumn{2}{|c|}{ Artículos originales } & \multicolumn{2}{c}{ Críticas de libros } \\
\cline { 2 - 5 } \multirow{2}{*}{ Recibidos } & Número & Porcentaje & Número & Porcentaje \\
\cline { 2 - 5 } & 35 & & 6 & \\
\hline Pendientes & 3 & $9 \%$ & 0 & $0 \%$ \\
\hline Evaluados, de los cuales: & 32 & $91 \%$ & 6 & $100 \%$ \\
\hline - Rechazados & 18 & $56 \%$ & 2 & $33 \%$ \\
\hline - Aceptados, de los cuales & 14 & $44 \%$ & 4 & $67 \%$ \\
\hline -- Aceptados con modificaciones & 14 & $100 \%$ & 0 & 0 \\
\hline
\end{tabular}

Tabla 2. Tiempos del proceso editorial

\begin{tabular}{|c|c|c|}
\hline Tiempos entre & Artículos originales & Críticas de libros \\
\hline & $\begin{array}{l}\text { 2014. Días } \\
\mathrm{M} / \pm \mathrm{DS} / \mathrm{Me}\end{array}$ & 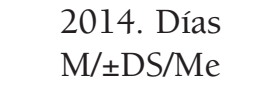 \\
\hline Recepción/aceptación & $88 / 60 / 67$ & $81 / 28 / 84$ \\
\hline Aceptación/publicación & $14 / 14 / 12$ & $117 / 89 / 84$ \\
\hline
\end{tabular}

Nota: $\mathrm{M} / \pm D S / M e=$ Media/Desviación Estándar/Mediana 


\section{INDICE}

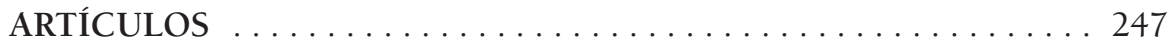

Cruz García Lirios, Javier Carreón Guillén, Daniela Mendoza

Alboreida, José Alfonso Aguilar Fuentes, Jorge Hernández Valdés,

Silvia Mejía Rubio, Florencio Manuel Estrada Maldonado

Especificación de un modelo de agenda sociopolítica en torno a los conflictos hídricos y la pacificación retributiva . . . . . . . . . . . . . . . 249

Specification of a model of socio-political agenda around water disputes

and remuneration pacification

\section{Vanesa Hervías Parejo}

Inconvenientes de género en los reagrupamientos familiares hacia

España: propuestas desde el Trabajo Social . . . . . . . . . . . . . . . . 267

Disadvantages of gender in family reunification to Spain: proposals

from Social Work

\section{Denise Kasparian}

Protección social y políticas de promoción del trabajo asociativo y autogestionado en la Argentina (2003-2013): el Programa Argentina Trabaja . . . . . . . . . . . . . . . . . . . . . . 303

Social protection and policies of promotion of associated and self-managed work in Argentina (2003-2013): the Argentina Trabaja Programme

\section{Antonio Martín Cabello}

Teorías sobre la globalización: una evaluación crítica . . . . . . . . . . 333

Theories on globalization: a critical appraisal 


\section{María Isabel Punín Larrea}

Una visión comunicacional de la política en Ecuador: Rafael Correa y su bicicleta . . . . . . . . . . . . . . . . . . . . . 361 A vision of communication politics in Ecuador: Rafael Correa and your bicycle

Juan Manuel Romero Valiente, Antonio Luis Hidalgo-Capitán El subregistro consular: magnitudes y efectos en las estadísticas de emigración española . 377

Consulate underregistration: Magnitudes and effects on Spanish emigration statistics

CRÍTICA DE LIBROS 409

Eva Espinar Ruiz

Henri Lefebvre. La producción del espacio. Madrid: Capitán Swing, 2013. Introducción y traducción de Emilio Martínez

Maximiliano E. Korstanje

Edited by Jane L. Wood and Theresa A. Gannon. Crime and Crime Reduction. The importance of Group Processes.

2013. East Sussex, Routledge, pp. 206 
ARTículos ARTICLES 



\title{
ESPECIFICACIÓN DE UN MODELO DE AGENDA SOCIOPOLÍTICA EN TORNO A LOS CONFLICTOS HÍDRICOS Y LA PACIFICACIÓN RETRIBUTIVA \\ SPECIFICATION OF A MODEL OF SOCIO-POLITICAL AGENDA AROUND WATER DISPUTES AND REMUNERATION PACIFICATION
}

\author{
Cruz García Lirios \\ UAEMEX, UAPH, México \\ garcialirios@uaemex.mx \\ Javier Carreón Guillén \\ UNAM-ENTS, México \\ javierg@unam.mx \\ Daniela Mendoza Alboreida \\ UNAM-ENTS, México \\ danielamendozaunam@hotmail.com \\ José Alfonso Aguilar Fuentes \\ UAEMEX, México \\ jaaquilar@uaemex.mx
}

\author{
Jorge Hernández Valdés \\ UNAM-ENTS, México \\ jorheval@unam.mx \\ Silvia Mejía Rubio \\ INACIPE, México \\ silviamejiarubio@hotmail.com \\ Florencio Manuel \\ Estrada Maldonado \\ UAM-X, UAEMEX-UAP-H \\ manuel.estrada29@gmail.com
}

\begin{abstract}
Resumen
La relación en torno a las políticas de abastecimiento y los conflictos entre autoridades y usuarios es materia de análisis del presente trabajo el cual discute la construcción de una agenda sociopolítica a partir de especificar un modelo; considerando los marcos teóricos y conceptuales, así como el estado del conocimiento. En este sentido, dirimir las problemáticas derivadas del tandeo y el incremento de tarifas supone no sólo la ausencia de agresiones entre los actores, sino la emergencia de una cultura de la paz y la neutralidad de acciones que inhiban la espiral de violencia. Se trata de un sistema de valores y normas que incidirían en las creencias de escasez o abundancia de agua para con ello determinar percepciones y emociones de riesgo e incertidumbre que incentiven la participación civil ya no como beneficiarios de derechos a
\end{abstract}


los recursos y servicios hídricos, sino como responsables sociales de anticipar conflictos, aminorar desencuentros y coadyuvar a la equidad retributiva como símbolo de justicia.

Palabras claves: recursos hídricos, servicios municipales, conflictos de tandeo, aumento de tarifas, cultura de pacificación, agenda sociopolítica.

\begin{abstract}
The relationship around procurement policies and conflicts between authorities and users is the subject of analysis of this paper which discusses the construction of a sociopolitical agenda since specify a model; considering the theoretical and conceptual frameworks and the state of knowledge. In this sense, resolve the problem arising from the tandem and increased rates implies not only the absence of aggression between the actors, but the emergence of a culture of peace and neutrality of actions that inhibit the spiral of violence. It is a system of values and norms that would impact the beliefs of scarcity or abundance of water to thereby determine perceptions and emotions of risk and uncertainty that encourage civic participation not only as beneficiaries of rights to water resources and services, but as social responsibility to anticipate conflicts, misunderstandings and help to reduce the pay equity as a symbol of justice.
\end{abstract}

Keywords: water resources, municipal services, conflicts tandem, rate increase, peace culture, socio-political agenda.

\title{
Extended Abstract
}

The relationship around procurement policies and conflicts between authorities and users is the subject of analysis of this paper which discusses the construction of a sociopolitical agenda since specify a model; considering the theoretical and conceptual frameworks and the state of knowledge. In this sense, resolve the problem arising from the tandem and increased rates implies not only the absence of aggression between the actors, but the emergence of a culture of peace and neutrality of actions that inhibit the spiral of violence. It is a system of values and norms that would impact the beliefs of scarcity or abundance of water to thereby determine perceptions and emotions of risk and uncertainty that encourage civic participation not only as beneficiaries of rights to water resources and services, but as social responsibility to anticipate conflicts, misunderstandings and help to reduce the pay equity as a symbol of justice.

The construction of the socio-political agenda is carried out from the identity is a complex construct that includes a variety of psychosocial processes from which you can explain conflicts over resource management and municipal water services.

Social identity consists of three pillars that guide its negative sense, but also moving towards its positive sense. It is creativity, innovation and mobility, which explain the escalating crime, but also anticipate a virtuous scenario of commitment, confidence and life satisfaction.

Thus, creativity is an instrument of differentiation of a group for others; it is a process of symbolization, meaning and emotion framing conflict for reso- 
lution, or, framing situations pursuant to domination by ignorance or depersonalization of other individuals or groups.

For its part, innovation is the production of knowledge rather than of affection. It consists of proposals and initiatives for negotiation between groups and individuals. Unlike creativity, which is more affective, innovation is the result of systematic reasoning and planning.

As these styles of deliberate and planned life intensify, affect the decisions and actions of majority groups. In this sense, the consolidation of minorities is systematic, but these systematic styles are a defense to the influence of majorities or other minorities. Therefore, empathy, trust and reliability are essential in these processes of minority influence with respect to majority groups, however mobility is the result of personal initiative; therefore, is linked to entrepreneurship.

However, criminal identity, in its simplest sense, is a product of frustration as aggression towards any economic, political or social actor intensifies. However, this aggressiveness is inherited and learned by victims who played with more impact these hostile behaviors.

Therefore, the socio-political identity, meaning beliefs, perceptions, attitudes, decisions and actions on the evaluation of public policies and programs emanating State, is a construct that explains the relationship between citizens and government.

What are the dimensions of criminal sociopolitical identity seen in government and state forms regimens confrontational vocation rather than preventive conflicts around for the right to access water resources and services?

According to social identity, crime attributed to officials, leaders or politicians lies in the formation unrelated to collective needs groups and the public peace. Ie, citizenship and state form two spheres from which allocations of power and influence are built. From civil society, it is assumed that the government is the guiding principle in which political power is spread. From the State, it is considered that the public is able to develop new forms of state and government schemes not based on public safety, but public and private security. This is because as the corruption, negligence, nepotism or opacity are conceived, developed civil sphere perceptions of risk, insecurity and uncertainty that lead to social mobilization and collective action with emphasis on self-service.

The state is reduced to a group of individuals that promote impunity in the legal and political system. In this sense, political power disintegrates in civil influence, since decisions are no longer significant and overlapping in persuasive speeches for vulnerable, marginalized or excluded from public safety sectors. Thus, the perception of public safety, which is also considered perception of insecurity, private security or public safety justifies state deregulation or the exacerbation of political control over society. Coupled with government representation as a corrupt institution in parallel perceptions of government are developed with "tough" exercising power and implement decisions to reduce at least the perception of insecurity. 
Therefore, the socio-political identity is scattered in different latitudes, regions and territories subject to availability of resources and opportunities that the political and legal system give them. Indeed, if the socio-political identity is a parameter of citizen opinion regarding public safety attributed to the State and transformed into perceptions of insecurity, then you may notice that there are variations of representations as spaces of power and social control.

However, despite socio-political criminals, rulers or ruled, share beliefs, perceptions, attitudes, intentions and behaviors that could take as sociopolitical, ie caused by the absence of a governing state, the political dimension of crime varies every politician and citizen can now be negative (frustration-violence-aggression) or positive (creativity-peace-support).

Thus, the study of the socio-political identity, in criminal matters, possible to anticipate conflict scenarios and changes between offenders and victims. This is because both groups build asymmetrical relationships that exacerbate their differences as they intensify the biases of belonging to one group or another. The socio-political identity is characterized by a safety entrepreneurship citizens developed from the incompetence of the state. Symptoms of sociopolitical identity would be related to crime levels reported by the institution, but above all, fear, anger, anger or anxiety are indicators of civic identity that separates it from the political class. In this sense, it is necessary to consider the socio-political identity as a psychosocial response citizenship before the exacerbation of crime, violence and corruption brought about by deregulation of the state. Indeed, the socio-political identity is assumed as an experienced helplessness of citizens before the wave of violence and crime; symptoms would the powers that society gives to government action, the criminal justice system, prosecutors and police.

The precise purpose of this paper is to describe and contrast the theoretical, conceptual and empirical axes around sociopolitical identity on crime, violence, corruption, negligence, opacity or nepotism of the ruling regarding the governed in administration of water resources and services. This in order to anticipate scenarios of conflict and social change through the exercise of legal-political or, the spread of social influence into the public regarding their authorities and offenses power.

The analysis of the data, theories, concepts and findings are made based on documentary research that took place between 2010 and 2014. DIALNET bases, LATINDEX and REDALYC data, which are considered leaders in Latin America were selected. Information search was conducted from combinations of keywords such as: state, water, municipal services, citizenship, violence, crime, security, and risk perception. Those items with empirical results preferably from the region and locality were selected. Subsequently, information was systematized using the technique of symptoms for model specification.

\section{INTRODUCCIÓN}

El encuadre sociopolítico se caracteriza por asociaciones deliberadas en torno a acciones gubernamentales y problemáticas locales (León, 2013). Se trata de 
una difusión sistemática de la escasez de recursos no debidamente subsana por políticas públicas cuyos efectos en los sectores vulnerables, marginados o excluidos exacerban los conflictos entre autoridades y usuarios de servicios públicos (Durand, 2011).

Empero, el encuadre sociopolítico, a diferencia del encuadre socioeconómico en el que los recursos financieros son administrados con la finalidad de hacer más eficientes los servicios municipales, consiste en una serie de atribuciones de causalidad a las instituciones públicas que por su grado de intervención son consideradas como un problema más que como una gestión resolutiva (Joignant, 2012).

A medida que el encuadre socioeconómico explica la escasez de recursos naturales, justifica en aumento de tarifas, pero correlaciona negativamente con un disminución del encuadre sociopolítico que explica las sanciones y subsidios de los servicios públicos en los sectores que habitan la periferia urbana (Daher, 2013).

Los medios de comunicación han construido ambos encuadres para establecer temas de discusión ciudadana y así influir en las iniciativas gubernamentales, aunque por su grado de escasez y abastecimiento intermitente, el suministro de agua es un fenómeno que se complementa con la difusión de los medios de comunicación (Carreón, 2010).

Sin embargo, la difusión de los temas relativos a tarifas, insalubridad y desabasto forma opinión ciudadana y orienta el debate público, pero sobre todo se inserta en la agenda política. Tal proceso es un efecto del encuadre sociopolítico (García, 2014).

En cambio, si existe una difusión preponderante de la escasez, desabasto y tarifas como elementos centrales de la agenda ciudadana en materia de servicios públicos, entonces los medios de comunicación han construido un encuadre socioeconómico que legitima las políticas de tandeo y subsidio (García, 2010).

De este modo, el encuadre socioeconómico orienta la discusión a la oferta y demanda establecidas por un mercado de los servicios públicos, pero esencialmente su efecto en las políticas públicas se reduce a la justificación de aumentos, sanciones y subsidios (Abramo, 2012).

En efecto, según el tipo de encuadre es posible anticipar movilizaciones sociales y acciones colectivas en torno a la regulación del Estado por la dinámica del mercado hídrico, o bien, movimientos de protesta ambiental por las políticas de tandeo e insalubridad pública ambiental (Riojas, 2013).

El objetivo del presente estudio es explorar los encuadres socioeconómico y sociopolítico a fin de poder establecer los temas de discusión local relativos al sistema de cobro de los servicios hídricos municipales. 
La relevancia de esta investigación estriba en que la relación entre autoridades locales y usuarios de la red municipal de agua está mediada por los medios impresos de circulación nacional al momento de establecer los citados temas de discusión y materialización en el suministro de tandeo o el subsidio de tarifas.

\section{PROBLEMÁTICAS HÍDRICAS}

Las problemáticas hídricas identificadas por las diferencias entre disponibilidad hídrica y suministro público son materializadas en atribuciones de responsabilidad al Estado o al mercado.

La disponibilidad global en referencia a la cantidad de agua que se encuentra en los países integrantes de la Organización de la Cooperación y Desarrollo Económico (OECD) alcanza una diferencia de 2 millones y medio de metros cúbicos, aunque la diferencia entre América del Norte y la OECD es de la mitad (United Nations Habitad, 2010).

Sin embargo, el suministro de agua per cápita se reduce estrepitosamente a 1400 litros para los habitantes de América del Norte, 800 metros cúbicos para los residentes de la OECD y la mitad de esta disponibilidad para quienes viven en los países de la OECD en Europa. Es decir, a medida que la disponibilidad per cápita disminuye en los países desarrollados, parece corresponder con un mayor crecimiento económico y desarrollo humano indicado por políticas de optimización y cobro de los servicios hídricos (United Nations Water, 2010).

En referencia a los países que integran la OECD, Dinamarca tiene un menor volumen disponible que no supera los 200 metros cúbicos y los Estados Unidos de América tienen un mayor volumen por persona de alrededor de 1600 metros cúbicos (United Nations Habitad, 2010).

Sin embargo, si se considera la política de oferta de agua, Dinamarca es consecuente con su disponibilidad y suministra el menor volumen de agua a sus residentes con cerca de 100 metros cúbicos.

En contraste, México ocupa el primer lugar de suministro de agua con cerca de ocho mil metros cúbicos per cápita. Más aún, el cobro del suministro de agua es diferente en cada uno de los 32 estados que conforman al país. Llama la atención que el mayor costo del volumen unitario de agua ha sido asignado a la ciudad de Aguascalientes, aunque el Distrito Federal ocupa el segundo lugar en cuanto al aumento de tarifas (United Nations Water, 2010).

Precisamente, es la capital de México la que ha incrementado sustancialmente sus tarifas hídricas si se considera un periodo de 1997 a 2011 el costo aumento 17 veces. 
En síntesis, los medios de comunicación pueden haber difundido las problemáticas hídricas desde un encuadre socioeconómico, pero al implementar un encuadre sociopolítico orientan la discusión hacia la política de tandeo más que hacia los subsidios. El encuadre socioeconómico explicaría las diferencias entre la situación global y local, pero el encuadre sociopolítico anticiparía los conflictos entre gobernantes y gobernados

\section{TEORÍA DEL ENCUADRE SOCIOPOLÍTICO}

La Teoría del Encuadre Sociopolítico explica la relación entre medios de comunicación y Estado a través de la ciudadanía. En este sentido, la construcción de una agenda pública está matizada por los temas difundidos en televisión, radio, prensa, cine o Internet (Vargas, 2012). La recepción de los contenidos producidos por los medios de comunicación indica la formación de opinión pública. Se trata de asociaciones entre atribuciones causales de problemáticas globales o locales y sus efectos en los estilos de vida de los sectores marginados, excluidos o vulnerables (Guerra, 2010). En este proceso, los políticos son identificados por la sociedad civil como los responsables de la gestión de seguridad pública, misma que a su vez es planteada desde los medios como garante del Desarrollo Local Sustentable (Farías, 2010).

Empero, los medios de comunicación advierten que una gestión orientada por tarifas reducidas supone una ingobernabilidad que inhibiría el Desarrollo local ya que éste depende de la inversión pública y la recaudación hacendaría.

Si las autoridades locales no pueden siquiera recaudar el valor del suministro hídrico, entonces son responsables del sistema de sanciones y subsidios que benefician a sectores vulnerables, marginados o excluidos, pero también son responsables del deterioro y la baja calidad de los servicios públicos debido a la falta de inversión en modernización de los sistemas (Mendoza, 2010).

En el caso de los servicios hídricos, un porcentaje cercano al 60\% del agua suministrada se evapora y filtra ya que la red de abastecimiento ha sido edificada con materiales que han terminado su utilidad, o bien, requieren de un mantenimiento constante. En ambos casos, el costo no puede subsidiarse o condonarse (García, 2013).

Desde luego, los medios de comunicación lejos de analizar la gestión hídrica y sus implicaciones en las tarifas, asumen como valida la propuesta del incremento de tarifas e incluso su desregulación para la entrada de un sistema de cobro y su inserción en la lógica del mercado (Carreón, 2011).

No obstante que los medios difunden noticias en torno al abastecimiento intermitente y su solución a través del incremento de tarifas, su objetivo parece estar orientado hacia la agenda política (Carreón, 2014). 
Es cierto que la crítica de los medios a la administración pública, sus políticas y programas urbanos repercute en las decisiones electorales y la evaluación de la ciudadanía para con sus autoridades, pero los medios no sólo buscan influir en audiencias legas, su propósito es más bien incidir en la opinión pública ilustrada.

En efecto, son los sectores civiles informados los que no sólo contrastan la información difundida en los medios y observan su accionar con respecto a las iniciativas gubernamentales, además las esferas ciudadanas más ilustradas son aquellas que movilizan sus protestas a través de los mismos medios y los utilizan como contrapeso en el debate público (Cerón, 2013).

Si los medios de comunicación desarrollaron un encuadre socioeconómico para incidir sobre las preferencias electorales y la evaluación de ciudadanos sin acceso a información relativa a sus derechos, entonces el encuadre sociopolítica está dirigido a un sector crítico de los medios que al utilizarlos como instrumento de su indignación reducen su efecto sobre las demás esferas civiles (Quiroz, 2013).

Las consecuencias del encuadre socioeconómico sobre la participación civil son evidentes ya que las demandas ciudadanas respecto a su derecho a la ciudad y a sus servicios públicos consisten en exigir que se subsidie o condone el pago a quienes no pueden costear su uso (García, 2011).

$\mathrm{Al}$ ser las esferas ilustradas las que observan, analizan y diseminan la información sobre los demás sectores sociales, orientan la participación ciudadana al conflicto entre autoridades y usuarios de los servicios públicos, o bien, la participación ciudadana es reducida a su mínima expresión como instrumento de consenso.

Es por ello que los medios de comunicación implementan el encuadre sociopolítico para que las audiencias contrasten la información y la difundan como temas de discusión civil. A diferencia del encuadre socioeconómico que legitima políticas de tandeo, estilos de vida austeros y el incremento de tarifas, el encuadre sociopolítico acentúa la responsabilidad en la gestión pública y la necesidad de construir una identidad que sintetice las agendas ciudadanas con las agendas políticas (Oliver, 2012).

La construcción de una identidad sociopolítica ya no es el resultado de la racionalidad ambiental, reapropiación de la naturaleza y la conservación de los recursos, es el producto de dos encuadres, socioeconómico y sociopolítico, que buscan legitimar al mercado y al Estado como reguladores de tarifas y rectores de la gestión pública (Osorio, 2012).

En suma, la Teoría del Encuadre Sociopolítico advierte sobre la diversificación de la ciudadanía en audiencias críticas y emotivas. La teoría anticipa 
los conflictos entre los actores sociales y políticos observados en el grado de participación civil, movilización colectiva y acción social. Un incremento en estos fenómenos colectivos supone la influencia de los medios a través del encuadre sociopolítico, pero una disminución sustancial de los conflictos refleja la incidencia de los medios mediante el encuadre sociopolítico.

De este modo, la emergencia de una identidad sociopolítica en la que los expertos están dispuestos a debatir las reformas estructurales, en donde los políticos se muestran anuentes a la discusión pública y las audiencias manifiestan su derecho a la información es el síntoma inequívoco de que los medios de comunicación han diseminado sus temas en la ciudadanía crítica y con ello han influido en las iniciativas y leyes públicas.

\section{ESTADO DEL CONOCIMIENTO}

Los estudios relativos a las problemáticas hídricas advierten que el tandeo y las tarifas son temas centrales en la agenda pública. Esto es así porque la escasez fue considerada como el tema de discusión científica en las cumbres sobre el calentamiento global, el efecto invernadero y el cambio climático.

Los desastres naturales y las catástrofes ambientales, principales consecuencias del cambio climático, relacionadas con sequias, huracanes e inundaciones se insertaron en las agendas científicas y posteriormente, fueron diseminadas en los medios de comunicación como temas de preocupación ambiental y participación ecológica (Grosso, 2013).

Sin embargo, las autoridades diseñaron políticas públicas de tandeo para los sectores desfavorecidos del crecimiento económico. Los programas de distribución y suministro de recursos naturales a través de los servicios públicos fueron representados como errores de gestión y las instituciones comisionadas fueron percibidas como excluyentes. En esta coyuntura, los medios de comunicación explotaron la pérdida de rectoría del Estado y transformaron la seguridad pública en percepciones de inseguridad (Barba, 2013).

La salud pública no sólo fue desplazada por percepciones de riesgo, sino además fue confinada al espacio local como evidencia de desarrollo humano insostenible (Artaza, 2013). Una vez que la escasez de recursos se visualizó en servicios públicos deficientes, la opinión ciudadana designó como responsables a las autoridades (Escalante, 2012). Es así como la participación ciudadana se construyó en función de la acción gubernamental más que a partir de los saberes comunitarios o la racionalidad ambiental (Picazzo, 2011).

En otras palabras, la mediatización de la naturaleza y el encuadre de la escasez de los recursos vinculados a las políticas ambientales no sólo generaron una opinión pública condenatoria, además produjeron el consumismo y el posma- 
terialismo en clases sociales acomodadas mientras que propiciaron la indefensión y la hipermetropía en las clases medias y determinaron la austeridad en los sectores populares (García, 2013).

La participación ciudadana, en materia de políticas ambientales y sus efectos en los sectores periurbanos estriba en la compra excesiva de productos biodegradables (consumismo), la adopción de estilos de vida ecologistas (posmaterialismo), la desesperanza por la extinción de las especies (indefensión), la preocupación excesiva por las catástrofes ambientales lejana (hipermetropía) y la reutilización de productos (austeridad).

En resumen, las problemáticas ambientales en lo general e hídricas en lo particular fueron estudiadas según los estilos de vida consumistas, posmaterialistas, indefensionistas, hipermetropistas o austeros. A medida que las investigaciones explicaron estas formas de vida, olvidaron la influencia de los medios de comunicación en estos de modo de existencia y su impacto en la legitimación y evaluación de políticas ambientales (Vega, 2010).

Los estudios relativos a las problemáticas ambientales e hídricas consideraron que los medios de comunicación sólo serían trascendentes en cuanto a la difusión de las problemáticas y la apertura a denuncias ciudadanas.

Los medios de comunicación fueron asumidos como testigos del deterioro ambiental y la emergencia de la movilización social. Los conflictos entre autoridades y usuarios justificaron la observación y el análisis del fenómeno desde las ciencias sociales, pero confinados al impacto de la escasez en la vida cotidiana. La participación ciudadana fue reducida a la expresión de víctimas de la contaminación, la insalubridad o la inflación tarifaria, la movilización colectiva fue confinada a la observación del clientelismo político y la protesta social fue subyugada a la manipulación de los partidos opositores al gobierno local.

\section{ESPECIFICACIÓN DE RELACIONES}

Ante los hallazgos del estado del conocimiento y las situaciones hídricas, el encuadre de las tarifas puede ser analizado desde la asociación de tarifas y los fenómenos del tandeo, fugas, dispendio, boicots, sanciones, incrementos, austeridad y subsidios, o bien, desde la asociación de la gestión pública y los fenómenos esgrimidos.

En el caso de las problemáticas hídricas, el encuadre socioeconómico consiste en asociaciones que los reportajes, columnas o noticieros hacen del tandeo y las tarifas con respecto a la administración del servicio público de agua potable. A medida que el abastecimiento intermitente aumenta, los medios justifican el incremento de cuotas y la reducción de subsidios. En este sentido, 
la desregulación es planteada como solución a las problemáticas hídricas (Carreón, 2013). El mercado del agua es la figura socioeconómica que valoraría los recursos y garantizaría su conservación. Por su naturaleza socioeconómica, esta propuesta se infiltra en las agendas de los sectores populares ya que promete un abastecimiento financiado por el aumento de tarifas. Empero, la eliminación de subsidios y el aumento constante de las tarifas activan la movilización social, la acción colectiva y la protesta ciudadana (García, 2010).

En contraste, el incremento de subsidios y el aumento del desabasto son difundidos como evidencias de discrecionalidad y clientelismo político ante los cuales el encuadre sociopolítico exacerba la condena social y reduce la austeridad (Tosoni, 2010). Se trata de asociaciones entre atribuciones gubernamentales que los comunicadores, reporteros o periodistas hacen con respecto a la participación civil. De este modo, la rectoría del Estado como regulador del suministro y las tarifas es propuesta como solución a las problemáticas y los conflictos hídricos. Sin embargo, por su contenido sociopolítico este encuadre está dirigido a sectores reflexivos y críticos del accionar gubernamental ya que pretende reducir el conflicto transformando los derechos por percepciones de inseguridad, riesgo e incertidumbre que se materializaran en discursos condenatorios (Bourdieu, 2012).

Ambos encuadres, socioeconómico y sociopolítico inhiben el debate ciudadano porque reducen los derechos, oportunidades, capacidades y responsabilidades a su mínima expresión. Ambos generan una identidad conformista que suprime la sustentabilidad, una identidad consumista que inhibe el la producción orgánica, una identidad posmaterialista que cohíbe la innovación, una identidad hipermetropista que distorsiona el comportamiento proambiental y una identidad austera que exacerba a las otras identidades, o bien, subyuga los saberes, las racionalidades y las capacidades.

\section{DISCUSIÓN}

El presente trabajo ha expuesto los ejes de discusión y análisis en torno a los cuales se gestan representaciones sociopolíticas a partir del encuadre de verosimilitud y el encuadre de verificabilidad propios de los medios de comunicación en el proceso de construcción de una agenda pública.

Empero, los temas centrales de la agenda sociopolítica no sólo aluden al impacto del encuadre de los medios sobre la opinión ciudadana y su influencia en la agenda política. en el caso de la cultura de la paz, contraria a las representaciones sociopolíticas difundidas en los medios, cristalizada ésta última por creencias y percepciones de riesgo, materializada en emociones de indignación, miedo, enojo, zozobra y desesperanza. 
De este modo, la cultura de la paz aludiría a un encuadre sociopolíticos en que los medio promoverían el compromiso, la responsabilidad social, formas de convivencia y respeto (Chavarría, 2013). Se trata de virtudes cívicas motivadoras de la eficiencia de una acción pública orientada (Tena, 2010). Es la promoción de la justicia a partir del discernimiento del bien común. Es una reciprocidad o propensión a la cooperación facilitando la equidad y reduciendo las desigualdades en un nivel cívico.

Sin embargo, el encuadre verificabilidad que consiste en mostrar los hechos que se quieren transformar en temas y el encuadre de verosimilitud que consiste en embonar los hechos con las creencias de las audiencias, promoverían una cultura de la paz siempre y cuando los actores sociales; el Estado y la ciudadanía, instituciones y observatorios, generarán acciones de pacificación que pudiesen difundirse y generar representaciones de solidaridad, creencias de justicia y percepciones de utilidad en torno al estado de derecho y las garantías individuales, el debate y el consenso en plazas públicas. O bien, los medios de comunicación, siguiendo ambas lógicas, promoverían emociones, valores y normas que respalden a las autoridades.

Es así como la ideología política entendida como un sistema de creencias en torno a las relaciones asimétricas entre gobernados con respecto a sus formas de Estado y regímenes de gobierno, no sólo es explicada por la Teoría de la Amenaza Integrada que plantea relaciones asimétricas entre gobernados con respecto a las políticas públicas, pero a diferencia de la Teoría del Encuadre Sociopolítico que explicaría la difusión de las desigualdades, la amenaza integrada propondría a las percepciones de riesgo como el obstáculo de la pacificación entre sectores vulnerables, marginados o excluidos de los servicios públicos (Rottenbacher y De la Cruz, 2012).

La amenaza integrada explicaría la adopción, aceptación y uso intensivo de estrategias autoritarias entre la sociedad civil, motivada por actitudes favorables a la jerarquización social y la reproducción de la dominación social. Mientras que el encuadre sociopolítico anticiparía la emergencia de las creencias, percepciones y actitudes en contra de la violencia o a favor de la pacificación. O bien, el encuadre sociopolítico explicaría la emergencia de la desesperanza en torno a los servicios públicos como resultado de políticas de tandeo; la hipermetropía indicada por una preocupación excesiva, pero ligada a una inacción social al considerarse que la escasez y sequías de agua no afectarán la vida cotidiana y los estilos de vida de zonas con un abastecimiento regular.

En virtud de que el Estado transita de un liberalismo mercantil a un liberalismo igualitario, no sólo desregula el mercado, sino además asume una responsabilidad social que facilite la emergencia de actores civiles, éstos aporta- 
rían valor a la estructura, sistemas, políticas y estrategias orientados al bien común, pero sin una orientación equitativa (Zúñiga, 2011). En este sentido la Teoría de la Justicia Retributiva sostendría que el equilibrio entre los deseos personales y la disponibilidad de recursos soluciona las desigualdades cristalizadas en el abastecimiento intermitente de agua, pero la Teoría del Encuadre Sociopolítico advertiría que tal equilibrio no tendría sentido si las creencias sociales giran en torno a información relativa a la escasez de agua, más allá del equilibrio retributivo, la justicia consistiría en un sistema de subsidios y condonaciones más que de pago justo al consumo de agua.

Gasca y Olvera (2011) proponen construir el equilibrio retributivo a partir de la emergencia de esferas ciudadanas de responsabilidad social. Si los derechos y garantías individuales están reguladas por la ley, entonces el reconocimiento de una moral y ética retributiva materializada en virtudes cívicas de respeto, diálogo y consenso. La capacidad para identificar oportunidades de civilidad y el desarrollo de una identidad de responsabilidad son factores críticos de la racionalidad económica, la competencia desleal, el individualismo frente a la promoción de la solidaridad, cooperación, igualdad y respeto. Cada una de estas capacidades se materializaría en el derecho a la educación, salud, entorno y paz frente al hambre, la desnutrición y la corrupción.

Empero, la paz pública no sólo supone una ausencia de violencia directa en cuanto a la falta de conflictos (paz negativa), la reducción de violencia estructural o indirecta (paz positiva), la disolución de valores y normas convencionales que legitimen la violencia directa o indirecta (paz cultural), sino la emergencia de una paz neutra. Se trata de una implicación efectiva de la ciudadanía en cuanto a la abolición de la violencia simbólica. Es una inacción de la violencia como principio de la no cooperación, por ende es multifactorial (Jiménez, 2009).

No obstante, la paz neutra sugiere una participación mínima de los medios de comunicación en las relaciones civiles, conflictos con sus autoridades, discursos de apoyo o confrontación, así como debates en torno a consensos de gestión del bien común.

\section{CONCLUSIÓN}

El aporte del presente trabajo a los marcos teóricos y conceptuales, así como al estado del conocimiento estriba en discutir la emergencia de propuestas sociopolíticas frente al efecto del encuadre mediático indicado por su grado de verificabilidad y verosimilitud. A medida que se intensifica la diseminación de contenidos y el establecimiento de temas en la agenda pública, subyacen elementos sociopolíticos tales como la paz, el compromiso, la responsabilidad 
y el consenso frente a los temas de opinión civil materializados en violencia e inseguridad. En este sentido, la especificación de un modelo para el estudio de la agenda sociopolítica incluye los procesos expuestos ya que, en el caso de los conflictos hídricos, la relación entre gobernantes administradores y esferas civiles de usuarios está regulada por sistemas de cobro relativos a subsidios y condonaciones, políticas de tandeo y abastecimiento. En contraste, desde una perspectiva de cultura de la paz y/o pacificación neutra es posible advertir la construcción de un sistema equitativo y retributivo de justicia que complementaría la asistencia clientelar de las autoridades con respecto a los usuarios.

\section{REFERENCIAS}

Abramo, P. (2012). "La ciudad confusa: mercado y producción de la estructura urbana en las grandes metrópolis latinoamericanas". Eure, 38 (114), 35-69.

Artaza, O. (2013). "Gobierno de redes asistenciales: evaluación de los consejos integradores de la red asistencial en el contexto de la reforma del sector salud". Salud Pública de México, 55 (6), 650-658.

Barba, C. (2013). "Inseguridad y protección social en los países desarrollados y en América Latina". Revista Mexicana de Sociología, 75 (1), 29-61.

Bourdieu, P. (2012). "La economía de los bienes simbólicos". En I. Jiménez (coord.). Capital simbólico y magia social. (pp. 86-120). México: Siglo XXI.

Carreón, J. (2010). "La lucha contra la delincuencia organizada". Barataria, 14, 59-74.

Carreón, J. (2011). "Teorías psicosociales para explicar los conflictos derivados del abastecimiento de agua en México", Distrito federal. Pampedia, 8, 56-68.

Carreón, J. (2012). "Intenciones de voto a favor de propuestas verdes. ¿Nuevo paradigma ambiental y postmaterialismo social?" Entre Ciencias, 2, 211-224.

Carreón, J. (2013). "Una exploración al estudio de la violencia". Obets, 8 (1), 59-78.

Carreón, J. (2014). "Hacia una administración consensuada de los recursos hídricos en ecociudadanes". Interdisciplinaria, 31, 1-12.

Cerón, A. (2013). "Habitus y capitales: ¿Disposiciones o dispositivos sociales? Notas teórico metodológicas para la investigación social". Revista Latinoamericana de Metodología de Investigación Social, 4 (2), 68-82.

Chavarría, C. (2013). "Estructura social y Locus de Control en colegios catalogados como violentos en zonas urbanas y rurales. Evidencia de su relación como insumo para la promoción de una cultura de la Paz". Reflexiones, 92 (1), 77-96.

Daher, A. (2013). "El sector inmobiliario y las crisis económicas". Eure, 39 (118), 47-76.

Durand, L. (2011). "La ecología política en México ¿Dónde estamos y para dónde vamos?" Estudios Sociales, enero-junio, 285-307.

Escalante, F. (2012). "Crimen organizado. La dimensión imaginaria". Nexos, Octubre, $32-44$.

Farías, I. (2010). "Asimetrías, límites y paradojas en la noción de habitus". Covergenecia, 54, 11-34. 
García, C. (2010). "Exclusión hidrólogica". Entelequia, 11, 41-59.

García, C. (2011). "Estructura del antropocentrismo hídrico". Multidisciplinaria, 10, 33-42.

García, C. (2012). "Los estilos de vida en torno a las problemáticas hídricas". Sustentabilidades, 7, 84-92.

García, C. (2013). "Teoría de la actitud hacia el consumo sustentable de agua". Sustentabilidades, 8, 33-41.

García, C. (2014). "Sistemas sociopsicológicos de la propaganda sustentable". Enseñanza e Investigación en Psicología, 19, 219-244.

Gasca, E. y Olvera, J. (2011). "Gestión ciudadana desde las universidades, responsabilidad social universitaria y desafíos ante el siglo XXI". Convergencia, 56, 37-58.

Grosso, C. (2013). "La economía social desde tres perspectivas: tercer sector, organizaciones no gubernamentales y entidades sin ánimo de lucro". Tendencias y Retos, 18 (1), 143-158.

Guerra, E. (2010). "Los conceptos de campo social y habitus". Estudios Sociológicos, 83, 283-409.

Jiménez, F. (2009). "Hacia un paradigma pacífico: la paz neutra". Convergencia, Número Especial, 141-190.

Joignant, A. (2012). "Habitus, campo y capital. Elementos para una teoría general del capital político". Revista Mexicana de Sociología, 74 (4), 587-618.

León, S. (2013). "Indicadores de tercera generación para cuantificar la sustentabilidad urbana. ¿Avances o estancamiento?” Eure, 39 (118), 173-198.

Mendoza, H. (2010). "El concepto de pobreza y su evolución en la política social". Estudios Sociales, enero-junio, 225-251.

Oliver, M. (2012). "El proceso de incorporación del habitus en la hexis corporal". En I. Jiménez (coord.). Capital simbólico y magia social. (pp. 179-204). México: Siglo XXI .

Osorio, J. (2012). "Estado, biopoder, exclusión. Análisis desde la lógica del capital”. México: UAM-A.

Picazzo, E. (2011). "La Teoría del Desarrollo Humano Sustentable: hacia el reforzamiento de la salud como un derecho y libertad universal". Estudios Sociales, enerojunio, 255-279.

Quiroz, D. (2013). "Las ciudades y el cambio climático: el caso de la política climática de la Ciudad de México". Estudios Demográficos y Urbanos, 26 (2), 343-382.

Riojas, H. (2013). "La salud ambiental en México: situación actual y perspectivas futuras". Salud Pública de México, 55 (6), 638-648.

Rottenbacher, J. y De la Cruz, M. (2012). "Ideología política y actitudes hacia la minería. Entre el crecimiento económico, el respeto por las formas de vida tradicionales y el ambientalismo". Liberabit, 18 (1), 83-96.

Tena, J. (2010). "Hacia una definición de la virtud cívica". Convergencia, 53, 311-337.

Tosoni, M. (2010). "Claves teóricas par la interpretación del clientelismo". Estudios Sociológicos, 28, 359-379. 
United Nations Habitad (2010). Sick water? The central role of wastewater management in sustainable. A rapid response assessment. Birkiland: UN-Habitad

United Nations Water (2010). Water security \& the global water agenda. Ontario: United Nations University

Vargas, A. (2012). "El prisma de las seguridades en América Latina". Buenos Aires: CLACSO

Vega, J. (2010). "La seguridad pública en la era contemporánea". México: UAM-A

Zúñiga, A. (2011). "Teoría de la Justicia Distributiva: una fundamentación moral del derecho a la protección de la salud". Convergencia, 55, 191-211

CRUZ GARCÍA LIRIOS realizó estudios de doctorado en Psicología en la Universidad Nacional Autónoma de México. Profesor de asignatura en la Unidad Académica Profesional Huehuetoca de la Universidad Autónoma del Estado de México. Actualmente desarrolla el proyecto: "Impacto de las Tecnologías de Información y Comunicación en las Representaciones Sociales de Facebook, Twitter y Google+"

JAVIER CARREÓN GUILLÉN es Doctor en Administración por la Facultad de Contaduría y Administración de la Universidad Nacional Autónoma de México. Profesor de Carrera en la Escuela Nacional de Trabajo Social de la UNAM, y adscrito al Sistema Nacional de Investigadores. Línea de investigación: "Encuadre de la prensa en torno a la violencia sociopolítica en México. Análisis transcultural de la ciudad de Bogotá (Colombia), Caracas (Venezuela) y Distrito Federal (México)"

DANIELA MENDOZA ALBOREIRA es Licenciada, Especialista y Maestrante en Trabajo Social, Universidad Nacional Autónoma de México. Escuela Nacional de Trabajo Social. Colaboradora responsable en el área de servicios sociales y atención a la salud.

JOSÉ ALFONSO AGUILAR FUENTES es Doctor en Educación, Maestro en Educación Superior, Maestro en innovación curricular y Comunicólogo. Autor de textos diversos, conferencista y catedrático de posgrado en instituciones nacionales e internacionales. Profesor de tiempo completo, en la Unidad Académica Profesional Huehuetoca de la Universidad Autónoma del Estado de México.

JORGE HERNÁNDEZ VALDÉS es Maestro en Formación Docente por El Colegio de Estudios de Posgrado de la Ciudad de México, Secretario Académico 
de la Escuela Nacional de Trabajo Social de la UNAM, así como Profesor de Carrera de la misma institución, desarrolla las líneas de investigación sobre "migración, jóvenes y masculinidades".

SILVIA MEJÍA RUBIO es Maestrante en Victimología, Instituto Nacional de Ciencias Penales (INACIPE). Colaboradora responsable en el área de la seguridad pública y atención a víctimas.

FLORENCIO MANUEL ESTRADA MALDONADO es Licenciado en Comunicación, Universidad Autónoma Metropolitana, unidad Xochimilco. Profesor de asignatura, en la Universidad Autónoma del Estado de México. Unidad Académica Profesional Huehuetoca.

Recibido: 19/05/2014

Aceptado: 12/12/2014 



\title{
INCONVENIENTES DE GÉNERO EN LOS REAGRUPAMIENTOS FAMILIARES HACIA ESPAÑA: PROPUESTAS DESDE EL TRABAJO SOCIAL DISADVANTAGES OF GENDER IN FAMILY REUNIFICATION TO SPAIN: PROPOSALS FROM SOCIAL WORK
}

\author{
Vanesa Hervías Parejo ${ }^{1}$ \\ Facultad de Ciencias del Trabajo. Universidad de Cádiz. España \\ vanesa.hervias@uca.es
}

\begin{abstract}
Resumen
Las personas inmigrantes en España logran mejorar su acceso al Sistema de Protección Social mediante la convivencia en familia.

El estudio empírico realizado en una Unidad de Extranjería de la Comunidad Autónoma de Andalucía constata que, sin embargo, se producen desigualdades asociadas al género. Las mujeres inmigrantes encuentran más dificultades en el ejercicio del derecho a reagrupar debido a los puestos de trabajo que ocupan, a las responsabilidades en el ámbito privado, a la invisibilidad en los espacios públicos y a las trabas personales, sociales y administrativas impuestas desde los países de origen y en los países de acogida.

Palabras clave: Género, Familias, Políticas Migratorias, Reagrupación Familiar, Sistema Público de Protección Social, Integración Social.

Abstract

Immigrants in Spain gain easier access to Social Protection System by living in a family.

This empirical study, carried out in the Immigration Unit of the Autonomous Community of Andalusia, notes, however, that inequalities occur associated with the gender. Immigrant women find more difficulties in the right to regroup due to the jobs they occupy, their responsibilities in the private sphere, their invisibility in public spaces and their personal, social and administrative obstacles imposed from origin countries and in the host countries.
\end{abstract}

\footnotetext{
${ }^{1}$ Un agradecimiento especial a mi Director y Directora de Tesis Doctoral, el Profesor Dr. Antonio Álvarez del Cuvillo y la Profesora Dra. Gema González Ferrera, por sus comentarios y aportaciones que han servido de sustento en la elaboración de este trabajo.
} 
Keywords: Gender, Families, Migration Policies, Family Reunification, Public System of Social Protection, Social Integration.

\section{Resumen extenso}

El trabajo de investigación parte de dos hipótesis: 1) El reagrupamiento familiar es un instrumento para la integración que favorece el acceso en igualdad a los bienes, derechos y recursos que ofrece el Sistema Público de Protección Social. 2) El género condiciona el acceso a los derechos y la participación en igualdad de las mujeres inmigrantes en las sociedades españolas de acogida. La población objetivo son las mujeres extracomunitarias y sus familias ya que las mujeres comunitarias generalmente no encuentran especiales obstáculos en el ejercicio del derecho a convivir con sus familiares en España.

La finalidad es visibilizar los procesos migratorios y de reagrupación desarrollados por mujeres ya que éstas, normalmente, soportan situaciones de mayor vulnerabilidad social, laboral y cultural. Además, se considera la necesidad de romper con el tratamiento homogéneo que reciben mujeres y hombres inmigrantes en la investigación social y desde los medios de comunicación.

La investigación propone dos objetivos específicos: 1) Estudiar y visibilizar los proyectos migratorios con finalidad de reagrupamiento familiar iniciados hacia España desde el año 2000. 2) Explorar los inconvenientes específicos que experimentan las mujeres en el ejercicio de este derecho en términos comparativos con los hombres, entendiendo la reagrupación familiar como un requisito necesario para convivir e integrarse en las sociedades de establecimiento.

Para llevar a cabo lo anterior, se estudian los flujos migratorios con perspectiva de género y las limitaciones para la integración social de las mujeres inmigrantes en España. Se analiza el periodo 2000-2014 y se atiende a aspectos laborales, socio-culturales y de género. Asimismo, se lleva a cabo un estudio pormenorizado de la reagrupación familiar en España desde una perspectiva jurídica y administrativa.

En segundo lugar, se recogen las dificultades específicas de las mujeres inmigrantes para alcanzar la reunificación desde el punto de vista de las reagrupadoras y del personal funcionario encargado de la tramitación de los expedientes y se realizan seis entrevistas semi-dirigidas en Granada, Almería y Málaga a personal funcionario especializado. En una segunda fase del estudio cualitativo, se realizan entrevistas a treinta mujeres y a treinta hombres de las diez nacionalidades más frecuentes, establecidas en el territorio español. La muestra es seleccionada mediante la técnica de bola de nieve y atiende a diferentes categorías etarias, de género y profesionales. Las cuestiones planteadas tratan de indagar en los inconvenientes asociados al género en el ejercicio del derecho a reunificar. Son las siguientes:

1. Las mujeres inmigrantes, ¿Encuentran más o menos dificultades que los hombres para ejercer el derecho a convivir en familia?

2. Las mujeres inmigrantes, ¿Solicitan la reagrupación en mayor o menor medida que los hombres?

3. Las mujeres inmigrantes, ¿Reagrupan con mayor o menor frecuencia que los hombres? 
En tercer lugar, el trabajo cualitativo se enrique con un estudio cuantitativo en el que se analizan seiscientos cinco expedientes de reagrupación familiar consultados en una Unidad de Extranjería de la Comunidad Autónoma de Andalucía durante el periodo comprendido entre enero de 2010 y febrero de 2012. El objetivo es cuantificar algunas variables significativas tales como la frecuencia de solicitudes de reagrupación familiar así como las principales causas de denegación atendiendo al género, la nacionalidad y la situación laboral.

La consulta de la comunidad científica y las indagaciones realizadas mediante el estudio cualitativo y cuantitativo permiten extraer conclusiones y formular las propuestas siguientes:

1. Las migraciones contemporáneas en España son principalmente económicas. Sin embargo, para las mujeres las motivaciones familiares son tan poderosas o más que los estímulos laborales.

2. Las migraciones permiten desarrollar potencialidades individuales, familiares y comunitarias y exigen la puesta en marcha de estrategias para lograr, en primer lugar, la subsistencia y en segundo lugar, el bienestar.

3. Los datos revelan que es exagerado considerar que se asiste a una 'llegada masiva de personas inmigrantes'. Dicha idea, ampliamente interiorizada entre la opinión pública española, encuentra su fundamento en los mensajes emitidos por los medios de comunicación, en los difundidos por quienes gobiernan y también, en cierta medida, en el discurso de una parte de la comunidad científica. Así pues, se ha construido 'el problema social de la inmigración' que ha desarrollado todo tipo de actitudes xenófobas frente a quienes vienen 'a robar' recursos y derechos.

4. Los procesos migratorios son, sin embargo, hechos sociales y consustanciales a la naturaleza humana que acontecen en todas las épocas y en todos los territorios. Por ello, no habrían de ser tratados como acontecimientos ocasionales e imprevisibles.

5. El verdadero problema es que, a pesar de varios intentos fallidos desde el año 1994, los poderes públicos españoles no han sabido dar respuesta a las necesidades específicas de algo menos de dos millones y medio de personas, las llamadas inmigrantes y mucho menos atender a las especificidades del género.

6. Los medios de comunicación suelen presentar una imagen distorsionada del fenómeno migratorio, sobre todo de las mujeres, al mostrarlas como un colectivo homogéneo de personas desvalidas y susceptibles de asistencia, sin ponderar las dificultades específicas que las mujeres inmigrantes encuentran en los procesos de entrada y de reagrupamiento familiar.

7. El estudio de la reagrupación como instrumento para la participación en igualdad de las mujeres inmigrantes permite visibilizar la heterogeneidad de las situaciones, personales y familiares, detectar obstáculos y analizar problemas desde la perspectiva del género.

8. El modelo de reagrupación familiar en España está basado en parámetros masculinos que dificultan el ejercicio del derecho en igualdad y perjudica a las mujeres.

9. El análisis de la norma, la práctica administrativa, los medios de comunicación y los estudios desarrollados por la comunidad científica ponen de mani- 
fiesto que no existe una práctica homogénea ni un criterio unificado en cuanto a los requisitos necesarios para reagrupar en las diferentes provincias y comunidades autónomas de España.

10. La entrada al país y el ejercicio del derecho a reagrupar están supeditados, casi únicamente, a la existencia de una relación laboral con determinados condicionantes, relacionados con el ingreso y la residencia legal, que restringen las posibilidades de participación en igualdad de las mujeres inmigrantes en España.

11. Los procesos para lograr la igualdad de las mujeres inmigrantes en España no sólo están determinados por la situación de regularidad o irregularidad también influyen otras variables como el género, la clase social, los rasgos fenotípicos, la raza, la etnia y, principalmente, la nacionalidad.

12. La igualdad entre mujeres y hombres inmigrantes en España encuentran, además, obstáculos por causas estructurales y del mercado de trabajo. El mercado laboral, por ejemplo, discrimina a las mujeres cuando considera que determinadas nacionalidades son más idóneas que otras para definidos desempeños profesionales.

13. Las mujeres inmigrantes están discriminadas en el mercado de trabajo, además de por su condición de mujer e inmigrante, por las duras condiciones del mercado de trabajo, como la rotación, la parcialidad, la estratificación, la alta concentración en escasos sectores de producción, la temporalidad y el paro. 14. En la mayor parte de los casos estudiados, las mujeres inmigrantes han tenido más dificultades para ejercer el derecho a la reagrupación familiar que los hombres, debido a su posición en el mercado de trabajo.

15. La discriminación salarial entre hombres y mujeres inmigrantes también dificulta el acceso en igualdad a la reagrupación familiar.

16. Al ser el Estado español claramente familiarista en la provisión de bienestar, favorece la participación en igualdad a través de las familias, puesto que éstas permiten el acceso a las prestaciones, a los servicios y a los recursos sociales.

17. Para las mujeres inmigrantes el acceso a los bienes, derechos y prestaciones sociales está limitado por variables tales como la situación de residencia y empleabilidad en el mercado laboral.

18. A pesar de los inconvenientes detectados, se constata que las mujeres inmigrantes en España desarrollan estrategias familiares para hacer efectivos los procesos de reagrupamiento y participación familiar en igualdad.

19. Dichas estrategias, sin embargo, no siempre son efectivas y los inconvenientes son mayores en función de variables tales como el color de la piel, la nacionalidad, las creencias religiosas y la clase social.

20. Las estrategias para lograr la igualdad de todas las personas en convivencia no pueden reducirse a garantizar el acceso a los bienes y a los derechos individuales y necesitan la puesta en marcha de políticas familiares y comunitarias para que los procesos sean efectivos.

21. La igualdad no puede entenderse como un asunto individual sino colectivo, de familias y de comunidades. Por ello, las políticas de igualdad y las familiares habrán de formularse de manera transversal al género, comenzando por 
la necesaria ampliación y diversificación de la cartera de prestaciones que ofrece el sistema de protección social.

22. De igual modo, las personas y las familias constituyen elementos fundamentales para salvar los obstáculos asociados al género y alcanzar la participación social en igualdad desde la disciplina del Trabajo Social.

23. La igualdad participativa exige un marco de protección social igualitario que atienda a las dificultades específicas de las nuevas familias residentes, acercando los recursos y proporcionando la información necesaria con la intermediación de los/as profesionales de lo Social.

24. Desde el Trabajo Social de Casos se propone la puesta en marcha de servicios públicos de acogida y orientación de las mujeres inmigrantes que inician proyectos migratorios con finalidades de reagrupación familiar para que puedan acceder en igualdad a la amplia red de recursos, servicios y prestaciones, reduciendo así su vulnerabilidad.

\section{Extended abstract}

The present research has two hypotheses: 1) Family reunification is an instrument for the integration as it promotes the access to the goods, rights and resources provided by the Social Protection System. 2) Gender determines the access to the rights and the participation of immigrant women in the Spanish host societies.

The target population is non-EU women and their families, because, generally, EU women do not face particular constraints on the exercise of the right to live with their families in Spain.

The main goal is to show the migration processes and reunification carried out by women because they usually support situations of major social, labour and cultural vulnerability. Moreover, the need to break with the homogeneous treatment immigrant women and men receive in social research and the media is also considered.

This research proposes two specific objectives: 1) To study and highlight migration projects on family reunification in Spain since 2000. 2) To explore the specific disadvantages experienced by women in the exercise of this right compared to men, understanding that family reunification is a needed requirement to live and to integrate into the host societies.

To achieve these objectives, migration flows and limitations for social integration of immigrant women in Spain were studied from a gender perspective. Industrial, socio-cultural and gender aspects are analysed in the period 2000-2014. In addition, a detailed study of family reunification in Spain was attempted from a legal and administrative perspective.

In a second step, the specific difficulties of immigrant women to achieve reunification were treated. Contributions about women who had regrouped their families and official personnel responsible for the handling of cases were collected in six semi-structured interviews with civil servants in Granada, Almeria and Málaga. In a second phase of this qualitative step of the study, thirty men and thirty women, of the ten most frequent nationalities established in Spanish territory, were interviewed. The interviewees were contacted by the means of a snowball technique; they were representative of different age, 
gender and professional categories. The interviews aimed to explore the relation between gender and the difficulties found in family reunification. The questions were:

1) Do immigrant women find more or less difficulties than men to exercise the right to live together as a family?

2) Do immigrant women request reunification more or less often than men?

3) Do immigrant women regroup their families more or less often than men?

In a third step, the contributions from the qualitative interviews were put in perspective against a quantitative study in which six hundred and five cases of family reunification (consulted in the Immigration Unit of the Autonomous Community of Andalucía between January 2010 and February 2012) were analysed. The objective was to quantify some important variables such as the frequency of requests for family reunification and the main reasons for refusal, considering gender, nationality and employment status.

The query of the scientific community and the investigation carried out through the qualitative and quantitative studies, lead to draw conclusions and make the following proposals:

1) The contemporary migrations in Spain have mainly economic motivations. However, for women, family reasons are as, or even more, powerful than professional ones.

2) Migrations allow developing individual, family and community strengths, and they require the implementation of strategies to achieve initially mere survival and later higher standards of social welfare.

3) The data show that it is exaggerated to consider that there is a 'mass influx' of immigrants. This idea, widely internalized among the Spanish public opinion, is supported by the messages sent by the media, decision-makers and also, to some extent, in the discourses of the scientific community. Thus, the artificially built 'social problem of immigration' has fostered all kinds of xenophobia attitudes against those who are 'stealing' resources and rights.

4) Migration processes are, however, social facts. They are inherent to human nature and they occur in all ages and in all territories. Therefore, they should not be treated as occasional and unpredictable events.

5) The real problem is that, despite several attempts since 1994, the Spanish authorities have failed to address the specific needs of fewer than two and a half million immigrant people. In this context it is not surprising that gender specificities have not been treated.

6) The media often present a distorted picture of migration, especially of women, by showing them as a homogeneous group of deprived people prone to receive assistance, without weighing the specific difficulties that immigrant women confront in the process of entry and family reunification.

7) The study of reunification as an instrument for the equal participation of immigrant women allows appraising the heterogeneity of personal and family situations, detecting obstacles and analysing problems from a gender perspective.

8) The model of family reunification in Spain is based on masculine parameters that difficult the equality of rights and harm women. 
9) The analysis of the standard administrative practice, the media and studies developed by the scientific community demonstrates that in the different provinces and regions in Spain, there is not a unified and consistent practice and criteria regarding the requirements to regroup.

10) The arrival to the country and the exercise of the right to regroup are determined almost solely by the existence of an employment with certain conditions of income and legal residence. Thus, the chances of equal participation of immigrant women in Spain are conditioned by these variables.

11) The processes to achieve equality for immigrant women in Spain are not only determined by the situation of regularity or irregularity, other variables such as gender, social class, phenotypic traits, race, ethnicity, and mainly nationality are also influencing these processes.

12) Equality between immigrant women and men in Spain also face obstacles caused by structural and labour market characteristics. The labour market, for example, discriminates against women when it considers that certain nationalities are more appropriate than others for certain professional works. 13) Immigrant women are also discriminated in the labour market due to its harsh conditions, such as rotation, part time, stratification, the high concentration in a few sectors production, seasonality and unemployment.

14) In most of the cases in the present study, the exercise of the right to family reunification has been easier for immigrant men than women, because of their position in the labour market.

15) Wage discrimination between male and female immigrants also hinders equal access to family reunification.

16) Because the Spanish State is clearly 'familiarist' in what concerns welfare provision, it promotes equal participation through families, since they provide access to benefits, services and social resources.

17) For immigrant women access to the property, rights and benefits are conditioned by variables such as residential status and employability in the labour market.

18) Despite the identified shortcomings, this study shows that immigrant women in Spain develop effective strategies to undertake the processes of reunification and family participation in equal conditions.

19) Such strategies, however, are not always effective and the disadvantages are depending on variables such as skin colour, nationality, religious beliefs and social class.

20) Strategies to achieve the equality of all persons living together cannot be reduced to ensure access to property and individual rights, and they require the implementation of family and community policies.

21) Equality should not be understood as an individual matter but rather as a collective affair, of families and communities. Therefore, politics for family and equality must be formulated transversely to gender, beginning with the necessary expansion and diversification of the services offered by the Social Protection System.

22) From the Social Work perspective, individuals and families are essential elements to achieve gender and social equality in participation. 
23) Equality in participation requires a framework of equal social protection that meets the specific challenges of the new resident families, bringing the resources and providing the necessary information with the intermediation of professional social workers.

24) From Social Work of Cases we propose the implementation of public services of welcome and orientation of women immigrants who have initiated migration projects for family reunification purposes, therefore to support the equal access to the available resources, services and benefits, thereby reducing their vulnerabilities.

\section{INTRODUCCIÓN: GÉNERO Y DIVERSIDAD MIGRATORIA HACIA ESPAÑA 2000-2014}

Las personas extranjeras que viven en la Unión Europea representan el 6,5\% de la población. La mayoría (20,2 millones) son nacionales de países extracomunitarios mientras que 12,3 millones son ciudadanas de alguno de los estados miembros (Eurostat, 2013). Asimismo, la proporción de población extranjera según sexo en el espacio europeo es equilibrada, en torno al $51 \%$ de hombres y el $49 \%$ de mujeres.

En España y en Andalucía se observan algunas peculiaridades. En el ámbito nacional, de los casi seis millones de personas no nacionales, cerca de tres millones pertenecen a países no comunitarios y algo más de dos millones y medio son originarios/as de otros países europeos. Sin embargo, el número total de personas no comunitarias ha descendido; representaban el 59,7\% en el año 2009 (OREF, 2010) y suponen el 54,6\% en el año 2014 (INE, 2014).

Respecto al origen geográfico, los dos grupos mayoritarios son el latinoamericano y el africano (Padrón, 2011; INE, 2012) y por nacionalidades destacan trece países en el periodo 2000-2014. Así, las primeras posiciones son ocupadas por Rumania y Bulgaria, seguidas de Ecuador. Con porcentajes notablemente menores se disponen Colombia y Bulgaria, acompañadas de China y Perú. Por último y en proporciones muy parecidas, se encuentran las personas procedentes de Ucrania, Argelia, Argentina, Bolivia, República Dominicana y Cuba (Pajares, 2009; 2010:38).

En cuanto a la distribución por sexo, un elemento relevante en la caracterización de los flujos migratorios hacía España es el porcentaje equilibrado entre mujeres y hombres (Miyar Busto y Garrido Medina, 2010). Atendiendo a la nacionalidad y al género ${ }^{2}$, sin embargo, se observan algunas singularidades. Desde Latinoamérica, las mujeres superan en número a los hombres y man-

${ }^{2}$ Así, se atiende al género y no al sexo porque, unido a la condición biológica, el género engloba una serie de características culturales (Pérez de Río, 2009:8). 
tienen una media del 53\% mientras que las mujeres procedentes de Asia y África tienen una escasa presencia (INE, 2014). Además, a partir del año 2012 aumenta el número de ciudadanas rumanas empadronadas y de mujeres inmigrantes desde Marruecos (ambas nacionalidades continúan siendo las que reúnen mayor población femenina empadronada en España). Sin embargo, se reduce el número de mujeres procedentes de Ecuador, Colombia y Bolivia (PMC, 2012; PMC, 2014).

En relación a la distribución de la población inmigrante por grupos etarios, las mujeres son más jóvenes que los hombres inmigrantes en España. Así pues, reúnen mayor proporción de población en los tres grupos etarios que van desde los 20 a los 29 años y menor proporción en los cuatro grupos que van desde los 30 a los 44 años. Dichos intervalos de edad presentan, además, la tasa de actividad femenina más elevada (PMC, 2012; PMC, 2014). A pesar de que esta pauta se sigue con independencia de la nacionalidad de las mujeres, existen algunas diferencias reseñables. En primer lugar, la concentración en el intervalo 20-29 años es mayor para el grupo de mujeres procedentes de África (22\%, 25-29 años), en el momento de la entrada en el país. Para el grupo de Europa Oriental, la moda se adelanta ligeramente y se distribuye entre los 20 y los 24 años. Por otra parte, el tramo 30-44 años alcanza valores significativamente más altos para las mujeres nacidas en Asia. Entre las mujeres originarias de Latinoamérica se detecta un incremento en el tramo de los 5 a los 14 años. Dicho incremento podría sugerir la posibilidad de que hubieran sido reagrupadas por sus progenitores/as. Sin embargo, las familias latinoamericanas sobre todo utilizan los visados de turista para entrar al país al ser este un proceso más rápido y exigir menos requerimientos (INE, 2014).

Respecto al nivel educativo de las personas que inician procesos migratorios hacia España, las diferencias entre sexos se han reducido considerablemente en los últimos años y las mujeres muestran niveles educativos más altos que los hombres. A pesar de lo anterior, se mantiene una clara disparidad entre los niveles de estudios alcanzados, las posibilidades de proyección profesional y la nacionalidad (INE, 2014). Así, las mujeres inmigrantes desde África registran inferior formación académica y posibilidades de desarrollo profesional, mientras que las de procedencia latinoamericana concentran un nivel de estudios medio del $33 \%$ frente al $20 \%$ de las españolas y peores posibilidades de desarrollo profesional que estas últimas (INE, 2013).

En cuanto a los lugares de asentamiento y residencia, el 81\% de la población femenina está concentrada en seis comunidades autónomas: Cataluña, Madrid, Andalucía, Comunidad Valenciana, Canarias y Baleares. La proporción más baja de mujeres inmigrantes (por debajo del 5\%) se encuentra en Extremadura, 
Galicia y Principado de Asturias. La inmigración femenina se concentra sobre todo en la costa mediterránea, las dos Comunidades insulares y Madrid, en detrimento del noroeste español. La presencia de mujeres inmigrantes también tiene mucho peso en Murcia.

La concentración por comunidades autónomas varía, además, según nacionalidad. En Cataluña destacan las mujeres procedentes de Marruecos, Ecuador, Bolivia y China. En Madrid tienen una presencia importante las mujeres originarias de Marruecos, Ecuador y Perú. Por su parte, la Comunidad Autónoma de Andalucía presenta particularidades respecto a las anteriores y destacan las procedencias de Marruecos, Colombia, Bolivia, Argentina, Ecuador, Paraguay y Brasil.

Respecto a las formas de organización y convivencia familiar, la mayoría de las mujeres establecidas desde el año 2000 han formado familias siguiendo pautas endogámicas, mientras que bastantes menos se han unido con nacionales de la Unión Europea (Cortina y otras/os, 2006; 2010). Esta tendencia se mantiene en diciembre de 2012, donde el 12\% de las autorizaciones en el régimen comunitario se conceden a ciudadanas extracomunitarias. Estas mujeres acceden a dicho régimen en calidad de familiares de personas comunitarias o españolas mientras que el resto han de solicitar su autorización en el régimen general.

Por último, las mujeres desarrollan contactos familiares transnacionales mientras promueven la reunificación de sus familiares en España lo que les permite superar algunos de los obstáculos que enfrentan (Pedone, 2003).

\section{METODOLOGÍA}

El estudio parte de la hipótesis de que el reagrupamiento familiar es un instrumento para la integración que favorece el acceso en igualdad a los bienes, derechos y recursos que ofrece el Sistema público de protección social.

La población objetivo son las mujeres extracomunitarias y sus familias ya que las mujeres comunitarias, generalmente, no encuentran especiales obstáculos en el ejercicio del derecho a convivir con sus familiares en España. La finalidad es visibilizar los procesos migratorios y de reagrupación desarrollados por mujeres ya que éstas, normalmente, soportan situaciones de mayor vulnerabilidad social, laboral y cultural. Además, se considera la necesidad de romper con el tratamiento homogéneo que reciben las mujeres y hombres inmigrantes en la investigación social y en los medios de comunicación.

Se proponen dos objetivos específicos. En primer lugar, estudiar y visibilizar los proyectos migratorios con finalidad de reagrupamiento familiar iniciados hacia España desde el año 2000. Y, en segundo lugar, explorar los inconvenien- 
tes específicos que experimentan las mujeres en el ejercicio de este derecho en términos comparativos con los hombres, entendiendo la reagrupación familiar como un requisito necesario para convivir e integrarse en las sociedades de establecimiento.

Así pues, con el apoyo de la comunidad científica, se estudian los flujos migratorios con perspectiva de género y las limitaciones para la integración social de las mujeres inmigrantes en España. Se analiza el periodo 2000-2014 y se atiende a aspectos laborales, socio-culturales y de género. Junto a lo anterior, se lleva a cabo un estudio pormenorizado de la reagrupación familiar en España desde una perspectiva jurídica y administrativa. A este respecto, se han desarrollado los siguientes procedimientos: 1. Análisis de la normativa sobre reagrupación familiar, protección social e integración social de familias y mujeres migrantes en el ámbito andaluz, nacional y supranacional. 2. Contraste de la norma con la realidad desde la perspectiva de género mediante: el conocimiento extrajurídico obtenido a partir del estudio de fuentes primarias y secundarias, la comparación con situaciones diversas en el tiempo y el espacio y la consideración de problemas reales planteados en procesos judiciales y extraídos de fuentes empíricas primarias. 3. Identificación de problemas de eficacia en aplicaciones de la norma por parte de las administraciones públicas cuando no se atienden a las especificidades del género. 4. Formulación de conclusiones, propuestas de acción positiva y para la solución legislativa e interpretativa.

En paralelo, se recogen las dificultades específicas de las mujeres inmigrantes para alcanzar la reunificación desde la perspectiva de las reagrupadoras y del personal funcionario encargado de la tramitación de los expedientes y se realizan seis entrevistas semi-dirigidas en Granada, Almería y Málaga a personal funcionario especializado. En la segunda fase del estudio se realizan entrevistas a treinta mujeres y a treinta hombres de las diez nacionalidades más frecuentes, establecidas en el territorio español. La muestra fue seleccionada mediante la técnica de bola de nieve, atendiendo a diferentes categorías etarias, de género y profesionales.

Las cuestiones planteadas han tratado de indagar en los inconvenientes asociados al género en el ejercicio del derecho a reunificar y han sido las siguientes:

1. Las mujeres inmigrantes, ¿Encuentran más o menos dificultades que los hombres para ejercer el derecho a convivir en familia?

2. Las mujeres inmigrantes, ¿Solicitan la reagrupación en mayor o menor medida que los hombres?

3. Las mujeres inmigrantes, ¿Reagrupan con mayor o menor frecuencia que los hombres? 
El estudio cualitativo se ha enriquecido con el análisis de seiscientos cinco expedientes de reagrupación familiar consultados en una Unidad de Extranjería de la Comunidad Autónoma de Andalucía durante el periodo comprendido entre enero de 2010 y febrero de 2012. El objetivo ha sido cuantificar algunas variables significativas tales como la frecuencia de solicitudes de reagrupación familiar así como las principales causas de denegación atendiendo al género, la nacionalidad y la situación laboral. Los ítems extraídos han sido los siguientes:

1. Número de solicitudes de reagrupación familiar, según sexo y nacionalidad.

2. Número de solicitudes concedidas y denegadas, según sexo y nacionalidad.

3. Frecuencia de las solicitudes, según sexo y nacionalidad.

4. Frecuencia de las solicitudes concedidas y denegadas, según sexo y nacionalidad.

5. Denegaciones según sexo y nacionalidad de las personas reagrupantes.

6. Denegaciones según el sexo de la persona reagrupante y familiar que reagrupa.

7. Vínculo del primer familiar reagrupado/a, según sexo de la persona reagrupante.

8. Frecuencia en las concesiones del segundo familiar reagrupado/a, según sexo y nacionalidad de la persona reagrupante.

9. Frecuencia en las denegaciones del segundo familiar reagrupado/a, según sexo y nacionalidad de la persona reagrupante.

10. Incidencia de la causa económica en las denegaciones, según sexo y nacionalidad.

11. Incidencia de la causa económica y la base de cotización del último año en las denegaciones según sexo y nacionalidad.

12. Incidencia de la causa económica y los movimientos bancarios en las denegaciones según sexo y nacionalidad.

13. Incidencia del incumplimiento del requisito vivienda adecuada, según sexo y nacionalidad.

14. Incidencia de la falta de informe de habitabilidad, según sexo y nacionalidad.

15. Incumplimiento del requisito contrato de arrendamiento a nombre de la persona reagrupante, según sexo y nacionalidad.

16. Incumplimiento de contrato de trabajo a nombre de la persona reagrupante, según sexo y nacionalidad.

17. Incumplimiento del requisito de acta de matrimonio actualizada, según sexo y nacionalidad. 
18. Incumplimiento del requisito de acreditación de convivencia, según sexo y nacionalidad.

19. Incumplimiento de la acreditación de un sólo cónyuge, según sexo y nacionalidad.

20. Falta de acreditación de estar a cargo de la persona que reagrupa, según sexo y nacionalidad.

21. Incumplimiento de estar a cargo de la persona que reagrupa, según sexo.

22. Incumplimiento del requisito de empadronamiento, según sexo y nacionalidad.

23. Falta de autorización del otro/a progenitor/a, según sexo y nacionalidad.

24. Frecuencia de ocupaciones laborales en las denegaciones, según sexo y nacionalidad.

\section{RESULTADOS Y DISCUSIÓN}

\subsection{La construcción de la inmigración como problema social}

Sin lugar a dudas, el panorama migratorio español ha variado desde los años sesenta hasta la actualidad y, ahora más que antes, los poderes públicos enfrentan numerosos retos. A partir del año 2000, España es reconocida en el ámbito mundial como un país receptor de personas inmigrantes (Izquierdo, 1996; Aja y Arango, 2006). Además, las migraciones femeninas hacia España son más diversas así, por ejemplo, comienzan a llegar desde Marruecos (INE, 2012). A pesar de que los cambios son considerables, los resultados de varias investigaciones ponen en cuestión el extendido discurso de que a partir del año 2000 se ha producido en España un aumento excepcional y significativo de población inmigrante (Cachón, 2002; Pajares, 2010). En primer lugar, a principios de dicho año ninguno de los registros analizados contabilizaba el millón de personas inmigrantes ${ }^{3}$. En segundo lugar, el aumento de personas inmigrantes y extranjeras ha supuesto menos del $10 \%$ de la población en el periodo 2000-2014 (PMC, 2014). En tercer lugar, si bien es verdad que en el periodo citado se produce el mayor incremento, algo menos de la mitad de dichas personas no son consideradas un problema ya que provienen de países europeos. Por ello, el supuesto problema social de la inmigración queda reducido a poco más del 4\% de la población que es la que proviene de los países extracomunitarios. Lo anterior no pretende establecer la consideración de que el hecho inmigrante en España sea despreciable. Lo que sí procura evidenciar es que

\footnotetext{
${ }^{3}$ Según datos del Padrón Municipal de Habitantes, PHM, en enero de 2000, había en España 923.000 personas residentes con nacionalidad extranjera sobre una población total de 40,4 millones de habitantes (PMH, 2000).
} 
las afirmaciones alarmistas siguen provocando efectos desfavorables en los procesos de entrada y participación en igualdad de las mujeres inmigrantes. Dichas aseveraciones van en contra de la búsqueda de soluciones y alimentan la percepción de que las inmigraciones son hechos extraordinarios. De este modo a través de los medios de comunicación, por ejemplo, se tiende a especular sobre aumentos cuantitativos descontrolados y a la exageración de las cifras oficiales.

Algunos trabajos señalan, acertadamente, que la excepcionalidad de la realidad española reside en que dichos aumentos se han producido en un corto espacio de tiempo (Cachón, 2009). En este sentido, se habla de un excepcional flujo por su intensidad (Pajares, 2010). No obstante, en términos comparativos con otros países, los flujos migratorios hacia España han evolucionado de forma similar en Gran Bretaña, Italia y Alemania (Moreno y Bruquetas, 2011).

Respecto a la cantidad de personas inmigrantes, España se sitúa en segundo lugar por detrás de Alemania (Moreno y Bruquetas, 2011) y ocupa el segundo puesto de la OCDE por la inmigración recibida en términos absolutos. Por delante se sitúa Estados Unidos que recibe el doble de inmigración (Pajares, 2010:23-28; Eurostat, 2013). A pesar de lo anterior, no es menos cierto que las diferencias cuantitativas respecto a otros países próximos, tales como Reino Unido e Italia, son mínimas (INE, 2012; Eurostat, 2013). Además, a modo de ejemplo, los poderes públicos alemanes no han declarado en sus medios de difusión escrita tener un problema inmigratorio y, sin embargo, sí reconocen los beneficios económicos de esta nueva realidad.

En España, la construcción de la inmigración como problema social es un proceso institucional que tiene como punto de partida el Programa Global de Coordinación y Regulación de la Extranjería y la Inmigración, GRECO, del año 1994 (Cachón, 2002). A partir de dicho momento se establece la distinción administrativa entre dos categorías de personas no nacionales: las inmigrantes y las extranjeras. La pertenencia a alguno de estos estatus tiene importantes repercusiones para el acceso a derechos y para la participación en los espacios públicos y privados.

En realidad, si bien es cierto que hacia España se registran de manera significativa movimientos migratorios de mujeres desde el año 1996 (Bernárdez, 2007:9) muchas han llegado con anterioridad y desde algunos países antes que los hombres. Así, por ejemplo, los registros de afiliación y de altas y bajas en la Seguridad Social muestran cómo durante la década de los 70 y 80 el personal funcionario masculino que venía a trabajar a España contrataba a trabajadoras de su misma nacionalidad para atender las tareas del hogar. De 
igual modo, varios trabajos empíricos de la época recogen como funcionarios destinados en diferentes puntos del hemisferio terrestre mandaban traer a trabajadoras desde sus países de origen y justificaban sus decisiones cuando decían sentirse más cómodos y afines con éstas, por razones de cultura y gastronomía, para depositar los quehaceres de la casa y el cuidado de sus hijos e hijas (Sánchez, 2005).

El año 2000 supone un punto de inflexión en el proceso institucional de construcción de la inmigración como problema social ya que en torno a dicho año se produce el reconocimiento de la inmigración como un 'hecho social' y como un 'problema social' (Lenoir, 1993). Lo anterior viene, además, alimentado por un incremento del flujo migratorio a partir de las nuevas demandas del mercado laboral y por el reconocimiento público de 'la incapacidad de gestionar' el hecho migratorio.

El año 2006, ciertamente, supone otro cambio sustancial por varios motivos más. De un lado, se asiste a la consolidación de las redes migratorias en España y a cambios en las características de la población inmigrante tales como la ampliación de los tramos de edad. Esto último en parte es debido a la mayor utilización de la reagrupación familiar como forma de entrada al país a partir de las restricciones de la vía laboral. Además, se observa que las personas residentes construyen familias en los lugares de asentamiento, tienen descendencia y aparece un nuevo fenómeno, las incorrectamente llamadas 'segundas generaciones de inmigrantes'. Respecto a esto último, varios/as autores/as señalan que los/as descendientes de las personas inmigrantes en ningún caso realizan procesos migratorios por lo que si se trata de poner nombres sería más adecuada la denominación de primeras generaciones de nacionales (Gil, 2006).

Para terminar, se establece que la culminación del proceso de institucionalización del 'problema de la inmigración' se produce con la sucesión de una serie de acontecimientos que transforman el supuesto problema en un conflicto. Así, se suceden declaraciones desafortunadas por parte de diferentes responsables políticos, sindicales y sociales; solicitudes de mayores contingentes de trabajadores/as inmigrantes para cubrir puestos de trabajo que no resultan atractivos entre las poblaciones asentadas; llegadas y naufragios en pateras a Cádiz, Almería y Granada; sucesos violentos y racistas como los acaecidos en Almería y Murcia; protestas de las personas inmigrantes reivindicando mejoras laborales y sociales en Almería, Murcia y Madrid; manifestaciones de mujeres inmigrantes contra las restrictivas reformas de la Ley Orgánica de Extranjería en Madrid; desalojos de asentamientos en Barcelona; prohibiciones del uso del velo en los centros de educación secundaria de 
Madrid y Lleida; discusiones en los medios de comunicación de ámbito nacional sobre qué están aportado las personas inmigrantes al Estado de Bienestar; y vinculaciones mediáticas entre inmigración, cambios demográficos, aumentos de robos y desempleo.

En los últimos años y hasta el 2009, el debate social se amplía con los planteamientos sobre el acceso a la ciudadanía y la gestión de la multiculturalidad. A partir de finales del año 2011, sin embargo, la inmigración deja de tener una posición central en la escena política del país y esta tendencia se mantiene hasta la actualidad. Así puede observarse en las dos últimas encuestas del Centro de Investigaciones Sociológicas (CIS), realizadas durante los primeros meses del año 2013 y 2014, cuándo el ítem 'otros problemas' se sitúa por encima de la cuestión inmigratoria. Esto último supone una ruptura con la tendencia que venía desarrollándose desde el año 2000 y que incluía la inmigración entre las tres preocupaciones principales de las personas residentes en España. El hecho de que dicha inquietud haya dejado de ser expresada no es indicio de que las necesidades de las personas inmigrantes en España estén resueltas. Tampoco determina que estén superados los recelos de muchas personas respecto al reparto de los recursos entre viejos/as y nuevos/as residentes, más aun en época de escasez. Los cambios recogidos por el CIS, respecto a la percepción de los principales problemas en España, más bien son debidos a factores coyunturales en un contexto de crisis socio-económica. Por ello, cabe establecer que los problemas vinculados al hecho migratorio se mantienen, aunque en estado latente, ante la elevadísima tasa de desempleo (cercana a los seis millones de personas), los escándalos derivados de la corrupción de la clase dirigente, los suicidios de personas que pierden sus casas al ser desahuciadas por los bancos que gestionan sus hipotecas, los conflictos internacionales, etc.

\subsection{La entrada de mujeres inmigrantes en España: cuestionado el "efecto llamada"}

El efecto llamada de personas inmigrantes hacia España se puso en marcha a partir de un ciclo de expansión económica que exigió mano de obra para el desempeño de determinadas actividades (Colectivo IOE, 2005). También influyó la inversión de capital extranjero y en tecnología punta que generaron desarrollo económico y colocaron a España dentro de los países del primer mundo, a partir de su inclusión política y, especialmente, económica en la Unión Europea (Cachón, 2009:118). También ha impulsado el "efecto llamada" la democratización de España y la implantación del Estado de Bienestar. Otros acontecimientos han sido la Constitución española de 1978 y el establecimiento de un marco democrático para las relaciones salariales que ha reconfigurado 
el panorama social a través de la negociación colectiva y la libertad sindical (Cachón, 2009:118).

Junto a lo anterior, se recoge la universalización de las prestaciones sociales que han permitido el mantenimiento de las redes familiares y que éstas contribuyan mediante el llamado colchón familiar a amortiguar las dificultades y a sostener búsquedas de empleos convenientes y aceptables en otros países. De igual manera, se apunta el aumento del nivel educativo de la población activa y el incremento de las expectativas sociales de movilidad ascendente, que se trasladan por vía intergeneracional, junto con la elevación del nivel de aceptabilidad y deseabilidad de quienes trabajan autónomamente (Jiménez, 2011).

La idea del "efecto llamada" se ha extendido a la generalidad de las personas inmigrantes en España, olvidando la especificidad de las mujeres. Las circunstancias anteriores han confluido en la consideración del efecto llamada que ha operado como un fuerte factor de demanda de mano de obra inmigrante pero con resultados diferenciados según el género. Los resultados de esta investigación permiten poner en cuestión el "efecto llamada" a inicios del año 2000 e invitan a reflexionar sobre qué pudo provocar la llegada de mano de obra femenina inmigrante: ¿La existencia de un mercado segmentado y de una gran economía sumergida?, ¿Un creciente desajuste entre el nivel de aceptabilidad de los/as trabajadores/as en España y los puestos de trabajo ofrecidos?, ¿Los bajos salarios?, ¿La escasa movilidad laboral y la aún menor posibilidad de promoción profesional? Dichas cuestiones llevan a estudiar cómo las mujeres inmigrantes hacia España encuentran motivaciones familiares que priman sobre las laborales en sus emprendimientos migratorios. También que en la organización de la economía española por sectores de producción y en la importancia dada a cada uno de dichos sectores podría encontrarse el motivo principal del denominado "efecto llamada" de personas inmigrantes con fines laborales hacia España (Pajares, 2009).

\subsection{Limitaciones a la integración de mujeres inmigrantes en España: aspectos laborales y económicos}

3.3.1. La reducida participación de las mujeres inmigrantes en el mercado de trabajo español

El mercado de trabajo español se caracteriza por la segmentación laboral, entendida como la distinción entre dos tipos de puestos de trabajo: puestos muy cualificados y de altas productividades y otros que superan en número a los primeros y se definen por lo opuesto. También se caracteriza por la elevada 
temporalidad y la rotación así como por la existencia de una gran economía sumergida. Estas particularidades se vienen considerando desde hace tiempo problemas enraizados en la estructura laboral española.

En 2014, la tasa de temporalidad se sitúa en el 31\%, cifra que ya había sido alcanzada en el año 2007 y que supone el doble de la media de la zona euro, del 15,8\% (Eurostat, 2013). La elevada temporalidad encuentra causas muy complejas que están relacionadas, entre otras, con la incapacidad para estimular la contratación de carácter indefinido así como con la constante pérdida de empleo, especialmente en los sectores de mayor precariedad laboral.

Las acciones emprendidas en las sucesivas reformas legislativas, incluidas las de 2013 y 2014, muestran el arraigo de dicho fenómeno en el mercado de trabajo español. En España se han llegado a registrar índices de temporalidad del $91 \%$. Esto último significa que tan sólo el 9\% de los contratos, en el ámbito nacional, tienen carácter indefinido (Ceinos, 2006). Así pues, la temporalidad en España tiene carácter estructural y no está relacionada con los movimientos migratorios experimentados desde el año 2000.

En cuanto a la rotación, se recoge que un $44 \%$ de los contratos iniciales registrados en las oficinas de empleo, son menores de 3 meses y un 15\% inferiores o iguales a 7 días (INE, 2014). Estos datos permiten relacionar la temporalidad y la precariedad de los contratos que se celebran, en especial en determinadas ramas de actividad tales como la construcción, la hostelería, los servicios de proximidad y la agricultura. En dichas actividades, la proporción de población femenina activa e inmigrante está sobrerrepresentada, con respecto a otras ramas que soportan menor rotación.

De otro lado, los mercados laborales de España, Italia y Grecia se caracterizan por tener una economía sumergida de gran volumen, en comparación con otros países de la Unión Europea. Las actividades lucrativas que se desarrollan en la economía sumergida ocupan a gran parte de las personas inmigrantes desde el año 2000. También es cierto que la existencia del empleo sumergido no viene de la mano de la inmigración irregular ni ésta condiciona su aparición. El origen de la economía sumergida, según algunos trabajos, se sitúa en la Crisis del petróleo de 1973 (Martínez, 2007).

Por su parte, muchas mujeres inmigrantes, en situación regular e irregular, encuentran como única salida laboral el desempeño de actividades en la economía no declarada, como se puso de manifiesto tras el último proceso de regularización de personas inmigrantes del año 2005, al cual se presentaron 700.000 solicitudes vinculadas al mercado de trabajo informal. La mayor parte de estas solicitudes fueron presentadas por mujeres. 
El sistema español reproduce, además, un mercado de trabajo estratificado donde las diferencias entre regiones, sectores de producción, grupos de población, procedencias y género ponen de manifiesto las desiguales oportunidades entre hombres y mujeres inmigrantes. A nivel regional, las comunidades autónomas con mayores tasas de paro son por este orden: Andalucía, Extremadura y Murcia, mientras que las de mayor población activa son Baleares, Cataluña y Madrid ${ }^{4}$. Las regiones con mayores posibilidades de ocupación además son las que más atraen a las mujeres inmigrantes quienes también presentan mayor disponibilidad para la movilidad en busca de mejores oportunidades laborales.

Respecto a los sectores de producción, la economía española está definida en el siglo XXI como una economía de servicios. El sector servicios representa, cerca del 65\% del empleo total, tendencia que se ha visto acentuada a partir del año 1985 (Ceinos, 2006). A pesar de lo anterior, dicha economía se encuentra por debajo de las economías europeas más avanzadas. Esto último se debe, en parte, a las crisis económicas soportadas.

Con la Crisis de 1993, todos los sectores de producción experimentaron descensos inusuales, siendo ese año el peor desde que existen datos sobre empleo (Pajares, 2009a). La recuperación iniciada a partir del año 1994 se concentró en la construcción, los servicios avanzados y colectivos y, en menor medida, en la industria. La agricultura se ha mantenido en un tercer lugar hasta la actualidad, a pesar de los impulsos económicos proyectados desde la Unión Europea.

De otro lado, varios autores/as consideran que el español es un mercado de trabajo singular donde la posición de determinados grupos de población es especialmente conflictiva. En dicho sentido, las mujeres, los/as jóvenes y los/as inmigrantes son las personas más perjudicadas por el mercado español. Sin embargo, según sexo y desempeño de actividad laboral, la población inmigrante trabajadora de ambos sexos está en mayor medida representada en el mercado de trabajo respecto de la población autóctona (INE, 2013; EPA, 2013). Lo anterior quiere decir que, en primer lugar, las mujeres inmigrantes en España trabajan igual o más que los hombres inmigrantes. En segundo lugar, la población inmigrante en España trabaja más que la autóctona a pesar de que hay sectores de producción a los que no tienen acceso. En tercer lugar, el colectivo de mujeres consideradas jóvenes (hasta los 30 años de edad) triplica las tasas de paro de las personas denominadas adultas, siendo el índice mayor para las mujeres que para los hombres de todas las nacionalidades (INE, 2013). En cuarto

${ }^{4}$ Las diferencias regionales se analizan a través de la comparación de tres tasas que miden la actividad laboral en el mercado de trabajo de las personas trabajadoras potenciales entre los 16 y 65 años: las tasas de ocupación, las tasas de paro y las tasas de actividad. 
lugar, el colectivo de mujeres inmigrantes está en mayor medida sometido a la irregularidad laboral. En relación a esto último, según el INE el 63,5\% de las mujeres inmigrantes están afiliadas a la Seguridad Social (INE, 2013) mientras que para el mismo año según datos de la EPA, el 67,5\% de las mujeres inmigrantes se encuentran ocupadas (EPA, 2013).

\subsubsection{Actividad laboral y acceso a derechos de las mujeres inmigrantes}

En el periodo 2000-2014, la población extranjera y española no se ha visto afectada de igual manera ni con la misma intensidad por la coyuntura del mercado laboral español y son las mujeres inmigrantes las más perjudicadas (Carrasco, 2009:9). Las mujeres inmigrantes encuentran más o menos dificultades para participar en las ofertas del mercado laboral dependiendo del tiempo de residencia en España, de la provincia donde pretendan establecerse, de la nacionalidad y de la edad.

La tasa de actividad de las mujeres inmigrantes es más elevada que la de los hombres inmigrantes de todas las nacionalidades, a excepción de la africana. Asimismo, las mujeres inmigrantes suponen el $60 \%$ de la población no nacional y tienen una tasa de actividad de $23,7 \%$. De lo anterior se deduce que la mano de obra femenina inmigrante, a pesar de ser laboralmente más activa, desempeña con más frecuencia actividades en la economía no formal.

Además de la edad y el género, otros condicionantes de la igualdad son la clase social, el tiempo de residencia y la nacionalidad que actúan como excluyentes y ralentizadores de las oportunidades laborales (UNDP, 2010).

Según la estabilidad de los proyectos migratorios destacan en el tiempo las siguientes nacionalidades: Gambia, Filipinas, Marruecos, China y República Dominicana (Ribas, 2005:105-106). Estas personas llevan residiendo en España desde comienzos de los años noventa, sin embargo, se detectan diferencias de género respecto a la obtención de permisos de carácter permanente. En el caso de las personas de nacionalidad gambiana, las autorizaciones son disfrutadas, en su gran mayoría, sólo por hombres. Las mujeres procedentes de China, República Dominicana y Filipinas son las que con más frecuencia obtienen autorizaciones de carácter permanente (MIT, 2011).

En el extremo opuesto respecto a la obtención de autorizaciones de carácter permanente, se encuentran las personas nacionales de Ecuador, Bolivia y Colombia que no superan el 7\% (MIT, 2011). Esto está determinado por la inestabilidad laboral que soportan ambos sexos en las ocupaciones en las que se concentran; y, especialmente, en el caso de las mujeres por el desempeño en el servicio doméstico y en la economía informal. En este grupo también se incluyen las mujeres procedentes de Rumania debido a un periodo transitorio 
por el que se les exigía permisos de trabajo y residencia aun perteneciendo a la $\mathrm{UE}^{5} \mathrm{y}$, además, porque son uno de los colectivos más discriminados por el mercado de trabajo (Pajares, 2009).

En relación a la distribución según regímenes de afiliación durante el año $2014^{6}$, las mujeres inmigrantes se concentran en el régimen agrario y en el de empleadas de hogar. El régimen de empleadas de hogar cubre algo más del 90\% de las ocupaciones (Colectivo IOÉ, 2005).

En cuanto a la clasificación según regímenes y nacionalidad, se observan diferencias (Pajares, 2009:91-99). En términos absolutos, las mujeres procedentes de Rumania, Marruecos y Ecuador aportan mayor número de altas en el régimen agrario mientras que las procedentes de Bolivia presentan el mayor incremento en el de empleadas de hogar.

De otro lado, las mujeres muestran una representación desigual en los diferentes sectores de producción. El 88,4\% de las mujeres se ocupa en el sector servicios, el 9,4\% en el sector industria y el 2,2\% en el sector agricultura (INE, 2014). Además, las mujeres inmigrantes no participan en todas las ramas de actividad por lo que soportan una doble concentración en aquellas categorías menos o nada cualificadas (Parella, 2003). Y su exclusión persiste en el tiempo ya que las mujeres no se libran de estos desempeños una vez establecidas y finalizados los procesos migratorios.

Al disminuir las ocupaciones relacionadas con la construcción se detecta que los hombres inmigrantes empiezan a ocupar aquellos puestos que antes eran ocupados por mujeres. Así, ellas quedan híper-agrupadas en aquellas actividades no cualificadas y en el empleo sumergido donde ya estaban sobrerepresentadas.

La tasa de temporalidad de las mujeres inmigrantes es, en general, más alta que la de las españolas, las comunitarias y la de los hombres inmigrantes (Eurostat, 2013). Dicha temporalidad deriva, además, en situaciones de irregularidad pues la inserción laboral y la estabilidad legal están muy relacionadas con el tiempo de residencia en España (MIT, 2011). Así pues, se establece que las mujeres inmigrantes son más vulnerables a la irregularidad administrativa ya que encuentran más inconvenientes para alcanzar los meses de cotización exigidos para la renovación de las autorizaciones de trabajo y residencia. De lo anterior también se deduce una mayor disposición a la inestabilidad legal respecto de los hombres inmigrantes.

\footnotetext{
${ }^{5}$ Para más información, se puede consultar la Orden PRE/2072/2011, de 22 de julio, por la que se publica el Acuerdo de Consejo de Ministros por el que se establece la reactivación del periodo transitorio en relación con la libre circulación de los/as trabajadoras de Rumanía.

${ }^{6}$ Se puede consultar en $<$ http://www.seg-social.es/Internet_l/index.htm $>$ [Consultado 13/ 09/ 2014].
} 
De otro lado, las mujeres inmigrantes encuentran obstáculos para ascender verticalmente dentro del mercado de trabajo. Con carácter general, ocupan el doble de los puestos de trabajo no cualificados y cuando experimentan cierta movilidad entre sectores de producción, los descensos en las ocupaciones del servicio doméstico son suplidos por aumentos de las ocupaciones en el sector servicios. En este ámbito, además, desarrollan los puestos de trabajo menos cualificados. Esto último acontece no tanto por las exigencias del mercado de trabajo como porque los/as empresarias infravaloran a las mujeres, quienes representan más de la mitad de la mano de obra inmigrante disponible.

\subsubsection{Condiciones de trabajo de las mujeres inmigrantes}

Las mujeres inmigrantes son las principales responsables de las tareas referidas al cuidado de los hogares en los países denominados desarrollados. Una gran mayoría participa en el mercado laboral desarrollando trabajos en el ámbito privado como única salida profesional (Bernárdez, 2007:11).

El trabajo en el servicio doméstico se caracteriza por la parcialidad de las jornadas y por salarios que no superan el mínimo interprofesional.

La parcialidad es debida a decisiones personales y familiares además de a factores estructurales y coyunturales (Garrido, Miyar y Comet, 2010). En el desempeño de la parcialidad se aprecian diferencias de género (Aragón y otras/os, 2012:187). Entre las razones por las que se eligen situaciones de desarrollo laboral a tiempo parcial destacan dos: 'el desarrollo de cursos de formación' en el caso de los hombres y 'el cuidado de familiares' en el caso de las mujeres (EES, 2013).

En gran medida, las mujeres siguen haciendo frente en solitario a las responsabilidades de la casa, aun participando en el mercado laboral. La sujeción a jornadas parciales condiciona las carreras profesionales de las mujeres y su derecho a percibir determinadas prestaciones sociales tales como maternidad, desempleo, jubilación, invalidez e incapacidad.

La mayor parte de las jornadas parciales contratadas en España (el 98,5\%) están desarrolladas por mujeres inmigrantes. Los motivos del desempeño parcial están vinculados con el cuidado de niños/as, personas adultas enfermas o con algún grado de incapacidad, ancianas y personas dependientes. Igual ocurre cuando se opta por este tipo de jornadas para dedicarse a obligaciones familiares, las mujeres cubren el $94,7 \%$ de los puestos de trabajo ofertados.

De otro lado, las relaciones de género y la segregación por sectores de ocupación motivan que las mujeres tengan salarios más bajos que los hombres y que se tenga que hablar de discriminación salarial por razón de género (Saldaña, 2004). El salario medio de las mujeres inmigrantes, en casi todas las comuni- 
dades autónomas, es entre un 20\% y un 30\% inferior al salario medio de los hombres inmigrantes (EES, 2013). Las mayores divergencias entre sexos se producen en Aragón y Asturias y las menores en Canarias y Extremadura.

\subsection{La protección del derecho a reagrupar y los inconvenientes del género}

3.4.1. Evolución normativa en materia de extranjería: el derecho a reagrupar

El derecho a la reagrupación familiar, como instrumento que posibilita la vida familiar de las personas inmigrantes, está recogido por varios acuerdos de carácter internacional. Así, aparece contemplado en el artículo 8.1 del Convenio Europeo de Derechos Humanos de 1950 y en el artículo 16 de la Carta Social Europea de 1961. Igualmente, se encuentra protegido por el artículo 14 de la Convención sobre los Derechos Migratorios de los Trabajadores y sus Familias de 1990 y por los artículos 12, 13 y 23.1 del Pacto Internacional de Derechos Civiles y Políticos, como un derecho atribuido a todos los/as seres humanos. Junto a los anteriores, el derecho a vivir en familia también ha sido enunciado en el artículo 16.3 de la Declaración Universal de los Derechos Humanos. Los artículos citados vienen a expresar que las familias son elementos naturales y fundamentales de las sociedades y que tienen derecho a la protección de la sociedad y del estado.

En el ámbito europeo, en diciembre de 1999, la Comisión determina que desde hace algunos años la reagrupación familiar es la forma principal de inmigración legal entre los/as nacionales de terceros países hacía Europa. Así, la Comisión hace pública una propuesta ${ }^{7}$ para que desde el Consejo se enuncie una Directiva sobre la Reagrupación familiar.

La finalidad de la Comisión es establecer el derecho a la reagrupación familiar para beneficiar a los/as nacionales de terceros países que residen legalmente en el territorio de los estados miembros y a los/as ciudadanos de la Unión que no ejercen su derecho a la libre circulación. Dicha propuesta dio lugar a la Directiva 2003/86/CE del Consejo, de 22 de septiembre de 2003, sobre el Derecho a la Reagrupación Familiar, que garantiza que la reagrupación sea un derecho protegible en todo el territorio de la Unión (artículo 2) ya que contribuye a la creación de una estabilidad sociocultural que facilita la integración de los/as nacionales de terceros países en el estado miembro. Lo que por otra parte promueve la cohesión económica y social (artículo 4).

La reagrupación familiar también es un derecho subjetivo que se vincula al derecho a la vida privada familiar. En virtud del mismo, su titular puede

\footnotetext{
${ }^{7}$ Propuesta IP/99/920 de la Directiva sobre el derecho a la reagrupación familiar.
} 
solicitar la concesión de un permiso de residencia para determinados familiares que la Ley establece como beneficiarios/as del derecho. Es titular del derecho la persona extranjera que haya residido legamente en territorio español durante al menos un año y tenga autorización para residir al menos otro año más.

Por su parte, son familiares reagrupables el/la cónyuge o pareja de hecho, los hijos/as menores de edad o con discapacidad y los ascendientes que dependan económicamente de las personas reagrupantes. Dichos familiares deben residir fuera del país en el momento de ejercer el derecho.

El derecho a la reagrupación tiene carácter estable ya que no se extingue porque se rompa el vínculo familiar en el que se basa. Sin embargo, sí se vincula la duración del permiso de residencia de los/as familiares reagrupados/as a las personas reagrupantes.

En España, la protección constitucional del derecho a la reagrupación familiar aparece recogida en los artículos 18.1 y 39 de la Constitución que protegen el derecho fundamental a la intimidad familiar y el derecho a la protección de las familias. La figura de la reagrupación familiar se regula por primera vez mediante la Ley Orgánica 4/2000, de 11 de enero, sobre derechos y libertades de los extranjeros en España y su integración social, LOEx, Capítulo II, artículos 16 y 17. La LOEx pone el acento en la integración de las personas inmigrantes aunque con numerosas deficiencias técnicas y jurídicas. El artículo 16 enunciaba los derechos de las personas inmigrantes con residencia legal y el artículo 17 los/as familiares que podían ser reagrupados/as, incluyendo al/la cónyuge, a los hijos/as menores de edad o mayores con algún grado de discapacidad, así como a los/as ascendientes de las personas residentes sin mencionar, por el momento, a los/as ascendientes del cónyuge.

La LOEx 4/2000 fue aprobada durante la primera legislatura del Partido Popular y reformada durante la misma legislatura, mediante la Ley Orgánica 8/2000, de 22 de diciembre, de reforma de la Ley Orgánica 4/2000, de 11 de enero, sobre derechos y libertades de los extranjeros en España y su integración social. La LOEx 8/2000 modificó profundamente la LOEx 4/2000 reduciendo los derechos de las personas inmigrantes y cambiando, radicalmente, la orientación de la anterior por lo que tuvo que enfrentarse, varios años después, a diferentes recursos de inconstitucionalidad ${ }^{8}$.

${ }^{8}$ Recurso de inconstitucionalidad 1640/2001. Interpuesto por la Junta de Andalucía respecto a diversos preceptos de la Ley Orgánica 8/2000, de 22 de diciembre, de reforma de la Ley Orgánica 4/2000, de 11 de enero, sobre derechos y libertades de los extranjeros en España y su integración social. Sobre los derechos fundamentales de los extranjeros/as: reunión y manifestación, asociación, sindicación, huelga y tutela judicial cautelar. Recurso de inconstitucionalidad 1707-2001.Interpuesto por el Parlamento de Navarra contra diversos preceptos de la Ley Orgánica 8/2000, de 22 de diciembre, de reforma de la Ley Orgánica 
Así pues, la aprobación de la reforma de la LOEx 8/2000 obtuvo un fuerte rechazo social por parte de los sindicatos, las ONGs y las propias personas inmigrantes. Los argumentos esgrimidos por el Gobierno para modificar la LOEx fueron cuatro: 1) evitar el 'efecto llamada'; 2) luchar contra las redes de tráfico ilegal de personas; 3 ) cumplir con las normas comunitarias y 4) favorecer la inmigración regular (Cachón, 2004). El primero de dichos motivos ignoraba, sin embargo, que la 'llamada' de trabajadores/as se estaba produciendo desde el mercado de trabajo. El segundo estaba justificado, pero los instrumentos se revelaron insuficientes porque impidiendo el acceso legal al territorio no se evitaban las entradas irregulares ni que las mafias desarrollaran sus actividades con impunidad. El tercer argumento se basaba en los requerimientos comunitarios pero ni las conclusiones de la presidencia del Consejo Europeo de Tampere (1999), ni la Comunicación de la Comisión de noviembre de 2000, ni las dos Directivas aprobadas ese mismo año: Directiva 2000/43/CE contra la discriminación por origen racial o étnico y Directiva 2000/78/CE sobre igualdad de trato en el empleo, fundamentan los cambios introducidos. El cuarto motivo señalado hubiera resultado positivo si no se hubiera desarrollado vulnerando derechos humanos tales como el derecho a convivir en familia.

La Ley Orgánica 8/2000 tuvo su desarrollo a través del Real Decreto 864/2001, de 20 de julio, por el que se aprobó el Reglamento de ejecución de la Ley Orgánica 4/2000, de 11 de enero, sobre derechos y libertades de los extranjeros en España y su integración social, reformada por Ley Orgánica 8/2000, de 22 de diciembre. Este Reglamento ha sido objeto de varias sentencias contrarias del Tribunal Supremo anulando varios de sus artículos 9.

El cambio a peor continuó y se vio ampliado en 2003. La LOEx 14/2003 establecía que un/a familiar reagrupado/a sólo podría reagrupar a otro/a cuando obtuviera un permiso de residencia independiente del de su titular, por tanto prohibía la reagrupación 'en cadena'. Dicha prohibición ya había sido previa-

4/2000, de 11 de enero, sobre derechos y libertades de los extranjeros en España y su integración social. Sobre los Derechos fundamentales de los extranjeros/as: reunión y manifestación, asociación, educación, sindicación, intimidad familiar y reagrupación; motivación de la denegación de visado; asistencia jurídica gratuita; expulsión por conducta delictiva; internamiento de retornados; defensa en el procedimiento de expulsión preferente.

${ }^{9}$ Sentencia TC 236/2007, de 7 de noviembre de 2007 que declara la inconstitucionalidad con los efectos que se indican en el fundamento jurídico 17, de los arts. 7.1, 8 y 11.1, exclusivamente respecto al derecho a sindicarse libremente, de la Ley Orgánica 4/2000, de 11 de enero, en la redacción dada por la Ley Orgánica 8/2000, de 22 de diciembre; Sentencia TC 259/2007, de 19 de diciembre de 2007 que declara inconstitucional y nula la inclusión del término «residentes» en los arts. 9.3 y 22.2 de la Ley Orgánica 4/2000, de 11 de enero, en la redacción dada por la Ley Orgánica 8/2000, de 22 de diciembre. 
mente agregada por vía reglamentaria pero fue declarada nula por el Tribunal Supremo ya que en ese momento era una limitación sin soporte legal ${ }^{10}$.

La última reforma de la LOEx 2/2009 incluye diversas modificaciones a la reagrupación familiar. En primer lugar, sigue la tendencia iniciada por los países limítrofes y las/os posibles familiares a reagrupar se limitan al modelo de familia occidental, nuclear y patriarcal. Asimismo, supone el reconocimiento de las parejas de hecho que son incluidas dentro de la categoría de familias y se reconoce el derecho de las personas reagrupantes a reunificar a las parejas en relaciones de afectividad análoga a la conyugal. Además, a las personas reagrupadas se les facilita el acceso inmediato al mercado de trabajo, eliminando la situación de dependencia económica que promovía la Ley antes de la última reforma.

Otra de las modificaciones de la LOEx 2/2009 supone la inclusión de amplias restricciones en la reagrupación de familiares ascendientes. Con carácter general, se limita la reagrupación de familiares menores de sesenta y cinco años, con la previsión de que la anterior limitación no se tendrá en cuenta cuando existan razones humanitarias que así lo aconsejen. Dicha limitación etaria pretende controlar las entradas de familiares que vienen con proyectos laborales o para ayudar en el cuidado y crianza de los/as menores de la familia. Estas familias utilizan el instrumento jurídico de la reagrupación, en lugar del de la autorización de trabajo, porque este último se había restringido mucho a partir de la exigencia de presentar, junto con las solicitudes desde los países de origen, ofertas de trabajo en España.

Por último, la LOEx 2009 supone un cambio importante al enunciar la exigencia de políticas de integración de todas las personas y familias en sus comunidades y la ampliación de la cartera de derechos a la que tienen acceso las personas inmigrantes con independencia de su situación de residencia legal o ilegal en el territorio español. Sin embargo, por el momento, ni la LOEx ni su Reglamento de desarrollo recogen los derechos y las prestaciones familiares de las personas y familias inmigrantes en España y tampoco atiende a las especificidades del género, la nacionalidad, la clase social y la etnia.

\subsubsection{Principales obstáculos de las mujeres inmigrantes para reagrupar}

En primer lugar, siendo los requisitos para reagrupar: medios económicos suficientes, vivienda digna y situación de regularidad en España, la imposibili-

${ }^{10}$ Sentencia TS 1924/2003 de 20 de marzo de 2003, (Sala Tercera): por la que se anulan diversos preceptos del Reglamento de ejecución de la Ley Orgánica 4/2000, de 11 de enero, sobre derechos y libertades de los extranjeros en España, reformada por la Ley Orgánica 8/2000, de 22 de diciembre. 
dad de cumplir el requisito económico en igualdad se convierte en la principal dificultad de las mujeres inmigrantes. Máxime cuando hasta marzo de 2011, por parte de la Administración no ha existido una práctica homogénea en cuanto a los requisitos exigibles, ni un criterio unificado entre regiones para la acreditación de medios económicos, periódicos y suficientes. Cuando, incluso, no se están cumpliendo las recomendaciones de la Unión Europea de adecuación de los requerimientos establecidos al nivel económico de la zona.

El requisito económico está basado en un modelo masculino de persona reagrupante; considerando que, en España, el 90\% de las mujeres inmigrantes se ocupan en los servicios de proximidad y sus salarios son inferiores al criterio establecido. Dicha circunstancia no ha sido solventada con la entrada en vigor del nuevo Real Decreto por el que se regula la relación laboral de carácter especial del servicio del hogar familiar ${ }^{11}$.

En segundo lugar, el mercado de trabajo se presenta como el principal causante de la discriminación de las mujeres inmigrantes, debido a factores estructurales pero también a arquetipos relacionados con el género y con la nacionalidad de las trabajadoras.

Las mujeres inmigrantes resultan más productivas y, a partir de la crisis de la construcción, más activas cotizantes en la Seguridad Social. Sin embargo, tienen salarios inferiores y están sujetas, en mayor medida, al empleo sumergido, a la parcialidad, a la temporalidad y a la rotación entre puestos de trabajo.

Dicha inestabilidad laboral provoca situaciones de irregularidad, la imposibilidad de renovar los permisos de trabajo y de residencia, cuya posesión es exigida para reagrupar, así como que los procesos de reagrupación se alarguen en el tiempo.

Según la percepción mayoritaria del personal funcionario entrevistado, las mujeres inmigrantes solicitan la reagrupación en mayor porcentaje y, sin embargo, el resultado es que reagrupan en menor medida (Registro de campo. UEx. $21 / 5 / 2010)^{12}$.

A partir de las dos conclusiones anteriores, se puede determinar que el modelo de reunificación español se ha creado sobre la base de estándares masculinos puesto que:

\footnotetext{
${ }^{11}$ Real Decreto 1620/2011 de 14 de noviembre, por el que se regula la relación laboral de carácter especial del servicio del hogar familiar y que vendría a modificar el anterior Real Decreto 1424/1985 de 1 de agosto.

${ }^{12}$ Para tipificar el estudio cualitativo se distingue entre Registro de campo. UEx, que recoge las opiniones del personal funcionario de las unidades de extranjería y Registro de campo. RF, que atiende a las opiniones de las personas reagrupadoras familiares.
} 
1) El requerimiento de medios económicos suficientes se ha establecido a partir del salario medio de los hombres inmigrantes.

2) La exigencia de periodicidad de los ingresos no atiende a las características ocupacionales de las mujeres inmigrantes.

3) La temporalidad laboral a la que se encuentran sometidas las mujeres, dificulta su permanencia en situación regular en el país.

4) El salario medio de las mujeres inmigrantes y su vinculación a trabajos no cualificados entorpece el acceso a las viviendas consideradas dignas.

5) Los salarios medios de las mujeres inmigrantes son inferiores al criterio establecido a través del IPREM.

En tercer lugar, los estereotipos de género, clase y etnia obstaculizan los procesos de reunificación emprendidos tal y como se expondrá en las conclusiones siguientes. Las mujeres inmigrantes tienen que enfrentarse a estereotipos que distorsionan la realidad y dificultan la comprensión y el respeto por la diversidad.

La consideración de la superioridad masculina migrante, como fuerza de trabajo, implica que ante la escasez de ocupaciones, las mujeres quedan relegadas a aquellos puestos menos cualificados donde ya están sobrerrepresentadas, a pesar de que su nivel formativo y su capacidad para la movilidad laboral son mejores (Registro. Uex. 26/5/2010).

Otra falsa construcción social está relacionada con la idea de que las mujeres inmigrantes no reunifican (Registro de campo. UEx. 24/5/2010). En este sentido, la última reforma de la LOEx, permite la compensación de salarios entre cónyuges en los procesos de reagrupación pero olvida a las mujeres reagrupantes solitarias.

La percepción de que las mujeres son reagrupadas y no reagrupantes condiciona, además, el trabajo del personal funcionario en la gestión de solicitudes y del personal trabajador social en la emisión de informes favorables, aun cuando las mujeres presentan periodos de cotización más largos y permanentes en el tiempo respecto de los hombres inmigrantes (Registro. Uex. 26/5/2010).

Los estereotipos, de otra parte, no dependen de la situación de regularidad o irregularidad de las mujeres y son ejercidos a partir de la percepción de lo diferente como algo negativo (Registro de campo. RF. 18/5/2011).

La discriminación será más o menos intensa dependiendo de la formación, la clase social, la etnia, el tiempo de residencia, la situación de regularidad, el esfuerzo e interés mostrado en los procesos de integración y la actitud, más o menos receptiva, de las comunidades de acogida (Registro de campo. RF. 18/5/2011). Esto explica porque las mujeres de origen rumano son tratadas como inmigrantes por el mercado de trabajo y por los planes y políticas públicas, aun pertene- 
ciendo a la Unión Europea, mientras que las de origen cubano o las de nacionalidad argentina están ocupando puestos similares a las mujeres españolas, en algunos casos. Las mayores oportunidades de estas dos últimas procedencias están fundadas en las similitudes culturales y étnicas y en la existencia de vínculos históricos y familiares que se remontan varios siglos en el tiempo.

Los estereotipos asociados a las mujeres y a su responsabilidad como sustentadoras de las familias desarrollan, en ellas, mayores sentimientos de culpa, si las reagrupaciones no se consiguen efectivamente (Registro de campo. RF. 15/9/2011). Sin embargo, las mujeres suelen ser más productivas económicamente si pueden convivir con sus seres queridos en España ya que gozan de mayor salud y estabilidad emocional (Registro de campo. Uex. 23/9/2010).

En cuarto lugar, los medios de comunicación muestran a las mujeres inmigrantes como una masa homogénea y sin capacidad de decisión. Son responsables directos de que el mercado de trabajo considere a unas nacionalidades más atractivas que a otras y de la distribución de las personas inmigrantes entre categorías profesionales, según esta misma condición. Los medios difunden ideas preconcebidas como que las mujeres de origen ecuatoriano tienen gran capacidad para trabajar en los servicios de proximidad mientras las mujeres de raza negra presentan un carácter desordenado (Registro. RF. 2/9/2011).

En quinto lugar, el nivel de discriminación depende de la nacionalidad y del tiempo de residencia y, por tanto, de la mayor posibilidad para establecer vínculos interpersonales así como de la actitud de las comunidades donde pretendan integrarse dichas mujeres.

Si ellas se encuentran apoyadas por sus familias, en el desarrollo de sus estrategias migratorias y si deciden proyectos empresariales propios, como es el caso de la mayoría de las mujeres de nacionalidad china, tendrán más oportunidades de prosperar (Registro de campo. Uex. 17/9/2010).

Por último, se exige que en los procesos de reagrupación familiar sean analizadas las situaciones particulares de las personas solicitantes para reducir las situaciones de desigualdad entre hombres y mujeres y promover el acceso de las mujeres a dicho derecho en igualdad de condiciones.

Asimismo, se propone que el análisis de los expedientes, por parte de los/as profesionales del Trabajo Social, se extienda a todos los requerimientos exigidos en materia de reagrupamiento familiar. Así, por ejemplo, que puedan supervisar la exigencia de acreditar medios económicos suficientes y que se plantee la posibilidad de diversificar el cumplimiento de dicho requisito o, al menos, de establecer diferencias que atiendan al género.

Las actuaciones estatales deben estar dirigidas a la consecución de un mercado de trabajo más digno y equitativo desde el punto de vista del género, que 
permita a las mujeres inmigrantes abandonar los nichos laborales que en su día facilitaron su acceso al mercado laboral, consiguiendo la merecida promoción social y el acceso a los derechos, los recursos y las prestaciones en igualdad de condiciones en las sociedades de acogida.

Las acciones públicas habrán de ir destinadas a gestionar de forma equitativa los recursos pero también hacía atenciones más personalizadas desde el Trabajo Social y los Servicios Sociales. Ahora bien, esta labor no puede ser emprendida únicamente por el personal trabajador social. Los poderes públicos habrán de actuar ante los factores estructurales y coyunturales, las ineficaces políticas públicas, la ausencia de inspecciones, las insuficiencias jurídicas y las carencias administrativas que gestionan y dan respuestas en los nuevos contextos.

\section{CONCLUSIONES Y PROPUESTAS}

1. Las migraciones contemporáneas en España son principalmente económicas. Sin embargo, para las mujeres las motivaciones familiares son tan poderosas o más que los estímulos laborales.

2. Las migraciones permiten desarrollar potencialidades individuales, familiares y comunitarias y exigen la puesta en marcha de estrategias para lograr, en primer lugar, la subsistencia y en segundo lugar, el bienestar.

3. Los datos revelan que es exagerado considerar que se asiste a una 'llegada masiva de personas inmigrantes'. Dicha idea, ampliamente interiorizada entre la opinión pública española, encuentra su fundamento en los mensajes emitidos por los medios de comunicación, en los difundidos por quienes gobiernan y también, en cierta medida, en el discurso de una parte de la comunidad científica. De este modo se ha construido 'el problema social de la inmigración' que ha desarrollado todo tipo de actitudes xenófobas frente a quienes vienen 'a robar' recursos y derechos.

4. Los procesos migratorios son, sin embargo, hechos sociales y consustanciales a la naturaleza humana que acontecen en todas las épocas y en todos los territorios. Por ello, no habrían de ser tratados como acontecimientos ocasionales e imprevisibles.

5. El verdadero problema es que, a pesar de varios intentos fallidos desde el año 1994, los poderes públicos españoles no han sabido dar respuesta a las necesidades específicas de algo menos de dos millones y medio de personas, las llamadas inmigrantes y mucho menos atender a las especificidades del género.

6. Los medios de comunicación suelen presentar una imagen distorsionada del fenómeno migratorio, sobre todo de las mujeres, al mostrarlas como 
un colectivo homogéneo de personas desvalidas y susceptibles de asistencia, sin ponderar las dificultades específicas que éstas enfrentan en los procesos de entrada y reagrupamiento familiar.

7. El estudio de la reagrupación, como instrumento para la participación en igualdad de las mujeres inmigrantes, permite visibilizar la heterogeneidad de las situaciones personales y familiares, detectar obstáculos y analizar problemas desde la perspectiva del género.

8. El modelo de reagrupación familiar en España está basado en parámetros masculinos que dificultan el ejercicio del derecho en igualdad y perjudica a las mujeres.

9. El análisis de la norma, la práctica administrativa, los medios de comunicación y los estudios desarrollados por la comunidad científica ponen de manifiesto que no existe una práctica homogénea ni un criterio unificado en cuanto a los requisitos necesarios para reagrupar en las diferentes provincias y comunidades autónomas de España. Por ello, se comprueba que no se están cumpliendo las directrices marcadas por la Directiva 2003/86/CE del Consejo sobre el Derecho a la Reagrupación familiar, relativas a la necesidad de adecuación de los requisitos establecidos al nivel económico de la zona.

10. La entrada al país y el ejercicio del derecho a reagrupar están determinados, casi únicamente, por la existencia de una relación laboral con determinados condicionantes de ingreso y residencia legal. Así pues, las posibilidades de participación en igualdad de las mujeres inmigrantes en España están condicionadas por dichas variables.

11. Los procesos para lograr la igualdad de las mujeres inmigrantes en España no sólo están determinados por la situación de regularidad o irregularidad, también influyen otras variables como el género, la clase social, los rasgos fenotípicos, la raza, la etnia y, principalmente, la nacionalidad.

12. La igualdad entre mujeres y hombres inmigrantes en España encuentran, además, obstáculos por causas estructurales y del mercado de trabajo. El mercado laboral, por ejemplo, discrimina a las mujeres cuando considera que determinadas nacionalidades son más idóneas que otras para el desempeño profesional.

13. Las mujeres inmigrantes también están discriminadas en el mercado de trabajo, por su condición de mujer e inmigrante, por las actividades profesionales a las que tienen acceso y su frecuente sujeción a la rotación, la parcialidad, la estratificación, la alta concentración en escasos sectores de producción, la temporalidad y el paro. 
14. En la mayor parte de los casos estudiados, las mujeres inmigrantes han tenido más dificultades para ejercer el derecho a la reagrupación familiar que los hombres, debido a su posición en el mercado de trabajo.

15. La discriminación salarial entre hombres y mujeres inmigrantes también dificulta el acceso en igualdad a la reagrupación familiar.

16. Al ser el Estado español claramente familiarista en la provisión de bienestar, favorece la participación en igualdad a través de las familias, puesto que éstas permiten el acceso a las prestaciones, a los servicios y a los recursos sociales.

17. Para las mujeres inmigrantes el acceso a los bienes, derechos y prestaciones sociales está condicionado por variables tales como la situación de residencia y empleabilidad en el mercado laboral.

18. A pesar de los inconvenientes detectados, se constata que las mujeres inmigrantes en España desarrollan estrategias familiares para hacer efectivos los procesos de reagrupamiento y participación familiar en igualdad.

19. Dichas estrategias, sin embargo, no siempre son efectivas y los inconvenientes son mayores en función de variables tales como el color de la piel, la nacionalidad, las creencias religiosas y la clase social.

20. Las estrategias para lograr la igualdad de todas las personas en convivencia no pueden reducirse a garantizar el acceso a los bienes y a los derechos individuales sino que necesitan de la puesta en marcha de políticas familiares y comunitarias para que los procesos sean efectivos.

21. La igualdad no puede entenderse como un asunto individual sino colectivo, de familias y de comunidades. Por ello, las políticas de igualdad y las familiares habrán de formularse de manera transversal al género, comenzando por la necesaria ampliación y diversificación de la cartera de prestaciones que ofrece el Sistema de protección social.

22. De igual modo, las personas y las familias constituyen elementos fundamentales para salvar los obstáculos asociados al género y alcanzar la participación social en igualdad desde la disciplina del Trabajo Social.

23. La igualdad participativa exige un marco de protección social igualitario que atienda a las dificultades específicas de las nuevas familias residentes, acercando los recursos y proporcionando la información necesaria con la intermediación de los/as profesionales de lo social.

24. Desde el Trabajo Social de Casos se propone la puesta en marcha de servicios públicos de acogida y orientación de las mujeres inmigrantes que inician proyectos migratorios con finalidades de reagrupación familiar para que puedan acceder en igualdad a la red de recursos, servicios y prestaciones, reduciendo así su vulnerabilidad. 


\section{BIBLIOGRAFÍA}

Aja, E. y Arango, J. (ed). (2006). Veinte años de inmigración en España. Perspectiva jurídica y sociológica. Barcelona: Fundación CIDOB.

Bernárdez, A. (Dir.). (2007). Mujeres inmigrantes en España: representaciones en la información y percepción social. Madrid: Editorial Fragua.

Cachón, L. (2002). "La formación de la España inmigrante: mercado y ciudadanía". Revista Española de Investigaciones Sociológicas, 97, 95-126.

Cachón, L. (2004). "Los acuerdos bilaterales celebrados por España con Ecuador y Colombia”. En E. Geronimi, L. Cachón, E. Texidó, Acuerdos bilaterales de migración de mano de obra: estudio de casos. Estudios sobre migraciones internacionales, Ginebra: OIT, 23-93.

Cachón, L. (2009). La España inmigrante: Marco discriminatorio, mercado de trabajo y políticas de integración. Madrid: Anthropos.

Carrasco, C. (2009). Metodología para la inserción laboral de personas inmigrantes. Inserción de los extranjeros en el mercado de trabajo español: variables determinantes de las diferencias. Madrid. <http: http://www.redacoge.org/empresas/redacoge/documentos/intervencion/Metodologiainsercion.pdf > [1-9-2014].

Ceinos, A. (2006). "Flujo de extranjeros en mercado de trabajo". En, A. Ceinos, El trabajo de los extranjeros en España. Madrid: Wolters Kluwer España, S.A. La Ley, 253-261.

Colectivo IOÉ, Pereda, C., Actis, W. De Prada, M. A. (2005). "Mujeres inmigrantes y trabajo". En, F. Checa y Olmos, (ed.), Mujeres en el camino, Barcelona: Icaria editorial, 43-62.

Cortina, C., Esteve, A., Domingo, A. (2006). "Crecimiento y singularidades demográficas de los matrimonios de extranjeros en España”. Migraciones, 20, 75-105.

Cortina, C., Bueno, X. y Castro, T. (2010). “¿Modelos familiares de aquí o de allá? Pautas de cohabitación entre las mujeres latinoamericanas en España”. América Latina Hoy, 55, 61-84.

Estadística del Padrón Continuo (2012). Datos a nivel nacional, comunidad autónoma y provincia.<http://www.ine.es/jaxi/tabla.d> [10-1-2014].

Eurostat(2013).<http://epp.eurostat.ec.europa.eu/portal/page/portal/eurostat/home> [15-5-2014].

Encuesta Nacional de Inmigrantes (2008). Avance de resultados. Instituto Nacional de estadística. <http:www.ine.es/prensa/np499.pdf>. [2-2-2014].

Garrido, L., Miyar, M. y Comet, J. (2010). "La dinámica laboral de los inmigrantes en el cambio de fase del ciclo económico". Presupuesto y Gasto Público, 4, 201-221.

Gil, S. (2006). "Las políticas de integración de inmigrantes en el contexto español. Entre la normalización y el derecho a la diferencia". En, F. Vidal (ed.), Exclusión social y Estado de Bienestar en España, Madrid: FUHEM, 441-460.

Izquierdo, A. (1996). La inmigración inesperada. Barcelona: Trotta.

Instituto Nacional de Estadística, INE. (2012). Estadística del Padrón Continuo a 1 de enero de 2012. Datos a nivel nacional, comunidad autónoma y provincia. 
$<$ http://www.ine.es/jaxi/menu.do?type=pcaxis\&file=pcaxis\&path=\%2Ft20\%2Fe2 45\%2Fp04\%2F\%2Fa2012> [4-4-2014].

Instituto Nacional de Estadística, INE. (2012). Cifras INE (6/2012). Extranjeros en la Unión Europea y en España. Boletín informativo del Instituto Nacional de Estadística. Instituto Nacional de Estadística.<http://www.ine.es/inebmenu/mnu_sintesis. htm\#4> [12-4-2014].

Instituto Nacional de Estadística, INE. (2014). <http://www.ine.es> [30-4-2014].

Jimenez, C. I. (2011). "Inserciones de argentinos en sociedades etno-fragmentadas". Temas de antropología y migración. Migrantes latinoamericanos en Europa: lo singular en lo general, 2, 46-73.

Lenoir, R. (1993). "Objeto sociológico y problema social”. En, P. Champagne y otras/os, Iniciación a la práctica sociológica, Madrid: Siglo XXI, 57-102.

Martínez, R. (2007). "La inmigración en España y mercado de trabajo". Aposta, Revista de ciencias sociales, 32, 1-21.

Moreno, F. J. y Bruquetas, M. (2011). Inmigración y Estado de Bienestar en España. Barcelona: Fundación la Caixa.

Pajares, M. (2010). "Flujo migratorio en el contexto de la crisis económica". En, M. Pajares, Inmigración y mercado de trabajo, Observatorio Permanente de la Inmigración: Secretaría de Estado e Inmigración, 23-28.

Pajares, M. (2009). "Sectores y categorías laborales de ocupación de la población inmigrada". En, M. Pajares, Inmigración y mercado de trabajo, Madrid: Secretaría de Estado e Inmigración, 79-94.

Parella, S. (2003). Mujer, inmigrante y trabajadora. La triple discriminación. Barcelona: Anthropos Editorial.

Pedone, C. (2003). Tú siempre jalas a los tuyos. Cadena y redes migratorias de las familias ecuatorianas hacia España. Barcelona: Universidad Autónoma de Barcelona.

Pérez de Río, T. (2009). La Violencia de Género en el ámbito laboral: el acoso sexual y el acoso sexista. Albacete: Bomarzo Editorial.

Sánchez, R. (2005). Mandar a traer, Antropología, migraciones y transnacionalismo. Salvadoreños en Washington. Madrid: Editorial Universitas, S.A.

Saldaña, E. (2004). Discriminación retributiva en función del género. Un análisis técnico y jurídico. Cádiz: Monografías de temas laborales, Melgablum, S.L.

VANESA HERVÍAS PAREJO es licenciada en Ciencias Políticas y en Sociología por la Universidad de Granada y por la Universidad de Limerick, estudiante del Grado en Trabajo Social y Doctora con mención Internacional por la Universidad de Cádiz. Desde el año 2009, trabaja en el Área de Trabajo Social y Servicios Sociales del Departamento de Derecho del Trabajo y de la Seguridad Social de la Universidad de Cádiz. Imparte docencia en el Grado de Trabajo 
Social y en el Grado de Criminología y sus áreas de investigación prioritarias son: Género, Familias, Políticas Sociales, Trabajo Social en Comunidades y con Familias, Desarrollo Social, Migraciones y Extranjería. Su Tesis Doctoral se titula Reagrupación e Integración de mujeres inmigrantes desde la perspectiva familiar y del Trabajo Social.

Recibido: 20/09/2014 Aceptado: 30/12/2014 



\title{
PROTECCIÓN SOCIAL Y POLÍTICAS DE PROMOCIÓN DEL TRABAJO ASOCIATIVO Y AUTOGESTIONADO EN LA ARGENTINA (2003-2013): EL PROGRAMA ARGENTINA TRABAJA SOCIAL PROTECTION AND POLICIES OF PROMOTION OF ASSOCIATED AND SELF-MANAGED WORK IN ARGENTINA (2003-2013): THE ARGENTINA TRABAJA PROGRAMME
}

\author{
Denise Kasparian \\ Instituto de Investigaciones Gino Germani, Facultad de Ciencias \\ Sociales, Universidad de Buenos Aires, Argentina \\ denise.kasparian@gmail.com
}

\begin{abstract}
Resumen
El objetivo del artículo es examinar los modos de protección social que instaura el Programa Argentina Trabaja, de modo de aproximarnos al análisis de la calidad del trabajo generado por el Programa. A través de la revisión bibliográfica y el análisis documental, se identificaron aspectos positivos al respecto: la inscripción de los beneficiarios en el monotributo social, la percepción de la Asignación Universal por Hijo, y la conformación de cooperativas como modalidad de trabajo. La masividad del Programa y el monto del ingreso son elementos que potencian los cambios sociales que se proponen desde el diseño. No obstante, existen tensiones y limitaciones: las escasas posibilidades de diseñar e implementar autónomamente las actividades de las cooperativas; la percepción individual de los ingresos, y que los mismos no alcancen el salario mínimo vital y móvil, ni sean actualizados según los estándares del empleo asalariado formal; y los límites que aún acarrea el monotributo social en cuanto al efectivo uso de los beneficios que contempla. Se concluye que el Programa aporta mejorías para los trabajadores provenientes de la informalidad, mientras que, en comparación con la protección social anclada en el empleo formal asalariado, evidencia carencias.
\end{abstract}

Palabras clave: trabajo asociativo y autogestionado; sistemas de protección social; política social; integración social; contra-reforma. 


\begin{abstract}
The objective of the paper is to examine the modes of social protection established by the Argentina Trabaja Programme, so as to analyse the quality of the work generated by the Programme. Through bibliographic review and document analysis, positive elements in this regard were identified: the registration of the beneficiaries in the social monotribute, the perception of the universal child income, and the formation of cooperatives as a mode of work. The massiveness of the Programme and the amount of the income are elements that enhance the social changes proposed in the design. However, there are tensions and limitations: the limited possibilities of designing and implementing the activities of the cooperatives autonomously; the individual perception of the incomes, and that they neither reach the minimum wage, nor are updated by the standards of formal salaried employment; and the limits that still carries the social monotribute regarding the effective use of the benefits that provides. It is concluded that the Programme improves the conditions of workers coming from informality, while, in comparison with social protection provided to formal salaried workers, it shows deficiencies.
\end{abstract}

Keywords: associated and self-managed work; social protection systems; social policy; social integration; counter-reformation.

Extended abstract: The objective of this paper is to examine the modes of social protection established by the Argentina Trabaja Programme, so as to analyse the quality of the work generated by the Programme. Our main questions are: How have social policy and social protection evolved in Argentina? At what point in the field of social policy do the policies of promotion of associative and self-managed work and, more specifically, the Argentina Trabaja Programme arise? What kind of social protection does the Programme introduce? What are the differences with the social protection system anchored in formal salaried employment? To what extent does the Programme contribute to the promotion of "quality" work? Through bibliographic review and document analysis, especially of official documents, we analyse the Programme in terms of its innovations and limitations regarding social protection and social policy, aiming to make an assessment of its contribution to the construction of "quality" work.

By the mid-twentieth century in Argentina, although in much lower degrees than those achieved in core countries, the ability to protect of the social security had reached high levels. From the seventies, in line with the transformation of the Welfare State in core countries, rising levels of unemployment began to be observed in Argentinean labor market. Added to this, the classical form of employment with protection and social security began to mutate into ways of employment with different forms of precarization. The dismantling of social protection systems associated with formal salaried employment began. This process was deepened during the nineties, as a financial valuation model with neoliberal hegemony was consolidated. 
Through the workfare scheme, this neoliberal logic was imposed in policies of intervention upon unemployment from 1996. This scheme of social policy conceives the poor as an abnormal social sector which needs to be socialized in the "culture of work". In this sense, beneficiaries of conditional cash transfer programmes must develop compensations in work.

In late 2001 and early 2002, the socially and economically regressive model introduced in Argentina from the mid-seventies, and with more power in the nineties, imploded through a generalized crisis, altering the entire social order. After the crisis, a cycle of political-institutional recomposition and economic growth was inaugurated. From 2003 employment levels and wages were recovered, increasing the proportion of registered workers, so that a reduction in levels of precariousness was observed. Within this cycle, social protection was reconfigured and expanded, to the point that this period has been conceptualized as a "counter-reform" in the field of social policy (Danani and Hintze, 2011). One of the main objectives of social protection during these years has been to develop -and enlarge- coverage of vulnerable sectors affected by decades of unemployment and precariousness. In this context, we are particularly interested in the centrality the "quality" work acquired in public policy since 2003.

Along these lines, associative and self-managed work has been promoted through various public policies as a way of getting access to a "quality" work, that is to say, a work -though different from the formal salaried employmentwhich allows the access to social protection. In this article we focus specifically on the Programa de Ingreso Social con Trabajo, better known as Argentina Trabaja Programme (PAT). Launched in 2009, its objective has been to include vulnerable social sectors and achieve genuine work alternatives through the promotion of cooperatives. The centrality of this Programme resides in the fact that it replicates in a national scale similar programs that had been promoting associated and self-managed work in a smaller scale since 2003.

The analysis of Argentina Trabaja Programme allowed us identify innovations and positive aspects regarding social protection: the registration of beneficiaries in the social monotribute, the perception of the universal child income, and the formation of cooperatives as a mode of work. The massiveness of the Programme and the amount of the income are elements that enhance the social changes proposed in the design. However, tensions and limitations arising mainly from the hybrid nature of the Programme were observed, as it has some elements that tend to the social inclusion of vulnerable social sectors and others that maintain characteristics of assistance. In this second sense we observed: the limited possibilities of autonomously designing and implementing the activities of the cooperatives, the individual perception of the incomes, and that they neither reach the minimum wage, nor are updated by the standards of formal salaried employment, and the limits that still carries the social monotribute regarding the effective use of the benefits that provides. It is concluded that the Programme improves the conditions of workers coming from informality, while, in comparison with social protection provided to formal salaried workers, it shows deficiencies. 
In short, social protection established by the Programme generates an improvement of living conditions in social sectors coming from informality. Through alternative forms of work, such as the participation in cooperatives, provides greater levels of social protection, contributing to building "quality" work. However, compared to social protection destined to formal salaried work, it evidences its weaknesses and the long way ahead towards ensuring "quality" work for all members of society.

\section{INTRODUCCIÓN}

Los sistemas de protección social, a través de diversos dispositivos y a lo largo de la historia moderna y contemporánea, han sido construidos persiguiendo el objetivo del bienestar social. Con el ascenso del capitalismo industrial y los Estados de Bienestar ${ }^{1}$, las intervenciones del Estado tendientes a la producción de las condiciones de vida y a la protección de la sociedad frente a los riesgos, cristalizaron principalmente en sistemas de seguridad social basados en el tipo de inserción de las personas en el mercado de trabajo.

Hacia mediados del siglo XX en la Argentina, aunque en grados muy inferiores a los alcanzados en los países centrales, la capacidad de protección de la seguridad social había alcanzado altos niveles. En sintonía con las transformaciones del Estado de Bienestar en los países centrales, a partir de la década del setenta, comenzaron a observarse niveles crecientes de desempleo en el mercado de trabajo argentino. Sumado a esto, la forma clásica de empleo con protección y seguridad social comenzó a mutar hacia modos de empleo con distintas formas de precarización. De este modo, se iniciaba el desmantelamiento de los sistemas de protección social asociados al trabajo asalariado. Este proceso se profundizó durante la década del noventa, momento en el cual se consolidó un modelo de acumulación marcado por el régimen de convertibilidad de la moneda ${ }^{2}$, las privatizaciones, y la liberalización, que impactó fuertemente

${ }^{1}$ El Estado de bienestar o Estado social proporciona un sistema de pensiones, de educación y de prestaciones sanitarias, en el marco de una sociedad salarial que establece una gestión regulada de las desigualdades, cuyo horizonte es la reducción de las mismas (Castel, 2012).

${ }^{2}$ El régimen de convertibilidad de la moneda, popularmente conocido como "el 1 a l", establecía un tipo de cambio fijo de la moneda argentina, en el cual un peso equivalía a un dólar estadounidense. La convertibilidad fue instaurada en marzo de 1991 a través de la Ley 23.928 sancionada por el Congreso Nacional durante el Gobierno de Carlos Saúl Menem y se extendió hasta el año 2002. Cabe mencionar que los gobiernos de Menem se caracterizaron por su alineación con los valores, las ideas y las políticas postuladas por el neoliberalismo (privatización de empresas estatales, reforma del Estado, apertura comercial, desregulación económica y financiera, etc.). El objetivo principal del régimen de convertibilidad fue detener el proceso inflacionario, es decir, estabilizar el nivel de precios. En un 
en la dinámica del mercado de trabajo y en la distribución del ingreso (Damill y Frenkel, 2006).

Hacia finales de 2001 y comienzos de 2002, el modelo social, económico y político de carácter regresivo instaurado en la Argentina a partir de mediados de la década del setenta, y con mayor potencia en la década del noventa, hizo implosión a través de una inusitada crisis generalizada, alterando la totalidad del ordenamiento social. Luego de dicha crisis, se inauguró un ciclo de recomposición político-institucional y de crecimiento económico. En el año 2003, asumió el gobierno del Estado nacional una alianza social progresista con eje en el peronismo que produjo importantes rupturas políticas, económicas y sociales con los gobiernos de la década anterior ${ }^{3}$. A partir de aquí, se recuperaron los niveles de empleo y los salarios, incrementándose la proporción de trabajadores registrados, de modo que se observó una reducción de los niveles de precariedad laboral ${ }^{4}$ (Groisman, 2010). Dentro de este ciclo, destacan los modos en que se reconfiguró y amplió la protección social, siendo tal la resignificación operada sobre la misma que esta etapa ha sido conceptualizada como de contra-reforma -respecto al período de hegemonía neoliberal5 ${ }^{5}$ en el campo de la política social (Danani y Hintze, 2011). Uno de los objetivos principales de la protección social en este marco de contra-reforma se centró en desarrollar -y ampliar- mecanismos de cobertura de los sectores vulne-

primer momento, resultó exitoso en cuanto a la estabilización de precios y motorizó un proceso de crecimiento económico. No obstante, a medida que disminuía la capacidad ociosa se evidenciaba la imposibilidad de la convertibilidad de desarrollar un proceso económico sustentable en términos de distribución del ingreso y de crecimiento económico (Basualdo, 2003). La crisis generalizada de los años 2001 y 2002 puso de manifiesto con una extrema crudeza los perjuicios y consecuencias negativas de aquel régimen, en términos no sólo económicos, sino también políticos, sociales y culturales.

${ }^{3}$ La presidencia del Estado nacional es asumida por Néstor Kirchner (2003-2007) y posteriormente por Cristina Fernández (2007-2011). Actualmente, Cristina Fernández se encuentra en ejercicio de su segundo mandato presidencial, el cual finaliza en diciembre de 2015 .

${ }^{4}$ Cabe aclarar que la problemática de la informalidad laboral -factor nodal de la precarización en la Argentina- con sus efectos regresivos en términos de protección social, persistió como un límite de difícil reversión del modelo actual. En el año 2010 el 45\% de los ocupados urbanos estaba conformado por trabajadores asalariados no registrados y por cuenta propia no profesionales, es decir, aún permanecían en condiciones de informalidad (Groisman, 2011), mientras que en el segundo trimestre de 2013 el porcentaje de asalariados no registrados en la seguridad social continuaba siendo elevado: ascendía al 34,4\% (Encuesta Permanente de Hogares, Instituto Nacional de Estadística y Censos).

${ }^{5}$ El período de hegemonía neoliberal refiere a las dos presidencias de Carlos Menem, las cuales se desarrollaron entre los años 1989 y 1999, y a la presidencia de Fernando De la Rúa que comenzó en el año 1999 y finalizó antes de la culminación de su mandato en el contexto de la crisis generalizada que se desató en diciembre de 2001 y precipitó su renuncia. 
rables afectados por décadas de desempleo y precarización laboral. En este contexto, nos interesa particularmente la centralidad que adquirió el trabajo "de calidad" en las políticas públicas del Estado nacional a partir del año 2003, afirmándose que aquél brinda dignidad, socializa, incluye, y provee los medios de vida; colocándose consecuentemente en él las expectativas de inclusión y de seguridad de la reproducción de las personas (Grassi, 2012).

En esta línea, el trabajo asociativo y autogestionado ha sido fomentado a través de diversas políticas públicas en tanto vía de acceso a un trabajo "de calidad", es decir, a un trabajo que, aunque distinto del empleo formal asalariado, permita acceder a la protección social. En el presente artículo nos enfocaremos específicamente en el Programa de Ingreso Social con Trabajo, más conocido como Programa Argentina Trabaja (PAT). Lanzado el 15 de agosto de 2009, a través de la Resolución N³182/09 del Ministerio de Desarrollo Social de la Nación, se planteó como objetivo avanzar hacia la inclusión de los sectores sociales en situación de mayor vulnerabilidad y lograr genuinas alternativas de trabajo a través de la promoción de cooperativas de trabajo para la ejecución de obras de infraestructura (Memoria detallada del estado de la Nación, 2013). La centralidad de este Programa radica en que replicó a nivel nacional programas de características similares en cuanto al fomento del trabajo asociativo y autogestionado que se venían desarrollando a menor escala en la Argentina desde el año $2003^{6}$.

El objetivo del presente artículo es examinar los modos de protección social que establece el Programa Argentina Trabaja, de modo de aproximarnos al análisis de la calidad del trabajo generado por el Programa. Para esto, en primer lugar, revisaremos los principales conceptos concernientes a la política social y realizaremos un breve racconto de la política social argentina reciente. Luego, describiremos de manera detallada los lineamientos del Programa Argentina Trabaja y las singularidades de su implementación en territorio. De este modo, identificaremos las innovaciones, las continuidades y los límites que introduce en el contexto de la política social argentina, realizando un balance respecto

${ }^{6}$ Algunos planes y programas que antecedieron -y algunos de los cuales continúan funcionando- al Programa Argentina Trabaja en la creación de cooperativas de trabajo desde el Estado nacional fueron el Plan Nacional de Desarrollo Local y Economía Social "Manos a la Obra", que funcionó bajo la órbita del Ministerio de Desarrollo Social de la Nación y fue puesto en marcha en agosto de 2003; el subprograma Mejoramiento del Hábitat Urbano, el Programa Federal de Mejoramiento de Viviendas "Mejor Vivir", y la construcción de Centros Integradores Comunitarios, los cuales fueron ejecutados bajo el paraguas institucional del Programa Federal de Emergencia Habitacional concertado en el 2003 por el Ministerio de Planificación, Inversión Pública y Servicios de la Nación y el Ministerio de Desarrollo Social de la Nación; y el Plan Agua + Trabajo lanzado en el 2004, entre otros. 
a los modos de protección social que instaura. A lo largo del presente escrito nos aproximaremos a las siguientes preguntas: ¿Cómo han evolucionado la política social y la protección social en la Argentina reciente? ¿En qué momento del campo de la política social surgen las políticas de promoción del trabajo asociativo y autogestionado, y más específicamente, el PAT? ¿Qué tipo de protección social instaura? ¿En qué se diferencia o aparta del sistema de protección social anclado en el empleo formal asalariado? ¿En qué medida contribuye o, por el contrario, limita la promoción del trabajo "de calidad"?

\section{LA POLÍTICA SOCIAL: PRECISIONES CONCEPTUALES Y SU DESARROLLO EN LA ARGENTINA}

Danani (2009) propone definir el concepto de política social, en primera instancia, a partir de su objeto directo de intervención. En este sentido, afirma que la política social refiere al conjunto de intervenciones sociales del Estado que producen las condiciones de vida y de reproducción de la vida, tanto social como de los sujetos. No obstante, advierte la autora, esta definición es incompleta. Mientras que las intervenciones sociales pueden rastrearse a través de la larga historia de la sociedad humana, la política social nació al calor de la modernidad capitalista. Es allí donde la relación capital-trabajo (la forma mercancía de la fuerza de trabajo) se constituye en la relación fundamental, revistiendo centralidad en la conformación de las condiciones de vida de los sujetos y de las sociedades. En el ámbito laboral se fundan las condiciones de vida, pues allí se obtienen los medios para satisfacer -claro que en diversos grados- las necesidades individuales y sociales. Desde la perspectiva de los sujetos, las protecciones representan necesidades de reproducción de la vida; y con respecto a la sociedad, son exigencia de la acumulación en términos de la reproducción de la fuerza de trabajo (Danani y Hintze, 2011). En este sentido, la seguridad social, considerada derecho de ciudadanía a la protección, está conformada por las políticas e instituciones que se abocan a la atención de las contingencias sociales mediante la distribución de las consecuencias económicas del padecimiento de los riesgos (Hintze, 2013). La mercantilización del trabajo humano que inaugura la modernidad enfrenta a la sociedad a la desprotección; y la política social se orienta a proteger a la sociedad del riesgo que implica esta mercantilización, es decir, la dependencia de los individuos de los ingresos laborales.

Para esto, opera diversos procesos de desmercantilización, definidos como procesos a través de los cuales se prestan servicios en calidad de derechos, de modo que éstos se sustraen del mercado y las personas pueden garantizarse la vida sin depender exclusivamente del mercado (Esping-Andersen, 1993). Dos 
tipos de procesos de desmercantilización pueden identificarse: de las necesidades y de las personas (Danani, 2009). En el caso de los primeros, ciertos bienes y servicios que satisfacen determinadas necesidades son desmercantilizados. En el segundo caso, y tomando en consideración la indicación de Polanyi (2007) respecto al estatus de mercancía ficticia de la fuerza de trabajo, el carácter mercantil del trabajo de las personas disminuye a través de políticas que transfieren ingresos sin contraprestación de trabajo, o que intervienen en los mecanismos de oferta y demanda del mercado de trabajo.

En definitiva, retomando la propuesta de definir a partir del objeto de intervención, la política social es, entonces, el conjunto de intervenciones sociales del Estado que regulan indirectamente la relación fundamental en la sociedad capitalista, operando sobre la distribución secundaria del ingreso (Danani, 2009) ${ }^{7}$. Por el contrario, la política laboral regula directamente la forma mercancía de la fuerza de trabajo e interviene en la distribución primaria del ingreso. Concretamente, regula las condiciones de venta y de uso de la fuerza de trabajo, siendo un ejemplo de este tipo de política el establecimiento de un salario mínimo y un seguro de desempleo.

El sistema más difundido de protección social, el Estado de Bienestar ${ }^{8}$, se constituyó sobre dos pilares fundamentales: el pleno empleo y la solidaridad sistémica (Tokman, 2006). La solidaridad sistémica se activaba a través de dos instituciones fundamentales. Por un lado, una legislación laboral que reconocía la no igualdad de las partes involucradas y, por tanto, estaba destinada a

${ }^{7}$ Desde otra perspectiva, la política social es una intervención de la sociedad sobre los modos en que individuos y grupos se integran a la sociedad; éstos actúan con un doble patrón. Por un lado, las intervenciones en el centro que refuerzan los procesos de integración, y por el otro, las intervenciones en los márgenes con el objeto de compensar a aquellos grupos que no pueden acceder a los mecanismos de integración centrales. En la Argentina, durante la década del noventa primó el segundo patrón, asistencializando la política social, a la vez que se desarrollaba la flexibilización y precarización del empleo (Soldano y Andrenacci, 2006).

${ }^{8} \mathrm{El}$ autor agrupa los sistemas de protección social en tres regímenes de bienestar que, aunque comparten el hecho de apoyar la demanda e indemnizar los riesgos sociales, han desarrollado distintos dispositivos de protección social: el Liberal-residual, centrado en el mercado; el Conservador-corporatista que tiene como pilar a la familia y/o la iglesia y; el Socialdemocrata-universalista que tiene como centralidad al Estado. El mercado, la familia y/o iglesia, y el Estado, respectivamente, son las instituciones de cada régimen encargadas de garantizar el bienestar. El primero se desarrolló principalmente en los países anglosajones y buscó la cobertura social de los pobres a través de políticas sociales dirigidas exclusivamente a dicho sector. El segundo definió como su objetivo el mantenimiento de los ingresos de los trabajadores y procuró garantizarlo a través de seguros sociales financiados por cotizaciones sociales. Finalmente, el régimen social-demócrata se orientó a la consecución de la igualdad entre los ciudadanos desarrollando políticas universales y servicios sociales gratuitos (Esping-Andersen y Palier, 2011). 
la protección de los trabajadores (estabilidad, condiciones de trabajo, remuneraciones, negociación colectiva). Por el otro, un sistema de seguridad social en un sentido amplio que brindaba protección frente a los riesgos (vejez, accidentes e incapacidades, desempleo) mediante seguros sobre base contributiva para quienes podían aportar, complementándose con asistencia social para quienes no tenían la capacidad suficiente para participar financieramente. Dicho diseño originario de Europa se trasladó, en diferentes medidas, a los países de América Latina. Tres diferencias estructurales marcaron este traslado de la cobertura universal al ámbito latinoamericano: la ubicación en el proceso de transición demográfica, el grado de modernidad de la estructura de ocupación y la capacidad fiscal para responder a las necesidades de protección. Como resultado, se arribó a una cobertura insuficiente de los riesgos: hacia 1980, momento en el cual los países europeos gozaban de una cobertura universal en pensiones, en América Latina sólo el 41\% de los asalariados tenía cobertura y cerca de la mitad de los países no alcanzaba al 25\% de cobertura (Tokman, 2006). No obstante, hacia mediados de la década del ochenta existía un grupo de países conformado por Argentina, Brasil, Chile y Uruguay que registraban una mayor cobertura de seguridad social, superior al 67\% (Tokman, 2006).

En este sentido, hacia mediados del siglo XX en la Argentina se había logrado una cierta amplitud de la protección social, basada en el reconocimiento de derechos, principalmente, del trabajador asalariado formal. A partir de allí, el sistema de seguridad social se estructuró en función del lugar que se ocupaba dentro del mercado de trabajo, y por lo tanto, los niveles de protección al alcance de las personas se hallaron supeditados a ese vínculo laboral-y su formalidad-. En tal sentido, en este modelo de política social que se orientaba a la integración de la sociedad, los atributos del trabajo de cada individuo se constituían en los elementos centrales que definían su tipo de inserción en la sociedad, en detrimento de otros sostenes de la identidad como la familia o la comunidad de pertenencia (Castel, 1995). Castel (2012) afirma que el trabajo era el epicentro de la cuestión social, dado que una relación laboral estable proporcionaba la base para la integración a la sociedad 9 .

A pesar de que los aportes de Esping-Andersen respecto a los regímenes de bienestar fueron pensados desde y para la realidad de países en los cuales

\footnotetext{
${ }^{9}$ La integración social puede ser definida como el proceso conflictivo e inacabado a través del cual una sociedad se mantiene cohesionada y construye un "nosotros" que lo distingue de otros colectivos (Hopp, 2013; Soldano y Andrenacci, 2006). En este contexto, las desiguales formas de reconocimiento institucional de los diversos grupos y prácticas sociales dan cuenta de los alcances y límites del acceso a derechos y de la calidad de los lazos sociales construidos por los distintos grupos y en el marco de diversas prácticas.
} 
la sociedad industrial se desarrolló en su máxima expresión, los modelos de política social que se derivan de los mismos permiten abordar, en cierta medi$\mathrm{da}$, el caso argentino. En este sentido, el "modelo conservador-corporativista" describe, en parte, la configuración de la política social argentina hasta la década del setenta: baja desmercantilización de la fuerza de trabajo, dado que las protecciones y beneficios solían estar atados a la participación en el mercado de trabajo; y formas y grados variables de desmercantilización de las necesidades y sus satisfactores (Danani, 2009).

De la mano de las sucesivas dictaduras militares, y con una mayor profundización en la década del noventa, este esquema se vio debilitado, siendo reemplazado progresivamente por espacios de valorización, remercantilizando la fuerza de trabajo y las necesidades (Danani y Hintze, 2011). El neoliberalismo emergió y con él la ponderación de atributos tales como la autosuficiencia, la autonomía, la flexibilidad, y la productividad, frente a los cuales la protección social se presentaba como signo de debilidad o ineficiencia (Sennett, 2012; Kessler y Merklen, 2013; Merklen, 2013). Las protecciones y la cobertura de los riesgos sociales comenzaron a ser cuestionadas y verse debilitadas (Castel, 2013). Los criterios de eficiencia, rentabilidad y riesgo pasaron de imperar en el ámbito empresarial a impregnar múltiples dimensiones de la vida social (Sennet, 2003); y las políticas comenzaron a diseñarse bajo el imperativo de la reducción del gasto estatal y el déficit fiscal. Se actualizó la cuestión en torno a las posibles interacciones entre el mercado laboral y los sistemas de protección social -o entre las decisiones de participación en el mercado de trabajo y las transferencias de ingresos-, sosteniendo la hipótesis de que una mayor flexibilidad en los mercados laborales, junto con sistemas de protección menos generosos, permitirían realizar un ajuste más veloz en el ascendente desempleo. El argumento central sostenía que los excesivos beneficios que otorgaban los estados de bienestar a los desocupados u ocupados de bajos ingresos conspiraban contra la retención de las personas en la actividad económica (Groisman, Bossert y Sconfienza, 2011). En este sentido, El Estado comenzó a reducir sus responsabilidades mediante la limitación de las garantías fijas o permanentes y las sustituyó por actos de ayuda más temporales (Sennett, 2003). Una profunda reorientación de la forma de la relación entre el Estado y la sociedad tuvo lugar, redefiniendo las causas, los efectos y las posibles soluciones de los problemas sociales (Merklen, 2013).

La metamorfosis de la cuestión social se puso de manifiesto con los crecientes índices de desocupación, subocupación e informalidad, dejando en el olvido la sociedad del -casi- pleno empleo e inaugurando una etapa de creciente y persistente precarización laboral (Castel, 1995). La noción de preca- 
riedad fue definida en el sentido de la desvinculación del salario de la protección social provocada por una serie de fenómenos de desestructuración de los mercados de trabajo; y en la Argentina esto se dio principalmente a través de la no registración de los asalariados en la seguridad social por parte de sus empleadores (Palomino, 2008). En el plano subjetivo, el trabajo se vio disminuido en su potencial identitario (Castel, 1995.). La capacidad integradora del trabajo fue debilitada por estos cambios, hasta el punto de generalizarse el diagnóstico de la "pérdida de la centralidad del trabajo" (Castel, 2012). A pesar de dichas transformaciones, el trabajo continuó revistiendo centralidad en la cultura de los trabajadores en la Argentina. Algunos estudios dieron cuenta de la vigencia de esta cultura, incluso cuando el desempleo y la precarización alcanzaron sus valores máximos (e.g. Férnandez Álvarez, 2007; Danani y Grassi, 2009; Maneiro, 2012).

En cuanto a la política social, la reorientación en la relación entre Estado y sociedad se evidenció en políticas de individuación. Éstas se caracterizaron por abandonar el objetivo moderno de integración y socialización a través de regulaciones y protecciones orientadas a la construcción de un orden social, cuyos sujetos eran "derechohabientes"; y pasar a intervenir sobre el otro "con el propósito de transformar a cada sujeto en un individuo en acuerdo con los valores de la autonomía, la responsabilidad, la activación y el seguro de sí mismo ante los riesgos"(Merklen, 2013: 73), de modo de prepararlo para la competencia que implica la vida social.

Por su parte, Castel conceptualiza este cambio en el terreno de la política social como el pasaje desde políticas de integración hacia políticas de inserción (1995). Se asiste al progresivo abandono de los mecanismos estables de la integración social, es decir, políticas universales, homogeneizantes y generadoras de grandes equilibrios (acceso universal a servicios sociales considerados derechos de modo de tender a la igualdad de posiciones y de oportunidades); y al desarrollo de políticas y estrategias específicas con una lógica de discriminación positiva cuyo objetivo es focalizar en poblaciones y zonas particulares. La distinción entre políticas universales y focalizadas no surge de la mano de las políticas de inserción. Por el contrario, ésta ya existe en la relación clásica de complementariedad entre seguro social y ayuda social. Mientras el primero realiza una socialización generalizada de los riesgos al cubrir a los asalariados y sus familias, la segunda destina recursos subsidiarios a aquellos cuya reproducción no está asegurada por el trabajo, por recursos insuficientes o invalidez. A diferencia de la ayuda social, las políticas de inserción se manejan en una zona incierta en la que aumenta la desocupación y la precarización, 
no dependiendo las situaciones de la nueva población destinataria de las políticas de factores individuales de anormalidad o inadaptación.

La crisis social, económica y política del año 2001 en la Argentina marcó un punto de inflexión, fuertemente cargado de críticas hacia dicho esquema acompañado de revisiones, transformaciones, marchas y contramarchas respecto a la protección social. A partir del año 2003, revertida la crisis y en un proceso de fuerte recuperación económica y social, se pasó de los programas de transferencia de emergencia a las estrategias de protección social (Vuotto, 2013). Los primeros años del siglo XXI fueron testigo de la revitalización de las políticas públicas con un enfoque de derechos. Por un lado, Palomino (2008) observa la emergencia de un nuevo régimen de empleo con protección social a partir de 2005, que se diferencia del anterior régimen de precarización laboral instalado a partir de la década del noventa con el modelo de la convertibilidad. Por el otro, a partir del 2003, en términos de Danani y Hintze (2011), se asiste a una contra-reforma-respecto al período de hegemonía neoliberal- en el campo de la política social, en el cual se da un proceso de resignificación de la protección social. Destacan en este proceso las transformaciones en el sistema previsional y en el sistema de asignaciones familiares.

Con respecto al sistema previsional, el Programa de Inclusión Previsional del año 2005 junto a la re-estatización de los fondos en el año $2008^{10}$, permitieron aumentar el cociente entre los beneficios previsionales y la población en edad jubilatoria del 65,8\% en diciembre 2004 a 94\% en marzo 2010 (Groisman et al., 2011). Sumado a la expansión de la cobertura, hubo un fuerte incremento del haber previsional mínimo. En cuanto al sistema de asignaciones familiares, la Asignación Universal por Hijo ${ }^{11}$ puesta en marcha en el año 2009 instauró un seguro de protección social a la niñez destinada a hijos de personas desocupadas, que trabajan en el mercado informal o que ganan menos o igual que el salario mínimo, vital y móvil. Actualmente más de 3.500 .000 niños son

${ }^{10}$ La estatización de los fondos jubilatorios implicó la sustitución del Sistema Integrado de Jubilaciones y Pensiones establecido en el año 1994, en el cual los trabajadores podían optar por realizar sus aportes al régimen de reparto de administración estatal o realizarlos a un sistema de capitalización individual de administración privada en manos de las Administradoras de Fondos de Jubilaciones y Pensiones (AFJP); por la instauración del Sistema Integrado Previsional Argentino. De este modo, se eliminó el sistema de capitalización individual, se recreó el sistema único de reparto administrado por el Estado y se transfirieron los fondos acumulados en el sistema privado a la administración estatal. (Danani y Beccaria, 2001).

${ }^{11}$ Consiste en el pago mensual de 644 pesos (aproximadamente 80 dólares estadounidenses) para niños menores de 18 años. El $80 \%$ se cobra de manera mensual y el restante $20 \%$ acumulado anualmente se percibe luego de presentar los certificados de vacunación y control sanitario, y de acreditación de asistencia escolar. 
beneficiarios de esta asignación (Página Web de la Administración Nacional de la Seguridad Social).

Por último, y aún más relevante a los fines de este artículo, es a partir de 2003 que comienzan a advertirse políticas de promoción y protección del trabajo asociativo y autogestionado. En este contexto, el trabajo pretende realizar un aporte respecto a los avances que se instituyen en el sentido de la protección de los trabajadores no asalariados incluidos en estas políticas.

\section{LAS POLÍTICAS DE GENERACIÓN DE EMPLEO A PARTIR DE 1996: DE LOS PROGRAMAS DE EMERGENCIA OCUPACIONAL AL PROGRAMA ARGENTINA TRABAJA}

Tal como afirma Sennett en su célebre El Respeto (2003), en los sistemas de protección social, las personas toman conciencia de que sus derechos a la atención residen en su desvalimiento, en su padecimiento de necesidades. La necesidad se constituye en reflejo de debilidad, y ésta se posiciona en las antípodas del respeto por uno mismo y de los demás. El respeto no sólo se consigue a través de la autosuficiencia material, sino que ésta deber ser obtenida haciendo uso de la plenitud de las propias capacidades. La estima social que genera la autosuficiencia deriva del rechazo de la sociedad moderna al parasitismo y el derroche.

En contraposición a la pereza y el ocio, el trabajo es la fuente más importante del respeto mutuo y del respeto por uno mismo; y en el capitalismo industrial del siglo XIX éste se erige como valor moral absoluto. En este sentido, del mismo siglo data la distinción entre indigentes y trabajadores pobres, considerados los primeros no sólo pobres, sino también sujetos degradados y corruptos. Al incrementar tanto la autoestima como el respeto de los demás, se considera que el trabajo forma el carácter (Sennett, 2003).

Claro que lo que en la esfera pública es vivido como debilidad, no es percibido de la misma manera en la vida privada; ámbito en el cual la dependencia y la necesidad del otro son constituyentes de las relaciones -de amor, amistad y paternidad-. Es principalmente a partir del neoliberalismo que se desarrolla este "impulso a sacar a la gente de la dependencia" (Sennett, 2003: 109), extendiendo incluso las esferas dentro de las cuales las personas deben evitar caer en ella (educación, salud, seguro de desempleo, protección de los ancianos).

En la Argentina, esta lógica neoliberal imprimió su sello en las políticas de intervención en el desempleo a partir del año 1996 de la mano del workfare. Este esquema de política social provenía de los Estados de Bienestar de los países anglosajones. Ingresó a la política argentina mediante la Ley Nacional de Empleo sancionada en el año 1991 (Ley N²4.013) y se concretó en los progra- 
mas de emergencia ocupacional (Grondona, 2012). Esta reforma de la protección social implicó recortes en los criterios de elegibilidad y en la duración de los beneficios, así como un refuerzo de los mecanismos de re-vinculación con el mercado de trabajo, forzando a los beneficiarios a aceptar condiciones de trabajo no favorables. Además de esto, el esquema del workfare se constituía en "un tratamiento moral sobre la patología que aquejaba a esta población parasitaria de la asistencia (universalizada): la dependencia."(Grondona, 2012: 433). Dicho esquema nació bajo la sospecha del carácter moralmente desviado y tramposo de los beneficiarios. Inspirado en la concepción de sujeto pobre clásica del estado de bienestar liberal-anglosajón, en la cual se reconocen necesidades en lugar de derechos asociados al asalariado, la obligatoriedad de la prestación laboral de los programas condicionados de transferencia se sustentaba en una justificación moral tendiente a evitar la dependencia de los sujetos.

Generalmente, se conformó de dos tipos de programas: capacitación para los desempleados y esquemas de empleo transitorio. El workfare no se trataba de una política de creación de puestos de trabajo para los desempleados, sino de producción de trabajadores para empleos que nadie quería, o más aún, de trabajadores para empleos que no existían. En este sentido, en la Argentina, el workfare supuso la creación del espacio híbrido de la contraprestación; espacio transitorio pero vivido como permanente debido a que el pasaje a un nuevo programa era mucho más factible que el ingreso a un empleo (Grondona, 2012).

El primer esquema de workfare en la Argentina fue el Plan Trabajar inaugurado en el año 1996 (Grondona, 2012). El período abierto por este programa se destacó por el protagonismo que adquirió el Banco Mundial en el diseño y evaluación de las políticas sociales. El beneficio monetario se entregaba a cambio de trabajos públicos o comunitarios y en el año 1998 llegó a cubrir más de 1.100 .000 beneficiarios. El Programa fue de gestión local, mientras que los organismos responsables y ejecutores fueron organizaciones de la sociedad civil. La contraprestación laboral, según la normativa del Programa, cumplía con los objetivos de contribuir al desarrollo de las comunidades e incrementar la empleabilidad de las personas. El beneficio de 200 pesos $^{12}$ se encontraba por debajo del salario mínimo de mercado e incluso de la canasta básica, convirtiendo el trabajo en una especie de trabajo forzado, muy alejado de la concepción de trabajo como creación y fuente de desarrollo personal (Grondona, 2012).

Su principal sucesor fue el Plan Jefes y Jefas de Hogar Desocupados (PJJHD), el cual fue lanzado en el marco de la crisis de 2001 y la decretada emergencia

${ }^{12}$ Dado que en esos años regía el régimen de convertibilidad de la moneda, el beneficio equivalía a 200 dólares estadounidenses. 
ocupacional, marcando la masificación del workfare en la Argentina (Grondona, 2012). El Programa brindaba una ayuda económica a jefe/as de hogar desocupados con hijos de hasta 18 años de edad, de modo de garantizar su inclusión social (escolarización de los hijos, escolarización de los beneficiarios, controles de salud), a cambio de la realización de contraprestaciones laborales en proyectos comunitarios o de cursos de capacitación, con una dedicación horaria de entre cuatro y seis horas (Velásquez, 2010). Si bien se preveía la inclusión de 500.000 beneficiarios, debido a la profundidad de la crisis, el Programa llegó a cubrir a 2.000.000 de hogares en mayo de 2003, aproximadamente el $20 \%$ de los existentes en el país, llegando a tener una incidencia entre el 7\% y al 8\% en el total del empleo (Cortés, Groisman y Hoszowki, 2004; Golbert, 2007; Groisman, 2011; Groisman et al., 2011; Velásquez, 2010) ${ }^{13}$. El Programa contrastó por su magnitud con otros programas de empleo desarrollados durante la década del noventa, superando la suma de todos ellos: en 1997, año en que se distribuía el mayor número de beneficios, en el conjunto de los distintos programas de empleo no se alcanzaba a los 140.000 beneficios mensuales (Golbert, 2007). Con respecto a la transferencia monetaria, en el momento inicial, equivalía al $75 \%$ del salario mínimo; monto que se fue deteriorando hasta representar sólo el 23,8\% del salario mínimo en julio de 2005 (Golbert, 2007).

A partir del año 2003, se inició una progresiva disminución de la cantidad de beneficiarios del PJJHD, se mantuvo la misma retribución monetaria y se aumentaron las exigencias con el cumplimiento de las contraprestaciones (Natalucci y PaschkesRonis, 2011). Hacia el año 2007, los beneficiarios del PJJHD disminuyeron notablemente. Esto se debió a la combinación de dos factores: los efectos de la recuperación económica en el mercado de trabajo y la realización de un re-perfilamiento poblacional que distinguía entre vulnerables y empleables. A partir de este procedimiento, se dividió la población beneficiaria del esquema workfare entre el Programa Familias por la Inclusión para los primeros, considerados no empleables; y el Programa Seguro de Capacitación y Empleo para los segundos, con el fin de fortalecer sus capacidades e intermediar entre ellos y el mercado laboral (Grondona, 2012). El objetivo de este re-perfilamiento era dejar atrás de modo progresivo la política de contención que representaba el PJJHD para pasar a la implementación de políticas activas (Vuotto, 2013).

${ }^{13}$ A partir de 1995 los planes de empleo de emergencia fueron centrales para mantener el nivel de empleo y bajar la tasa de desempleo. En 2001, considerando a los beneficiarios de los planes de empleo como ocupados, el desempleo bajaba del 22\% al 20\% de la PEA, y en octubre del 2002, bajaba del 23.7\% al 17,9\% (Cortés et al., 2004). 
Asimismo, en el 2003 había comenzado a diseñarse otra estrategia de reperfilamiento de la población a través del fomento del asociativismo y la autogestión como salida de la pobreza, de modo de incluir a los beneficiarios del PJJHD en emprendimientos productivos enmarcados en la economía social (Vuotto, 2013; Natalucci y Paschkes Ronis, 2011). La promoción del trabajo asociativo y autogestionado obtuvo una fabulosa jerarquización en tanto estrategia central de política social - no económica ni de empleo- que buscaba reinsertar social y económicamente a los sectores excluidos y vulnerables ${ }^{14}$. La contracara de esta jerarquización como estrategia social fue el posicionamiento del trabajo asociativo y autogestionado en un lugar secundario del modelo socio-económico instaurado a partir de 2003 (Hopp, 2013).

Dos son los principales programas que se enmarcan en esta estrategia. En agosto de 2003 se pone en marcha el Programa Manos a la Obra del Ministerio de Desarrollo Social. Éste se plantea tres objetivos: contribuir a la mejora del ingreso de la población en situación de vulnerabilidad social, promover la economía social mediante el apoyo técnico y financiero, y fortalecer a organizaciones públicas y privadas, así como espacios asociativos y redes, a fin de mejorar los procesos de desarrollo local e incrementar el capital social, mejorar su efectividad y generar mayores capacidades y opciones a las personas, promoviendo la descentralización de los diversos actores sociales de cada localidad (Res. MD No 1.375/04). En este sentido, el programa se desarrolló a través de dos modalidades. Por un lado, el trabajo con las organizaciones estuvo a cargo del gobierno nacional. Por el otro, fueron principalmente los municipios quienes asumieron la gestión relacionada al subsidio de actividades de grupos de individuos (Natalucci y Paschkes Ronis, 2011). En el marco del Programa Manos a la Obra se firmaron convenios para la realización de 84 proyectos productivos de 17 organizaciones sociales que, se proyectaba, crearían 2.000 puestos de trabajo (Natalucci y Paschkes Ronis, 2011). A partir del año 2005, una reformulación del programa postuló la necesidad de enmarcar sus acciones en Proyectos Integrales de Desarrollo Regional definidos en Mesas Locales de Actores, las cuales debían priorizar proyectos de acuerdo a su propia definición de la problemática de la economía social en la región. La segunda gran iniciativa dentro de las políticas de promoción de la economía social

${ }^{14}$ Los programas incluidos en esta línea pueden ser considerados políticas socio-productivas (Hopp, 2012). Las mismas son definidas como intervenciones sociales del Estado en dos sentidos. Por un lado, son políticas sociales porque su objetivo es la reproducción de la vida de los individuos y las sociedades. Por el otro, pueden considerarse como políticas económicas-laborales que, mediante prestaciones económicas, intervienen en la distribución primaria del ingreso, estimulando la producción para el mercado. 
y el trabajo asociativo, es el Programa de Ingreso Social con Trabajo -o Programa Argentina Trabaja- surgido en el año 2009. Este Programa, es el objeto de análisis directo de este artículo, razón por la cual profundizaremos en sus características e implicancias en el próximo apartado.

\section{EL PROGRAMA ARGENTINA TRABAJA}

En esta sección analizaremos el Programa Argentina Trabaja principalmente en términos de los grados de protección social a los que acceden los trabajadores que se insertan en el mismo, los cuales pertenecen a una categoría más amplia de trabajadores asociativos y autogestionados. Asimismo, señalaremos las innovaciones y continuidades que establece en el contexto de la política social argentina.

El Programa Ingreso Social con Trabajo, más comúnmente conocido como Argentina Trabaja ${ }^{15}$, fue creado en el año 2009, en el marco del desaceleramiento del crecimiento económico producto de la crisis internacional de 2009. Esta crisis le había demostrado al gobierno nacional que el crecimiento económico experimentado durante los años anteriores no había sido suficiente para integrar al mercado de trabajo a sectores sociales excluidos. En este sentido, el gobierno nacional profundizó el enfoque de política socio-laboral que venía desarrollando desde el 2003 en el cual destacaba la generación de empleo a través de la política social (Hopp y Frega, 2012).

Anunciado por la presidenta Cristina Fernández de Kirchner el 14 de agosto de 2009 por cadena nacional, el PAT comenzó a implementarse en el mes de octubre y se estimó que crearía 100.000 puestos de trabajo. En el discurso de lanzamiento del Programa, Cristina Fernández de Kirchner precisó que la primera etapa tendría un costo de 1.500 millones de pesos (aproximadamente 400 millones de dólares estadounidenses en el año 2009) y estaría focalizada en el conurbano bonaerense, al cual le seguirían otras zonas geográficas con esa "densidad de vulnerabilidad social" (Diario Clarín, 15 de agosto de 2009). Desde el discurso oficial se enfatizó en la novedad del abordaje que propuso el Programa: dado que "tiende a que la gente tenga trabajo y se organice socialmente", se diferencia de los esquemas asistencialistas de política social (Diario Clarín, 15 de agosto de 2009). El beneficio monetario se percibiría en cuentas personales, a través de tarjetas bancarias, de modo de evitar

\footnotetext{
${ }^{15}$ El Programa Ingreso Social con Trabajo es una línea de acción del Programa Argentina Trabaja, junto con Proyectos Socioproductivos "Manos a la Obra", Marca Colectiva, Microcréditos, y Monotributo Social. No obstante, suele referirse comúnmente al Programa Argentina Trabaja para designar solamente la línea del Programa Ingreso Social con Trabajo.
} 
mediadores políticos y garantizar la transparencia del procedimiento. Finalmente, otra de las innovaciones destacadas en aquella oportunidad fue que los beneficiarios del Programa serían inscriptos en el monotributo social ${ }^{16}$. En esa misma oportunidad resulta sugerente el diagnóstico que la Presidenta realizó sobre la pobreza, haciendo referencia al problema de la inequidad en la Argentina ${ }^{17}$, en detrimento de los discursos que consideran la pobreza como un problema de carencia individual.

De la descripción oficial del PAT, se desprende que actúa a través de la generación de puestos de trabajo, la capacitación y la promoción de la organización cooperativa para la ejecución de obras de infraestructura. Está dirigido a personas en situación de vulnerabilidad, es decir, sin ingresos formales en el grupo familiar, ni pensiones, jubilaciones u otros planes sociales, a excepción del Plan Nacional de Seguridad Alimentaria (Página web del Ministerio de Desarrollo Social). Este primer paso en la identificación de la población objetivo es seguido de un proceso de evaluación de los potenciales beneficiarios mediante una visita domiciliaria y la aplicación de una encuesta socioeconómica. En su implementación, los Entes Ejecutores (municipios, provincias, federaciones y/o mutuales), a través del Instituto Nacional de Asociativismo y Economía Social (INAES), forman y capacitan cooperativas compuestas por alrededor de 30 trabajadores cada una ${ }^{18}$, las cuales realizan obras públicas locales mano de obra intensivas.

Según los últimos datos disponibles, en el año 2012 eran 202.178 los cooperativistas incorporados al Programa de Ingreso Social con Trabajo (Memoria detallada del estado de la Nación, 2013), mientras que la cantidad desciende

${ }^{16}$ El monotributo social es un régimen tributario optativo, creado con el objeto de facilitar y promover la incorporación a la economía formal de aquellas personas en situación de vulnerabilidad social que han estado históricamente excluidas. A partir de la inscripción en el mismo, los contribuyentes están en condiciones de emitir facturas, ser proveedores del Estado por contratación directa, acceder a las prestaciones de las obras sociales del Sistema Nacional de Salud e ingresar al sistema previsional (jubilación). Además, los monotributistas sociales no pierden el acceso a la Asignación Universal por Hijo. En todos los casos, deben tratarse de emprendedores en situación de vulnerabilidad social que no generen ingresos anuales superiores a 48.000 pesos, monto vigente desde el mes de septiembre de 2013. Los contribuyentes sólo deben abonar el monto correspondiente al $50 \%$ del componente de la obra social. Los componentes impositivos y de aportes previsionales son subsidiados por el Estado nacional (Página web del Ministerio de Desarrollo Social de la Nación).

17 "No vamos a discutir si es 15, 20 o 30 [el porcentaje de la pobreza] (...) En la Argentina hay pobres, pero el problema es la inequidad [que es] la verdadera fábrica de pobres". (Diario Clárin, 15 de agosto de 2009)

${ }^{18}$ El Programa comenzó constituyendo cooperativas de 60 personas. En el año 2012, a través de la resolución 1499/2012, éstas pasaron a conformarse con 30 trabajadores. 
a 131.800 si se consideran los titulares que se mantienen activos (Secretaría de Comunicación Pública, 21 de junio de 2013). En junio de 2011, los beneficiarios estaban conformados por hombres y mujeres, con bajos niveles de instrucción (el 80\% no había concluido los estudios secundarios), en proporciones casi semejantes (53\% de mujeres y 47\% de hombres) (Ministerio de Desarrollo Social, 2011). El 38\% pertenecía a hogares de jefatura femenina y casi la mitad provenía de empleos precarios (49\%) (Ministerio de Desarrollo Social, 2011). Los beneficiarios del Programa pertenecen a las provincias de Buenos Aires, Tucumán, Corrientes, Mendoza, Entre Ríos, Salta, Santiago del Estero, San Juan, La Rioja, Río Negro, Misiones, Catamarca y San Luis.

Con respecto a la cantidad de cooperativas formadas, en noviembre de 2011 se verificaba la existencia de 2.107 (Pedido de Acceso a la Información, 2011). Hacia marzo de 2013, en el discurso de apertura de las sesiones ordinarias del Congreso de la Nación, la presidenta Cristina Fernández de Kirchner afirmó que el número de cooperativas ascendía a 6.626 .

En el año 2009, al momento del lanzamiento del Programa, el ingreso de los participantes se definió en 1200 pesos (aproximadamente 320 dólares estadounidenses). En febrero de 2012 se percibió un significativo aumento: a los 1200 pesos de ingreso básico (aproximadamente 280 dólares estadounidenses) se sumaron 300 pesos por productividad y 250 pesos por presentismo (aproximadamente 130 dólares estadounidenses en total) (Cristina Fernández de Kirchner, 28 de febrero de 2012). Finalmente, el último aumento llegó en abril de 2013, momento en el cual se anunció un aumento de 250 pesos (100 pesos por presentismo y 150 pesos por productividad), llegando a ubicarse en 2000 pesos (aproximadamente 400 dólares estadounidenses) el haber percibido por los trabajadores de las cooperativas de trabajo (Cristina Fernández de Kirchner, 14 de marzo de 2013).

El Programa se erige sobre la reivindicación del trabajo en tanto es considerado "el mejor organizador e integrador social y constituye la herramienta más eficaz para combatir la pobreza y distribuir la riqueza" (Página web del Ministerio de Desarrollo Social de la Nación). Vuotto (2013) afirma que el PAT se inscribe en un enfoque integracionista, el cual se caracteriza por convertir al empleo en el elemento de inserción, dado que éste condiciona los ingresos, la identidad y la autoestima. A diferencia de este enfoque, el de la pobreza considera que ésta es una cuestión de insuficiencia de recursos; y el de la marginalidad diagnostica una "cultura de la dependencia" o "cultura de la pobreza" en los individuos situados fuera de las normas sociales y por lo tanto los considera, en parte, responsables de su estado de pobreza. 
En este sentido, desde el Ministerio de Desarrollo Social se afirma que este programa de inclusión social realiza, por un lado, inversiones para generar oportunidades de desarrollo de capacidades socio ocupacionales, y a la vez realiza transferencias monetarias directas a los titulares que desarrollen actividades, a modo de incentivos para la inclusión social. Estas actividades son consideradas como "puentes" formativos, integrativos y de revalorización de hábitos y capacidades individuales y colectivas (Pedido de Acceso a la información, 2011: 4).

Dado que exige una contraprestación a cambio del beneficio, la iniciativa parece inscribirse en las líneas del workfare descripto en el apartado anterior. No obstante, el PAT plantea una diferencia no menor: lleva a cabo esta exigencia, más que a través de una contraprestación, a partir de la creación y apoyo de cooperativas de trabajo, en un intento por generar "empleo digno y genuino", acción considerada la "mejor política social" (Página web del Ministerio de Desarrollo Social de la Nación). Se afirma que el PAT se constituye en una herramienta especial para el entrenamiento en la cultura del trabajo y para el redescubrimiento de la autoestima mediante la realización de acciones útiles para sí mismos y para otros (Pedido de Acceso a la información, 2011).

En numerosas oportunidades, el gobierno nacional, encarnado en distintos funcionarios, enfatizó en la voluntad de sustituir la figura del "beneficiario" de planes sociales por la de "trabajador con derechos y obligaciones" (Vuotto, 2013). En este sentido, la Presidenta enfatizó en varias oportunidades en la "vuelta de tuerca cardinal" que se estaba llevando a cabo en materia social (28 de febrero de 2012). En sus propias palabras, esta vuelta se daba porque:

Decidimos -a partir del año 2003- que no podía haber más beneficiarios en material social; beneficiarios indica asistencialismo, nosotros creemos en la promoción y en la inclusión y fundamentalmente en la organización de la sociedad. Porque tener una cooperativa, organizarse junto a otros para llevar un objetivo, para tener una meta, para fijarse un tiempo es organizar a la sociedad, aprender a organizarse.

A partir de un diagnóstico acerca del Programa que lo posicionó como un ámbito de contención y generación de espacios de trabajo, así como un entorno propicio para la capacitación y la terminalidad educativa, en el año 2012 se planteó la necesidad de proporcionar oportunidades superadoras (Vuotto, 2013). En este sentido, durante ese año se sucedieron una serie de cambios respecto a la estructuración de las cooperativas, los criterios de remuneración y las condiciones de trabajo (Res. 1499/2012). Uno de los cambios más importantes fue la disminución en el número de integrantes de las cooperativas: de 60 integrantes pasaron a ser 30 . Por otro lado, las cooperativas volvieron a elegir 
autoridades y se comenzó a tomar en consideración la ubicación geográfica de sus integrantes. Otro de los cambios más relevantes refiere a la remuneración; es en este momento que se pasa de los $\$ 1.200$ a los $\$ 1.750$. Por último, la jornada laboral se redujo de seis a cuatro horas para favorecer la asistencia a talleres de capacitación. En este sentido, el diseño del PAT, así como los cambios introducidos en el mismo a partir del año 2012, intentan constituir la figura del "trabajador con derechos y obligaciones" mencionada.

A continuación repasaremos las principales innovaciones que supuso el PAT. En primer lugar, la centralidad que revistió el trabajo como núcleo de organización (Natalucci y Paschkes Ronis, 2011). Si bien, las experiencias de workfare databan de varios años y el Ministerio de Desarrollo Social ya había implementado programas de corte productivo, la realización de las contraprestaciones nunca había sido rigurosamente controlada ni se había enmarcado en la generación de cooperativas desde el propio programa. En el caso del PAT se establecieron mecanismos que permiten comprobar el cumplimiento de las horas y del trabajo, y se dispone de formas de sanción que llegan a incluir la exclusión del Programa. Por ejemplo, la suma de dinero que perciben los integrantes del programa por el presentismo conlleva el control de las asistencias, las cuales de no cumplirse significan la pérdida de dicho plus. En segundo lugar, la forma cooperativa de organizar el trabajo de los beneficiarios (Natalucci y Paschkes Ronis, 2011). Esto implicó un aprendizaje de ambos lados. Por su parte, el Ministerio debió poner en marcha capacitaciones ${ }^{19}$ y asistencia técnica para garantizar el funcionamiento cooperativo del colectivo de trabajadores. Si bien las cooperativas pueden no funcionar como tales desde los comienzos, son múltiples los esfuerzos en capacitación diseñados desde el Ministerio de Desarrollo Social. Por otro lado, los trabajadores debieron adentrarse en esta modalidad de organización productiva y, aunque quizá en dimensiones menores a las proyectadas, múltiples colectivos de trabajadores han logrado adquirir grados importantes de cohesión y autonomía, lo que los posiciona en un lugar privilegiado para diseñar proyectos productivos de gestión asociada. Otra de las características innovadoras del programa es que a pesar de que mantuvo su carácter focalizado, al igual que los anteriores programas de políti-

\footnotetext{
${ }^{19}$ Destaca en este sentido la Diplomatura de Operador Socioeducativo en Economía Social y Solidaria dirigida a trabajadores del Programa. Este diploma de Extensión Universitaria se desarrolla en forma conjunta entre el Ministerio de Desarrollo Social de la Nación y el Ministerio de Educación de la Nación en convenio con Universidades nacionales. En su primera edición (2010-2011) cursaron aproximadamente 900 cooperativistas y se diplomaron 675. En su segunda edición (2012-2013) cursaron 2800 trabajadores. (Pastore et al., 2013).
} 
ca socio-laboral, su masividad contrarrestó el carácter selectivo que estos programas venían operando al momento de la implementación de los mismos, y sobre todo, al momento de la distribución de los beneficios (Natalucci y Paschkes Ronis, 2011). La selección de los beneficiarios -claro que al interior de las zonas geográficas consideradas las más vulnerables- se implementó a través de modalidades que procuraron no constituir sujetos de la beneficencia, sino integrarlos a partir del cooperativismo de trabajo. Por último, la innovación principal desde la mirada de este análisis refiere a las prestaciones sociales (obra social y aportes previsionales) a las que accedieron los cooperativistas a través del monotributo social. Hacia junio de 2011, 157.745 integrantes del Programa Argentina Trabaja estaban incluidos en el sistema de salud gracias a los aportes a obra social realizados a través del monotributo social (Ministerio de Desarrollo Social, 2011). Un aspecto positivo a destacar es el proceso de ampliación de la seguridad social mediante la creación de la Asignación Universal por Hijo. En su carácter de monotributistas sociales, los trabajadores de las cooperativas del PAT han sido incorporados al sistema de asignaciones familiares. De este modo, aunque de manera precaria en relación al trabajo asalariado registrado en la seguridad social, los beneficiarios del Programa acceden a un abanico de mecanismos de protección social que los posiciona ventajosamente respecto a la situación de informalidad de la cual la mitad de ellos provienen.

Ahora bien, una vez repasadas las voces oficiales en torno al PAT y pasar revista a sus elementos más innovadores, realizamos una aproximación desde la implementación del Programa en el territorio, la cual nos permitirá conocer las tensiones que se juegan en la misma. Para realizar este análisis, haremos uso del trabajo de Hopp y Frega (2012), el cual cuenta con un sólido trabajo de campo. El principal aporte de estas autoras radica en la identificación de obstáculos para la consecución del objetivo de generación de cooperativas de trabajo como alternativas laborales sostenibles; obstáculos que dan cuenta de una tensión entre trabajo asociativo y autogestionado, y política social asistencial. Las autoras subrayan que los mismos se hallan en la forma en que las cooperativas se constituyen, en los vaivenes burocráticos, y en las disputas por la autonomía de las organizaciones respecto de los recursos estatales. Esta tensión se manifiesta concretamente en: a) la modalidad de constitución de las cooperativas y la forma de pago del subsidio, y b) la organización de las tareas que realizan las cooperativas y las condiciones laborales. Ambas dimensiones de la tensión tienen como consecuencia un tercer elemento, c) las dificultades tanto materiales como simbólicas para sostener la cooperativa en tanto alternativa laboral decente (Hopp y Frega, 2012). 
En cuanto al primer punto, las cooperativas son conformadas desde los entes estatales, ajustándose a criterios que pueden desestimar los de pertenencia organizacional y/o barrial, y por lo tanto, dejar de lado el objetivo de organización de la sociedad. Por otra parte, la compra de los materiales y las herramientas necesarios para la realización de las actividades es llevada adelante por los gobiernos provinciales o municipales mediante el financiamiento del gobierno nacional (Res. MDS 3182/09). Con respecto al pago de los haberes, a pesar de ganar en transparencia a través de la transferencia de los subsidios individuales a las cuentas bancarias personales de cada cooperativista, esto actúa en detrimento de la efectiva constitución de la cooperativa de trabajo. La no mediación de la cooperativa en tanto colectivo autogestionado de trabajadores, instaura una lógica individualizante contraria a las prácticas del cooperativismo.

En cuanto a la organización de las tareas que realizan las cooperativas, las situaciones son diversas. Existen cooperativas que alcanzan altos grados de autonomía en el diseño e implementación de las actividades. Estas cooperativas suelen partir de grupos de militancia pre-constituidos y sus miembros generalmente pertenecen, en términos formales, a distintas cooperativas. No obstante, exceptuando estos grupos, las posibilidades de llevar a cabo los propios proyectos productivos resultan sumamente dificultosas para colectivos de trabajadores sin experiencia previa en cooperativismo ni militancia compartida. En este sentido, las cooperativas generalmente se ciñen a la ejecución de obras de infraestructura o mejoramiento barrial diseñadas y determinadas por las instancias gubernamentales, y no por la propia cooperativa. Con respecto a las condiciones laborales, a pesar de que los ingresos son de un monto alto en comparación a otros programas sociales, éste no llega a igualar al salario mínimo, vital y móvil ${ }^{20}$. Por otro lado, tampoco permite contar con un trabajo que, por la cantidad de horas que implica, permita acceder a recursos suficientes para obtener condiciones de vida dignas. Sumado a esto, los ingresos no son actualizados según los valores de la canasta básica familiar. Por esto, el ingreso que perciben los cooperativistas no se asemeja completamente al salario de un trabajador formal en relación de dependencia, ni al retiro a cuenta de utilidades

${ }^{20}$ El Salario Mínimo Vital y Móvil se define como "la menor remuneración que debe percibir en efectivo el trabajador sin cargas de familia, en su jornada legal de trabajo, de modo que le asegure alimentación adecuada, vivienda digna, educación, vestuario, asistencia sanitaria, transporte y esparcimiento, vacaciones y previsión". El valor del mismo se establece en forma tripartita en el marco del Consejo del Empleo, la Productividad y el Salario Mínimo Vital y Móvil. (Página web del Ministerio de Trabajo, Empleo y Seguridad Social de la Nación). Actualmente se encuentra en los 3.600 pesos (aproximadamente 450 dólares estadounidenses). 
por el trabajo realizado en una cooperativa. En cuanto a la construcción de marcos legales y regulatorios para la forma de trabajo cooperativa que se fomenta desde el PAT, destacan la creación del Registro Nacional de Efectores de la Economía Social a través del cual se accede al monotributo social; y la sanción de la Ley de Microcrédito que les permite a las cooperativas -y demás miembros de emprendimientos de la economía social- que deseen desarrollar su propio proyecto productivo acceder a financiamiento barato -aunque también con montos muy bajos-. Sin embargo, las formas de protección social a las que da lugar este marco regulatorio son limitadas. El monotributo social presenta limitaciones respecto al acceso y la calidad a las prestaciones que ofrece (Hopp, 2013).

Múltiples son las innovaciones que introduce el Programa. Desde la perspectiva de este trabajo, destaca la inclusión de los trabajadores en el monotributo social y la generación de cooperativas de trabajo más que la exigencia de contraprestaciones laborales tradicionales e individuales. No obstante, las condiciones de desprotección respecto a los ingresos, las modalidades de protección social, y las tensiones que atraviesan las cooperativas en la implementación concreta del PAT en los territorios, limitan las posibilidades de afianzar la estrategia de generación de trabajo "de calidad", es decir, con acceso pleno a la protección social.

\section{CONCLUSIONES}

A lo largo de este trabajo, hemos realizado un abordaje del Programa Argentina Trabaja desde la perspectiva de la protección social, de modo de visibilizar los modos de protección que instaura, y las innovaciones y limitaciones que introduce en el campo de la política socio-laboral de cara a la generación de trabajo "de calidad".

Iniciamos el escrito realizando una revisión de los principales conceptos necesarios para llevar a cabo el análisis propuesto, para luego repasar brevemente el devenir de la protección social en la Argentina. La evolución de la misma dio cuenta de importantes transformaciones. Partiendo de una situación de amplia cobertura hasta la década del setenta, la protección social se vio debilitada frente a la creciente mercantilización de la fuerza de trabajo y de las necesidades sociales. De la mano de estas transformaciones, la política social también atravesó fuertes mutaciones. Destacan la introducción del esquema workfare en la política socio-laboral de la década del noventa, la redefinición de la cuestión social y de los patrones de integración social. El análisis de estos cambios resultó ineludible de cara al conocimiento de los cambios y las continuidades en cuanto a la protección social que plantea el momento actual. 
Con la introducción del workfare en la Argentina, a partir del Plan Trabajar en el año 1996, la generación de trabajo como modalidad de intervención en lo social sería cada vez más frecuente. A partir del año 2003, como producto de la profunda crisis social, política y económica que había atravesado el país en los años 2001-2002, las modalidades de protección social se fueron redefiniendo. En un contexto de contra-reforma en el campo de la política social respecto a la década del noventa, el fomento del asociativismo y el trabajo autogestionado en el marco de la economía social se transformó en la estrategia fundamental del Ministerio de Desarrollo Social para la generación de trabajo "de calidad". En el año 2009 surgió el Programa Argentina Trabaja con el objetivo explícito de crear fuentes de trabajo a través de la creación de cooperativas de trabajo para la realización de obras de infraestructura local. Como dimensión privilegiada de la calidad de un trabajo consideramos el grado en que permite la integración social de un sujeto, y por lo tanto observamos la protección social a la que permite acceder aquel trabajo.

El análisis del Programa Argentina Trabaja permitió identificar innovaciones y aspectos positivos en este sentido, entre las que destacan la inscripción de los beneficiarios en el monotributo social, la posibilidad de percibir la Asignación Universal por Hijo y por Embarazo, y la conformación de cooperativas como modalidad de trabajo en lugar de exigir la contraprestación tradicional de los programas sociales previamente existentes. Por otro lado, la masividad del PAT, junto al ingreso -mayor al de programas de transferencia de ingresos anteriores- percibido por los trabajadores, son elementos que suman potencialidad a los cambios que se proponen desde el diseño.

No obstante, la revisión de la literatura existente sobre el Programa, nos permite delinear tensiones y limitaciones que derivan fundamentalmente de su carácter híbrido (Hopp, 2013), en tanto posee elementos que tienden al posicionamiento del trabajo asociativo como una vía para la integración social, y por otro lado, al uso del trabajo como un recurso de la asistencia. En este segundo sentido, resaltan las escasas posibilidades de diseñar e implementar las actividades que se llevan a cabo en el marco de la cooperativa de manera autogestiva; el hecho de que los ingresos sean percibidos de manera individual, y que los mismos no alcancen el salario mínimo vital y móvil, ni sean actualizados según los estándares del empleo asalariado formal; así como los límites que aún acarrea el monotributo social en cuanto al efectivo uso de los beneficios que contempla.

En síntesis, la protección social que instaura el Programa genera un mejoramiento de las condiciones de vida de sectores sociales provenientes de las filas de la informalidad y el desempleo. A partir de formas alternativas de trabajo 
como lo es la participación en cooperativas, brinda mayores grados de protección social, contribuyendo a la construcción de trabajo "de calidad". No obstante, en comparación con la protección social destinada al empleo formal asalariado, evidencia sus debilidades y el largo camino por recorrer.

El análisis realizado no pretende soslayar las potencialidades que contiene una política social que busca -y en algunos aspectos lo consigue exitosamente- ampliar los grados de protección a los que acceden sectores sociales largamente excluidos, a través de la generación de trabajo asociativo y autogestionado como una vía de integración social.

\section{REFERENCIAS BIBLIOGRÁFICAS}

Basualdo, E. (2003). "Las reformas estructurales y el Plan de Convertibilidad durante la década de los noventa. El auge y la crisis de la valorización financiera". Realidad Económica, 200, 42-83.

Castel, R. (1995). La metamorfosis de la cuestión social. Una crónica del salariado. Disponible online: https://catedracoi2.files.wordpress.com/2013/05/castel-robertla-metamorfosis-de-la-cuestic3b3n-social.pdf

Castel, R. (2012). El ascenso de las incertidumbres. Trabajo, protecciones, estatuto del individuo. Buenos Aires: Fondo de Cultura Económica.

Castel, R. (2013). "Políticas del riesgo y sentimiento de inseguridad". En Castel, R., Kessler, G., Merklen, D., Murand, N. Individuación, precariedad, inseguridad. ¿Desindustrialización del presente? Buenos Aires: Editorial Paidós, 33-43.

Cortés, R., F. Groisman y A. Hoszowki (2004). "Transiciones ocupacionales: el caso del plan jefes y jefas". Realidad Económica, 202.

Curcio, J. (2011). "Descripción del Sistema de Seguridad Social: componentes al cabo de la década del '90 y de la primera década del siglo XXI. En Danani, C.; Hintze, S. (coord.). Protecciones y desprotecciones: la seguridad social en la Argentina 19902010. Los Polvorines: Universidad Nacional de General Sarmiento, 33-60.

Curcio, J.; Beccaria, A.; Fournier, M. (2011). "Sistema de Seguridad Social y mercado de trabajo: evolución de la cobertura en la Argentina entre 1990 y 2010". En Danani, C.; Hintze, S. (coord.). Protecciones y desprotecciones: la seguridad social en la Argentina 1990-2010. Los Polvorines: Universidad Nacional de General Sarmiento, 61-101.

Damill, M. y R. Frenkel (2006). "El mercado de trabajo argentino en la globalización financiera". Revista de la Cepal, 88.

Danani, C. (2009). "La gestión de la política social: un intento de aportar a su problematización”. En Chiara, M. y M.M. Di Virgilio (Org.). La gestión de la política social. Conceptos y herramientas. Buenos Aires: UNGS-Editorial Prometeo, 11-34.

Danani, C.; Beccaria, A. (2011). "La (contra) reforma previsional argentina 2004-2008: aspectos institucionales y político-culturales del proceso de transformación de la protección". En Danani, C.; Hintze, S. (coord.). Protecciones y desprotecciones: la seguridad social en la Argentina 1990-2010. Los Polvorines: Universidad Nacional de General Sarmiento, 103-151. 
Danani, C.; Hintze, S. (2011). "Introducción. Protección y seguridad social para distintas categorías de trabajadores: definiciones conceptuales, propuestas de abordaje e intento de interpretación". En Danani, C.; Hintze, S. (coord.). Protecciones y desprotecciones: la seguridad social en la Argentina 1990-2010. Los Polvorines: Universidad Nacional de General Sarmiento, 9-29

Esping-Andersen, G. (1993). Los tres mundos del Estado del Bienestar. Valencia: Edicions Alfons El Magnánim/Generalitat Valenciana/Diputació Provincial de Valéncia.

Esping-Anderson, G.; Palier, B. (2011). Los tres grandes retos del Estado del bienestar. Barcelona: Ariel.

Fernández Alvarez, M. I. (2007). "En defensa de la fuente de trabajo": demandas y prácticas de movilización en una empresa recuperada de Buenos Aires." Avá. Revista de Antropología, 11, 63-85.

Golbert, L. (2007). "Argentina: aprendizajes del Programa Jefes y Jefas de Hogar Desocupados". En Arriagada, I (ed.) Familias y políticas públicas en América Latina: una historia de desencuentros. Santiago de Chile: CEPAL.

Grassi, E. (2012). "Política sociolaboral en la Argentina contemporánea. Alcances, novedades y salvedades." Revista de Ciencias Sociales de la Universidad de Costa Rica, 135-136, 185-198.

Groisman, F. (2010). "Inestabilidad de ingresos y desigualdad durante la reciente fase de recuperación económica en Argentina”. Estudios del Trabajo, 36.

Groisman, F. (2011). "Argentina: Los hogares y los cambios en el mercado laboral (2004-2009)". Revista de la CEPAL, 104.

Groisman, F., F. Bossert, M.E. Sconfienza (2011). Políticas de protección social y participación económica de la población en Argentina (2003-2010). En VI Jornadas de Jóvenes Investigadores, Instituto de Investigaciones Gino Germani, Universidad de Buenos Aires. 10, 11 y 12 de noviembre de 2011.

Grondona, A. (2012). "Tradición" y "traducción": un estudio de las formas contemporáneas del gobierno de las poblaciones desempleadas en la Argentina." Tesis de Doctorado de Ciencias Sociales de la Universidad de Buenos Aires. Biblioteca Virtual del Centro Cultural de la Cooperación Floreal Gorini.

Hintze, S. (2013). "Las políticas públicas de promoción del trabajo asociativo autogestionado en América Latina". Revista del Observatorio Social sobre Empresas Recuperadas y Autogestionadas, 9.

Hopp, M. (2012). "La sostenibilidad de los emprendimientos asociativos y autogestionados: Reflexiones para la construcción de la Economía Social en Argentina". Revista Org E Demo, 12 (2), 39-58.

Hopp, M. (2013). "Políticas de promoción del trabajo asociativo y autogestionado en la Argentina actual: un balance". Revista del Observatorio Social sobre Empresas Recuperadas y Autogestionadas, 9.

Hopp, M.; Frega, M. (2012). "Trabajo asociativo y políticas sociales: Tensiones y potencialidades en la experiencia de implementación del Programa Argentina Trabaja”. Revista Debate Público. Reflexión de Trabajo Social, 2 (3), 71-81. 
Kessler, G.; Merklen, D. (2013). "Una introducción cruzando el Atlántico". En Castel, R., Kessler, G.,Merklen, D., Murand, N. Individuación, precariedad, Inseguridad. ¿Desinstitucionalización del presente? Buenos Aires: Editorial Paidós, 9-31.

Maneiro, M. (2012). De Encuentros y desencuentros. Estado, gobiernos y movimientos de trabajadores desocupados. Buenos Aires: Editorial Biblos.

Memoria detallada del estado de la Nación, año 2012. $1^{\circ}$ de marzo de 2013. Buenos Aires: Presidencia de la Nación.

Merklen, D. (2013). "Las dinámicas contemporáneas de la individuación". En Castel, R., Kessler, G.,Merklen, D., Murand, N. Individuación, precariedad, Inseguridad. ¿Desinstitucionalización del presente? Buenos Aires: Editorial Paidós, 45-86.

Ministerio de Desarrollo Social (2011). Ejecución del Programa: Principales resultados al primer semestre 2011. Perfil de titulares. Disponible online: http://www.desarrollosocial.gob.ar/Uploads/i1/PRISTresultados2011.pdf (fecha de consulta: 20 de enero de 2014)

Natalucci, A.; Paschkes Ronis, M. (2011). “Avatares en la implementación de políticas sociales. Concepciones y prácticas de las organizaciones sociopolíticas que participan en el programa Argentina Trabaja (2009-2010)". En Ana Arias; Alejandra Bazzalo; Bárbara García Godoy. Políticas públicas y Trabajo Social. Aportes para la reconstrucción de lo público. Buenos Aires: Editorial Espacio.

Palomino, H. (2008). "La instalación de un nuevo régimen de empleo en Argentina: de la precarización a la regulación". Revista Latinoamericana de Estudios del Trabajo, 13 (19), 121-144.

Pastore, R; Tedeschi, L.; Iglesias, M. F; Plasencia, A.; Basterrechea, M; Repetto, V.; Haddad, V; Barrios, A. (2013). Módulo de Economía Social y Solidaria. Buenos Aires: UNQ-UNM-UNSAM-MDS.

Polanyi, K. (2007). La gran transformación. Crítica del liberalismo económico. Buenos Aires: Fondo de Cultura Económico.

Sennett, R. (2003). El respeto. Sobre la dignidad del hombre en un mundo de desigualdad. Barcelona: Anagrama.

Sennett, R. (2012). La corrosión del carácter. Las consecuencias personales del trabajo en el nuevo capitalismo. Barcelona: Editorial Anagrama.

Soldano, D; Andrenacci, L. (2006). "Aproximación a las teorías de la política social a partir del caso argentino". En Andrenacci, L. Problemas de politica social en la Argentina contemporánea. Buenos Aires: Prometeo.

Tokman, V. (2006). Inserción laboral, mercados de trabajo y protección social. Serie Financiamiento del Desarrollo 170. Santiago de Chile.

Velásquez, M. (2010). Seguros de desempleo y reformas recientes en América Latina (Serie macroeconomía del desarrollo $N^{\circ}$ 99). Santiago de Chile: División de desarrollo económico-CEPAL-Naciones Unidas.

Vuotto, M. (2013). "Las oportunidades de inclusión en iniciativas de la economía social en la Argentina: consideraciones sobre el programa Ingreso Social con Trabajo". En Novena Conferencia Regional ISTR LAC Participación y Representación:nuevos 
paradigmas para la sociedad civil latinoamericana. Santiago de Chile, 28 al 30 de agosto de 2013. Disponible en: http://www.lasociedadcivil.org/docs/ciberteca/IS TR2013/mirta_vuotto.pdf (consultado el 15 de enero de 2014)

\section{LEYES Y RESOLUCIONES}

Ley $\mathrm{N}^{\circ} 24.013$ (Ley Nacional de Empleo)

Resolución MDS No 1375/04

Resolución MDS No 3182/09

Resolución MDS No 1499/12

\section{PÁGINAS WEB CONSULTADAS}

Página web del Ministerio de Desarrollo Social de la Nación: http://www.desarrollosocial.gov.ar/

Página web de Administración Nacional de la Seguridad Social (ANSeS): http://www. anses.gob.ar/

Página web del Ministerio de Trabajo, Empleo y Seguridad Social de la Nación: http:// www.trabajo.gov.ar/

\section{DISCURSOS-PRESIDENCIA DE LA NACIÓN}

Cristina Fernández de Kirchner. 28 de febrero de 2012. Acto sobre anuncios de temas de Desarrollo Social: Palabras de la Presidenta de la Nación. Disponible en: http://www. presidencia.gov.ar/discursos/25720-acto-sobre-anuncios-de-temas-de-desarrollosocial-palabras-de-la-presidenta-de-la-nacion

Cristina Fernández de Kirchner. 1 de marzo de 2013. Inauguración del $131^{\circ}$ periodo de sesiones ordinarias del Congreso: Discurso de la Presidenta de la Nación. Disponible en: http://www.presidencia.gob.ar/discursos/26370-inauguracion-del-131o-periodo-de-sesiones-ordinarias-del-congreso-discurso-de-la-presidenta-de-la-nacion

\section{ENTRADAS DE FACEBOOK}

Cristina Fernández de Kirchner. 14 de marzo de 2013. Presentación del plan "Ellas Hacen" para 100.000 mujeres. Disponible en: https://www.facebook.com/media/set/?set=a.51 $1165998947940.1073741829 .115689108495633 \&$ type $=1$

\section{CABLES DE PRENSA-PRESIDENCIA DE LA NACIÓN}

Secretaría de Comunicación Pública, Sala de Prensa, República Argentina. 21 de junio de 2013. 130 mil cooperativistas en el Plan Argentina Trabaja. Disponible en: http:// www.prensa.argentina.ar/2013/06/21/41810-130-mil-cooperativistas-en-el-planargentina-trabaja.php 


\section{NOTAS DE DIARIO}

Diario Clarín. Pobreza: Cristina rechazó críticas y anunció un plan de empleo. 15 de agosto de 2009. Disponible en: http://edant.clarin.com/diario/2009/08/15/elpais /p-01978818.htm

\section{PEDIDOS DE ACCESO A LA INFORMACIÓN}

Pedido de acceso a la información al Ministerio de Desarrollo Social realizado por Poder Ciudadano. 4 de noviembre de 2011.

DENISE KASPARIAN es socióloga y becaria doctoral del Consejo Nacional de Investigaciones Científicas y Técnicas con sede en el Instituto de Investigaciones Gino Germani de la Universidad de Buenos Aires. Además es docente en la carrera de Sociología de la Universidad de Buenos Aires.

Recibido: 18/06/2014

Aceptado: 12/12/2014 
OBETS. Revista de Ciencias Sociales

Vol. 9, n. ${ }^{\circ}$ 2, 2014; pp. 333-359

ISSN: $1989-1385$

DOI: 10.14198/OBETS2014.9.2.04

\title{
TEORÍAS SOBRE LA GLOBALIZACIÓN: UNA EVALUACIÓN CRÍTICA ${ }^{1}$ THEORIES ON GLOBALIZATION: A CRITICAL APPRAISAL
}

\author{
Antonio Martín Cabello \\ Departamento de Derecho Público, Ciencia Política y Sociología, \\ Facultad de Ciencias Jurídicas y Sociales \\ Universidad Rey Juan Carlos, España \\ antonio.martin@urjc.es
}

\begin{abstract}
Resumen
Este artículo trata de revisar la abundante y dispersas literatura científica con el objetivo de identificar las principales explicaciones del proceso de globalización. El objetivo es construir una perspectiva meta-teórica que nos permita desarrollar una teoría de la globalización más analítica para evitar las trampas del debate político. Las diferentes teorías son analizadas utilizando una aproximación histórica y analítica para detectar el mecanismo explicativo propuesto para interpretar la globalización. Se han encontrado cuatro aproximaciones principales: la tesis del comercio, la tesis de la modernización, la tesis tecnológica y la tesis del capitalismo. Después, el artículo trata de hacer una evaluación crítica de las cuatro tesis sobre la globalización. Por último, concluye discutiendo las críticas posmodernas al carácter moderno de la teoría de la globalización.
\end{abstract}

Palabras clave: Capitalismo; comercio internacional; modernidad; tecnología; ventaja comparativa.

\footnotetext{
${ }^{1}$ Este artículo forma parte de una investigación más amplia para la que se contó con financiación a través de una Beca de movilidad postdoctoral para PDI concedida por la URJC y el Banco de Santander Universidades en su convocatoria 2012-13, que se realizó en el Institut für Asien und Afrikawissenschaften de la Humboldt-Universität zu Berlín (Alemania). El autor desea agradecer el apoyo y comentarios recibidos durante la misma del profesor Boike Rehbein.
} 


\begin{abstract}
This paper tries to review the abundant and scattered scientific literature in order to identify the main scientific explanations of the globalization process. The global objective is to build a meta-theoretical perspective that allows us to develop a more analytical globalization theory to avoid the political debate traps. Diverse theories are analysed using a historical and analytical approach to detect the explanatory mechanism proposed to interpret globalization. Four main approaches have been found: the thesis of international trade, the modernization thesis, the technological thesis and the thesis of capitalism. Afterwards, the paper tries to make a critical appraisal of the four globalization thesis. Finally, the article concludes discussing the postmodern criticism to the modern character of the globalization theory.
\end{abstract}

Key-words: Capitalism; Comparative Advantage; International Trade; Modernity; Technology.

\title{
Extended abstract
}

The goal of this paper is to review the wide-ranging and diffuse scientific literature on the globalization process in order to identify its main explanations. The intention is to construct a meta-theoretical viewpoint that will enable the development of a more analytical theory of globalization that avoids the pitfalls of political debate. Specifically, the aim is to fill a gap in the theory of globalization: the lack of systemization in the different theoretical approaches. This might seem paradoxical, since plentiful literature exists on the subject. The idea is to describe the underlying model behind different theoretical constructions in relation to their essential explanatory mechanisms, in order to subsequently make a critical analysis of their analytical and empirical bases. In short, it is a question of answering the questions posed by Roland Robertson: "What drives the globalization process? What is its "motor force'?" (2001: 461). As part of the analysis of these theories, a review has been made of the most important work most frequently quoted by the scientific community, which tries to explain globalization as an all-encompassing process of change. This includes work written by some of the most outstanding social-science analysts in the fields of anthropology (Appadurai, 1996), philosophy (Safranski, 2005), sociology (Bauman, 1998; Beck, 2000; Berger and Huntington, 2002; Casttels, 2000; Giddens, 1993, 2000; Ritzer, 2004; Robertson, 1992; Urry, 2002), economics (de la Dehesa, 2006; Stiglitz, 2002, 2006), political science (Barber, 1996; Held and McGrew, 2002, 2007) and human geography (Anderson, Brook and Cochrane, 1995; Harvey, 2008) among others. In order to systemize the range of theories of globalization, a classification is set up to attempt to group them according to the "explanatory mechanism" they propose explicitly or implicitly, when presenting their development. The mechanism is frequently mono-causal, although this is not necessarily the case in every theory. Four major theses have been detected in accordance with the explanatory mechanism used to explain the globalization process. They can be referred to as follows: the commercial interchange thesis, the modernization thesis, the technology thesis, and the capitalism thesis. 
First, the commercial interchange thesis argues that it is a process of increasing interconnection based on an historic growth in commerce on a planetary level. The origins of commercial interchanges can be found in the natural tendency of human beings towards interchange. This is the predominant version describing globalization in the main economic schools. Specifically, globalization, it is argued, merely reflects the expansion of the markets worldwide. Without any barriers or distortions, such as imperfect information or the intervention of third agents, this process would arrive at a situation of perfect beneficial balance for all the players in the market. Free trade would ensure the supply and demand of goods reach a balance in which everyone involved obtains benefits, thereby reducing possible initial inequalities. The mechanism making this possible would be comparative advantage.

The second thesis posits that globalization involves the expansion of the modernization process, originally emerging in Europe, worldwide. Modernization undoubtedly implies a technical dimension, commercial interchange and capitalist accumulation, but also includes political elements such as democracy, the rule of law and the control of physical violence, as well as cultural elements such as secularization and individualism. Globalization viewed from this perspective entails the expansion of a civilizing model, summed up by the word modernity, all around the planet and its assimilation in nonwestern peoples.

The third thesis, one of the most popular and widespread, looks to explain globalization from an essentially technical basis. This position postulates that physical communications and Information and Communications Technologies (ICTs) are behind globalization.

The last thesis emphasizes the expansion of capitalism, which it views as a broader phenomenon than the market, and as the main engine driving globalization. These authors typically believe capitalism is an institutional phenomenon over and above simple interchange. They regularly cite at least three major elements among conditions required for the existence of capitalism: a monetary system that enables the existence of money in the form of banking credit, commercial exchanges and the production of goods in the private business system. The existence of a State that provides the necessary backing and institutional coverage for setting up a capitalist system is usually added. In short, this position argues that the development of capitalism as an economic (and political) system would explain globalization, with this constituting the latest phase in its development.

The paper then makes a critical evaluation of the four theses of globalization. The commercial interchange thesis has been attacked on five flanks: its ideological assumptions, the naturalization of the economic system, the role of the State, the results of globalization and the mechanism regulating international trade, or in other words, the theory of comparative advantage. The modernization thesis has been criticized because of its holistic, euro-centric nature and because of the impossibility of finding causal relationships using this model. The technology thesis has been censured for its technological determinism. Lastly, the capitalism thesis has been criticized because it exaggerates 
the importance of the "rich and powerful" as essential agents in the globalization process, as a result of its left-wing ideological basis, and because the consequence of the globalization process is the opposite of what the thesis postulates.

The paper concludes that the four theses under discussion operate on two levels of abstraction. The first describes the cause of globalization according to two relatively simple and homogenous variables: technology and commercial interchange. An increase in these variables inevitably leads to globalization. The second looks to multi-causal models, which usually combine these simple variables in more analytically complex models. Capitalism is therefore defined as a construction that unites several institutions: commercial interchange, markets, money, credit and private business. Modernity involves new technologies, a capitalist economy, a democratic and rational State, active citizenry and a culturally secular and individualist society, among other institutional features. The combination of these variables in varying degrees conforms the mechanism that explains the globalization process. Whatever the case may be, all these theories are unified by their attempts at constituting one "big theory" to explain the globalization process as a whole.

This big theory aims to create an all-encompassing narrative, which provides a "primary cause" for the explanations of the social phenomena of our time. It is therefore a theory deeply imbedded in modern thought. That is why it has been attacked from the postmodern theoretical viewpoint, which rather than rejecting specific aspects of the theses presented, tends to reject the very possibility of an all-encompassing globalization theory. In the opinion of the postmodernists, the age of grand narratives is behind us. These normally just legitimize processes, set in motion by Caucasian men, rather than truly describing worldwide dynamics. Consequently, they exclude non-western peoples, who are obliged to participate in a narrative written by and for the West.

Moreover, a typical feature of the theory of globalization is how it commonly unites regulatory and de facto elements. Globalization theory is therefore constituted as a powerful justification for economic, political or social action, and establishes a corrosive debate between those supporting the process and those who reject it. In short, globalization theory as reflected here is faced with both specific and general problems, which restrict its analytical and descriptive capacity. Its success could reside more in its capacity to draw up an enormously valuable cognitive map for members of societies undergoing profound and accelerating economic, political and cultural change, than in its analytical capacity to describe this reality in scientific terms.

\section{INTRODUCCIÓN}

El fenómeno de la globalización ha provocado, como es sabido, uno de los debates más intensos y fructíferos dentro de las ciencias sociales de los últimos tiempos. Ahora bien, las teorías sobre la globalización están sujetas al paso del tiempo y, cómo no, también a las modas académicas. Esto ha producido que recien- 
temente algunos autores hayan rechazado la teorización sobre la globalización como un camino fructífero para explicar las relaciones internacionales y hayan dictaminado su defunción (Rosenberg, 2005). Sin embargo, y sin entrar en el debate entre globalizadores y escépticos (Held y McGrew, 2002), lo cierto es que es un concepto vivo en el debate académico, político y social. En este sentido es posible afirmar que es una perspectiva que ha modificado profundamente la visión tradicional de las ciencias sociales permitiendo la superación del marco de referencia nacional (Albert, 2007) y que su desaparición como teoría no parece cercana (Bude y Durrschmidt, 2010). En 2006 un estudio recogió 114 definiciones diferentes del término globalización (Al-Rodhan, 2006) y existe un amplio corpus teórico sobre el fenómeno con múltiples autores de referencia (Boli y Lechner, 2009; Jones, 2010; Stohl, 2005). Las teorías sobre la globalización, además, cruzan las fronteras disciplinarias y ayudan a construir los modelos teóricos de todas las ciencias sociales.

Este artículo pretende cubrir una carencia de la teoría de la globalización: la falta de sistematización de sus diferentes aproximaciones teóricas. Esto puede parecer paradójico, porque la producción sobre el tema es muy abundante. Se pretende describir el modelo subyacente a las distintas construcciones teóricas en torno a su mecanismo explicativo fundamental para posteriormente realizar una crítica sobre sus fundamentos analíticos y empíricos. Se trata, en definitiva, de responder a las preguntas que planteó Roland Robertson: “¿Qué impulsa el proceso de globalización? ¿Cuál es su fuerza motriz?” (2001: 461).

Para ello, en primer lugar y tras realizar una breve descripción de la metodología, el artículo presenta las cuatro tesis principales que se han identificado dentro de las ciencias sociales a la hora de explicar el proceso de globalización. En segundo lugar se discutirán las principales críticas que se han realizado a cada una de estas tesis, intentando sistematizarlos en el mayor grado posible. Finalmente se planteará en las conclusiones la existencia de una crítica general que más allá de las virtudes o defectos de las diferentes tesis, plantea la necesidad de revisar toda la teoría de la globalización como un intento postrero de utilizar categorías analíticas modernas en un entorno intelectual posmoderno que ya no las contempla como básicas para las ciencias sociales.

\section{METODOLOGÍA}

Un aspecto peculiar de la teoría de la globalización es su carácter de "gran teoría", que vive en libros y monografías más que en artículos científicos, dedicados en su mayor parte a analizar aspectos concretos del proceso de globalización o, a lo sumo, a intentar construir teorías de alcance medio en el sentido que le confirió Robert K. Merton al término. Posee un carácter de relato totalizador, 
que sirve como ultima explicación de todo tipo de fenómenos económicos, políticos, sociales o culturales y de justificación de actuaciones y políticas concretas. Por ese motivo la globalización se constituye en un campo de continuas y virulentas discusiones teóricas, ideológicas y políticas (Trigo, 2004). Es uno de los últimos grandes relatos de sobre la modernidad tardía.

En el análisis de estas teorías se han revisado las obras más relevantes y citadas por la comunidad científica que intentan explicar la globalización como un proceso totalizador de cambio. Entre ellas se encuentran trabajos escritos por algunos de los más destacados analistas sociales en el campo de la antropología (Appadurai, 1996), filosofía (Safranski, 2005), sociología (Bauman, 1998; Beck, 2000; Berger y Huntington, 2002; Casttels, 2000; Giddens, 1993, 2000; Ritzer, 2004; Robertson, 1992; Urry, 2002), economía (de la Dehesa, 2006; Stiglitz, 2002, 2006), ciencia política (Barber, 1996; Held y McGrew, 2002, 2007) o, entre otros, geografía humana (Anderson, Brook y Cochrane, 1995; Harvey, 2008). Para sistematizar las diferentes teorías sobre la globalización se propone una clasificación que trata de agruparlas en función del "mecanismo explicativo" que plantean, explícita o implícitamente, a la hora de exponer su desarrollo. El mecanismo es con frecuencia monocausal, aunque esto no ocurre necesariamente en todas las teorías. Se han detectado cuatro grandes tesis en función del mecanismo explicativo que utilizan para explicar el proceso de globalización. Es posible denominarlas: la tesis del intercambio comercial, la tesis modernizadora, la tesis tecnológica y la tesis del capitalismo.

Dentro la descripción de cada una de las tesis se ha intentado presentar sus principales líneas analíticas, ligándolas con un recuento histórico de su gestación. El objetivo es presentar cada una de las mismas en su contexto para posteriormente poder enmarcar las principales críticas de las que han sido objeto. En las conclusiones se argumentarán que la principal crítica a estas tesis deriva del posmodernismo, que rechaza la idea de construir una gran teoría (Ritzer, 2004). Se trata de una crítica meta-teórica que afirma la imposibilidad de construir una teoría de la globalización como un gran relato de la modernidad.

\section{TESIS DEL INTERCAMBIO COMERCIAL}

Una de las tesis más influyentes a la hora de explicar la globalización sostiene que esta es un proceso de creciente interconexión basado en un aumento histórico del comercio a escala planetaria. El origen de los intercambios comerciales descansaría, como afirmaba Adam Smith (1723-1790), en la propensión natural del ser humano hacia el intercambio. Destacan dos escuelas económicas a la hora de situar los intercambios comerciales como la base de la 
globalización, que además suelen contemplar de un modo positivo. Desde la escuela neoclásica y monetarista se ha afirmado que la globalización no es sino la extensión de los mercados a escala mundial. Este es un proceso en el cual si no existen barreras o distorsiones, por ejemplo, una información imperfecta o la intervención de terceros agentes, se llegará a una situación de perfecto equilibro beneficiosa para todos los partícipes en el mercado. El libre comercio producirá que la oferta y la demanda de bienes lleguen a un equilibro en el cual todas las partes implicadas obtengan beneficios, reduciendo las posibles desigualdades de partida. El mecanismo que posibilitaría esto sería la ventaja comparativa.

Según esta teoría, cuya versión canónica propuso el año 1817 David Ricardo (1772-1823) en Inglaterra, el libre comercio internacional permitiría que cada nación se especializara en producir aquellos productos y servicios para los que está especialmente dotada, por los que obtendría rentas en el mercado internacional. Con las mismas compraría el resto de productos y servicios que precisara a menor costo que si los tuviese que producir por sí misma. Este sistema haría que todas las naciones ganaran con la apertura de los mercados y que a largo plazo se produjera una equiparación de rentas (steady state). La globalización sería, por tanto, un proceso con el que los actores individuales buscando su propio beneficio se especializarían y a través del libre comercio alcanzarían una situación de equilibrio en la cual todos saldrían ganando. Posteriormente, en 1933, los economistas suecos Bertil Ohlin (1899-1979) y Eli Hecksher (1879-1952) reformularon este planteamiento, en el llamado modelo HecksherOhlin, manteniendo sin embargo el carácter beneficiosos de la especialización y del comercio internacional para todas las partes implicadas.

Desde otra óptica, los economistas de la llamada Escuela Austriaca -Ludwig von Mises (1881-1973) o Friedrich A. Hayek (1899-1992)-, describían los mercados como un proceso espontáneo, que no admitía planificación y en el que no se llegaba a un equilibro (Huerta de Soto, 2010). La globalización desde esta perspectiva implicaría una extensión natural de los mercados, en la que aumentan su tamaño y complejidad hasta adquirir una dimensión global. Un epígono de esta tendencia afirma actualmente que, por tanto, "no es un fenómeno nuevo, sino que se trata de un proceso evolutivo, que emerge espontáneamente de la interacción de diversos individuos en el mercado y cuyo resultado presenta un orden abstracto o extendido que ninguno de esos individuos tenían en cuenta al actuar" (Ravier, 2012: 23). El proceso de globalización resultará beneficioso siempre que el Estado no intervenga, pues se ve como un desarrollo propio de los mercados en el que el Estado no tiene más papel que entorpecer su extensión. El fundamento de este proceso descansaría en el 
comercio, que es una actividad anterior incluso a todas las demás tareas productivas.

En lo que coinciden ambas corrientes, si bien la segunda de un modo más marcado, es en la consideración del Estado como un peligro para el desarrollo "equilibrado" y "espontáneo" de los mercados y por extensión de la globalización. Además ambas coinciden en valorar positivamente la globalización como prolongación del mercado capitalista, lo cual supone ventajas evidentes para los actores implicados que mejoran su situación inicial.

Los defensores del libre comercio y la teoría de la ventaja comparativa fueron especialmente activos durante el siglo XIX, especialmente durante la denominada "primera globalización" que se ha datado entre 1890 y 1914 (Bayly, 2010). Posteriormente se produjo un reflujo, coincidiendo con las dos Guerras Mundiales, que supuso un aumento del proteccionismo nacional y en el plano teórico la aparición de dudas acerca de la teoría de la ventaja comparativa y de su papel beneficioso para todas las partes implicadas en el comercio mundial. El consenso de postguerra y el keynesianismo trajeron una reapertura de los mercados mundiales que se solidificó en torno a los acuerdos de libre comercio (GATT). La crisis de los años 70 fue un reto para la consolidación de un sistema de libre comercio mundial. En un informe dirigido a la Comisión Trilateral se planteaba en 1975 que:

Por regla general, el cuarto de siglo inmediatamente posterior a la Segunda Guerra Mundial fue testigo de la eliminación de las restricciones al comercio y la inversión, y de una apertura general de las economías de los países industrializados, capitalistas. Sin embargo, en tiempos de escasez económica, inflación y posibles recesiones económicas a largo plazo, aumentan las presiones a favor del nacionalismo y el neo-mercantilismo y los sistemas políticos democráticos se ven particularmente vulnerables a la presión de esos grupos de la industria, de las localidades y de las organizaciones laborales, que se ven desfavorablemente afectados por la competencia extranjera (Crozier, Huntington y Watanuki, 2012: 325-326).

Para combatir dichas "presiones" se orquestó toda una respuesta con el objetivo de favorecer el libre comercio y la globalización, que tuvo su máxima expresión en el Consenso de Washington (Williamson, 1993). Estas políticas, firmemente apoyadas por los gobiernos conservadores de Estados Unidos e Inglaterra y seguidas por la mayoría de las economías más desarrolladas, tuvieron éxito y en 1994 se creó la Organización Mundial del Comercio, que profundizaba en los acuerdos de libre comercio y les daba mayor cobertura institucional (Martín-Cabello, 2013). En todo caso, pese a su largo recorrido histórico la tesis del intercambio comercial ha mantenido básicamente inalteradas 
sus premisas de partida, a saber, que la especialización y división internacional del trabajo combinada con un comercio internacional abierto -sin interferencias estatales- es fruto de la propensión natural del ser humano a comerciar y crear mercados cada vez más amplios y que sus consecuencias son beneficiosas para todos los implicados. La globalización como expresión última de esta dinámica retendría este carácter positivo.

\section{TESIS MODERNIZADORA}

La segunda tesis plantea que la globalización supone la extensión del proceso modernizador surgido originalmente en Europa a escala planetaria. La modernización implicaría una dimensión técnica, de intercambio comercial y de acumulación capitalista, sin duda, pero también aspectos políticos como la democracia, el imperio de la ley o el control de la violencia física, y culturales como la secularización o el individualismo. Esta visión estuvo ampliamente extendida dentro de la Historische Schule der Nationalökonomie en Alemania, de la escuela institucionalista económica norteamericana y de la corriente sociológica principal. En general, y pese a sus diferencias, contemplaba que la economía se encontraba integrada en una sociedad y una cultura histórica concreta. Por lo tanto, los desarrollos económicos como el mercado, el capitalismo o el comercio internacional debían estudiarse conjuntamente con el resto de instituciones sociales que permitían su existencia.

Quizá la versión más famosa de esta tesis fue la desarrollada por Max Weber a finales del siglo XIX y principios del XX. Hacía hincapié, entre otros, en los factores culturales como elementos codeterminantes en la aparición del capitalismo (Weber, 1998). Pensaba que la ética protestante influyó en un primer momento en la aparición de un ethos capitalista. En consecuencia, la cultura de los distintos países influía en el éxito del sistema capitalista en ese territorio. Sostenía, asimismo, que históricamente el capitalismo era una forma específica de economía, que implicaba un conjunto de instituciones en la esfera económica: contabilidad racional, propiedad privada, técnica racional, libertad mercantil, trabajo libre y mercantilización de la economía; y en las esferas política, social y cultural como el Estado racional, con su derecho y burocracia racionales, o una ideología propia del capitalismo (Weber, 2011).

La globalización vista desde esta perspectiva conllevaría la extensión de un modelo civilizatorio, resumido en la palabra modernidad, por todo el planeta y su incorporación por parte de pueblos no occidentales. Las tesis modernizadoras fluctúan desde un modernismo difusionista, en el que el resto de países van incorporando poco a poco las instituciones Occidentales, hasta la teoría de las modernidades múltiples, para la cual existen diferentes caminos 
o vías hacia la modernidad, que puede desarrollarse en entornos culturales muy diversos. La primera versión se encontraba ampliamente extendida después de la Segunda Guerra Mundial con las llamadas teorías del desarrollo o de la modernización (Curran y Park, 2000: 3). De hecho, la globalización era vista como una teoría del desarrollo (Reyes, 2001). Se planteaba que todos los países, una vez superadas las barreras institucionales y culturales locales, podían llegar a convertirse en países desarrollados similares a los occidentales. Solamente había un camino hacia la modernidad, un progreso lineal que consistía en la asunción de las instituciones occidentales.

En esta línea, el historiador Niall Ferguson (2012) ha interpretado tardíamente la globalización, que supone un retroceso o una decadencia de Occidente y un avance del resto del mundo, como un proceso en el que países no occidentales han conseguido "descargarse" las instituciones clave (a las cuales denomina killer aps o aplicaciones asesinas) que permitieron el desarrollo occidental: la competencia en la esfera de la economía, la ciencia, la medicina moderna, la sociedad de consumo y la ética del trabajo. De este modo aunque no asumen todo el aparato institucional occidental ni su cultura completa, si incorporan las instituciones clave que permitieron la modernización. Es decir, la globalización sería algo más que economía, pues incluiría la aceptación de las instituciones claves de la modernidad occidental por parte de las naciones no occidentales exitosas. La contraparte la pondrían las naciones fracasadas, que no han conseguido integrar esas instituciones clave.

La segunda versión surgió con posterioridad para tratar de explicar el éxito de países como Japón o los llamados Tigres Asiáticos (Hong Kong, Corea del Sur, Singapur y Taiwán) a la hora de desarrollar un sistema capitalista competitivo sin necesidad de incorporar la cultura y las instituciones occidentales como un todo. Anthony Giddens (1993) planteaba que la modernidad pivota sobre cuatro dimensiones institucionales clave: el capitalismo, el industrialismo, la vigilancia y el poder militar, a los que habría que añadir la cultura. La misma dinámica de la modernidad lleva a su extensión ya que esta es "intrínsecamente globalizadora", lo cual produce que se pueda hablar de cuatro dimensiones institucionales clave de la globalización: el capitalismo mundial, la división internacional del trabajo, el sistema de Estados mundial y el orden militar mundial, sobre los que pivota igualmente la globalización de la cultura. Cree que la modernidad es occidental desde el punto de vista del Estado-nación y de la producción capitalista, ya que son dimensiones institucionales que han aparecido y se han desarrollado allí. Sin embargo, cuando se globalizan pierden esa característica, pues es un proceso abierto de interdependencia en el cual lo no occidental tiene su peso. Así, "se pueden dar muchas 
clases de respuesta cultural a esas instituciones dada la diversidad cultural del mundo en su conjunto" (1993: 163). Dicho de otro modo, la modernidad es adaptativa y adquiere un perfil diferente según el contexto en el que se desarrolla.

Grosso modo, esta versión mantiene que la globalización surge de la expansión de la civilización occidental, europea en un primer momento, por todo el mundo. No se trata simplemente del crecimiento de un sistema económico basado en el intercambio mercantil, sino de la extensión planetaria de un conjunto institucional que configura una forma civilizatoria específica: la modernidad. Esta posteriormente se incorporaría a otras civilizaciones y adquiriría un carácter global.

Esta nueva perspectiva de la modernización rechaza la visión de que el mismo proceso de modernización genera el potencial de evolución compartido por todas las sociedades sino que estima que la modernización o la modernidad son un tipo específico de civilización que surgió en Europa y se expandió a través del mundo, abarcándolo -sobre todo después de la Segunda Guerra Mundial- casi en su totalidad. (...) Al igual que hicieron las civilizaciones históricas en su expansión, el despliegue de la modernidad desafía las premisas simbólicas e institucionales de las sociedades que quedan incorporadas. (...) Estas diferencias se cristalizan en el marco de la incorporación selectiva -y transformación- tanto de las principales premisas simbólicas y formaciones institucionales de la original civilización occidental como de las tradiciones y de la experiencias históricas de sus propias civilizaciones (Eisenstadt, 2010: 99-100).

En consecuencia la globalización además de comercio internacional y flujo de mercancías, capitales y personas supone cambios técnicos, políticos, sociales y culturales que son incorporados a través de una compleja negociación -no simplemente de "descargas" selectivas- en las culturas no occidentales.

\section{TESIS TECNOLÓGICA}

Otra de las tesis, una de las más populares y extendidas, considera que la globalización ha de explicarse fundamentalmente desde su base técnica. Desde esta posición se afirma que las comunicaciones físicas y las Tecnologías de la Información y la Comunicación (TIC) están detrás de la globalización (Castells, 2000; Cebrián, 2000; Langhorne, 2001; Negroponte, 1995). Manuel Castells, uno de los más famosos defensores de esa posición, considera que son fundamentalmente las TIC -entre las que incluye las biotecnologías- las que explican los cambios que conducen hacia la globalización y generan una sociedad basada en los flujos de información que denomina sociedad red. Así, "el núcleo 
de la transformación que estamos experimentando en la revolución en curso remite a las tecnologías del procesamiento de la información y la comunicación" (2000: 57). También se puede citar, entre otros, a Richard Langhorne (2001) para el cual las redes de comunicación, primero físicas con la invención de la máquina de vapor y posteriormente de la información con el hito iniciático de la invención del telégrafo, marcan el punto de partida de la globalización y le confieren su carácter distintivo. En todo caso, para esta tesis el factor fundamental que explica los orígenes y las características actuales de la globalización es la aparición, mejora y extensión de las comunicaciones físicas y sobre todo de las TIC.

En este sentido, las TIC ejercerían su influencia en dos campos diferenciales: la evanescencia de las barreras geográficas de un lado y de los límites temporales de otro. La globalización, en primer lugar, supone el fin o al menos la disminución de la importancia de los límites territoriales (Cairncross, 1997; Virilio, 1997). Se produce un estrechamiento de los límites del planeta en todos los ámbitos de la vida social. La globalización implica, por un lado, la pérdida de la conexión de las sociedades y las culturas con el territorio con el que antes se consideraba unidas de un modo natural y, por otro, su reubicación en nuevos entornos geográficos (García Canclini, 2001). Es por tanto un proceso paradójico que si bien no hace desaparecer el territorio, lugar donde se da la existencia de los seres humanos, sí disminuye su importancia y fomenta la aparición de nuevos espacios donde opera una lógica global. Marc Augé (2000) denomina "no lugares" a estos nuevos espacios globales. Los lugares tradicionales se caracterizaban por ser históricos, relacionales y generadores de identidad, mientras que los no lugares no pueden definirse así en modo alguno. Cita algunos de estos espacios: las cadenas hoteleras, los complejos vacacionales, los medios de transporte, los campos de refugiados, los centros comerciales o los parques de atracciones. En general la experiencia del viaje resulta arquetípica de estos no lugares, como nuevos espacios sin historia en los que no se establecen relaciones humanas generadoras de identidad. Friedman (2003) habla de la "experiencia de volar" y Echeverría (1999) de "los señores del aire" como metáfora de este espacio de flujos asociado al transitar por todo el planeta.

También supone un nuevo modo de encarar nuestras relaciones con el tiempo, preso de ese estrechamiento del espacio. Manuel Castells denomina "tiempo atemporal" a este cambio, que se identificaría por romper los ciclos biológicos tradicionales y la temporalidad social lineal asociada al reloj. Crearía, en su lugar, un tiempo simultáneo al enlazar todo el planeta en "tiempo real" y atemporal al diluir la secuenciación y la historia, lo efímero y lo permanente. 
De este modo, "el tiempo atemporal pertenece al espacio de los flujos, mientras que la disciplina temporal, el tiempo biológico y la secuenciación determinada por la sociedad caracterizan a los lugares de todo el mundo" (Castells, 2000: 500). Esta tendencia al desdibujamiento de las restricciones de la geografía y del tiempo supone un estrechamiento "espacio-temporal" (Harvey, 2008). Lo global, en consecuencia, parece existir más allá de las limitaciones que el tiempo y el espacio imponían a los seres humanos en el pasado. Para los defensores de esta tesis, la tecnología está en la base de estos cambios y del proceso de globalización.

\section{TESIS DEL CAPITALISMO}

La última de las tesis pone el énfasis en la expansión del capitalismo, contemplándolo como un fenómeno más amplio que el mercado y como el motor fundamental de la globalización. Estos autores suelen creer que el capitalismo es un fenómeno institucional que va más allá del simple intercambio. Es frecuente que citen entre las condiciones necesarias para la existencia del capitalismo al menos tres grandes elementos: un sistema monetario que permita la existencia de dinero en forma de crédito bancario, el intercambio mercantil y la producción de mercancías dentro del sistema de empresa privada (Ingham, 2010: 68). Suele añadirse la existencia de un Estado que apoye y de la cobertura institucional necesaria para la instalación del sistema capitalista.

Según esta corriente, cuyos orígenes se pueden rastrear en el trabajo de Karl Marx (1818-1883), el capitalismo no sería la forma natural de la economía surgida del intercambio y el comercio. Al contrario, se trataría de un tipo o modelo específico de economía que apareció en un periodo concreto de la historia y que requiere la existencia de un conjunto específico de instituciones. Desde esta óptica existen tres grandes teorías que han tratado de explicar la globalización como un proceso de extensión planetaria del sistema capitalista (Sztompka, 2008: 113-116). En primer lugar se encuentra la teoría del imperialismo tal como la formularon Vladimir Lenin (1870-1924) o Nikolai Bujarin (1888-1938) en los años 30 del siglo pasado. Para ellos, la última fase del capitalismo sería el imperialismo, que busca evitar el colapso del sistema a través de la búsqueda de nuevos mercado y de mano de obrar y de materias primas baratas. Con ese fin, los países capitalistas no dudaban en usar la violencia cuando resultaba necesario a fin de mantener la balanza del comercio mundial a su favor.

En segundo lugar, durante los años 50 y 60 teóricos como André Gunder Frank (1929-2005) o Fernando Cardoso (1931-...) formularon la teoría de la dependencia en Latinoamérica. Planteaban que el comercio internacional se 
fundaba en las relaciones de los países desarrollados, "centro" del sistema, con los países no desarrollados o "periféricos", que se mantenían en una situación de dependencia respecto a los primeros. Como resultado de esta situación, los beneficios del comercio internacional y del proceso de globalización recaían en los países centrales y no en los periféricos.

Finalmente, en tercer lugar, durante los años 70 el propio André Gunder Frank y otros teóricos como Immanuel Wallerstein (1930-...) o Samir Amin (1931-...) desarrollaron la llamada teoría del sistema mundial. Wallerstein (1999, 2011a, 2011b, 2012a, 2012b) sostiene que el mercado no es un hecho natural, sino que ha tenido que ser creado y mantenido constantemente. En su construcción histórica el Estado ha sido básico, ya que la idea de que el mercado crece enfrentado al Estado es mera ideología. El Estado y el mercado han operado conjuntamente en la extensión del sistema capitalista. Al desarrollarse, el capitalismo ha intentado mercantilizar cada vez más facetas de la vida y ha querido hacer aparecer como un hecho dado la institución del mercado.

Distingue diferentes etapas en el desarrollo de una economía-mundo capitalista desde el siglo XVI, donde sitúa sus orígenes, hasta la actualidad. Esta economía-mundo es, a su vez, un tipo de sistema-mundo junto a los imperios mundiales. Se diferenciarían de estos últimos por no tener un centro político definido con fronteras estables, sino múltiples centros. Considera que la globalización es tanto la última etapa en la consolidación de la economía-mundo capitalista como la ideología del capitalismo actual que naturaliza la idea de mercado y de libre comercio (Robinson, 2011).

Samir Amin $(1993,1997,1998)$ sostiene que el libre comercio no genera por sí mismo un sistema capitalista. Históricamente ha existido comercio en múltiples partes del planeta sin que surgiese un sistema capitalista. Este presupone una estructura social, política y económica específica. La globalización sería la palabra que definiría el triunfo de un sistema capitalista a escala mundial que permite la integración de todo el planeta. De hecho, "será el capitalismo el que realizará por primera vez un verdadero y auténtico sistema mundial único, que imprimirá a la historia una aceleración logarítmica" (Amin, 1976: 147). La globalización y consolidación del sistema mundial, en consecuencia, es fruto de la expansión del sistema capitalista.

En resumen, esta posición sostiene que el desarrollo del capitalismo como sistema económico (y político) explicaría la globalización, que se constituiría en la última fase del mismo. La globalización implicaría que las fuerzas del mercado, apoyadas por el Estado, desbordarían las fronteras nacionales y crearían un mercado mundial o global bajo las leyes de la oferta y la demanda. Para conseguirlo tratarían de desregular las economías nacionales y de favorecer la no 
interferencia de terceros en las leyes del mercado consideradas como naturales. En consecuencia, la globalización sería la última fase de un proceso de extensión planetaria de los mercados. Todo intento de limitar o de regular dicha expansión sería contemplado por las fuerzas que lo impulsan como una "distorsión" o "barrera" al natural desarrollo de la economía. Lo cual, afirman, no sería más que una forma de oscurecimiento de la verdadera naturaleza del proceso. Un proceso que lejos de responder a leyes inscritas en la naturaleza (tesis del intercambio comercial) descansa en los intereses de los colectivos e individuos que centralizan los beneficios del sistema.

\section{DISCUSIÓN}

Hasta el momento se han presentado las cuatro grandes tesis que coexisten en el espacio de discusión intelectual para explicar el proceso de globalización (véase un resumen en la Tabla 1, pág. 348). Todas ellas, pese a su popularidad y extensión, han sido objeto de duros ataques cruzados. Los defensores de una tesis suelen criticar a las demás, poniendo de relieve sus carencias a la hora de explicar el proceso de globalización pasado, presente o futuro. Se tratarán de resumir las críticas más frecuentes que se han formulado a cada una de las cuatro tesis.

\subsection{Críticas a la tesis del intercambio comercial}

Esta posición es la más controvertida y ha recibido gran cantidad de críticas. De hecho, en buena medida el resto de tesis surgió en confrontación con sus postulados. Las críticas se pueden agrupar en cinco grandes categorías: sobre sus presupuestos ideológicos, acerca de la naturalización del sistema económico, sobre el papel del Estado, sobre los resultados de la globalización y, finalmente, acerca del mecanismo que regula el comercio internacional.

En primer lugar, los críticos a esta tesis suelen afirmar que se presenta como una teoría científica, pero que en realidad es ampliamente ideológica. Suelen denominarla neoliberalismo, pensamiento único o fundamentalismo de mercado -también, en una denominación con menos éxito se le ha llamado "turbocapitalismo" (Luttwak, 2000) y en otra con mayor fortuna "capitalismo líquido" (Bauman, 2003)-. Piensan que esta ideología concibe la historia de un modo teleológico. El desarrollo de los mercados se contempla como el paso natural de los primeros y limitados mercados hasta el gran mercado abierto de la globalización. En todo caso, el mercado se considera una realidad natural preexistente, que solamente tiene que desarrollarse frente al Estado. La idea básica es que la globalización es un proceso espontáneo que si no se ve obstaculizado 
Tabla 1. Resumen de las cuatro tesis fundamentales en la explicación del proceso de globalización

\begin{tabular}{|c|c|c|c|c|}
\hline Tesis & $\begin{array}{c}\text { Causa principal } \\
\text { del proceso de } \\
\text { globalización }\end{array}$ & Motor del cambio & $\begin{array}{c}\text { Principales teorías } \\
\text { en que cristaliza } \\
\text { cada tesis }\end{array}$ & $\begin{array}{c}\text { Origen } \\
\text { aproximado del } \\
\text { proceso de } \\
\text { globalización } \\
\end{array}$ \\
\hline $\begin{array}{l}\text { Intercambio } \\
\text { comercial }\end{array}$ & \begin{tabular}{|c|} 
Extensión y \\
consolidación en \\
forma de \\
mercados de las \\
redes de \\
intercambio \\
comercial \\
\end{tabular} & $\begin{array}{c}\text { Propensión del } \\
\text { ser humano hacia } \\
\text { el trueque y } \\
\text { el intercambio }\end{array}$ & $\begin{array}{c}\text { Teoría de la ventaja } \\
\text { comparativa y } \\
\text { teoría del comercio } \\
\text { internacional }\end{array}$ & 3000-2000 a.C. \\
\hline Modernizadora & $\begin{array}{c}\text { Expansión de la } \\
\text { civilización } \\
\text { occidental }\end{array}$ & $\begin{array}{c}\text { Aparición } \\
\text { combinada de una } \\
\text { serie de } \\
\text { instituciones clave }\end{array}$ & $\begin{array}{c}\text { Teorías de la } \\
\text { modernización } \\
\text { y teoría de las } \\
\text { modernidades } \\
\text { múltiples }\end{array}$ & 1500 d.C. \\
\hline Tecnológica & \begin{tabular}{|c|} 
Invención y \\
mejora de las \\
comunicaciones \\
físicas y de \\
las TIC
\end{tabular} & $\begin{array}{l}\text { Extensión de las } \\
\text { facultades } \\
\text { comunicativas } \\
\text { del ser humano }\end{array}$ & $\begin{array}{c}\text { Teorías del } \\
\text { industrialismo } \\
\text { y teorías de la } \\
\text { sociedad de la } \\
\text { información }\end{array}$ & 1800 d.C. \\
\hline Capitalismo & \begin{tabular}{|} 
Expansión del \\
sistema \\
capitalista: dinero \\
y crédito, \\
intercambio \\
mercantil y \\
empresa privada
\end{tabular} & $\begin{array}{l}\text { Unión del poder } \\
\text { político y } \\
\text { económico para } \\
\text { crear un sistema } \\
\text { de mercado } \\
\text { autorregulado }\end{array}$ & $\begin{array}{c}\text { Teoría del } \\
\text { imperialismo, } \\
\text { teoría de la } \\
\text { dependencia y } \\
\text { teoría del } \\
\text { sistema mundial }\end{array}$ & 1980 d.C. \\
\hline
\end{tabular}

Fuente: elaboración propia

por el Estado (stateless global governance) conseguirá una mejora en todo el planeta mediante los mecanismos de la oferta y la demanda, que aseguran el equilibro de mercado, y la ventaja comparativa, que confiere un lugar en el comercio mundial a todas las naciones. Rechazan esta forma de contemplar la globalización, porque no refleja los hechos que se describen a continuación.

En segundo lugar, se ha combatido la idea de que la globalización es un proceso espontáneo. Suelen argüir que el mercado no es un orden espontáneo, sino que es una creación de los Estados o grupos políticos así como de los colectivos sociales interesados en su aparición y mantenimiento. La globalización estaría sustentada activamente por gobiernos, grupos financieros, industriales 
o terratenientes, es decir, por los agentes que se benefician de ella (Frieden, 2013). En este sentido existen fuerzas que contribuyen a la creación y desarrollo de la globalización. Aún aceptado que los actores influyen limitadamente en la globalización y que su actuación genera "consecuencias no intencionales", también sería cierto que parten de posición de poder diferenciales y que su actuación tiene un peso distinto en el proceso.

También se ha rechazado la idea de que el mercado sea una realidad natural, surgida en la antigüedad y desarrollada hasta la globalización actual. Como afirmó Karl Polanyi (1994), el libre mercado es un hecho específico y los intercambios en la antigüedad se encontraban regulados por otras formas institucionales que en nada se le parecen. Se sostiene, por tanto, que no es posible equiparar las formas actuales de intercambio propias de la globalización con las que se daban en el pasado. La circulación de bienes suntuarios en la Europa prehistórica (Kristiansen, 2001), el fenómeno del Kula entre los melanesios (Malinowski, 2001) o del Potlatch entre algunas tribus de la costa del Pacífico en Norteamérica (Mauss, 2009), no son situaciones que se expliquen según las leyes del mercado, aunque sí del intercambio. La confusión radicaría en confundir los sistemas de intercambio con el mercado. Otros autores afirman que no es posible equiparar la existencia de mercados con la del sistema capitalista (Braudel, 1985; George, 2010). Los primeros históricamente han existido sin que existiera un sistema capitalista que gobernara la economía de un territorio. Esta posición ya fue sustentada por Max Weber, para el cual:

Los mercados modernos no surgen de la "propensión natural al trueque, pago en especies e intercambio" descubierta por Adam Smith. Tampoco surgen de las elecciones racionales de los individuos. Para su surgimiento deben desarrollarse con anterioridad varias "condiciones sustantivas", tales como los modos racionales de contabilidad y administración, la promulgación de un derecho formal "interpretado y aplicado racionalmente" por juristas, el concepto de ciudadano, una ciencia y tecnología avanzadas, una ética económica moderna, la separación entre la economía doméstica y la de la empresa y la ausencia de monopolios absolutos en el mercado (Kalberg, 2008: 107).

Se ha afirmado, en tercer lugar, que es incierto considerar que el mercado exista o pueda existir sin el concurso del Estado. Diversos autores han señalado la importancia histórica del Estado en la gestación y mantenimiento del sistema capitalista y de los mercados asociados al mismo (Ingham, 2010; Polanyi, 2011; Rodrik, 2011; Wallerstein, 2012a). Max Weber incluso llegó a afirmar al hablar de los orígenes del capitalismo que "es, pues, el Estado racional cerrado el que procura al capitalismo las posibilidades de subsistencia” (2011: 341). Más recientemente Charles E. Lindblom ha afirmado que vista la evidencia, 
el sistema de mercado de nuestros días no es el laissez-faire de Adam Smith ni tampoco un sistema de mercado ligado a un Estado mínimo. Hoy, el sistema de mercado es un sistema dirigido, fuertemente cargado o adornado con lo que los partidarios del libre mercado de la vieja escuela describen despectivamente como "interferencias" (2002: 20).

Los mercados globales, argumentan, no han crecido "frente" a los Estados, más bien lo han hecho "con" los mismos. Los acuerdos de libre comercio han sido gestados por los Estados o al menos por los más poderosos. En este sentido, no son fruto de un mercado autorregulado y anónimo, aunque los agentes que juegan en el mercado interactúan con los Estados para consolidar su lógica y en esa actuación pueden contribuir a configurar los acuerdos interestatales

La cuarta crítica descansa en el resultado de la globalización. Se niega que la ley de la oferta y la demanda conduzcan a una convergencia planetaria real. Se ha afirmado que la idea de un mercado autorregulado que llega a un equilibrio -que debemos entre otros a economistas como Adam Smith, Vilfredo Pareto (1848-1923) o Leon Walras (1834-1910)-, solo funciona aplicando una serie de presupuestos abstractos simplificados, por ejemplo, que todos los agentes tienen una información perfecta y completa sobre la situación del mercado, lo cual no tiene correlato con la realidad. Los agentes económicos más bien parecen convivir permanentemente con una situación donde predomina la información imperfecta o distorsionada (Stiglitz, 2002). Cuando se aplican modelos matemáticos complejos, con simulaciones mediante ordenador, para analizar la emergencia de sistemas como el comercio internacional, el resultado tiene a ser distinto del que los modelos económicos ortodoxos pronostican (Ball, 2008). La distribución no termina siendo óptima y se suele producir un aumento de la desigualdad de renta entre los actores implicados, no una reducción de la misma.

Por último, en la que es quizá la crítica de mayor calado, también se ha discutido el mecanismo que según la economía ortodoxa explicaría el equilibro en los mercados internacionales: la ventaja comparativa. Los economistas Wolfgang Stolper (1912-2002) y Paul Samuelson (1915-2009) argumentaron en 1941 que el comercio internacional era beneficioso para algunos actores y perjudicial para otros dentro del mismo contexto geográfico. Los exportadores de un factor de producción abundante en una nación se beneficiaban del comercio, mientras que los productores de un bien escaso sufrían la competencia de productos extranjeros - provenientes de entornos donde eran abundantes- que terminaban arruinándolos. Esto suponía que dentro de una nación había ganadores y perdedores, aun cuando el cómputo total para la economía pudiese resultar beneficioso (Frieden, 2013: 152-155). 
Apenas unos años más tarde, en 1944, Karl Polanyi (1886-1964) publicó La gran transformación en la que retomaba parcialmente estas tesis al afirmar que el libre comercio y el sistema de mercado producían graves dislocaciones sociales. La consecuencia era que la sociedad debía "autoprotegerse". Obviamente, quienes se autoprotegían eran aquellos que perdían con el intercambio. Así, los países europeos durante la primera globalización protegieron a sus agricultores en desventaja frente a las importaciones, mientras que las revueltas antiimperialistas representaban en muchas ocasiones a las clases productores locales que no podían competir con las exportaciones de las metrópolis (Polanyi, 2011: 243). Y todo eso aún a expensas de una mejora económica global, ya que el sufrimiento de un sector específico de la economía podía condicionar una desorganización social inasumible para el conjunto de la sociedad. En este sentido, Dani Rodrik (2011) ha llegado a afirmar que la globalización económica tal como aparece hoy día es incompatible con la democracia y el Estado-nación.

Actualmente algunos autores consideran que la ventaja comparativa no se encuentra respaldada ni por la evidencia empírica, ni por el análisis racional. Los datos disponibles muestran que en general el crecimiento económico precede más que acompaña a la apertura del comercio internacional, que los países más exitosos suelen ser puertos francos comerciales y que las economías con corporaciones multinacionales pertenecen a países que han defendido sus intereses al tiempo que mantenían su centro independiente con un Estado fuerte. Además, los países que se especializaban en un nicho de mercado habitualmente no han tenido la capacidad de reconvertirse cuando este nicho fallaba por algún motivo (Mangabeira Unger, 2011: 33-35). Habría que sumar que la teoría de la ventaja comparativa está basa en un presupuesto teórico cuestionable: el nacionalismo metodológico. Es decir, soslaya el hecho de que muchos de los intercambios comerciales se producen dentro y entre grandes corporaciones transnacionales que operan por todo el planeta superando los límites territoriales de las naciones.

\subsection{Críticas a la tesis modernizadora}

La principal crítica que se ha realizado a esta tesis es que entiende la modernidad como un "paquete", en el que todos los elementos han de estar presentes (Jones, 2006). Algunos autores consideran que la globalización económica no precisa del resto del "aparato institucional" para triunfar y que "nunca ha habido la menor probabilidad de que las numerosas variedades de capitalismo se vieran sustituidas por una pálida monocultura anglosajona" (Gray, 2004: 81). En este sentido, Roberto Mangabeira Unger (2011) sugiere que no existe 
un único sistema de mercado, ya que cada nación presenta formas institucionales específicas que además pueden cambiar con el tiempo.

También se ha criticado que esta concepción es excesivamente eurocéntrica y que estas teorías, comunes dentro de la sociología, suelen ser un discurso centrado en el "norte" rico. No incluye visiones alternativas surgidas desde los países no centrales (Connell, 2007). Conceptos como capitalismo, democracia, mercado o modernidad han sido creados para imponer la visión occidental del mundo y ocultan otras realidades y otros modos de vida. Jack Goody $(2011,2012)$ ha descrito la aparición de la modernidad como un proceso de interconexión entre las economías y las culturas del gran continente Euroasiático. En el mismo, algunas partes del continente adquirieron ventaja temporal en función de los flujos comerciales y de intercambio de ideas. En algunos momentos algunas regiones tomaron la delantera, pero al estar las culturas en un proceso de "constante comunicación", los avances tienden a igualarse con el tiempo. No puede afirmarse, por tanto, que Occidente o Europa tengan instituciones singulares y únicas. Simplemente han disfrutado de un momento de bonanza temporal que ahora parece estarse igualando.

Por último, se ha planteado que desde este modelo no se pueden hallar relaciones causales, pues las diferentes dimensiones institucionales o culturales son vistas como causas y resultados de la globalización al mismo tiempo. La globalización supone una extensión mundial de todas las dimensiones de la modernidad, pero no queda claro cuáles son los factores impulsores del proceso en un momento concreto, ni el peso de los mismos en caso de operar al mismo tiempo. Las teorías modernistas suelen reprochar al resto de puntos de vista su determinismo y es frecuente que busquen explicar la globalización como un proceso conducido por un conjunto de relaciones e instituciones diversas (Kellner, 2002). Sin embargo, el problema radicaría en determinar y definir esas instituciones, sobre las que no hay acuerdo. Además, las culturas tienen tal grado de complejidad interna que es difícil saber qué instituciones son importantes para el desarrollo económico en concreto (de la Dehesa, 2006) y para la extensión de un sistema civilizatorio como la modernidad en general.

\subsection{Críticas a la tesis tecnológica}

A esta postura se le ha achacado sobre todo el caer en un determinismo tecnológico, del estilo del practicado por Marshall McLuhan (1993). Así, la primera modernidad y el primer proceso de globalización se explicaban apelando a la máquina de vapor y la globalización actual a Internet. Respecto a la explicación de la modernidad en términos tecnológicos replicaba Edward P. Thompson (1989) que era imposible entender la modernidad como la suma de la máquina 
de vapor y la organización fabril, ya que en la misma estaban implicados factores sociales, culturales y políticos además de económicos. Y Raymond Williams (1974) apuntaba que no existe una determinación tecnológica directa, pues toda tecnología se haya inserta en un contexto social específico.

Posteriormente, como se mantuvo antes, se pasó a centrar el foco en las TIC, que fueron vistas como la base tecnológica que permite la ampliación de los intercambios y del comercio. Frente a esto, los críticos consideran que la tecnología no es una variable independiente, sino un elemento interrelacionados con "los deseos, las costumbres, las ideas y las metas" (Mumford, 1998: 22). Es decir, las tecnologías no sería la causa de la globalización. Al contrario, el proceso de interconexión global sería el acicate para el desarrollo de las tecnologías de la comunicación.

\subsection{Críticas a la tesis del capitalismo}

Este planteamiento ha sido criticado primariamente por contemplar la globalización como un proceso dirigido por "nuevos amos" (Ziegler, 2013), unas "castas rápidas" (George, 2010), una "aristocracia del dinero" (Corm, 2012) o los "Davos Man" (Robinson, 2013). La idea de que ciertos colectivos controlan el mercado global es vista como una irrealidad cercana a las más rancias tesis del complot. Un ejemplo clásico de estas teorías sería la descripción de Carroll Quigley (1981) del Milner Group durante la primera globalización y durante la segunda el llamado Club Bilderberg (Estulin, 2005). Los críticos a esta posición mantienen que esto simplemente no puede ser cierto, ya que cualquier interferencia en el desarrollo natural de los mercados es un proceso de "ingeniería social", que obstaculiza su progreso e impide la extensión de las ventajas de la globalización por todo el planeta. No es posible controlar la globalización, pues surge de un modo natural de las miles de intercambios no planificados que realizan los seres humanos por todo el planeta. De hecho, incluso algunos autores críticos con la globalización aceptan la legitimidad de la misma, pues no sería posible ver la globalización como una conspiración de los poderosos. Mantienen, sin embargo, que está configurada del modo en que lo está porque refleja los intereses de la comunidad financiera internacional (Stiglitz, 2002).

Asimismo se han realizado toda una serie de invectivas sobre los fundamentos ideológicos de esta posición (Bhagwati, 2004: 13-27). Se ha afirmado que es una posición anticapitalista, que siente nostalgia de posiciones fracasadas, y que se encuentra asentada en disciplinas como la literatura, los estudios culturales o la sociología (pero no en la economía). También se liga con los movimientos contrarios al imperialismo, anticolonialistas y antiestadounidenses, y 
a la lucha contra las corporaciones transnacionales. Estos movimientos estarían dentro de la izquierda política, pero también se encuentran en la derecha desde posiciones que apoyan en comunitarismo y la sociedad civil frente al poder disgregador del capitalismo. En todo caso, se achacaría a esa posición su fundamento claramente ideológico, que no se corresponde con la evidencia empírica y con los efectos beneficiosos de la globalización.

Finalmente se ha criticado que aunque es frecuente afirmar que quienes más sufren las consecuencias negativas del proceso de globalización son los pobres en las economías menos avanzadas y los obreros no cualificados de las avanzadas (Bauman, 1998), la globalización puede beneficiar en algunos aspectos más a los países pobres que a los más ricos, por ejemplo mediante la destrucción de empleos industriales en los últimos y su traslado a los primeros (Munck, 2002). El computo final podría ser más beneficioso para los países menos desarrollados que para los más avanzados. Dicho de otro modo, la globalización sería más un transferencia que una polarización de la riqueza.

\section{CONCLUSIONES}

Este artículo ha tratado de elaborar un modelo meta-teórico con objeto de analizar las principales tesis sobre el proceso de globalización. Para ello se ha creado una tipología que en función del mecanismo explicativo fundamental encuentra cuatro grandes aproximaciones. En primer lugar, la tesis del intercambio comercial para la cual la globalización es producto del comercio y de la propensión natural del ser humano hacia el trueque. En segundo lugar, la tesis modernizadora que describe la globalización como el proceso de extensión de un modelo civilizatorio europeo u occidental. En tercer lugar, la tesis tecnológica que encuentra en la mejora de los medios de comunicación físicos y virtuales la principal explicación del proceso de mundialización. Y finalmente la tesis del capitalismo que mantiene que la creación de un sistema económico específico y su posterior extensión por todo el planeta explican la globalización.

Las cuatro tesis exploradas operan en dos niveles de abstracción. El primero describe la causa de la globalización en función de dos variables relativamente simples y homogéneas: la tecnología o el intercambio comercial. El incremento de esas variables conduce inevitablemente a la globalización. El segundo busca modelos multicausales, que habitualmente combinan estas variables simples en modelos analíticamente más complejos. De este modo el capitalismo es definido como una construcción que aúna varias instituciones: intercambio comercial, mercados, dinero, crédito y empresa privada. La modernidad implicaría, entro otros rasgos institucionales, nuevas tecnologías, una economía 
capitalista, un Estado democrático y racional, una ciudadanía activa y una sociedad culturalmente secular e individualista. La combinación de dichas variables, en diverso grado, sería el mecanismo que explicase el proceso de globalización. En todo caso, todas estas teorías quedan unificadas por su intento de constituirse en una "gran teoría" que explique el proceso de globalización como un todo.

Esta gran teoría trata de crear un relato totalizador y que proporcione una "causa primera" a las explicaciones sobre los fenómenos sociales de nuestro tiempo. En este sentido es una teoría profundamente imbuida en el pensamiento moderno. Por este motivo ha sido objeto de ataques desde la teoría posmoderna que más que rechazar aspectos concretos de las tesis expuestas, tienden a rechazar la posibilidad de una teoría de la globalización como un todo. Para los posmodernistas, el tiempo de los grandes relatos ya pasó. Estos suelen ser más una legitimación del proceso, creada por varones caucásicos, que una verdadera descripción de las dinámicas mundiales. Excluyen, por tanto, a los pueblos no occidentales, que son obligados a participar en un relato construido desde y para occidente.

Asimismo, un rasgo característico de la teoría de la globalización es que habitualmente aúna aspectos normativos y de facto. En este sentido, la teoría de la globalización se constituye en una poderosa justificación de la acción económica, política o social y crea un virulento debate entre aquellos que apoyan el proceso y los que lo rechazan. En definitiva, la teoría de la globalización como se ha reflejado afronta tanto problemas concretos como generales, que hacen que su capacidad analítica y descriptiva sea limitada. Su éxito puede radicar más en la capacidad de elaborar un mapa cognitivo de enorme valor para los miembros de sociedades inmersas en profundos y acelerados cambios económicos, políticos y culturales, que en su capacidad analítica para describir esa realidad en términos científicos.

\section{BIBLIOGRAFÍA}

Albert, M. (2007). "Globalzation theory: Yesterday's fad or more lively than ever?". International Political Sociology, 1 (2), 165-182.

Al-Rodhan, N. R. F. (2006). Definitions of Globalization. A Comprehensive Overview and a Proposed Definition. Geneva: GCSP.

Amin, S. (1976). Sobre el desarrollo desigual de las formaciones sociales. Barcelona: Anagrama.

Amin, S. (1993). Capitalismo y sistema mundo. Barcelona: Lafarga.

Amin, S. (1997). Los desafios de la mundialización. México: Siglo XXI.

Amin, S. (1998). El capitalismo en la era de la globalización. Barcelona: Paidós. 
Anderson, J., Brook, C. y Cochrane, A. (Eds.) (1995). A Global World? Re-ordering Political Space. Milton Keynes: The Open University-Oxford University Press.

Appadurai, A. (1996). Modernity at Large. Cultural Dimensions of Globalization. Minneapolis: University of Minesota Press.

Augé, M. (2000). Los no lugares. Espacios del anominato. Una antropología de la sobremodernidad. Barcelona: Gedisa.

Barber, B. R. (1996). Jihad Versus McWorld. How Globalism and Tribalism are Reshaping the World. New York: Ballantine Books.

Ball, P. (2008). Masa crítica. Cambio, caos y complejidad. Madrid-México: Turner-FCE.

Bauman, Z. (1998). Globalization. The Human Consequences. New York: Columbia University Press.

Bauman, Z. (2003). Modernidad líquida. México: FCE.

Bayly, C. A. (2010). El nacimiento del mundo moderno. 1780-1914. Conexiones y comparaciones globales. Madrid: Siglo XXI.

Beck, U. (2000). What is Globalization? Cambridge: Polity.

Berger, P. y Huntington, S. (Eds.) (2002). Many Globalizations. Cultural Diversity in the Contemporary World. Oxford: Oxford University Press.

Bhagwati, J. (2004). In Defense of Globalization. Oxford: Oxford University Press.

Boli, J. y Lechner, F. J. (2009). "Globalization theory". En B. S. Turner (Ed.), The New Blackwell Companion to Social Theory. Oxford: Blackwell, 321-340.

Braudel, F. (1985). La dinámica del capitalismo. Madrid: Alianza.

Bude, H. y Durrschmidt, J. (2010). "What's wrong with globalization? Contra "flow speak-towards an existential turn in the theory of globalization", European Journal of Social Theory, 13 (4), 481-500.

Cairncross, F. (1997). The Death of Distance. How the Communications Revolution will Change Our Lives. Boston: Harvard Business School Press.

Castells, M. (2000). La era de la información. Economía, sociedad y cultura. Vol. 1. La sociedad red. Madrid: Alianza.

Cebrián, J. L. (2000). La red. Barcelona: Suma de Letras.

Connell, R. (2007). "The Northern theory of globalization", Sociological Theory, 25 (4), 368-385.

Corm, G. (2012). El nuevo gobierno del mundo. Ideologías, estructuras, contrapoderes. Barcelona: Península.

Crozier, M. J., Huntington, S. P. y Watanuki, J. (2012). "The crisis of democracy. Report on the governability of democracies to the Trilateral Commission", Sociología histórica, 1, 311-329.

Curran, J. y Park, M.-J. (2000). "Beyond globalization theory". En J. Curran y M.-J. Park (Eds.), De-Westernizing Media Studies. London: Routledge, 2-15.

de la Dehesa, G. (2006). Winners and Losers in Globalization. New York: Blackwell.

de la Dehesa, G. (2007). What do we Knew about Globalization? Issues of Poverty and Income Distribution. Oxford: Blackwell.

Echeverría, J. (1999). Los señores del aire. Telépolis y el tercer entorno. Barcelona: Destino. 
Eisenstadt, S. N. (2010). "Las dimensiones del análisis comparativo y el estudio de las dinámicas sociales: de la política comparada al análisis comparado de civilizaciones". En J. Schriewer y H. Haelble (Comps.), La comparación en las ciencias sociales e históricas. Un debate interdisciplinar. Barcelona: Octaedro e ICE-UB, 85-105.

Estulin, D. (2005). La verdadera historia del Club Bilderberg. Barcelona: Ediciones del Bronce.

Ferguson, N. (2012). Civilización. Occidente y el resto. Barcelona: Crítica.

Frieden, J. A. (2013). Capitalismo global. El transfondo económico de la historia del siglo XX. Barcelona: Crítica.

Friedman, J. (2003): "Los liberales de champagne y las nuevas clases peligrosas: reconfiguraciones de clase, identidad y producción cultural". En J. L. García y A. Barañano (Coords.), Culturas en contacto. Encuentros y desencuentros. Madrid: Ministerio de Educación, Cultura y Deporte, 161-197.

García Canclini, N. (2001). Culturas híbridas. Estrategias para entrar y salir de la modernidad. Barcelona: Paidós.

George, S. (2010). El informe Lugano. Barcelona: Icaria e Intermón-Oxfam.

Giddens, A. (1993). Consecuencias de la modernidad. Madrid: Alianza.

Giddens, A. (2000). Runaway World. How Globalization is Reshaping our Lives. London: Routledge.

Goody, J. (2011). El robo de la historia. Madrid: Akal.

Goody, J. (2012). El milagro euroasiático. Madrid: Alianza.

Gray, J. (2004). Al Qaeda y lo que significa ser moderno. Barcelona: Paidós.

Harvey, D. (2008). La condición de la posmodernidad. Investigación sobre los orígenes del cambio cultural. Buenos Aires: Amorrortu.

Held, D. y McGrew, A. (2002). Globalization/Anti-Globalization. Cambridge: Polity Press.

Held, D. y McGrew, A. (Eds.) (2007). Globalization Theory: Approaches and Controversies. Cambridge: Polity Press.

Huerta de Soto, J. (2010). La Escuela Austriaca. Mercado y creatividad empresarial. Madrid: Síntesis.

Ingham, G. (2010). Capitalismo. Madrid: Alianza.

Jones, E. L. (2006). Cultures Merging. A Historical and Economic Critique of Culture. Priceton: Priceton University Press.

Jones, A. (2010). Globalization. Key Thinkers. Cambridge: Polity.

Kalberg, S. (2008). Max Weber. Principales dimensiones de su obra. Buenos Aires: Prometeo.

Kellner, D. (2002). "Theorizing globalization”, Sociological Theory, 20 (3), 285-305.

Kristiansen, K. (2001). Europa antes de la historia. Los fundamentos prehistóricos de la Europa de la Edad de Bronce y de la primera Edad del Hierro. Barcelona: Península.

Langhorne, R. (2001). The Coming of Globalization. Its Evolution and Contemporary Consequences. Basingstoke: Palgrave.

Lindblom, C. E. (2002). El sistema de Mercado. Qué es, cómo funciona y cómo entenderlo. Madrid: Alianza. 
Luttwak, E. (2000). Turbocapitalismo. Quiénes ganan y quiénes pierden en la globalización. Crítica: Barcelona.

Malinowski, B. (2001). Los argonautas del Pacífico occidental. Comercio y aventura entre los indígenas de la Nueva Guinea melanésica. Barcelona: Península.

Mangabeira Unger, R. (2011). La reinvención del libre comercio. La división mundial del trabajo y el método de la economía. Buenos Aires: FCE.

Martín-Cabello, A. (2013). "Sobre los orígenes de la globalización", methaodos.revista de ciencias sociales, 1: 7-20.

Mauss, M. (2009). Ensayo sobre el don. Forma y función del intercambio en las sociedades arcaicas. Buenos Aires: Katz.

McLuhan, M. (1993). La galaxia Gutenberg. Génesis del "Homo Typographicus”. Barcelona: Galaxia Gutenberg-Círculo de Lectores.

Munck, R. (2002): "Globalization: Deconstruction and beyond", Latin American Perspectives, 29 (6), 24-31.

Mumford, L. (1998). Técnica y civilización. Madrid: Alianza.

Negroponte, N. (1995). Being Digital. New York: Alfred A. Knopf.

Polanyi, K. (1994). El sustento del hombre. Barcelona: Mondadori.

Polanyi, K. (2011). La gran transformación. Los orígenes políticos y económicos de nuestro tiempo. México: FCE.

Quigley, C. (1981). The Anglo-American Establishment: From Rhodes to Cliveden. New York: Books in Focus.

Ravier, A. O. (2012). La globalización como orden espontáneo. Madrid: Unión Editorial.

Reyes, G. E. (2001). "Teoría de la globalización. Bases fundamentales", Nómadas. Revista crítica de ciencias sociales y jurídicas, 3, 173-180.

Ritzer, G. (2004). The Globalization of Nothing. Thousand Oaks, CA: Sage.

Robertson, R. (1992). Globalization. Social Theory and Global Culture. London: Sage.

Robertson, R. (2001). "Globalization theory 2000+: Major problematics". En G. Ritzer, y B. Smart (Eds.). Handbook of Social Theory. London: Sage, 458-471.

Robinson, A. (2013). Un reportero en la montaña mágica. Cómo la élite económica de Davos hundió el mundo. Barcelona: Ariel.

Robinson, W. I. (2011). "Globalization and the sociology of Immanuel Wallerstein: A critical appraisal”, International Sociology, 26 (6), 723-745.

Rodrik, D. (2011). La paradoja de la globalización. Democracia y el futuro de la economía mundial. Barcelona: Antoni Bosch.

Rosenberg, J. (2005). "Globalization Theory: A Post Mortem", International Politics, 42, 2-74.

Safranski, R. (2005). How Much Globalization can we bear? Cambridge: Polity.

Stiglitz, J. E. (2002). Globalization and its Discontents. New York: W. W. Norton.

Stiglitz, J. E. (2006). Making Globalization Work. New York: W. W. Norton.

Stohl, C. (2005): "Globalization theory". En S. May y D. K. Mumby (Eds.), Engaging Organizational Communication. Theory and Research. London: Sage, 22-261. 
Thompson, E.P. (1989). Tradición, revuelta y consciencia de clase. Estudios sobre la crisis de la sociedad preindustrial. Barcelona: Crítica.

Trigo, A. (2004). What Do you Mean by "Cultural Globalization"? Bowling Green, Ohio: Working Paper Series on Historical Systems, Peoples and Cultures, 17.

Urry, J. (2002). Global Complexity. Cambridge: Polity.

Virilio, P. (1997). Open Sky. London: Verso.

Wallerstein, I. (1999). El moderno sistema mundial. Vol.2. El mercantilismo y la consolidación de la economía-mundo europea, 1600-1750. México: Siglo XXI.

Wallerstein, I. (2011a). El moderno sistema mundial. Vol. 1. La agricultura capitalista y los orígenes de la economía mundo europea en el siglo XVI. México: Siglo XXI.

Wallerstein, I. (2011b). The Modern World System. Vol. 4. Centrist Liberalism Triumphant, 1789-1914. Berkeley: University of California Press.

Wallerstein, I. (2012a). El capitalismo histórico. Madrid: Siglo XXI.

Wallerstein, I. (2012b). El moderno sistema mundial. Vol. 3. La segunda era de gran expansión de la economía-mundo capitalista, 1730-1850. México: Siglo XXI.

Weber, M. (1998). La ética protestante y el espíritu del capitalismo. Madrid: Istmo.

Weber, M. (2011). Historia económica general. México: FCE.

Williams, R. (1974). Television: Technology and Cultural Form. London: Fontana.

Williamson, J. (1993). "Democracy and the «Washington Consensus»", World Development, 21 (8), 1329-1336.

Ziegler, J. (2013). Los nuevos amos del mundo. Y la lucha de aquellos que se resisten a dejarse engullir por la globalización. Barcelona: Destino.

ANTONIO MARTIN CABELLO es licenciado y doctor en Sociología por la Universidad Pontificia de Salamanca y posee un Master en Gestión de Recursos Humanos por la Universidad San Pablo-CEU. Amplió estudios en la University of Central England en Birmingham (Reino Unido). Tras su paso por la empresa privada, ha sido profesor de Sociología en la Universidad Alfonso X el Sabio (Madrid) y en la actualidad ejerce su labor docente en la Universidad Rey Juan Carlos (Madrid). También ha sido profesor e investigador invitado en la Universidad Alberto Hurtado (Santiago de Chile), en la HumboldtUniversität zu Berlin (Alemania) y en la Università degli Studi Roma "Tor Vergata" (Italia). Es miembro del grupo de investigación methaodos.org y director adjunto de methaodos.revista de ciencias sociales. Sus líneas de investigación se centran en la sociología de la cultura, los estudios culturales y el fenómeno de la globalización.

Recibido: $20 / 11 / 2014$

Aceptado: 12/12/2014 



\title{
UNA VISIÓN COMUNICACIONAL DE LA POLÍTICA EN ECUADOR: RAFAEL CORREA Y SU BICICLETA ${ }^{1}$ A VISION OF COMMUNICATION POLITICS IN ECUADOR: RAFAEL CORREA AND YOUR BICYCLE
}

\author{
María Isabel Punín Larrea \\ Universidad Técnica Particular de Loja \\ San Cayetano Alto s/n. Loja-Ecuador \\ mipunin@utpl.edu.ec
}

\begin{abstract}
Resumen
Este artículo analiza el video oficial de la campaña del Presidente Correa denominado "spot bicicleta", elemento promocional usado en las elecciones seccionales del 2013, toma como referencia de análisis las estructuras fonológicas, gráficas, sintácticas y semánticas.

La pieza con una duración de 3:30 minutos, recuerda el proceso de "Revolución Ciudadana", emprendido por el partido Alianza País (35); y resalta la condición de servicio del Presidente, cuyo eje principal es la Patria.

El discurso gira entorno a la pobreza, la esperanza y el deseo del Presidente de continuar en el poder. Toda la pieza audiovisual está matizada con elementos posicionados en la mente de los ecuatorianos, usados como una estrategia de persuasión.

Palabras claves: Publicidad; Política; Elecciones; Democracia; Rafael Correa.

\section{Abstract}

This article analyzes the official "bicicleta" publicity video for President Rafael Correa's campaign in the Sectional Elections in 2013 by examining its phonological, graphical, syntactic and semantic structures.

The video, which runs for three minutes and 30 seconds, recalls the development of the "Citizens' Revolution" by the Alianza País political party (35); it highlights the President's service to the country, and its core idea is the Homeland.
\end{abstract}

${ }^{1}$ El trabajo se refiere al video promocional del Presidente Rafael Correa, durante su última campaña electoral. La versión tomada para el estudio se encuentra disponible en internet en: http://www.youtube.com/watch?v=iLgiElnQ0j4 
The discourse talks of poverty, hope and the desire of the President to remain in power. The audiovisual content contains elements designed to strike a chord in Ecuadorians, and the strategy is clearly one of persuasion.

Key words: Advertising; politics; elections; democracy; Rafael Correa.

\section{Extended Abstract}

This article analyzes the official "bicicleta" publicity video for President Rafael Correa's campaign in the Sectional Elections in 2013, as an audiovisual resource in which the discourse is designed to persuade and convince its viewers.

The study examines the phonological, graphical, syntactic and semantic structures to reach the critical discourse as proposed by Van Dijk.

The video runs for three minutes and 30 seconds and recalls the development of the "Citizens' Revolution" by Alianza País (35), Ecuador's leading political party. Ecuador was once seen as ungovernable due to the overthrow of several of the country's presidents, but stability has returned in the figure of Rafael Correa who has been in power now for three legislative terms.

The video contains images that highlight the President's service to the country through slogans whose main focus is the Homeland. Other elements typical of advertising campaigns feature, including slogans proclaiming that "The Homeland now belongs to all of us", "The Homeland for all is here to stay"; these are part of a political communication strategy not normally seen in Ecuador.

The study identifies and describes mindsets in the script apparent in the video's discourse and voiceover in order to build a general semantic structure of the video, in which the Presidents appears as a mediatory figure.

The discourse speaks of poverty, hope and the homeland, and the desire of the President to retain power. The video contains elements designed to strike a chord in Ecuadorians, and concludes with a classic "happy ending".

\section{INTRODUCCIÓN: UN COMERCIAL CON EL PRESIDENTE COMO EJE CENTRAL DE LA CAMPAÑA SELECCIONES 2013}

Planificar estratégicamente una campaña electoral requiere la utilización de métodos cuantitativos (que respondan a las preguntas de qué y cuántos) y cualitativos (por qué) (Rúas, 2011: 25). En el último proceso electoral ecuatoriano, celebrado el pasado 17 de febrero del 2014, quienes mejor utilizaron estos métodos fueron los integrantes del partido de Gobierno denominado Alianza País $(A P)^{2}$, partido con un "fuerte discurso antipartidario, y una orga-

${ }^{2}$ Alianza País. Patria altiva y soberana. Listas 35 es un movimiento político que nace el 2006. La propuesta se fundamenta en Socialismo del Siglo XXI o el "Socialismo del Buen Vivir”. Su página oficial es: http://www.movimientoalianzapais.com.ec/ (17/07/2014) 
nización sin una historia previa al ejercicio del poder estatal" (Hernández; Buendía, 2011: 129).

Este artículo tiene como objetivo el análisis de la pieza publicitaria y audiovisual denominada "spot bicicleta", que contiene algunos elementos novedosos para el manejo de la comunicación política en Ecuador, usa recursos de la comunicación 2.0, y apela al uso del discurso como arma de persuasión y convencimiento.

El artículo hace una descripción de carácter semiótico del discurso, tomando la referencia la propuesta denominada: Análisis crítico del discurso (Van Dijk, 2000), esto quiere decir el análisis de las:

1. Estructuras fonológicas

2. Estructuras gráficas

3. Estructuras sintácticas y semánticas

En resumen, el estudio y descripción modelos mentales que se emiten tanto en el guión, como en el discurso (voz en off); la macro estructura semántica, expresada en la condición de mediador del Presidente y además protagonista de la historia.

La imagen del Presidente asoma como una fotografía continua, la fotografía lleva siempre un referente consigo y es literalmente una emanación del referente (Barthes, 1981) donde él es el sujeto autor de la historia, que relata su plan de gestión, matizado por sus sueños e ideales.

Se analiza además el contexto y las relaciones de poder usadas en el video promocional, difundido por el canal de Youtube por EcuaTVmedia. El video tiene una duración de 3:30 minutos, y hasta finales del 2014 registra un total de 28.011visitas, fue producido por Vertigo Films 3 .

Para la musicalización (estructuras fonológicas) se usa poema épico denominado "Patria", cuya letra está atribuida a Manuel María Sánchez y la música de Sixto María Durán. El uso de esta pieza musical no es una decisión improvisada, en el 2007, existió una insinuación por parte del entonces Ministro de Educación Raúl Vallejo ${ }^{4}$, para la escucha de este himno en los establecimientos educativos del país, la melodía que tiene un particular significado de patriotismo para los ecuatorianos y ecuatorianas.

\footnotetext{
${ }^{3}$ Esta productora funciona en la ciudad de Quito, y ha logrado captar importantes proyectos audiovisuales del gobierno, entre ellos la campaña "All you need is Ecuador". Su sitio oficial es: www.vertigosite.com

${ }^{4}$ Aunque la petición del entonces Ministro no llegó a constituirse en un decreto, la acción no estuvo libre de críticas. Aquí una reseña de Diario El Universo es: http://www. eluniverso.com/2007/09/26/0001/18/BA3002F6F3B84E2190D67ED451DCC4D0.html $(10 / 08 / 2014)$
} 
Más tarde, Alianza País realizó algunas modificaciones y lo tomó como el himno oficial del movimiento. En el video en referencia la letra oficial incluye una serie de arreglos con violines y guitarras.

\section{SECUENCIAS DE LA HISTORIA. UN SUEÑO, UNA PATRIA}

El trabajo audiovisual y publicitario, en mención, inicia una escena que evidencia el abandono del poder presidencial de R. Correa, el Presidente deja el Palacio de Carondelet, y asume un rol aparentemente nuevo y refrescante, un ciclista común (Ver fotograma No. 1, 2, 3 y 4) (estructuras gráficas).

El presidente asoma solo, lo cual evidencia otros rasgos de su personalidad que han sido duramente cuestionados "Liderazgo personal y hegemónico del Presidente que actúa como obstáculo para institucionalización" (Panchano, 2010), criticas que no son objetivo de este artículo, pero se citan por formar parte de los rasgos del Presidente, protagonista de la historia, y que marcan la imagen del Presidente en el electorado.

El Presidente está dispuesto a recorrer cada rincón del Ecuador, usando una bicicleta. La prominencia de la imagen personal del Presidente apela a la credibilidad del candidato, es uno de los recursos de la comunicación política, y con él "la competencia y la confiabilidad del candidato" (Petit \& Cilimbini, 2009), mientras recorre sus obras, resalta sus logros, las escenas son una acción más de "activismo estatal" (Fiss, 1997) y de la consolidación de un "estado comunicador" (Rincón, 2010).

La pieza expresa un arte de "puesta en escena" y su eficacia específica radica en la capacidad de los gobernantes y jefes para generar emociones y sentimientos (Bustamante, 2002). En las tomas se aprecia además el uso de elementos oficiales como la banda presidencial, el Palacio de Carondelet (casa oficial del Mandatario), armonizado por un discurso ideológico, que considera la relación sociedad-individuo (Knorr-Cetina; Cicourel, 1981), y su derecho pero a su vez un poder, el voto.

En este escenario Correa inicia con su propia voz a comentar su sueño (estructuras sintácticas/semánticas), al que denomina: "el sueño ecuatoriano", pero también es una oportunidad para recordar frases usadas de manera recurrente en sus discursos anteriores como: "manos limpias, mentes lucidas y corazones ardientes"

${ }^{5}$ En este link se puede observar la versión oficial del discurso de R. Correa (Informe a la Nación 2014: https://www.youtube.com/watch?v=wMYhTzU83-w\&feature=youtu.be\&list= UUn2XiuAROvRcqscSI2Ni-6A La frase se volvió a usar en la noche cultura en Barcelona/ España a inicios del 2014 https://www.youtube.com/watch?v=45t9UXKcS_Y\&list=UUn2Xiu AROvRcqscSI2Ni-6A 
Con esta introducción Correa Delgado echa mano de la retórica clásica que sugiere el uso de los argumentos y de las emociones, como camino seguro para convencer al electorado "La imagen ya no ilustra a la palabra; es la palabra lo que se convierte estructuralmente en un parásito de la imagen" (Barthes, 1981: 21).

Es importante para lograr una mayor contextualización del tema revisar el plan de gobierno (eje de su estrategia) documento en el cual se cita lo siguiente: "Es nuestro deber desterrar el hambre y la pobreza. Mientras subsista una sola injusticia en nuestra Patria, allí estaremos, con un vendaval de amor y ternura siempre con el oído atento a la demanda y a la voz de los humildes y desampa-

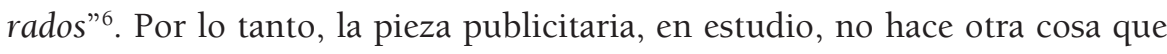
reforzar lo dicho en los discursos magistrales en los primeros períodos presidenciales, que han sido difundidos de manera sistemáticas en los medios de comunicación.

Por ello, al inicio de la pieza audiovisual se destaca el tema que seguramente preocupa al electorado ecuatoriano: la pobreza, lo cual también puede llevarnos a un discurso de ideologías contradictorias, por un lado, la igualdad y por otro la libertad económica (Tetlock, 1989).

Según un informe del Cepal (2012), Ecuador tuvo una reducción de los índices de pobreza que pasaron del 35,3\% al 32,2\% entre el 2011 y el 2012, pese a ello, de la pobreza, es un tema de consideración mayor en el vídeo en referencia.

La pieza en estudio también deja espacio para otro de los factores que están presentes en el imaginario popular: la violencia. Por ello, el combate a la inequidad se realiza con "con un vendaval de amor y ternura", lo cual también podría expresar de manera velada como " tolerancia", que se aprecia como un valor sociocultural positivo de "apariencia" (Van Dijk, 1984)

La última frase "siempre con el oído atento a la demanda y a la voz de los humildes y desamparados", se refiere al desencanto del sistema democrático y al anhelo de establecer una verdadera democracia representativa, actitud que podría tener una variante en relación a su discurso de campaña (2006/2007), en la cual se usó como un elemento "una correa" (Ver Foto No.1), sin que ello implique un distanciamiento del ciudadano común, sino por el contrario un hombre que impone justicia.

\footnotetext{
${ }^{6}$ Cf. Programa de Gobierno 2013 - 2017 disponible en internet en: http://www.movi mientoalianzapais.com.ec/index.php?option $=$ com_content\&view=article\&id=10:plan-degobierno-2013-2017\&catid=22\&Itemid $=126 \&$ tmpl=component $\&$ print $=1 \&$ layout $=$ default\&page $=$ consultado el 3 de julio de 2014 .
} 


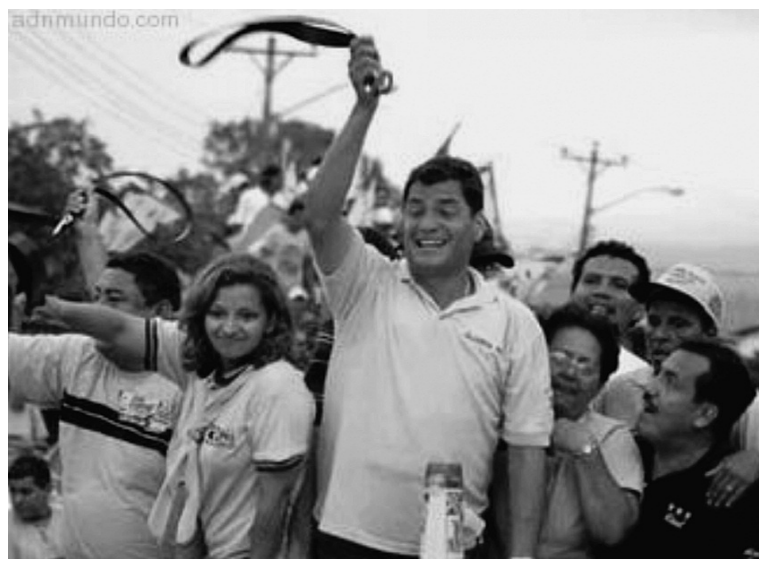

Fuente: www.ecuaword.com (Foto n. ${ }^{\circ} 1$ )

Pero ¿es este un uso «comercial» de las necesidades populares? O, en realidad, ¿es una manera «democrática» de formular un plan de gobierno, atendiendo a las necesidades de la mayoría? aunque las preguntas no son parte de este análisis, quedan planteadas para el debate, por ser elementos de persuasión usados por el mandatario.

La estrategia audiovisual, se usa varios elementos. Las imágenes representan una persona capaz de dejar el poder (ver fotograma n. ${ }^{\circ} 1$ ), vestirse como el pueblo (ver fotograma . $^{\circ}$ 2) porque lleva el país en el corazón (ver fotograma n. ${ }^{\circ}$ ), dejar su comodidad (entiéndase Palacio Presidencial) (ver fotograma n. ${ }^{\circ}$ ) y salir a ver la realidad del país (ver fotograma n. ${ }^{o}$ 5), usando para ello las tres estructuras recomendadas por Van Dijk y referencia de análisis del presente estudio.

Es decir alguien que usa el poder para el servicio. Entonces, esta primera parte del video principal de la campaña de AP, es coherente con su estrategia vemos a un mandatario que, en el fondo, trata de representar democráticamente a sus mandantes.

Las escenas muestran un hombre fuerte y el audio nos va hablando de «luchas», «golpes», «traiciones», con el fondo musical sinfónico ya comentado. El video originó la difusión de una pieza relacionada con elementos de la publicidad negativa ${ }^{7}$, cuyo protagonista es el hijo del ex presidente Dalo Bucaram, uno de los líderes visibles de la oposición en el país. Los elementos audiovisuales de la pieza de Bucaram representan la antítesis de los usados por el Presidente.

${ }^{7}$ El video en referencia se puede visualizar en el siguiente link: https://www.youtube. com/watch?v=T-40XsREczk 


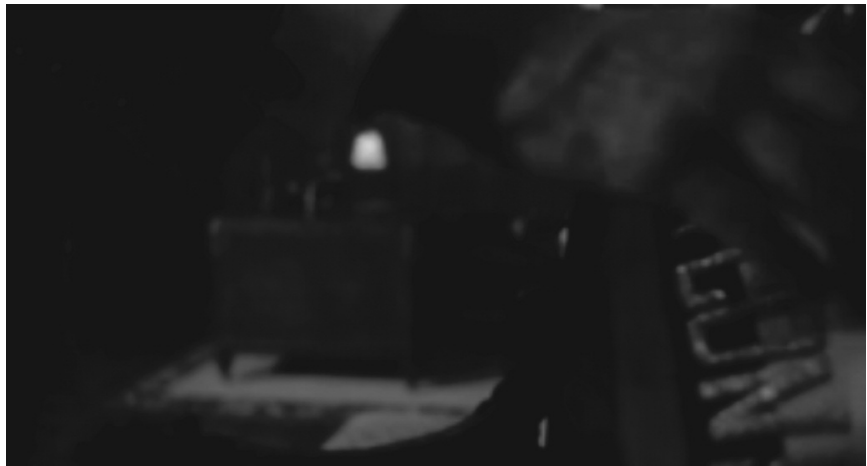

Fotograma.$^{\circ} 1$

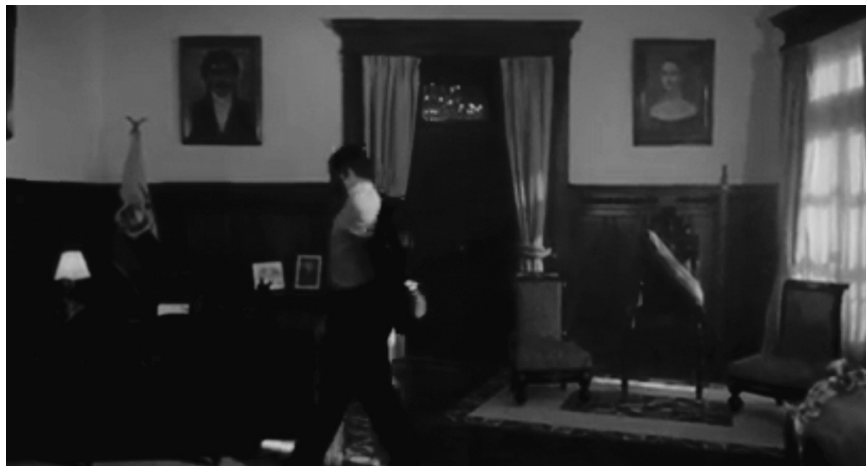

Fotograma n. ${ }^{\circ} 2$

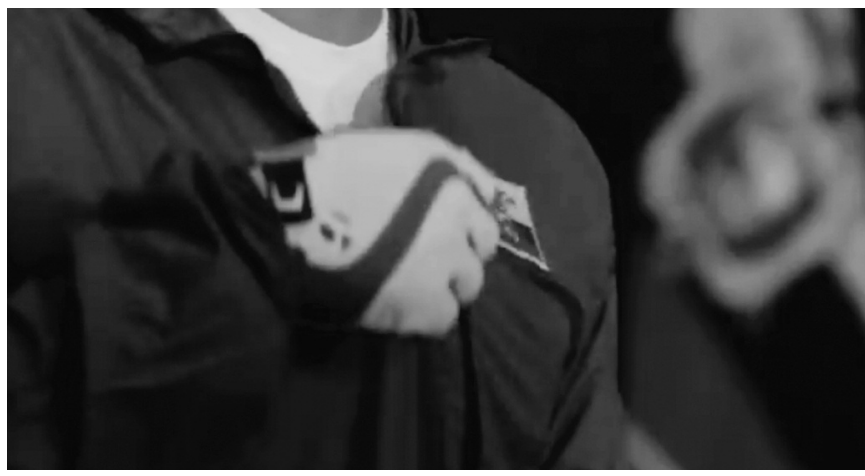

Fotograma n. ${ }^{\circ} 3$ 


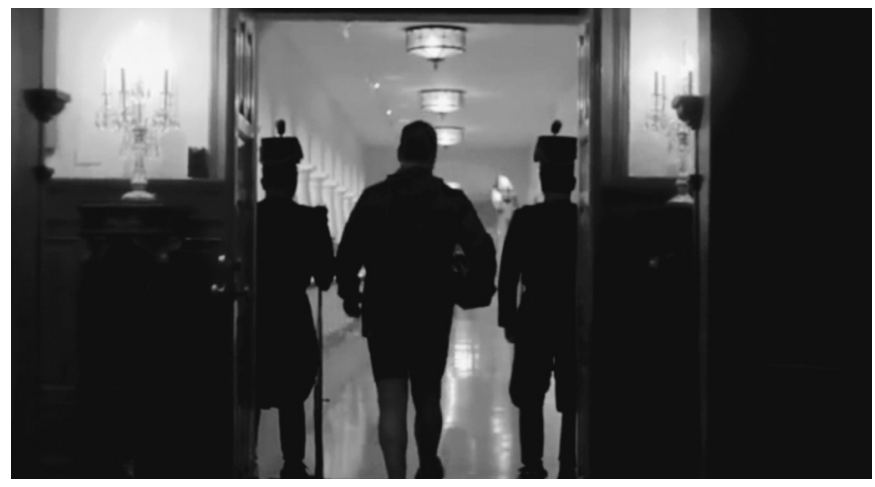

Fotograma n. ${ }^{\circ} 4$

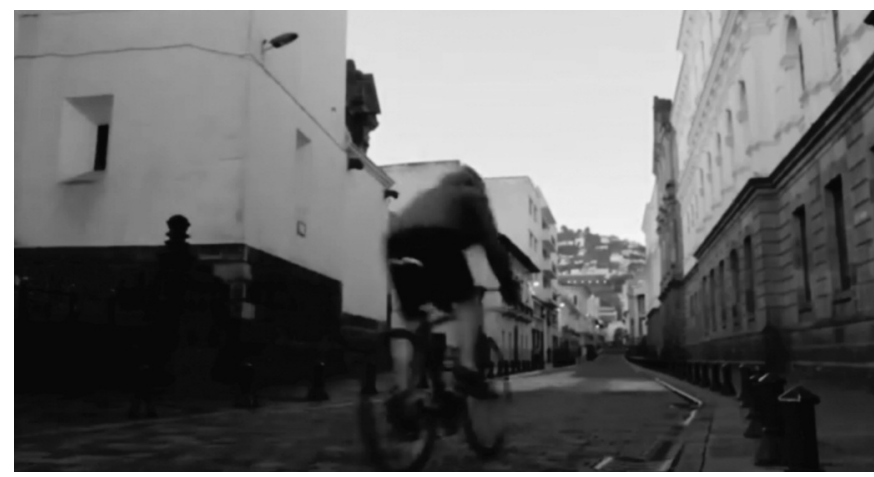

Fotograma n. ${ }^{\circ} 5$

Más adelante el video logra configurar una especie de «superhombre» dispuesto a pelear por todos, enfrentando retos importantes y enemigos poderosos, en una clara alusión a los grupos de poder que gobernaron al Ecuador, recordando la crisis de gobernabilidad del país, que en palabras del Presidente de puede resumir con "el fin de larga y oscura noche neoliberal".

El tema de la pobreza, vuelve a ser un tema recurrente en el spot:

Nuestro "superhéroe", o el superhombre de masas (Eco, 1995), que en su inseparable bicicleta empezó recorriendo la sierra ha llegado a lo que parecería ser el litoral ecuatoriano, por grandes carreteras construidas como parte de su plan de gobierno. Ahora, queda todavía el problema de la pobreza. No es un tema extremo, pero lo recuerdan dos hombres, uno sentando a la vera del camino sin camiseta y otro, en el fondo, parado frente a una humilde casa (fotograma n. ${ }^{\circ} 6$ ), lo ven pasar aparentemente esperanzados de lo que pueda hacer en su nuevo mandato presidencial. Entonces, el video muestra nuevamente coherencia, ante una pobreza que todavía está presente pero que debe combatirse, 


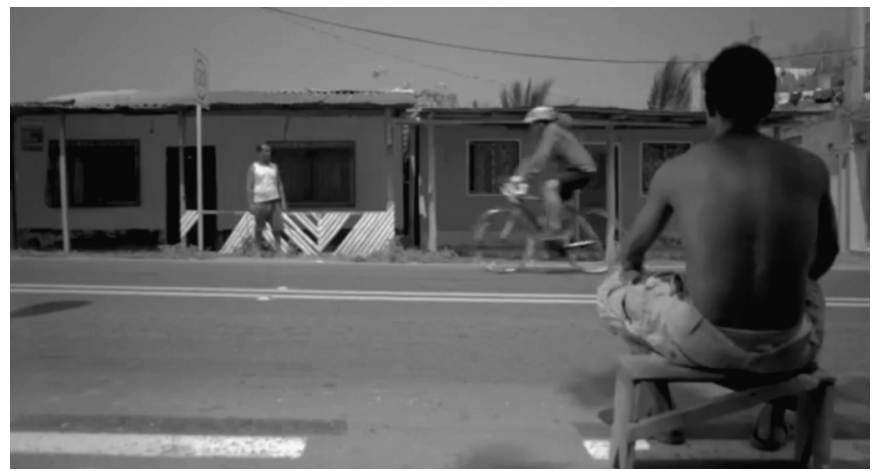

Fotograma n. ${ }^{\circ} 6$

como lo demostramos usando información del Cepal. Claro, este combate, entiéndase gestión presidencial, deber hacerse con «amor y ternura» y nada representa mejor estas dos cosas que los niños (fotograma $n .^{\circ} 7$ ).

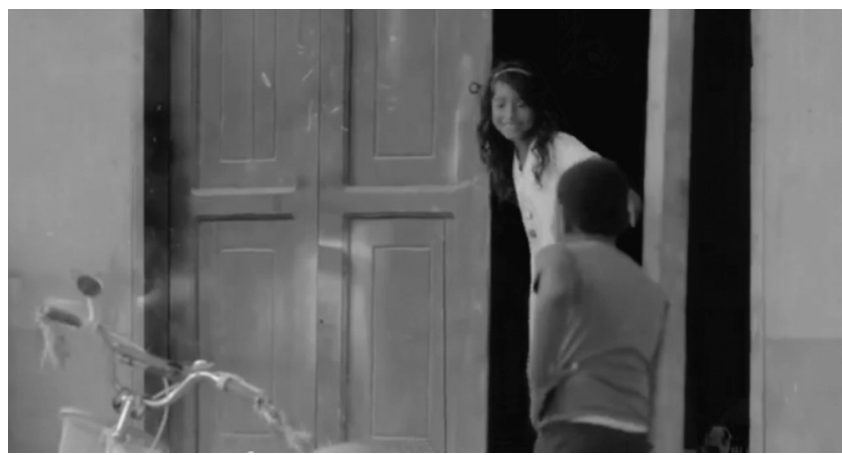

Fotograma n. ${ }^{\circ} 7$

Son estos niños que ven pasar a su superhéroe (ver fotograma n. ${ }^{\circ} 7$ ), toman sus bicicletas (ver fotograma 8) y lo acompañan, no lo siguen, evitando así la sensación de jerarquía y poder (ver fotograma 9).

Al televidente, que seguramente ha tenido formación cristiana, este hecho le recuerda el famoso pasaje bíblico «Dejad a los niños, y no les impidáis que vengan a mi» (Mateo 19: vr. 14) se ve un mandatario sonriente y que tiene como sus compañeros (¿y guardianes?) a los niños, por ello, durante toda la escena los niños están siempre a su lado, lo cual también responda a una macro estructura semántica, sobre todo para la población ecuatoriana mayoritariamente católica. También puede interpretarse a la luz del siguiente pasaje bíblico «Mirad que no menospreciéis a uno de estos pequeños; porque os digo que son sus ángeles en los cielos» (Mateo 18: vr. 10). 


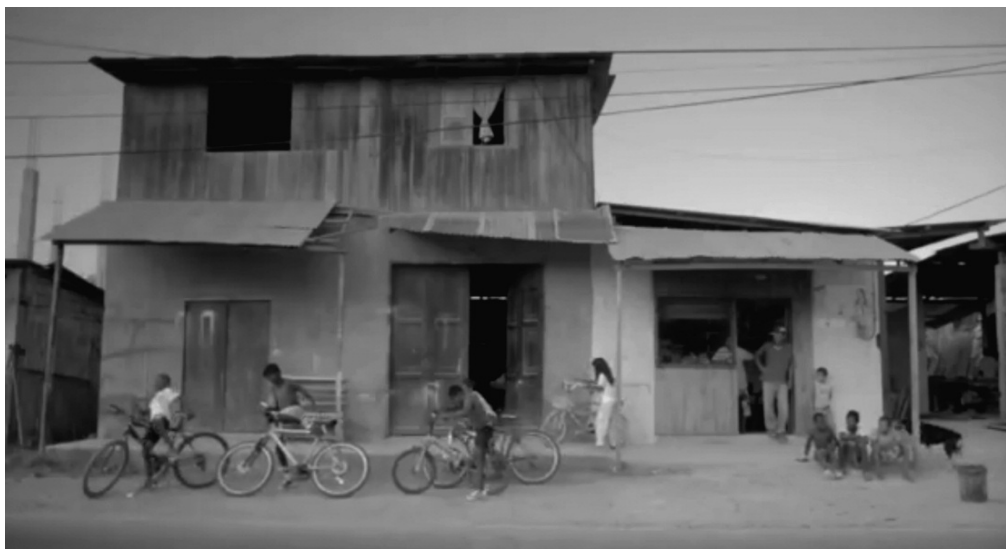

Fotograma n. ${ }^{\circ} 8$

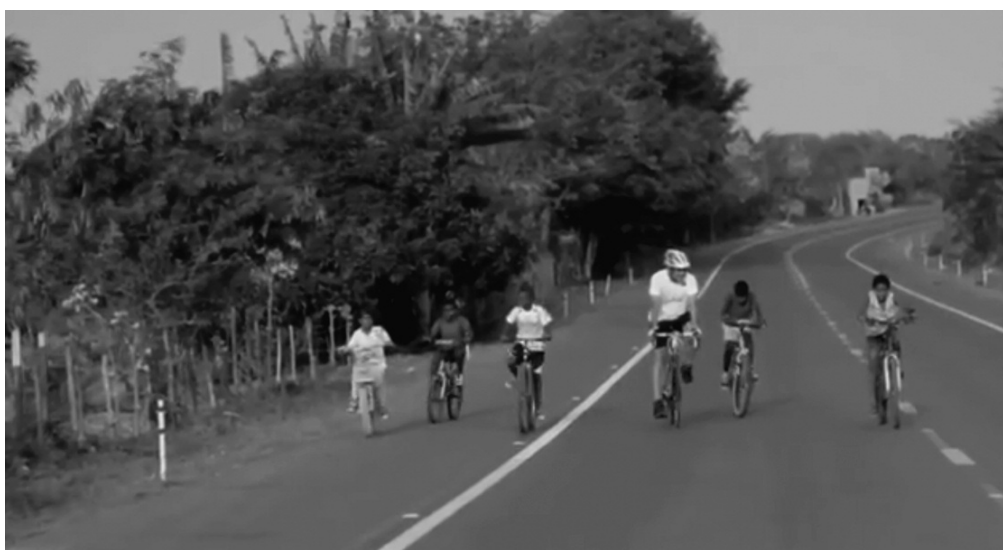

Fotograma n. ${ }^{\circ} 9$

Es un superhombre de carne y hueso. Merece un descanso junto a la naturaleza, nótese el verde réflex de la camisa, en clara sintonía con los colores de su partido, que han sido usados a lo largo de los procesos de campaña. Nada mejor para representar esto que la siguiente escena:

El hombre toma un sorbo de agua en lo que parece una playa solitaria (ver fotograma n. ${ }^{\circ} 10$ ). El protagonista se quita el casco, al fondo se ven seis humildes embarcaciones de pescadores (ver fotograma n. ${ }^{\circ} 11$ ), con los que se va a seguir su recorrido (ver fotograma n. ${ }^{\circ}$ 12). La selección del rol y de los personajes en escena no es improvisada, considerando que "la sociedad real se desinteresa de la clase política sin perderse el espectáculo"(Baudrillard, 2000: 96), como una vía efectiva para llegar al electorado. 


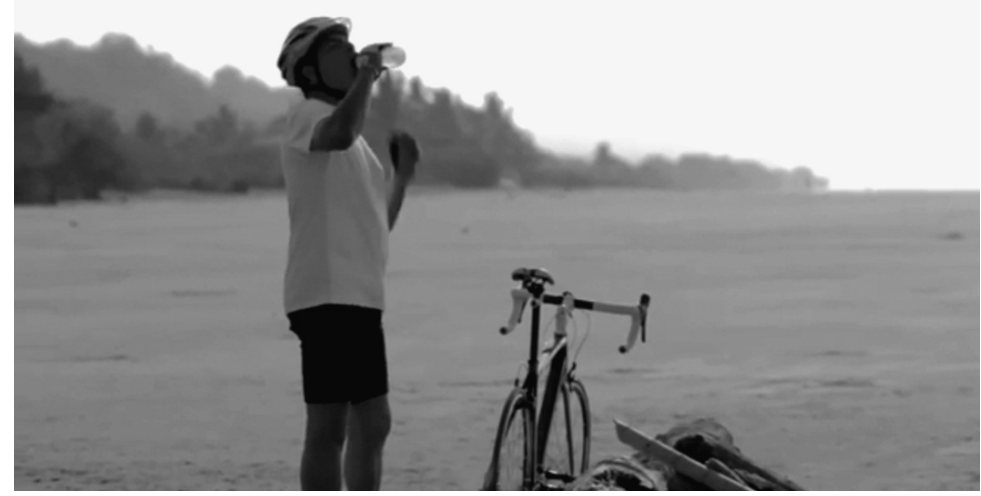

Fotograma n. ${ }^{\circ} 10$

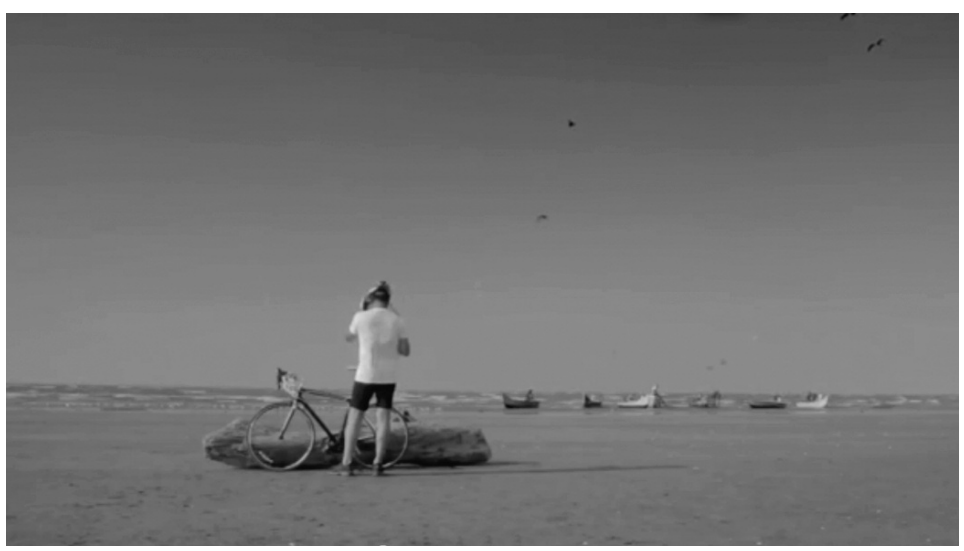

Fotograma n. ${ }^{\circ} 11$

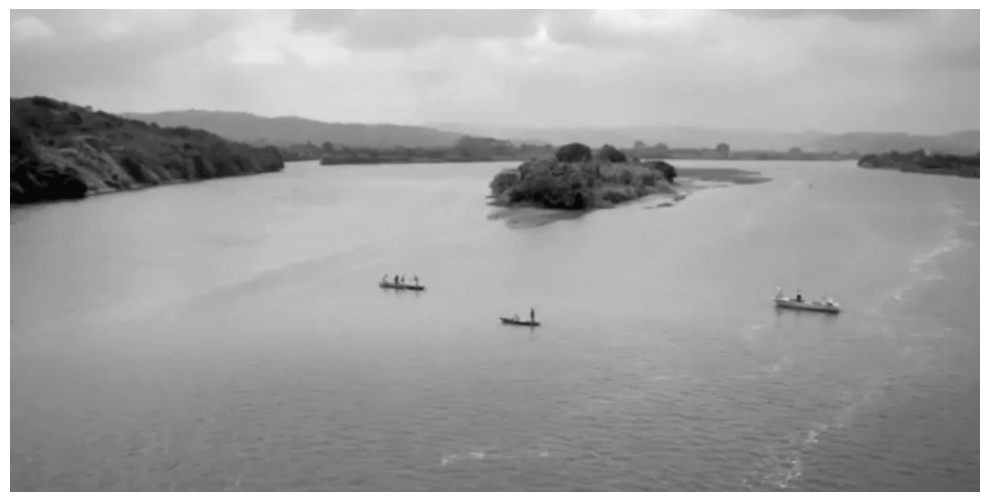

Fotograma n. ${ }^{\circ} 12$ 


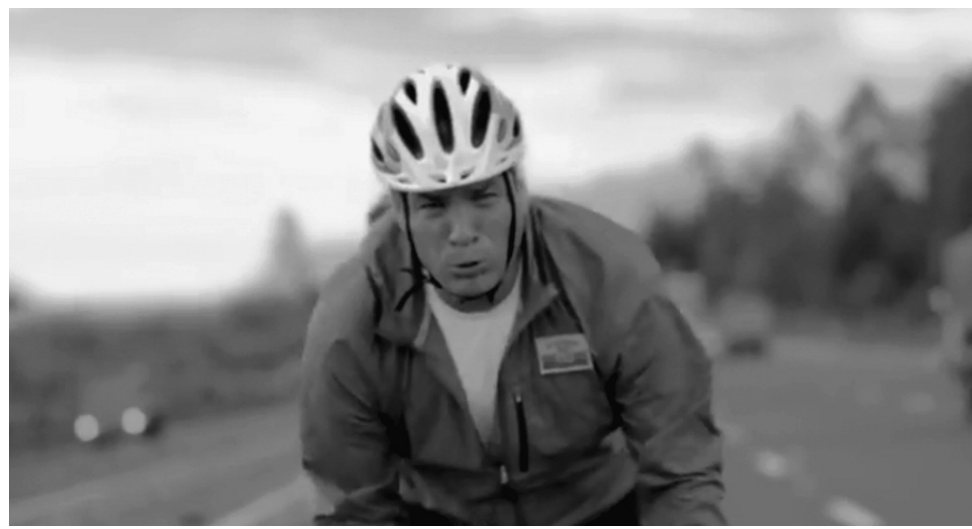

Fotograma n. ${ }^{\circ} 13$

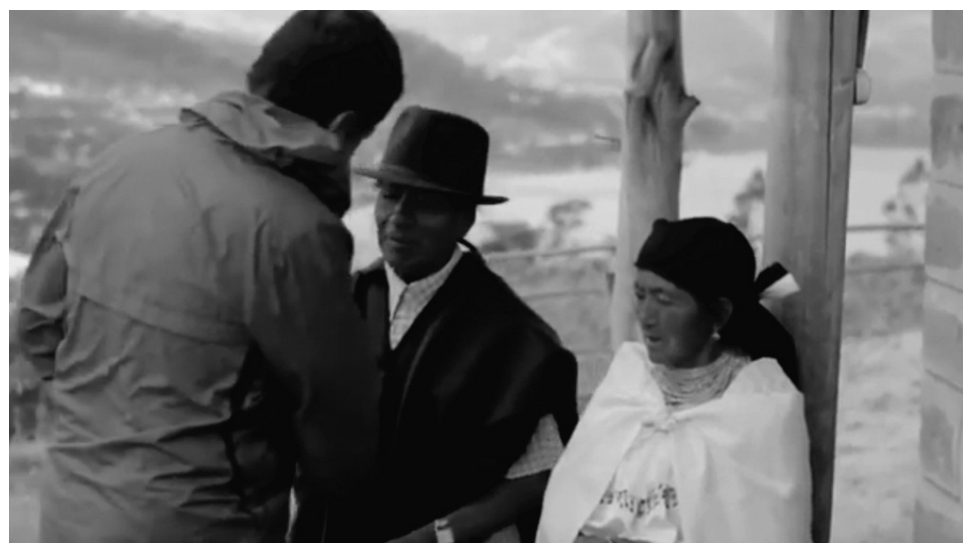

Fotograma n. ${ }^{\circ} 14$

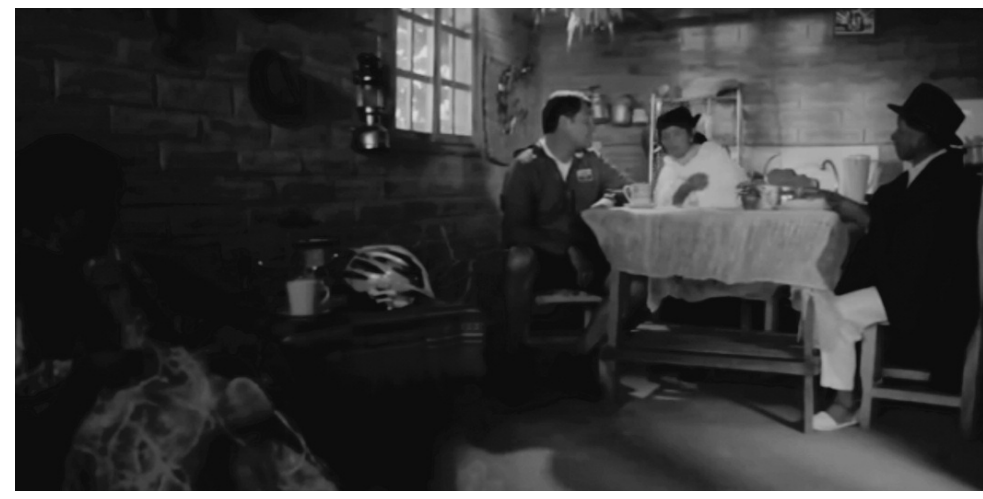

Fotograma n. ${ }^{\circ} 15$ 
Con mucho esfuerzo físico (ver fotograma n. ${ }^{\circ} 13$ ), llega hasta la alta serranía nacional, saluda con indígenas ancianos (isabios?), pobres pero dignos, su casa ya no es una humilde choza de barro sino una vivienda construida con ladrillo (ver fotograma n. ${ }^{\circ} 14$ ). Entra, y sentados a la mesa, conversan en quichua sobre lo que parecería ser la problemática del país (ver fotograma ${ }^{\circ}{ }^{\circ}$ 15), que bien puede relacionarse con los postulados del "Buen Vivir" (Sumak Kawsay), es decir imaginario (ideal de vida) (Avila, 2014).

Entendemos el "Buen Vivir" como un concepto en construcción (Gudynas; Acosta, 2011), que se encuentra reflejado a lo largo de la Constitución Ecuatoriana. El Buen Vivir forma parte de una larga búsqueda de alternativas de vida fraguadas en el calor de las luchas populares, particularmente indígenas, desde mucho antes de que acceda al poder político el presidente Rafael Correa (Acosta, 2010: 7).

Con ello se cumple la última parte del postulado de Alianza País: «con el oído atento a la demanda y a la voz de los humildes y desamparados». El hecho que el Presidente habla quichua, tiene sentido si nos remitimos a la Constitución Ecuatoriana (2009). Artículo No. 1, que considera a este idioma junto al shuar, como lenguas oficiales de los indígenas.

En resumen, niños, pescadores y los indígenas, son usados como los buenos" dentro del discursos ideológico de grupo (Van Dijk, 1996), elemento que no es ajeno del lenguaje audiovisual, en general.

\section{CONCLUSIONES: UN FINAL FELIZ SIEMPRE}

El video está marcado por el uso armónico de las estructuras fonológicas, gráficas, sintácticas y semánticas, cuyo objetivo máximo es el apoyo y la consolidación del movimiento y los postulados de Alianza País. Aunque el Presidente no fue candidato en esta ocasión, usó su imagen como refuerzo para las candidaturas seccionales de todo el país.

El video tiene un «happy end», nuestro héroe deja la banda que se quitara al inicio del spot, y que representa el poder constitucional de la presidencia, sobre una silla en la casa de los ancianos (ver fotograma n. ${ }^{\circ} 16$ ). El poder es del pueblo, no de él, lo que también justifica el uso de otros individuos a lo largo de toda la pieza.

Se trata de un video coherente con sus eslóganes en el que las ideas se centran en la lucha contra la inequidad y la capacidad del candidato para enfrentar el reto, compromiso que está constantemente siendo reforzado con la postura discursiva del presidente, dispuesta a combatir la pobreza sin violencia, aunque los resultados en las urnas no fueron del todo positivos. 


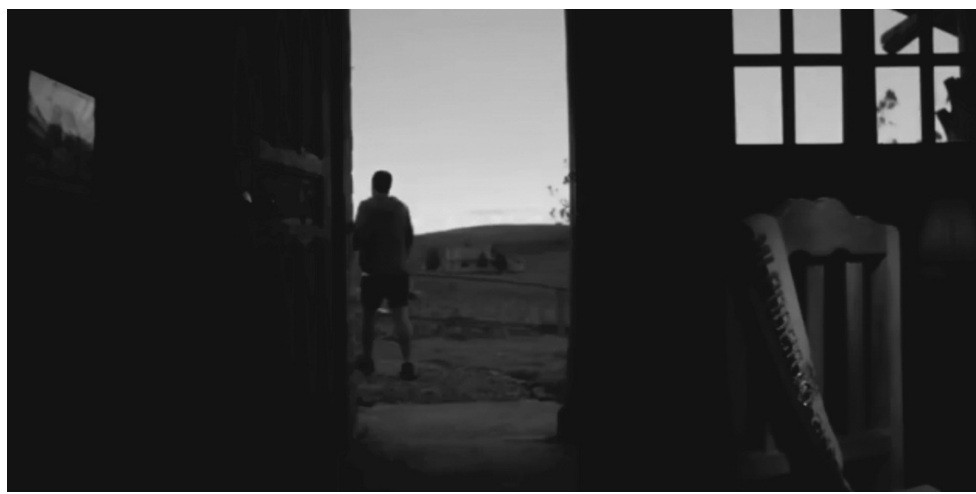

Fotograma n. ${ }^{\circ} 16$

Existe una variante significativa entre el inicio del proyecto política liderado por Correa y el recurrente uso del slogan: "La patria ya es de todos" con nueva variante con la que se cierra el discurso escénico "La patria volvió para siempre", que asoman como elementos de convencimiento y persuasión.

Este análisis podría continuar y, muy probablemente, encontraríamos más elementos coherentes entre el ideario de AP y su realización publicitaria en campaña y otras propias del espectáculo televisivo.

\section{BIBLIOGRAFÍA}

Acosta, A. (2010). "El buen vivir en el camino del post-desarrollo. Una Lectura desde la Constitución de Montecristi". Policy Paper 9. Friedrich Ebert Stiftung. Pp. 7. Disponible en: http://cadtm.org/IMG/pdf/El_Buen_Vivir_en_el_camino_del_ post-desarrollo-_Una_lectura_desde_la_Constitucion_de_Montecristi.pdf (Fecha de consulta 22-12- 2014).

Avila, J. (2014). "El enfoque del buen vivir como una visión colectiva". OBETS. Revista de Ciencias Sociales. Vol. 9, n. ${ }^{\circ}$ 1, 2014; pp. 43-72. DOI: 10.14198/OBETS 2014.9.1.02. Disponible en: http://dx.doi.org/10.14198/OBETS2014.9.1.02 | http: //hdl.handle.net/10045/39557 (Fecha de consulta 12-11- 2014).

Barthes, R (1981). Camera Lucida. Hill and Wand. New York Baudrillard, J (2000). Pantalla total. Anagrama. Colección de argumentos.

Biblia (s/n) Mateo 19: versículo14. Nueva versión internacional Biblia (s/n) Mateo 18: versículo10. Nueva versión internacional Cepal (2013). "Panorama Social de América Latina". Naciones Unidas Cepal. Disponible en: http://www.cepal.org/publicaciones/xml/9/51769/PanoramaSocial 2013.pdf) (Fecha de consulta 10-05-2014).

Bustamante, F (2002). La cultura política y ciudadanía en el Ecuador. Antología Democracia, Gobernabilidad y Cultura política. SERIE: Antología CCSS. Disponible 
en: http://www.plataformademocratica.org/Publicacoes/183.pdf (Fecha de consulta 10-12-2014).

Eco, U. (1995). El superhombre de masas. Barcelona. Lumen.

Fiss, O. (1997). Libertad de expresión y estructura social. México. Distribuciones Fontamara.

Gudynas E; Acosta, A. (2011). "El buen vivir o la disolución de la idea de progreso" En: La medición del progreso y del bienestar. Propuestas desde América Latina. Foro consultivo, científico y tecnológico. A.C México DF. Disponible en: http://www. gudynas.com/publicaciones/capitulos/GudynasAcostaDisolucionProgresoMx1lr. pdf (Fecha de consulta 20-12- 2014).

Hernández V; Buendía F (2011). "Ecuador: avances y desafíos de Alianza País”. Revista Nueva Sociedad No. 234. Julio-Agosto. Disponible en: http://nuso.org/upload/ articulos/3790_1.pdf (Fecha de consulta 19-12- 2014).

Knorr- Cetina, K. Cicourel (Eds) (1981). "Advances in social theory and methodology: towards an integration of micro and macrosociologies". London. Routledge and Kegan Paul.

Panchano, S. (2010). "Ecuador: El nuevo sistema político en funcionamiento". Revista de Ciencia Política. Volumen 30. No.2. 297-317. Disponible en: http://www.scielo. cl/scielo.php?pid=S0718-090X2010000200007\&script=sci_arttext (Fecha de consulta 15-11- 2014).

Petit \& Cilimbini, A.L (2009). "Medios y Tecnologías de la Información y la Comunicación. Socialización y Nuevas Apropiaciones”. Argentina: Editorial: Brujas.

Rincón, O y otros (2010): “¿Por qué nos odian tanto? Estado y medios de comunicación en América Latina". En Centro de Competencias en Comunicación para América Latina. Disponible en: http://library.fes.de/pdf-files/bueros/c3-comunicacion/ 07475.pdf (Fecha de consulta 22-12- 2014).

Rúas, J. (2011). Manual del candidato electoral. Cómo no perder las elecciones. Catara Madrid. Pp. 25.

Tetlock, P. (1989). Structure and function in political belief systems. In A.R. Pratkanis, S.J. Breckler, \& A.G. Greenwald (Eds.), Attitude Structure \& Function

TA Van Dijk. (1984). Prejudice in Discourse. An Analysis of Ethnic Prejudice in Cognition and conversation.

TA Van Dijk. (1996). "Análisis del discurso ideológico. Versión No. 6. Unam México". Disponible en: http://segundaslenguaseinmigracion.com/L2ycomptext/Anlisisi deolgico.pdf (Fecha de consulta 15-09- 2014).

TA Van Dijk. (2000). El discurso como estructura y proceso. Barcelona: Editorial Gedisa.

MARIA ISABEL PUNÍN es PhD. en Comunicación y Periodismo por la Universidad Santiago de Compostela, Diplomado Superior Experto en Gestión y Calidad Universitaria. Universidad de Sevilla. Licenciada en Ciencias de la Comunicación Social. Universidad Católica del Azuay- Ecuador. Ex directora 
de la titulación de Comunicación Social, Modalidad Abierta y Modalidad Presencial. Docente investigadora del Departamento de Ciencias de la Comunicación y Profesor titular de la materia de Géneros Periodísticos. Universidad Técnica Particular de Loja. Integrante del equipo académico para el proceso de evaluación y acreditación ante el Consejo Latinoamericano de Altos Estudios de Periodismo (CLAEP) de la Titulación en Comunicación Social de la UTPL.

Recibido: 20/09/2014

Aceptado: 30/12/2014 
OBETS. Revista de Ciencias Sociales

Vol. 9, n. ${ }^{\circ}$ 2, 2014; pp. 377-407

ISSN: $1989-1385$

DOI: 10.14198/OBETS2014.9.2.06

\title{
EL SUBREGISTRO CONSULAR: MAGNITUDES Y EFECTOS EN LAS ESTADÍSTICAS DE EMIGRACIÓN ESPAÑOLA ${ }^{1}$ CONSULATE UNDERREGISTRATION: MAGNITUDES AND EFFECTS ON SPANISH EMIGRATION STATISTICS
}

\author{
Juan Manuel Romero Valiente \\ Centro de Investigación en Migraciones \\ Universidad de Huelva, España \\ valiente@uhu.es \\ Antonio Luis Hidalgo-Capitán \\ Centro de Investigación en Migraciones \\ Universidad de Huelva, España \\ alhc@uhu.es
}

\begin{abstract}
Resumen
El subregistro consular representa uno de los principales problemas para la adecuada observación y medición estadística de la emigración española actual. Tomando como base los datos de una encuesta realizada en 2012 a más de cuatro mil emigrantes españoles residentes en el extranjero, se ha tratado de conocer las magnitudes del subregistro y sus efectos en las estadísticas oficiales. Los análisis realizados ponen en evidencia un subregistro en torno al 50\% entre los emigrados españoles en el período 2008-2012. Esta cifra se eleva a cerca del $60 \%$ entre los que han tenido como destino la Unión Europea y del 75\% en el caso del Reino Unido.
\end{abstract}

\footnotetext{
${ }^{1}$ Este trabajo constituye un resultado del Proyecto de Investigación "Movilidad Humana, con especial énfasis en las migraciones de España y Ecuador" (coordinado por Juan Manuel Romero Valiente), que forma parte del Proyecto de Cooperación Interuniversitaria FIUCUHU que se desarrolla entre la Universidad de Huelva (España) y la Universidad de Cuenca (Ecuador) bajo el auspicio de la Agencia Andaluza de Cooperación Internacional al Desarrollo (AACID). Agradecemos al Dr. Andrés Arroyo, Profesor Titular del Departamento de Estadística de la Universidad de Sevilla, la revisión del texto y sugerencias en la materia.
} 
Palabras clave: Emigración española; subregistro consular; estadísticas migratorias.

\begin{abstract}
The consulate underregistration represents one of the main problems for the proper observation and measurement of the statistics of the current Spanish emigration. Based on data from a survey conducted in 2012 to more than four thousand Spanish emigrants living abroad, we have tried to know the magnitude of underregistration and its impact on the official statistics. Our analyses show underregistration by about 50\% among Spanish emigrants in the period 2008-2012. This data rises to nearly $60 \%$ among those who had emigrated to the European Union and $75 \%$ in the case of the UK.
\end{abstract}

Keywords: Spanish emigration; consulate underregistration; migration statistics.

\title{
Extended abstract
}

The consulate underregistration is one of the main problems for proper observation and statistical measurement of the current Spanish emigration. This phenomenon raises serious concern in the society of Spain.

Official statistics of Spanish out-migration have notable deficiencies in quantifying the flows from the beginning in the last third of the nineteenth century. These statistics, published by the Instituto Nacional de Estadística (INE) since 2002, are mainly based in residential variations between Spain and abroad. Such variations are recorded as a result of registration as residents in the Consular Register (and the consequent registration in the Register of Spanish Residents Abroad), and the corresponding deregistration in the Municipal Register. Despite the progress that entailed for the knowledge of the Spanish emigration, there are still problems for proper observation and measurement. This is because many emigrants do not perform their registration in the Spanish consulates and / or delayed in doing it longer than it should.

In this paper we present an approach to the phenomenon of consulate underregistration trying to meet its key figures and effects in official statistics of Spanish emigration. To this aim mainly we have used data from a survey conducted in 2012 to 4,058 Spanish emigrants living abroad, spread across 120 countries. We poll more than three thousand interviews $(3,026)$ to Spanish emigrants in the present century, of which 2,138 were people who come out of Spain between 2008 and 2012 coinciding with the economic crisis.

First, the results of this study show the existence of a major consulate underregistration among Spaniards living abroad, especially among those who have recently emigrated. At least one of every two Spaniards emigrated between 2008 and 2012 had not been registered as resident in the Consular Register at the end of that period. Therefore, the change of residence was not recorded and computed by Spanish emigration statistics, these people remain for all purposes as population residing in Spain.

Moreover, these results also show the existence of certain patterns in the consular registration, which are related to the age of migration (variation in time), and the destination / residence (variation in space). 
The consulate registration is lower, as expected, with increasing time of migration and residence outside Spain. The data allow observe that this decrease underregistration presents a pattern in relation to the age of migration, which greatly fits a logarithmic trend line. The decline is more rapid among people who have recently migrated (last five years); then this decline gradually becomes softer with increasing residence time outside Spain.

The highest levels of consulate underregistration take places by far among emigrants to the EU, especially to countries like the UK; about $60 \%$ of emigrants to the EU between 2008 and 2012 had not been registered as resident in the Consular Register at the time of the survey; this ratio is around $75 \%$ among emigrants to the UK. By contrast, the lowest levels take places among people who have emigrated to Africa and Asia, especially in countries like China and UAE, two emerging destinations in recent years. The observed differences regarding the age of emigration from Spain are repeated, with nuances and particularities, in different geographical areas and countries of residence. These differences in the magnitude of underregistration affect the reliability of the statistics of Spanish emigration to any territory, especially for the observation and measurement in tempore of this phenomenon. The statistics of Spanish emigration to countries with low levels of consulate underregistration and a rapid decrease of the latter (shorter delay in registration) measure the phenomenon (in tempore) in a more correctly way and reflex better the observed reality. On the contrary, the statistics Spanish emigration to countries with significant levels of consulate underregistration and a slower decrease present major deficiencies in that sense. This is, paradoxically, the case of the main destinations of Spanish emigration in recent years (UK, France, USA, and Germany).

The consulate underregistration in a given period expresses the underestimation of the actual migration in it. And in that sense, we can estimate, based on the data handled and analyzes performed in this study, about half of Spaniards emigrated abroad in 2008-2012 had not been entered in the Register of Spanish Residents Abroad at the end thereof. However, we cannot deduce, directly and exclusively from the data of consular registration, the extent to which annual data on Spanish emigration to publish official statistics underestimate the real migration flow. The main reason is that the latter reflect all consular inscriptions that occur each year, regardless of the date and length of migration of people who make them.

Therefore, in this article we do not specifically discuss the extent to which emigration data published by the Spanish statistics may be lower than actual, because for this purpose we should also consider other information in the calculations and analyzes, such as those relating to the delay in the consulate registration of emigrants. In any case, the analysis that the authors of this article are underway to this regard suggests that Spanish emigration data for 2008-2012 are higher than those reported by official statistics (just over 200,000), even with compensation effect registrations ex tempore (emigrated before 2008 to formalize their registration in that period); but these data probably will also be lower than the 700,000 people reporting some analysts. 
The results of this study may have a useful and practical application. On the one hand, they should serve as a call to the Spanish administration and especially the competent bodies on migration (Dirección General de Inmigración of Ministerio de Empleo y Seguridad Social, Dirección General de Asuntos Consulares y de Españoles Residentes en el Exterior of Ministerio de Asuntos Exteriores y Cooperación) and statistics (INE) to adopt measures aimed at reducing the consular underreporting. A wide information campaign among Spanish emigrants about the need and the benefits of consular registration to raise awareness of the issue is essential for this. Of course, it must be accompanied by other measures such as increasing the facilities of access to consular services and improving them. This might be an excessive demand in times of crisis, in which the plans themselves of strengthening foreign service have been partially paralyzed and are closing some consulates in countries with a large colony of old and new migrants. However, reducing the consular underreporting must be an unavoidable and urgent objective. And this must be so by the effects it has on the knowledge of the new Spanish emigration and the exercise of rights attached to the registration of Spanish citizens residing abroad.

Moreover, data and results of this work can perhaps serve as a reference and informational input to the work developed for the INE, improving its statistics on Spanish emigration. In this line, we believe it would be interesting to perform similar analyzes in other countries where emigration statistics also have the consular registration as a basis of its registration system as Italy. Such work would diagnose common problems and carry out strategic actions for improvement.

The study of consulate underregistration and its effects on migration statistics is not exhausted, of course, with this work. By contrast, observations and analyzes carried out show that there are still many aspects to scrutinize such as those relating to differences related to the profile of migrants, the incidence of delayed registration consular or the factors underlying it all. Some of these issues have already been analyzed by the authors of this article; they hope to offer short-term results.

\section{INTRODUCCIÓN}

Los problemas y dificultades para cuantificar las migraciones internacionales y conocer sus características son hechos bien conocidos que han sido puestos en evidencia en numerosos trabajos y foros. La mayoría de los analistas ponen de relieve la existencia de mayores dificultades para el conocimiento de las corrientes de salida (emigración) que de las de entrada (inmigración). Este hecho se ha explicado aludiendo a que la emigración suele requerir menores trámites administrativos por parte del país emisor, siendo pocos además los incentivos para su notificación a las autoridades del mismo (Lemaître, 2005: 3; Thierry el al., 2005: 19; Beer et al., 2010: 461-462; UNECE, 2009: 1, 3, 6; UNECE, 
2010: 7; Nowok, 2010: 1-2; Galgóczi et al., 2011: 7; OIM, 2013: 80; entre otros). Como consecuencia de ello, las cifras de emigración que reportan la mayoría de los países suelen ser inferiores a las de inmigración de personas procedentes de los mismos que ofrecen los países receptores (Poulain y Perrin, 2001: 10; Raymer y Abel, 2006: 2; Beer et al., 2010: 464). Este problema de subestimación del flujo emigratorio es un hecho generalizado en la mayoría de los países, alcanzando niveles superiores al $50 \%$ en un número significativo de ellos (Poulain, 2006: 2-3).

Estos problemas y limitaciones no son ajenos a las estadísticas españolas de migración exterior, especialmente a las de emigración. España cuenta desde el último tercio del siglo XIX con estadísticas de emigración elaboradas utilizando diferentes fuentes, criterios y métodos. Los distintos trabajos realizados sobre la emigración española contemporánea ponen de manifiesto las limitaciones de dichas estadísticas, especialmente en lo que concierne a la cuantificación de los flujos $^{2}$. La gran mayoría pone de relieve la existencia de diferencias muy notables entre las cifras que ofrecen las estadísticas oficiales españoles y la magnitud real del fenómeno. Hecho éste, que evidencian principalmente al comparar dichas estadísticas con las de inmigración española de los países receptores, las cuales ofrecen en general cifras sensiblemente superiores.

Desde principios del presente siglo las estadísticas de emigración exterior española tienen como base fundamental las variaciones residenciales entre España y el extranjero que se registran como fruto de las inscripciones (altas) en el Padrón de Españoles Residentes en el Extranjero (en adelante, PERE) y las consiguientes bajas en el Padrón municipal. Pese al significativo avance que ha supuesto la utilización de estos registros de población para la elaboración de estas estadísticas y, por ende, en la medición y conocimiento de la emigración exterior española, los problemas de subestimación siguen persistiendo. Así lo ponen en evidencia varios trabajos como los realizados en el marco del proyecto MIMOSA (Model for Estimating International Migration Flows in the European Union) cuyos resultados son fruto del análisis comparativo entre las estadísticas de emigración e inmigración de varios países europeos, entre ellos España, para el período 2002-2007 (Poulain y Dal, 2008: 5; Beer et al., 2010: 473).

En las estadísticas de emigración exterior española previas a las actuales (estadística de emigración asistida), elaboradas y publicadas por el organismo

\footnotetext{
${ }^{2}$ Existe una bibliografía relativamente abundante sobre el tema. Cabe citar, entre otros, los trabajos de García Fernández (1965), Sánchez Alonso (1990), Yáñez Gallardo (1993), Palazón (1995), Vilar y Vilar (1999), Babiano y Fernández (2002 y 2009), Sanz Díaz (2004), Durán Villa (2008), Sanz Lafuente (2008 y 2009), Romero Valiente (2013).
} 
competente en materia de migraciones (dependiente del Ministerio de Trabajo), los problemas de subestimación se relacionaban fundamentalmente con el concepto de emigrante utilizado (muy restrictivo) para la elaboración de las mismas. En las actuales, la Estadística de Variaciones Residenciales (EVR) y la Estadística de Migraciones (EM) que elabora el Instituto Nacional de Estadística (INE) tomando como base las altas como residentes en el Registro de Matrícula Consular (RMC) -y consiguientemente en el PERE-, los mencionados problemas se deben principalmente a que muchos de los españoles que emigran a otros países no efectúan dicha inscripción o demoran mucho tiempo en hacerlo. Aunque varios trabajos hacen referencia expresa a este problema de subregistro consular (Prieto Rosas, 2008: 23-26; Recaño y de Miguel, 2009: 4; Moscoso y Moyano, 2010: 78; González Enríquez, 2013: 5; González Ferrer, 2013: 6), en ninguno se ofrecen datos y evidencias empíricas, directas y específicas, sobre el mismo que avalen dicha afirmación.

¿Cuál es la magnitud del subregistro consular de los españoles emigrados al extranjero entre 2008 y 2012? ¿Cómo varía dicha magnitud en función de la antigüedad de la emigración y el área geográfica / país de residencia de los emigrados? ¿Cómo afecta ello a las estadísticas oficiales sobre emigración española al extranjero para dicho periodo?

En este contexto surge este trabajo cuyos objetivos son: estimar la magnitud del subregistro consular de los españoles emigrados al extranjero entre 2008 y 2012; conocer sus variaciones en función de la antigüedad de la emigración y el lugar de destino/residencia de los emigrados; e identificar los efectos del subregistro consular en las estadísticas de emigración española al exterior.

Este trabajo constituye la primera aproximación al problema de la subestimación de la emigración española actual de forma directa a partir del análisis de datos relativos a la situación respecto a la inscripción consular de los españoles que residen en el extranjero. Hasta la fecha, los pocos trabajos sobre el particular lo han hecho de una manera indirecta a través de la comparación entre las estadísticas de emigración española y las de inmigración de algunos países europeos receptores de la misma ${ }^{3}$ (p.e. González Ferrer, 2013). Este

${ }^{3}$ González Enríquez (2013: 5) realiza esta comparación tomando como base los datos tipo stock (PERE y estadísticas de los países de destino) llegando a la conclusión de que las fuentes estadísticas españolas "no infravaloran el número de españoles residentes en el extranjero". Este análisis, a nuestro juicio, puede presentar notables deficiencias de base por diversas razones. Por una parte, al utilizar como referencia para el análisis solo los datos tipo stock (y no de forma combinada con los datos tipo flujo de migración exterior española) del PERE en los que, por un lado, se incluyen tanto personas realmente emigradas como descendientes de españoles nacidos en el extranjero (en muchos casos con 
enfoque presenta algunos problemas. Por una parte, que las estadísticas de inmigración de estos países, sobre todo las relativas a ciudadanos comunitarios, suelen en muchos casos presentar notables problemas de sobreestimación ${ }^{4}$. Por otra, no se incluyen en el análisis a los flujos de emigración española que se dirigen a países de otros continentes de los que, cabe señalar, por otra parte, no se dispone, en la gran mayoría de los casos, de datos solventes sobre entradas de españoles (y stock de residentes) basados en registros y recuentos propios. La generalización de las estimaciones de subregistro basadas en las comparaciones con algunos países europeos al conjunto de la emigración española al exterior puede conllevar errores de cálculo importantes. De un lado, porque, según la EM, solo la mitad de los españoles emigrados en el período 2008-2012 se han dirigido a países europeos ( $42 \%$ a países de la Unión Europea). De otro, porque en muchos de los países receptores de emigración española (no considerados en dicho análisis comparativo) el nivel de subregistro puede ser muy inferior al detectado en los casos analizados, lo que afectaría sin duda, a la baja, la estimación global del flujo

Las cifras dispares sobre la magnitud de la emigración española que ofrecen algunos investigadores para el período 2008-2012 (en torno a 40.000 en el caso de González Enríquez, 700.000 en el caso de González Ferrer), muy alejadas de las oficiales que publica el INE (algo más de 200.000), ponen, en todo caso, claramente en solfa los problemas de estas últimas para la adecuada medición y observación de este fenómeno. Ello, unido a la importante y renovada preocupación en la sociedad española que ha generado en los últimos años esta corriente emigratoria, espoleada sin duda por la agudización de los

nacionalidad también del país de residencia, por lo que no se contabilizan en las estadísticas de extranjería del mismo). Por otra, no tiene suficientemente en cuenta que el reducido crecimiento entre 2009 y 2013 de la población nacida en España que se refleja en el PERE (y las estadísticas de extranjería de los países de destino, aunque no siempre se dispone de datos desagregados sobre el particular) puede estar en buena parte debido al efecto compensación de los flujos de retorno que se producen en dicho período, en los que tienen un importante protagonismo ciudadanos españoles emigrados antes de 2009. Este último hecho está siendo contrastado en los análisis que están realizando los autores de este artículo tomando como base los microdatos de la EVR.

${ }^{4}$ Cantisani y Greco (2006: 438) hacen referencia a este hecho en el caso de la migración italiana en otros países de la Unión Europea (Dinamarca, Países Bajos) indicando que ello puede estar relacionado con la utilización en los mismos de períodos de estancia más cortos (inferiores a un año o seis meses) para el registro y contabilización de los sucesos migratorios. Éste parece ser el caso también del Padrón municipal en España que, según se puede deducir de la comparación con los datos del Censo 2011, sobrestimaría en un 20\% la población residente de nacionales de Alemania, Reino Unido y Francia (Rodenas y Martí, 2013: 120). Los análisis que están llevando a cabo los autores de este artículo apuntan también a una sobreestimación de las cifras de inmigración española en muchos países europeos. 
efectos de la crisis económica en España, justifica aún más si cabe la oportunidad e interés de este trabajo.

\section{FUENTES Y METODOLOGÍA}

Para la aproximación al fenómeno en estudio y tratar de alcanzar los objetivos anteriormente indicados se han utilizado las fuentes y la metodología que se indican a continuación. Por una parte, se ha procedido a una revisión exhaustiva de la literatura existente sobre estadísticas de migraciones internacionales, particularmente sobre emigración, así como de los parámetros y factores involucrados en la confección de las mismas (forma de recogida de datos, etc.). Cabe destacar, en este sentido, la metodología de elaboración de las estadísticas actuales de emigración española (EVR y EM), así como la normativa que regula la inscripción en los registros de población española (RMC, PERE y Padrón Municipal) que sirven de base para la elaboración de las mismas.

Por otra, se ha llevado a cabo una explotación y análisis de los datos sobre emigración española en los últimos años (EVR y EM), así como, especialmente, la situación respecto a la inscripción consular de los españoles residentes en el extranjero. Para este segundo caso los únicos datos disponibles son los recogidos al efecto en una encuesta realizada por los autores de este artículo en el marco de una investigación sobre la situación de los españoles residentes en el extranjero, con especial atención a la emigración más reciente, llevada a cabo entre junio de 2011 y septiembre de $2012^{5}$. Dado que esta encuesta constituye pieza básica y base informativa fundamental de este artículo, se procede a continuación a una breve descripción de la misma.

Para la adecuada preparación de la encuesta se llevó a cabo, además de una revisión minuciosa de la literatura sobre el particular (Cea, 2004; entre otros) un amplio estudio exploratorio en el que se llevaron a cabo cerca de dos mil entrevistas estructuradas a emigrantes españoles residentes en el extranjero. El instrumento básico para la recogida de información fue un cuestionario de 13 preguntas abiertas, que fue ampliamente difundido entre la población en estudio utilizando todos los medios disponibles (redes sociales, listados de correo electrónico, instituciones españolas en el exterior, etc.).

Tomando como base la información obtenida en este estudio exploratorio y la red de contactos establecida se diseñó una encuesta con el fin de recoger

${ }^{5}$ Esta investigación se desarrolló en parte (noviembre 2011-junio 2012) en el contexto del "Estudio sobre la movilidad exterior de los españoles y las españolas en la actualidad" (Romero Valiente, 2012) auspiciado por la Dirección General de Migraciones (Secretaría General de Inmigración y Emigración) del Ministerio de Empleo y Seguridad Social. 
datos de carácter cuantitativo susceptibles de tratamiento y análisis estadístico. Esta encuesta fue aplicada por medios telemáticos (correo electrónico, redes sociales, webs institucionales, etc.) pudiéndose acceder al cuestionario de la misma a través de un enlace web $^{6}$.

La inexistencia de un marco muestral válido debido al propio subregistro consular (constatado claramente en el estudio exploratorio) y, en relación con ello, la presencia de una población oculta o de difícil alcance (Marpsat y Razanfindratsima, 2010: 4), hicieron que para la implementación de esta encuesta se utilizara un muestreo no probabilístico. Teniendo en cuenta los sesgos que podrían derivarse del método de recogida de información utilizado, y con objeto de mejorar la representatividad de los datos recogidos, la muestra obtenida fue ponderada (postestratificación) tomando como referencia la información disponible sobre variables significativas del flujo emigratorio (sexo y edad de los emigrantes, año de emigración, país de destino/residencia) extraída de las estadísticas oficiales españolas.

Esta encuesta (autoadministrada) permaneció abierta entre el 21 de mayo y el 7 de septiembre de 2012, período durante el cual se recogieron 4.058 entrevistas a españoles mayores de edad residentes en el extranjero, repartidos por 120 países. Algo más de tres mil entrevistas (3.026) fueron realizadas a españoles emigrados en el siglo actual, de las que 2.138 corresponden específicamente a personas que han salido de España entre 2008 y 2012.

El cuestionario, que incluía 73 preguntas sobre aspectos diversos, fue concienzudamente elaborado sobre la base de la información recopilada en el estudio exploratorio. Ello facilitó en gran medida la cumplimentación del mismo, favoreciendo tanto el incremento del número de observaciones (entrevistas), como los niveles de respuesta en cada pregunta (de ítem). En el mismo se incluyó una pregunta destinada específicamente a conocer la situación de los emigrantes españoles respecto a la inscripción consular: ¿Está usted inscrito/a en un consulado o sección consular de la embajada de España en el país en el que actualmente reside? La pregunta era cerrada, pudiéndose elegir sólo una opción entre las siguientes respuestas: 1. Si, como Residente; 2. Sí, como No Residente (residente temporal); y 3. No está inscrito/a. Las tasas de respuesta a esta pregunta fueron bastante elevadas: 99\% entre los españoles residentes en el extranjero; 99,1\% entre los emigrados en el siglo actual; 99,4\% entre los emigrados en el período 2008-2012.

\footnotetext{
${ }^{6}$ Las ventajas y limitaciones de este tipo de instrumentos, así como los criterios y recomendaciones para su aplicación han sido puestas en evidencia en diversos trabajos (ADM, 2000 y 2001; Díaz de Rada, 2004, 2010, 2011 y 2012; entre otros). Muchas de ellas fueron tenidas en cuenta a la hora de preparar y aplicar esta encuesta.
} 
Los datos obtenidos han sido objeto de una exhaustiva explotación y tratamiento estadístico utilizando los programas Excel y SPSS (tablas de contingencia, análisis de correlación, etc.). Los datos correspondientes a la citada pregunta han sido cruzados con los de otras variables de interés para los objetivos de este artículo (año de emigración desde España, país de residencia, sexo, edad) también recogidos en la encuesta. En los análisis que se llevan a cabo en este trabajo se han tomando como referencia los datos correspondientes al conjunto de españoles emigrados desde España residentes en el extranjero en el momento de la encuesta (independientemente del año de su emigración). No obstante, se presta una especial atención a los emigrados en el siglo actual y, sobre todo, en los últimos años (2008-2012), momento en el que se produce una reactivación de este fenómeno coincidiendo con el inicio y agudización de la crisis económica en España. El concepto de emigrante utilizado es el de migrante por largo plazo, tal como ha sido definido por las Naciones Unidas y el Reglamento 862/2007 de la Unión Europea (Naciones Unidas, 1998: 10; Reglamento 862/2007 de la Unión Europea).

Por último, cabe reseñar que en los análisis que se llevan a cabo en este trabajo se utiliza el término "subregistro consular" para hacer referencia a la proporción de emigrados españoles (en cada período y/o ámbito geográfico de referencia) que no se hayan inscritos en el PERE en el momento de la encuesta. No incluye, por tanto, a los emigrados inscritos en el RMC en la categoría de No Residentes.

\section{INSCRIPCIÓN CONSULAR Y ESTADÍSTICAS DE EMIGRACIÓN ESPAÑOLA}

La inscripción en el RMC de los españoles que emigran al extranjero es un acto administrativo esencial para que estos sucesos se reflejen y contabilicen en las estadísticas de emigración correspondientes. Así aparece claramente indicado tanto en la metodología de elaboración de la EVR como de la EM ${ }^{7}$. Según la normativa vigente (Real Decreto 3425/2000), la inscripción consular es un

${ }^{7}$ En la metodología de la EVR se indica que "A partir del año 2002 se incorpora el capítulo de emigración exterior teniendo en cuenta las bajas por cambio de residencia comunicadas por los Ayuntamientos, las cuales se refieren principalmente a salidas de españoles al extranjero que se han inscrito en los Registros de Matrícula de las Oficinas Consulares" (INE, 2014). En la de la EM se hace aún más hincapié en dicha dependencia: "en lo que respecta a la emigración al extranjero, el contraste mensual del Padrón continuo con los registros de matrícula consular en el extranjero permite registrar la emigración de españoles, pero siempre que estos se inscriban en el consulado correspondiente" (INE, 2013: 6) (en ambas citas la cursiva es nuestra). 
acto voluntario para los emigrantes españoles, que tiene carácter de deber, pero no parece que implique obligatoriedad ${ }^{8}$.

A diferencia de ello, la inscripción en el registro de población a partir del cual se genera la baja residencial en España (Padrón municipal) sí tiene carácter obligatorio ${ }^{9}$. Sea como fuere, tanto en la inscripción consular (deber) como en la del Padrón (obligación), la administración española no utiliza medios punitivos directos (multas o sanciones) por no llevarla a cabo, sino que estimula o favorece de alguna forma la misma al convertirla en requisito para el acceso a distintos servicios y ayudas, así como el ejercicio de determinados derechos.

El RMC contempla dos tipos de inscripción en el mismo, como residente o como no residente, que representarían dos maneras de estancia en el extranjero en función de su carácter y duración. En la categoría de residentes se deben inscribir aquellas personas que trasladan su residencia habitual a un país extranjero, lo que confiere a su emigración un carácter de mayor duración temporal y permanencia en el mismo. En la categoría de no residentes, por el contrario, se pueden inscribir las personas que marchan a vivir de forma temporal al extranjero, manteniendo a todos los efectos su residencia oficial en España.

La inscripción en una u otra categoría tiene efectos directos en las estadísticas oficiales sobre emigración y población española en el extranjero. La inscripción en el RMC como residente supone el alta en el PERE correspondiente al país al que se emigra (y en el Censo Electoral de Residentes Ausentes -CERA- en el caso de personas con mayoría de edad) y la baja en el Padrón del municipio de residencia en España (o en el PERE, cuando se trata de emigrantes desde otro país). Cuando el cambio de residencia se realiza directamente desde España, ello se traduce en un registro de emigración española al exterior, que se repercute en las estadísticas correspondientes (EVR y EM). Por el contrario, las personas que se inscriben como no residentes siguen a todos los efectos empadronadas en un municipio de España y, por tanto, no generan un alta en el PERE, ni obviamente un registro de emigración exterior. La

${ }^{8}$ Ello queda reflejado en sus disposiciones (Artículo 2. Obligación de inscribirse): "Los españoles que residan habitualmente en el extranjero y aquellos que trasladen allí su residencia habitual deberán inscribirse en el Registro de Matrícula de la Oficina Consular o de la Sección Consular de la Misión Diplomática que corresponda a la circunscripción donde se encuentren" (Art. 2.1.) (la cursiva es nuestra); "El hecho de no estar inscrito en el Registro de Matrícula Consular no menoscaba, en ningún caso, el derecho de protección consular que corresponde a todos los españoles en el extranjero" (Art. 2.3).

9 "Toda persona que viva en España está obligada a inscribirse en el Padrón del municipio en el que resida habitualmente" (Ley 4/1996, Art. único, apart. 2; la cursiva es nuestra). 
inscripción como no residente es, en todo caso, requisito indispensable para aquellas personas que, residiendo de forma temporal en el extranjero, deseen ejercer desde allí su derecho de sufragio en España (Real Decreto 1621/2007).

La inscripción consular tiene también una serie de implicaciones administrativas que, en general, pueden convertirse en factores incentivadores de la misma. Posibilita el acceso a determinados servicios que ofrece la administración española en el exterior, así como el ejercicio de derechos de ciudadanía: tramitación y renovación de documentos (pasaporte, fe de vida y estado, certificado de residencia y baja consular, etc.), acceso a determinadas prestaciones y ayudas públicas de las administraciones españolas para los residentes en el exterior (posibilidad de cotizar a la Seguridad Social española, pensiones por ancianidad y por razón de necesidad, becas, ayudas asistenciales, cursos de formación, etc.), ejercicio del derecho a voto en España desde el país en el que reside, recibir información de interés para la colonia española (a través de listados de correo electrónico, etc.), posibles ventajas fiscales y tributarias, franquicias y ayudas durante el proceso de retorno a España, etc.

La inscripción consular debe hacerse a través del consulado (o sección consular de la legación diplomática española) correspondiente a la demarcación de residencia del emigrante en el país de destino. Pero, aunque la red de oficinas consulares es bastante amplia y se halla repartida por todo el mundo (Martí, 2011: 9-10), las facilidades de acceso a las mismas no son comparables a las que se puede tener a una oficina municipal de empadronamiento en España ${ }^{10}$. Y, a pesar de que España adoptó en 2006 un plan para potenciar su acción exterior (Orden AEC/2783/2006), que contemplaba la apertura de nuevas oficinas consulares y el reforzamiento de las existentes, la situación económica por la que atraviesa España desde 2008 ha abortado, en parte, este proceso, e incluso ha obligado al cierre de algunos consulados generales en países como el Reino Unido (Manchester, en 2011), Alemania (Hannover, en 2011) y Estados Unidos (Nueva Orleans, en 2009). Por otro lado, a los problemas de distancia del lugar de residencia al consulado español más próximo, hay que sumar, en no pocos casos, los relacionados con el horario de atención al público y la notable afluencia de demandantes de los servicios consulares.

${ }^{10}$ En algunos de los principales países de destino de la emigración española actual sólo existen dos o tres consulados españoles cuya jurisdicción se extiende por un amplio territorio. Este es el caso, por ejemplo, del Reino Unido, donde España tiene sólo dos consulados de carrera (en Londres y Edimburgo) que deben dar servicio a una población de residentes españoles en torno a las 100.000 personas, a las que hay que sumar un flujo muy notable y constante de viajeros y migrantes temporales. 
Por último, conviene significar que la importancia del efecto en las estadísticas de emigración exterior española de la inscripción en el RMC como residente es aún mayor si se tiene en cuenta que es prácticamente el único medio administrativo que permite constatar el cambio de residencia habitual de España al extranjero. Cabe reseñar, en este sentido, que otros procedimientos de baja en el Padrón municipal, en no pocos casos por emigración al extranjero, no tienen, para el caso de los españoles (sí para los extranjeros, a través de las bajas por caducidad), repercusión directa en las estadísticas de emigración exterior.

\section{LAS MAGNITUDES DEL SUBREGISTRO CONSULAR}

Los datos disponibles permiten una estimación aproximada del subregistro consular existente entre los españoles que han emigrado al extranjero desde principios del siglo actual. Según dichos datos, más de la mitad de los emigrados entre 2008 y 2012 que residían en el extranjero en esta última fecha no se había inscrito en el PERE. El subregistro ofrece, no obstante, apreciables diferencias en función de la antigüedad de la emigración desde España y el país (o área geográfica) de destino/residencia de la misma.

\subsection{La relación con la antigüedad de la emigración desde España}

El subregistro consular es muy notable entre las personas que han emigrado de España en los últimos años, reduciéndose sensiblemente a medida que aumenta la antigüedad de la emigración (Figura 1). Algo más de la mitad de los emigrados entre 2008 y 2012 no se había inscrito en el PERE en el momento de realización de la encuesta. El subregistro experimenta, en todo caso, un pronunciado descenso entre los emigrados en este quinquenio en relación con la antigüedad de la emigración, pasando de niveles cercanos al 70\% entre los más recientes (años 2011-2012) a poco más del 40\% entre los que lo hicieron entre 2008 y 2010. Los niveles de subregistro se reducen de forma sensible entre los emigrados antes de 2008, situándose algo por debajo del $20 \%$ entre quienes lo hicieron en 2001-2007. Los datos disponibles relativos a personas emigradas en el último tercio del siglo pasado, aunque algo menos consistentes que los anteriores debido a la reducción del número de observaciones, indican la existencia de niveles de subregistro más bajos, en torno al 7\% entre quienes lo hicieron entre 1991 y 2000 y el 4\% antes de 1991.

La estrecha relación existente entre la antigüedad de la emigración desde España y el subregistro consular se aprecia muy claramente al representar en un diagrama de dispersión (Figura 2) la serie de datos correspondientes a dichas 
variables: tiempo de emigración desde España (en años) en el eje de abscisas (variable independiente) y porcentaje de emigrados cada año no inscritos en el PERE en el eje de ordenadas (variable dependiente). Como se observa, la serie de datos presenta una evolución temporal que se ajusta relativamente bien a una línea de tendencia logarítmica. La relación entre los datos de ambas variables es inversa, pero muy elevada y significativa, lo que queda claramente constatado a través del cálculo de sus coeficientes de correlación $(r=0,97)$ y de determinación $\left(R^{2}=0,94\right)^{11}$.

Figura 1. Subregistro consular según período de emigración desde España. Porcentaje de no inscritos en el PERE del total de emigrados en cada período

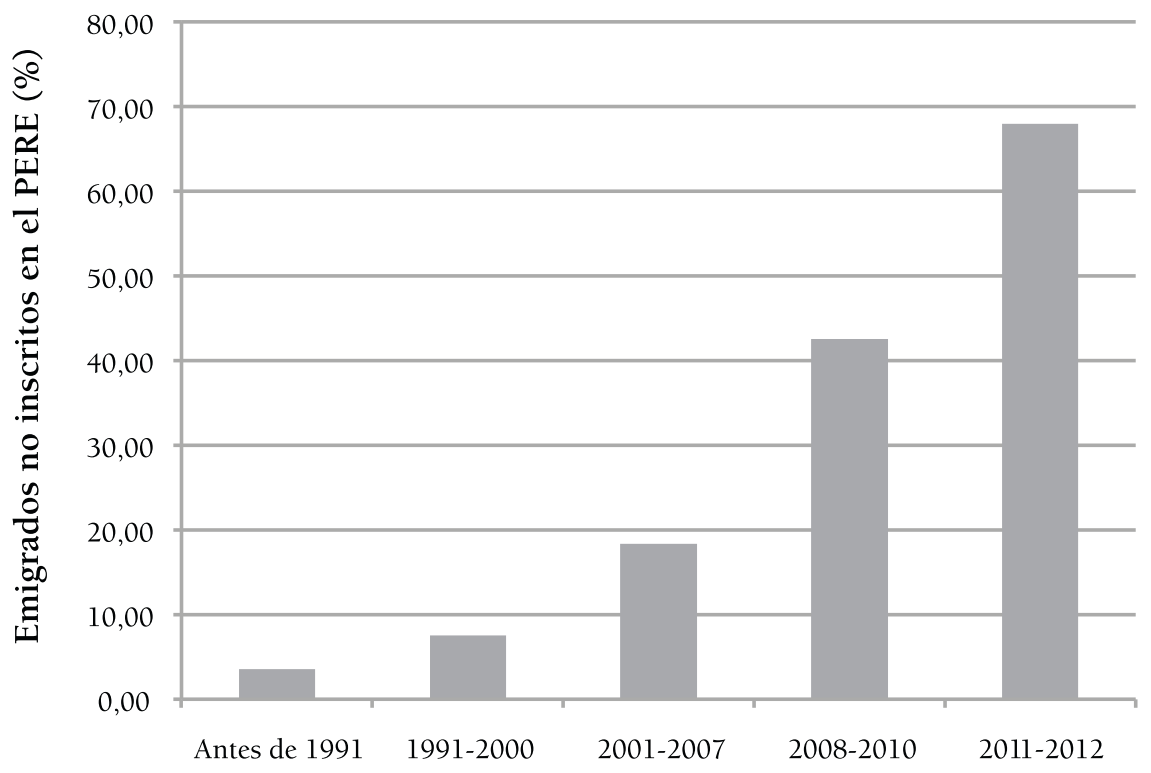

Año de emigración desde España

Fuente: Encuesta para conocer la situación de los españoles residentes en el extranjero 2012. Elaboración propia

${ }^{11}$ Para la variable dependiente se han utilizado los datos correspondientes a los últimos 20 años, de los que se dispone de observaciones suficientes para hacer consistentes los mismos (emigrados que han respondido a la pregunta correspondiente de la encuesta) relativamente suficiente. La correlación es aún más elevada $\left(r=0,988\right.$ y $\left.\mathrm{R}^{2}=0,976\right)$ en los datos correspondientes a los emigrados recientes (2008-2012). Cabe reseñar que el número de observaciones para estos cinco últimos años es muy notable, superando las 250 en todos los casos (media anual: 425 observaciones). 
Figura 2. Relación entre el subregistro consular y la antigüedad de la emigración desde España. Emigrados españoles residentes en el extranjero

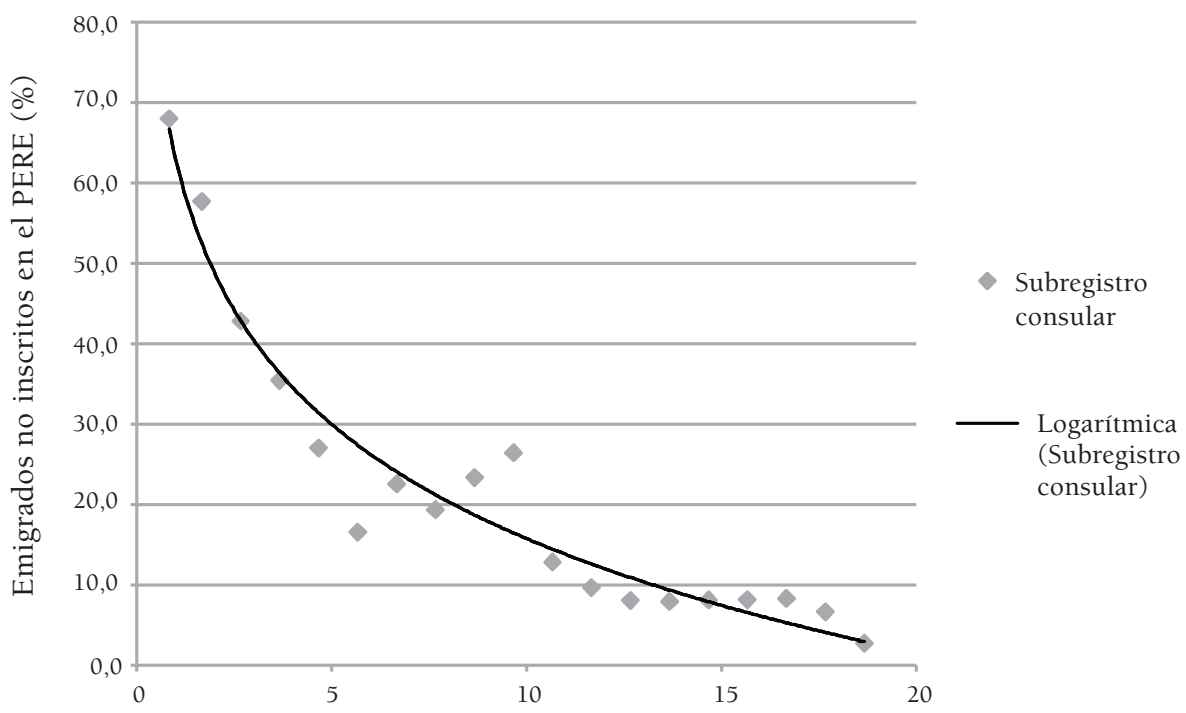

Antigüedad de la emigración desde España (número de años)

Fuente: Encuesta para conocer la situación de los españoles residentes en el extranjero 2012. Elaboración propia

Aunque se observan patrones algo diferentes en el tiempo, el modelo de ajuste logarítmico ofrece buenos resultados para expresar la evolución del subregistro consular en el medio largo-plazo. Las magnitudes del subregistro descienden a un ritmo muy notable entre los emigrados recientes (últimos 5 años) para luego hacerlo de forma más paulatina y suave a medida que aumenta el número de años desde que se llevó a cabo la salida de España (según una tendencia logarítmica). Entre los emigrados que llevan un año residiendo en el extranjero, prácticamente dos de cada tres no se han dado de alta en el PERE. Dicha proporción se reduce a la mitad de esta cifra (algo más del 30\%) entre los que llevan cinco años. Entre los emigrados que llevan diez y quince años la proporción de los que no se ha dado de alta en el PERE se sitúa algo por encima del $15 \%$ y $7 \%$ respectivamente. Aunque la tendencia es, desde luego, claramente descendente, los datos de la encuesta revelan la existencia de subregistro consular, aunque a niveles muy reducidos (por debajo del 2-4\%), entre las personas que han emigrado de España hace 20 y más años. 


\subsection{La relación con el lugar de residencia}

El subregistro consular ofrece también apreciables diferencias en función del lugar de residencia de los españoles emigrados en el extranjero. Este hecho se constata tanto en el ámbito de continentes o grandes áreas geográficas como de países. Ello guarda, sin duda, estrecha relación con el contexto socioeconómico y geopolítico de cada territorio, así como la situación y condiciones de vida en los mismos, y, sobre todo, con cómo esto es percibido por los propios emigrados en relación a las posibilidades y ventajas que puede conllevar la inscripción consular. Hay que señalar, por otra parte, que las diferencias observadas anteriormente en relación con la antigüedad de la emigración desde España se repiten, con matices y particularidades propias, en las distintas áreas geográficas y países de residencia.

\subsubsection{Según el continente o área geográfica de residencia}

A nivel de continentes o áreas geográficas de residencia, se observan sensibles diferencias (Figura 3), especialmente entre los emigrados en los últimos años ${ }^{12}$. Estas diferencias se reducen en gran parte, aunque no al mismo ritmo, a medida que aumenta la antigüedad de la emigración. Los niveles de subregistro más elevados se observan entre los emigrantes españoles residentes en el territorio de la Unión Europea. Cerca del 60\% de los emigrados entre 2008 y 2012 no se habían dado de alta en el PERE en el momento de la encuesta. Esta proporción es de casi el 75\% (dos de cada tres) entre los emigrados más recientes (años 2011-2012).

En un segundo nivel se sitúan los emigrados al resto de Europa y Latinoamérica, entre los que en torno a la mitad de los emigrados entre 2008 y 2012 no se habían inscrito en el PERE (algo más del 60\% y 65\%, respectivamente, entre los emigrados en 2011-2012). En un tercer nivel se sitúan los emigrados en Norteamérica y Oceanía donde algo más del 40\% y del 50\% de los emigrados entre 2008 y 2012 y entre 2011 y 2012, respectivamente, no se habían inscrito en el PERE en el momento de la encuesta. El subregistro consular ofrece magnitudes menos elevadas entre los emigrados a África y, sobre todo, a Asia. Algo menos de un tercio de los emigrados desde España entre 2008 y 2012 que residían en estos continentes no se había inscrito en el PERE en el momento de

${ }^{12}$ Se han agrupado los datos Norteamérica y Oceanía debido a que el relativamente reducido número de observaciones disponible para este último continente podría hacer poco consistentes los resultados obtenidos para el mismo. Por otra parte, esta agrupación se justifica por las similitudes existentes entre los países que los conforman desde el punto de vista socioeconómico, cultural y en materia migratoria. 
la encuesta (uno de cada cuatro en el caso de Asia). Esta proporción se eleva algo más (60\% y 40\%, respectivamente) entre los emigrados entre 2011 y 2012. Esta diferencia de cifras ofrece una idea de la celeridad del ritmo de reducción del subregistro entre los emigrados a dichos continentes.

Figura 3. Subregistro consular según continente o área geográfica de residencia y período de emigración desde España. Porcentaje de no inscritos en el PERE del total de emigrados en cada área y período

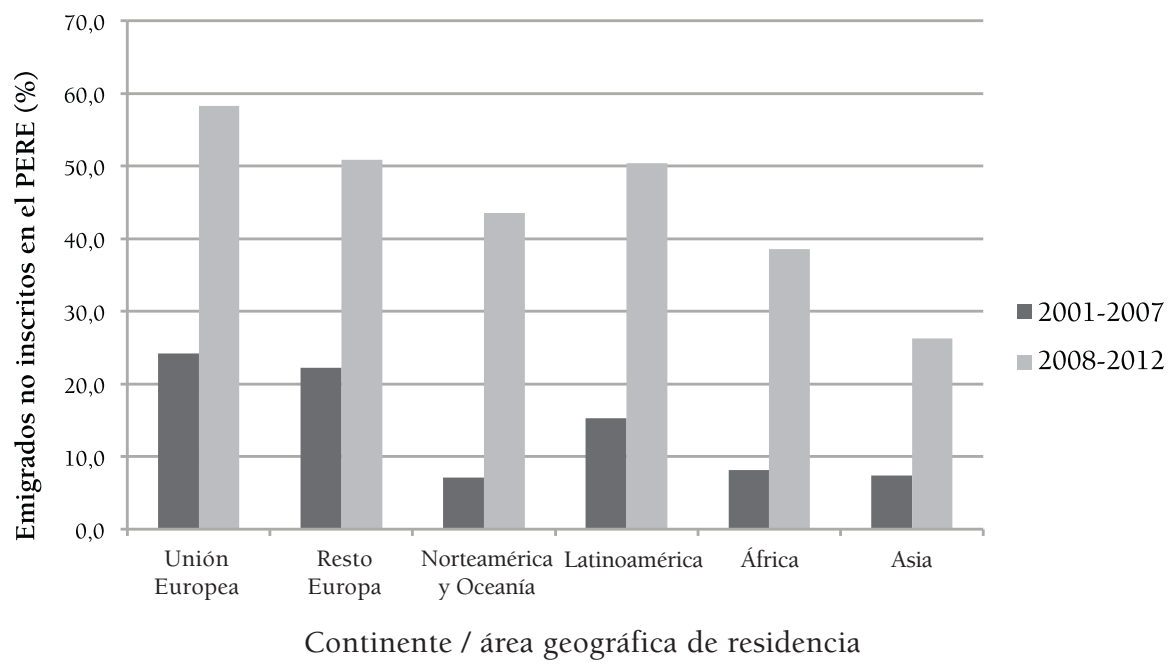

Fuente: Encuesta para conocer la situación de los españoles residentes en el extranjero 2012. Elaboración propia

Aunque la antigüedad de la emigración influye notablemente en la reducción de los niveles de subregistro en todas las áreas geográficas y continentes, este factor parece tener mayor grado de incidencia, al menos en el corto-medio plazo, en unos territorios que en otros. Ello se aprecia claramente al comparar el descenso en los niveles de subregistro entre los emigrados españoles a cada uno de ellos en los períodos 2008-2012 y 2001-2007. El descenso más acusado en los niveles de subregistro se aprecia entre los emigrados a los continentes africano y asiático. En estos territorios el nivel de subregistro se reduce en algo más cuatro veces (cinco veces en el caso de África) entre el conjunto de emigrados en dichos períodos.

El ritmo de reducción del subregistro es algo inferior entre los españoles emigrados al continente americano (y Oceanía). Tanto entre los residentes en 
Norteamérica y Oceanía como en Latinoamérica el subregistro entre los emigrados en los períodos indicados se reduce en algo más de tres veces. Algo inferior es todavía aún entre los emigrados al continente europeo, donde el nivel de subregistro entre los emigrados en 2001-2007 es entre 2 y 2,5 veces inferior al de los que lo hicieron en período 2008-2012, es decir, se reduce en poco más de la mitad.

La representación en un diagrama de dispersión de los datos de subregistro correspondientes a los emigrados españoles a la Unión Europea y al resto del mundo ${ }^{13}$ (Figura 4) permite otra observación de las diferencias en la evolución de este fenómeno en relación con la antigüedad de la emigración entre los residentes en ambos territorios. En ambos casos el ajuste a una línea de tendencia

Figura 4. Relación entre el subregistro consular y la antigüedad de la emigración desde España. Emigrados españoles residentes en la Unión Europea y el resto del mundo

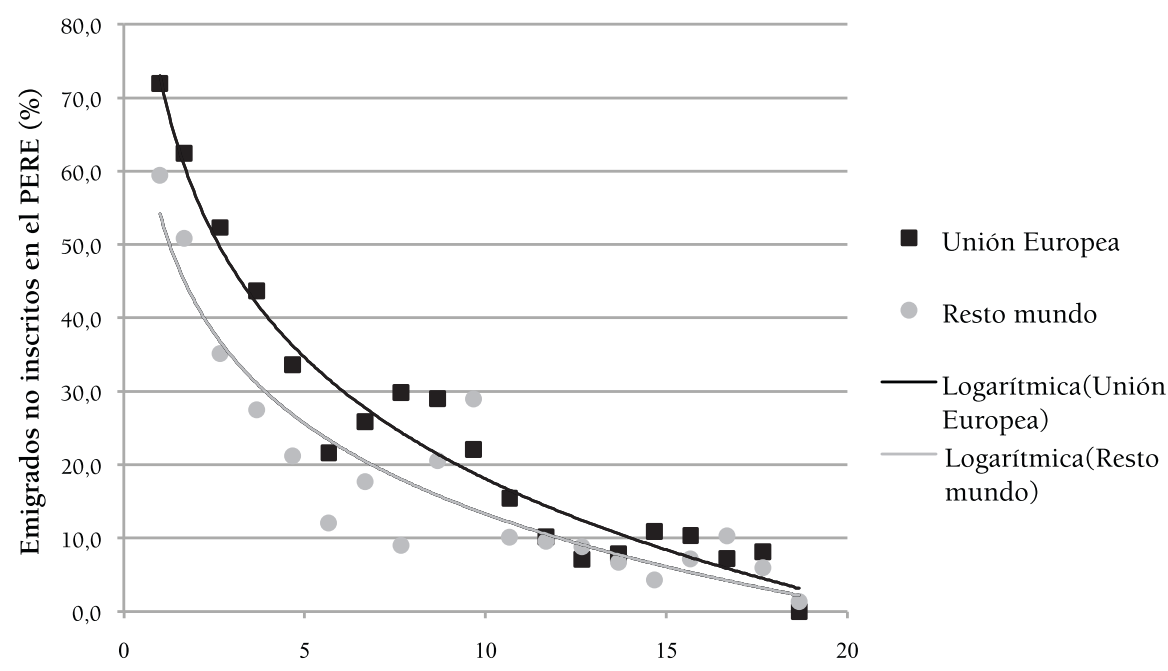

Antiguedad de la emigración desde España (número de años)

Fuente: Encuesta para conocer la situación de los españoles residentes en el extranjero 2012. Elaboración propia

${ }^{13}$ Se han tomado como referencia de forma agregada los datos correspondientes al resto del mundo (y no desagregada por continentes y grandes áreas geográficas). Ello se debe a que el número de observaciones realizadas en la encuesta no permiten, para el resto de continentes y grandes áreas geográficas, la construcción de una serie temporal de carácter anual con datos consistentes que se remonte cinco o diez años atrás. 
logarítmica es notable, tal como se puso en evidencia anteriormente para el conjunto de los emigrados españoles residentes en el extranjero. Aunque ambas líneas discurren de forma relativamente paralela, las diferencias de magnitud en el subregistro son relevantes, siendo significativamente más elevadas entre los emigrados a la Unión Europea en los últimos diez años. Sólo cuando la antigüedad en la emigración es superior a 10 ó 15 años las diferencias en los niveles de subregistro entre territorios se reducen sustancialmente y tienden a difuminarse.

\subsubsection{Según el país de residencia}

Los datos de la encuesta sólo permiten el análisis de las dimensiones del subregistro consular y su relación con la antigüedad de la emigración para aquellos países en los que se realizaron un número significativo de observaciones. La representación gráfica de los datos correspondientes a los principales de estos países (Figura 5) permite apreciar que los niveles de subregistro son especialmente elevados en el Reino Unido (sobre todo) y Francia. En el Reino Unido el subregistro ronda el 75\% entre los emigrados a dicho país entre 2008 y 2012

Figura 5. Subregistro consular según país de residencia y período de emigración desde España. Porcentaje de no inscritos en el PERE del total de emigrados en cada país y período

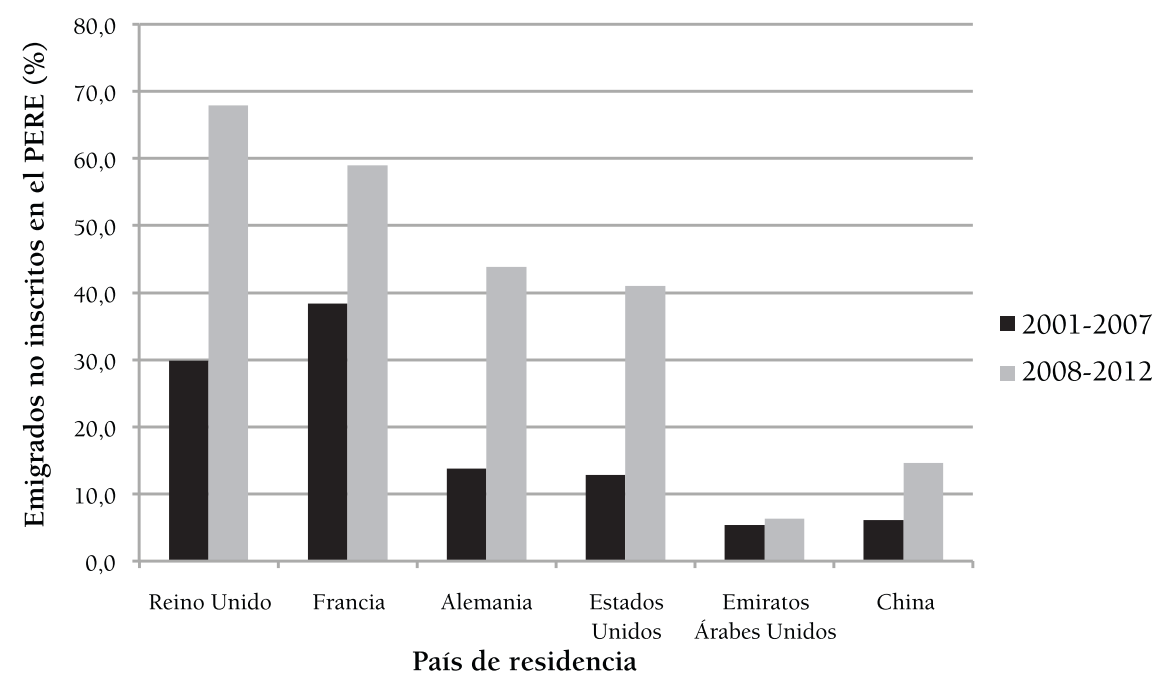

Fuente: Encuesta para conocer la situación de los españoles residentes en el extranjero 2012. Elaboración propia 
(dos de cada tres) y al 80\% entre los que lo hicieron específicamente entre 2011 y 2012. En el caso de Francia, estas proporciones rondaban el $60 \%$ y el $70 \%$ respectivamente para dichos períodos. Por el contrario, los niveles más bajos de subregistro consular se observan en países africanos y asiáticos. Entre los países asiáticos, cabe significar los casos de Emiratos Árabes Unidos, donde el subregistro es algo superior al 5\% entre los emigrados entre 2008 y 2012, así como en China donde ronda el 15\%.

El ritmo de descenso de los niveles de subregistro según la antigüedad de la emigración también ofrece diferencias notables entre los distintos países. Si se toman como referencia los niveles de subregistro que éstos presentan para los emigrados entre 2008 y2012 y entre 2001 y 2007, se puede apreciar que en los casos de Francia y el Reino Unido el subregistro desciende más lentamente. De tal manera, que sigue siendo aún notable, en ambos casos superior al 30\%, entre los emigrados en el período 2001-2007. El descenso es también reducido entre los residentes en los Emiratos Árabes Unidos y en China, si bien en estos dos casos hay que tener en cuenta que se parte de un nivel de subregistro ya muy bajo entre los emigrados en los últimos años (2008-2012) por lo que los márgenes de reducción del mismo son bastante pequeños. El descenso es más relevante entre los residentes en Estados Unidos y Alemania, donde el subregistro entre los emigrados entre 2001 y 2007 es tres veces inferior al de los que lo hicieron entre 2008 y 2012.

\section{EFECTOS DEL SUBREGISTRO CONSULAR EN LAS ESTADÍSTICAS DE EMIGRACIÓN ESPAÑOLA}

La situación respecto a la inscripción consular de los españoles que residen habitualmente en el extranjero tiene una repercusión directa sobre las estadísticas de emigración y población española en el exterior. El hecho de que una buena parte de los emigrantes españoles no se inscriban como residentes en el RMC correspondiente al país en el que residen, o se demoren en hacerlo más de un año, incide de forma muy negativa en la calidad y confiabilidad de las estadísticas oficiales de emigración exterior española. Especialmente, en lo que respecta a la observación y medición in tempore (en el mismo año en que tiene lugar) del fenómeno emigratorio.

Si se toman como referencia los datos de subregistro correspondientes a los emigrados españoles en el año más reciente disponible (2012), se aprecia que prácticamente tres de cada cuatro no se habían dado de alta en el PERE. Esta cifra se reduce aproximadamente a un $65 \%$ si se toma como referencia a los emigrados que llevan un año residiendo en el extranjero y, que por tanto, habrían dispuesto de doce meses para poder llevar a cabo su inscripción en el 
PERE. Los emigrados en el año 2012 habrían dispuesto, en todos los casos, de menos de ese tiempo para llevar a cabo en dicho año la inscripción en el PERE. Posiblemente el dato de subregistro relativo a los emigrados hace un año sea al más adecuado para expresar este fenómeno en tanto que tiene en cuenta la duración mínima de la estancia en el extranjero que debe ser de, al menos un año, para ser considerada como emigración de largo plazo. Este dato podría quizás ser extrapolado de forma general para cualquier otro año si se parte de la hipótesis que la actitud de los emigrados españoles respecto a la inscripción consular se mantiene relativamente constante en el tiempo. Es decir, que se mantienen ritmos y niveles de registro consular relativamente similares a lo largo de los años. Estos ritmos y niveles de registro consular podrían, no obstante, alterarse en el caso de que entraran en juego agentes externos (campaña publicitaria para incentivar la inscripción mostrando las ventajas de la misma, movilización extraordinaria para votar en elecciones, etc.).

Existe, por tanto, un importante número de migraciones de españoles al extranjero que no han sido registradas y contabilizadas en las estadísticas correspondientes. Como consecuencia, estas personas siguen siendo, a todos los efectos, población residente en España. Parece obvio que las estadísticas de emigración española publicadas para el año 2012 (y con toda seguridad para los años precedentes) no incluyen a una buena parte de los emigrados en el mismo. Este hecho, sin embargo, no debe inducir a pensar que las cifras reales de la emigración son, para dicho año, cuatro veces superiores a las publicadas por las estadísticas oficiales. La razón es que estas últimas incluyen a todos los emigrados españoles residentes en el extranjero que han formalizado su inscripción en el PERE en ese año, sea cual fuere su fecha real de emigración. Es decir, que incluyen tanto a los emigrados que se han inscrito en el PERE en el mismo año de su llegada al nuevo país de residencia (inscripción in tempore), como a otros muchos que formalizan la misma después de uno o más años desde su salida de España (inscripción ex tempore).

Estas inscripciones ex tempore podrían compensar, al menos en parte, las que no han realizado los verdaderos emigrados en dicho año. De tal manera que las cifras totales publicadas por las estadísticas oficiales, aunque alejadas de las reales, podrían, por este efecto compensación de las inscripciones ex tempore, estarlo algo menos de lo que sugieren algunos analistas y medios de comunicación. El retraso o demora en la inscripción consular tiene un efecto importante en las estadísticas de emigración española, aún por evaluar.

Si se toman como referencia los datos de subregistro correspondientes a los emigrados en el quinquenio 2008-2012 que residen en el extranjero, se observa que uno de cada dos no se ha inscrito en el PERE. Se puede inferir de ello 
que la mitad de los emigrados en dicho período no han sido registrados y contabilizados en las estadísticas correspondientes a esos cinco años. Y, aunque la magnitud real de la emigración no pueda calcularse, como se ha indicado anteriormente, directamente a partir de este dato, sí que nos ofrece una idea de la relevancia y, a su vez, del conocimiento inadecuado de este fenómeno.

Por otra parte, la diversidad de niveles de subregistro consular según el lugar de destino y residencia de los emigrados se traduce en notables diferencias en las estadísticas de emigración española para reflejar y contabilizar adecuadamente (in tempore) el flujo hacia los mismos. De este modo, las estadísticas de emigración española a áreas geográficas y países donde se observan mayores niveles de subregistro consular (especialmente entre los emigrados de los últimos años) y un ritmo de reducción más lento de los mismos (de acuerdo a la antigüedad de la emigración) serán más deficientes en dicho sentido.

Este es el caso, por ejemplo, de la emigración española a Unión Europea, donde en torno al $60 \%$ de los emigrados españoles en los últimos cinco años (2008-2012) y al 75\% de los que lo habían hecho más recientemente (20112012) no se habían inscrito como residentes en el RMC. Y, sobre todo, es el caso de la que tiene como destino países como el Reino Unido, donde los niveles de subregistro se sitúan diez puntos por encima de los anteriores (en torno a 70\% y $80 \%$, respectivamente) para los emigrados en dichos períodos. Una situación similar al caso británico se observa, aunque con magnitudes un poco inferiores, entre los emigrados españoles a países como Francia y, en menor medida, Estados Unidos y Alemania. Cabe reseñar que estos cuatro países son, según las cifras que ofrecen las propias estadísticas oficiales, los principales receptores de la emigración española en los últimos años. Cifras que, en buena parte, estarán nutridas por inscripciones ex tempore en el PERE de emigrados en años precedentes.

La situación contraria se puede observar en la emigración a algunos países, especialmente de África y Asia. Este es, sobre todo, el caso de los Emiratos Árabes Unidos donde la proporción de emigrados españoles en los últimos años (2011-2012) que no han realizado la inscripción consular es claramente inferior al 10\% y el ritmo de reducción del subregistro es, asimismo, muy acelerado. También, en algo de menor medida, el de China, donde dicha proporción se sitúa en torno al 15\%. Se puede inferir de ello que las estadísticas oficiales de emigración española a estos países observan y miden de forma bastante correcta este fenómeno, aproximándose con rigor a la verdadera realidad del mismo. Los datos que sirven de base a las estadísticas de emigración española a estos países, a diferencia de los anteriores en los que los niveles de subregistro son elevados, corresponden en su gran mayoría a inscripciones 
consulares llevadas a cabo de forma muy próxima en el tiempo de ocurrencia (in tempore) del suceso migratorio.

\section{CONCLUSIONES}

Los análisis realizados en este trabajo, tomando como base principalmente los datos de una encuesta realizada en 2012 para conocer la situación de los españoles en el extranjero, arrojan un poco de luz y algunos hallazgos de interés para el conocimiento de las magnitudes del subregistro consular y sus efectos en las estadísticas de emigración española actual. Por una parte, se constata de forma empírica la existencia de un subregistro consular de magnitudes relevantes entre los españoles residentes en el extranjero, especialmente entre los emigrados recientes. Al menos uno de cada dos emigrados españoles entre 2008 y 2012 no se había registrado como residente en el RMC al final de dicho período. Por tanto, su cambio de residencia no había sido registrado y computado por las estadísticas de emigración española, manteniéndose a todos los efectos como población residente en España.

Por otra parte, los resultados de este estudio ponen en evidencia la existencia de determinados patrones en el subregistro consular relacionados con parámetros significativos del proceso migratorio, como son la antigüedad de la emigración (variación en el tiempo) y el lugar de destino/residencia (variación en el espacio). El subregistro consular es menor, como era obviamente de prever, a medida que aumenta el tiempo de emigración y residencia fuera de España. Los datos permiten observar que este descenso del subregistro presenta, en una escala temporal de 15-20 años (antigüedad de la emigración), un patrón que se ajusta notablemente a una línea de tendencia logarítmica. El descenso es más acelerado entre los emigrados recientes (cinco últimos años) para luego hacerse paulatinamente más suave a medida que aumenta el tiempo de residencia fuera de España.

También se evidencian notables diferencias según el lugar de residencia en el extranjero de los españoles emigrados. Los niveles más elevados de subregistro consular se observan, con diferencia, entre los emigrados a la Unión Europea, especialmente a países como el Reino Unido. Cerca del $60 \%$ de los emigrados a la UE entre 2008 y 2012 no se habían inscrito como residentes en el RMC en el momento de la encuesta. Esta proporción ronda el $75 \%$ entre los emigrados al Reino Unido. Por el contrario, los niveles más bajos se observan entre los emigrados a África y Asia, siendo especialmente significativas las relativamente reducidas magnitudes que presentan en países como China y, sobre todo, en los Emiratos Árabes Unidos, dos de los destinos emergentes en los últimos años. Las diferencias observadas en relación con la antigüedad 
de la emigración desde España, se repiten, con matices y particularidades propias, en las distintas áreas geográficas y países de residencia.

Estas diferencias en la magnitud del subregistro repercuten en la confiabilidad de las estadísticas de emigración española hacia uno u otro territorio, especialmente en lo que respecta a la observación y medición in tempore de este fenómeno. Las estadísticas de emigración española a países en los que se observan bajos niveles de subregistro consular y un descenso rápido de los mismos (menor demora en la inscripción) miden de forma más correcta el fenómeno (in tempore) ajustándose más a la verdadera dimensión y realidad del mismo. Por el contrario, las estadísticas de emigración española a países donde se observan notables niveles de subregistro consular y un descenso más lento de los mismos presentarán mayores deficiencias en dicho sentido. Este es, paradójicamente, el caso de los principales destinos de la emigración española en los últimos años (Reino Unido, Francia, Estados Unidos, Alemania).

El subregistro consular en un determinado período expresa la subestimación de la emigración real en el mismo. Y, en ese sentido, se puede estimar, a partir de los datos manejados y los análisis realizados en este trabajo, que la mitad aproximadamente de los españoles que emigraron al extranjero en el período 2008-2012 no se habían inscrito en el PERE al final del mismo. No puede deducirse, sin embargo, directa y exclusivamente a partir de los datos del subregistro consular, en qué medida las cifras anuales sobre emigración española que publican las estadísticas oficiales subestiman el flujo migratorio real. La razón principal es que estas últimas reflejan todas las inscripciones consulares que se producen cada año independientemente de la fecha y antigüedad de la emigración de las personas que las realizan.

No se discuten, por tanto, específicamente en este artículo en qué medida las cifras de emigración publicadas por las estadísticas españolas pueden ser inferiores a las reales, ya que para ello habría que considerar también en los cálculos y los análisis datos como los relativos a la demora en la inscripción consular de los emigrados, entre otros. En cualquier caso, los análisis en este sentido que están llevando a cabo los autores de este artículo parecen sugerir que las cifras de emigración española para el período 2008-2012 son superiores a las publicadas por las estadísticas oficiales (algo más de 200 mil), incluso contando con el efecto compensación en estas últimas de las inscripciones ex tempore (emigrados antes de 2008 que formalizan su inscripción en dicho período), pero probablemente también inferiores a las que indican algunos analistas (en torno a 700 mil).

Hay que reseñar, además, que los resultados de este trabajo pueden tener una utilidad y aplicación práctica. Por una parte, deben servir de llamada de 
atención a la administración española y especialmente a los organismos competentes en materia de emigración (Dirección General de Migraciones del MEySS, Dirección General de Asuntos Consulares y los Españoles Residentes en el Exterior del MAEC) y estadística (INE) para que adopten medidas destinadas a la reducción del subregistro consular. Una amplia campaña de información entre los emigrantes españoles sobre la necesidad y ventajas de la inscripción consular que concientice sobre el particular es imprescindible para ello. Desde luego, debe ir acompañada de medidas como el incremento de las facilidades de acceso a los servicios consulares y la mejora de los mismos. Quizás sea mucho pedir en los tiempos de crisis que corren, en los que los propios planes de fortalecimiento del servicio exterior han quedado, en parte, paralizados (e incluso se esté procediendo al cierre de consulados en países con una nutrida colonia de viejos y nuevos emigrantes). No obstante, la reducción del subregistro consular debe ser un objetivo insoslayable e inaplazable, no solo por los efectos que tienen en el conocimiento de un fenómeno como el de la nueva emigración española que suscita una gran preocupación social, sino, sobre todo, porque afectan a los derechos inherentes a la inscripción de los ciudadanos españoles residentes en el extranjero.

Por otra, los datos y resultados que se ofrecen en este trabajo pueden quizás servir como referencia e insumo informativo para las tareas que desarrolla el INE destinadas a la mejora de las estadísticas sobre emigración española. En esta línea, cabe señalar además que sería interesante que se llevaran a cabo análisis como el realizado en este trabajo en países como Italia, donde las estadísticas de emigración tienen, al igual que en España, la inscripción consular como base de su sistema de registro ${ }^{14} \mathrm{y}$ donde, aunque varios trabajos aluden también a la existencia de un importante subregistro consular (Cantisani y Greco, 2006: 435; Rinauro, 2010: 413; Pelaggi, 2011: 64), no existen datos e informaciones publicadas sobre el mismo ni, por tanto, obviamente, en relación a sus efectos en las estadísticas de emigración italiana al exterior. Este tipo de trabajos permitiría diagnosticar problemas comunes y llevar a cabo actuaciones estratégicas de mejora en las mismas.

El estudio del subregistro consular y sus efectos en las estadísticas de emigración no se agota, por supuesto, con este trabajo. Todo lo contrario, las observaciones y análisis llevados a cabo en el mismo revelan que todavía quedan

${ }^{14}$ El modus operandi de este sistema en España e Italia ha sido descrito grosso modo, respectivamente, por Breem y Thierry (2006: 419) y Cantisani y Greco (2006: 435). En otros dos países, como Bélgica y Suiza, se utiliza un sistema relativamente parecido. En Bélgica se basa en la autodeclaración del emigrante, que suele omitirse en la práctica (Perrin y Poulain, 2006: 385-386). 
muchos aspectos por escudriñar, como son, entre otros, los relativos a las diferencias relacionadas con el perfil de los emigrantes, la incidencia de la demora en la inscripción consular, o los propios factores que subyacen a todo ello. Algunos de estos temas ya están siendo objeto de atención y análisis por los autores de este artículo, que esperan ofrecer resultados a corto plazo.

Señalar, finalmente, que más que entrar en especulaciones y debates, en buena parte estériles, aunque de gran impacto mediático y social, sobre las magnitudes reales de la emigración española actual (el hecho de que se esté manejando por distintos investigadores una horquilla que va de 40.000 a 700.000 emigrantes en el período 2008-2012 es claramente elocuente), los esfuerzos de investigación sobre la materia deben previamente tratar de conocer y analizar, con el rigor y la minuciosidad debidas, las debilidades y limitaciones de las estadísticas de emigración española (y de inmigración española en los países de destino), así como sus causas. Solo de esta forma, y con las medidas y correcciones oportunas, se podrá disponer en el futuro próximo de datos verdaderamente confiables sobre este fenómeno que permitan su adecuada medición y monitorización, y no den pábulo a diferentes especulaciones.

\section{BIBLIOGRAFÍA}

ADM (2000). Guideline for Online Surveys. [En línea]. Revisado en agosto de 2007. Frankfurt am Main: Arbeitskreis Deutscher Markt- und Sozialforschungsinstitute e.V. <http://www.adm-ev.de/fileadmin/user_upload/PDFS/R08_E_07_08.pdf>. [30/09/2014].

ADM (2001). Standards for Quality Assurance for Online Surveys. [En línea]. Frankfurt am Main: Arbeitskreis Deutscher Markt- und Sozialforschungsinstitute e.V. <http:// www.adm-ev.de/fileadmin/user_upload/PDFS/Onlinestandards_E.pdf>. [30/09/2014].

Babiano, J. y A. Fernández (2002). El fenómeno de la irregularidad en la emigración española de los años sesenta. DOC 3/2002. [En línea]. Madrid: Fundación $1^{\circ}$ de Mayo. <http://www2.1mayo.ccoo.es/publicaciones/doctrab/doc302.pdf>. [30/09/2014].

Babiano, J. y A. Fernández (2009). La patria en la maleta. Historia social de la emigración española a Europa. Madrid: Centro de Documentación de las Migraciones, Fundación $1^{\circ}$ de Mayo-Ediciones GPS.

Beer, J. de, J. Raymer, R. van der Erf y L. van Wissen (2010). "Overcoming the Problems of Inconsistent International Migration data: A New Method Applied to Flows in Europe". European Journal of Population, 26(4): 459-481.

Breen, Y. y X. Thierry (2006). "Spain”. En M. Poulain, N. Perrin y A. Singleton (eds.). THESIM. Towards Harmonised European Statistics on International Migration. Lovaina: UCL-Presses Universitaires de Louvain, 419-422. 
Cantisani, G. y V. Greco (2006). "Italy". En M. Poulain, N. Perrin y A. Singleton (eds.). THESIM. Towards Harmonised European Statistics on International Migration. Lovaina: UCL-Presses Universitaires de Louvain, 435-439.

Cea Dáncona, M. A. (2004). Métodos de encuesta. Teoría y práctica, errores y mejora. Madrid: Síntesis.

Díaz, V., C. Flavián y M. Guilaliu (2004). "Encuestas en Internet. Algo más que una simple versión mejorada de la tradicional encuesta autoadministrada". Investigación y Marketing, 82: 45-56.

Díaz de Rada, V. (2010). "Eficacia de las encuestas por internet: un estudio preliminar". Revista Española de Sociología, 13: 49-79.

Díaz de Rada, V. (2011). "Encuestas con encuestador y administradas por Internet. ¿Proporcionan resultados comparables?”. Revista Española de Investigaciones Sociológicas, 136: 49-90.

Díaz de Rada, V. (2012): "Ventajas e inconvenientes de la encuesta por Internet". Papers. Revista de Sociología, 97(1): 193-223.

Durán Villa, F. R. (2008). "Europa como destino de los trabajadores españoles". En X. A. Liñares, (coord.). Ciudadanos españoles en el mundo. Situación actual y recorrido histórico. Vigo: Grupo España Exterior, 179-198.

Galgóczi, B., J. Leschke y A. Watt (2011). Intra-EU Labour Migration: Flows, Effects and Policy Responses. ETUI Working Paper 2009.03. [En línea]. Bruselas, European Trade Union Institute (ETUI). <http://library.fes.de/pdf-files/gurn/00401.pdf>. [30/09/2014].

García Fernández, J. (1965). La emigración exterior de España. Barcelona: Ariel.

González Enríquez, C. (2013). ¿Emigran los españoles? ARI 39/2013. [En línea]. Madrid: Real Instituto Elcano. <http://www.realinstitutoelcano.org/wps/portal/rielcano/contenido?WCM_GLOBAL_CONTEXT=/elcano/elcano_es/zonas_es/demografia+y+p oblacion/ari39-2013-gonzalez-enriquez-emigran-los-espanoles>. [30/09/2014].

González Ferrer, A. (2013). La nueva emigración española. Lo que sabemos y lo que no. Zoom Político, no 2013/18. [En línea]. Madrid: Laboratorio de Alternativas. <http:// www.falternativas.org/laboratorio/libros-e-informes/zoom-politico/la-nueva-emigracion-espanola-lo-que-sabemos-y-lo-que-no>. [30/09/2014].

INE (2013). Estadística de Migraciones. Metodología. Madrid: Instituto Nacional de Estadística.

INE (2014). Estadística de Variaciones Residenciales. [En línea]. Madrid: Instituto Nacional de Estadística. <http://www.ine.es/daco/daco42/migracion/notaevr.htm>. [30/09/2014].

Jensen, E. B. (2013). A Review of Methods for Estimating Emigration. Population Division Working Paper, 101. [En línea]. Washington U.S. Census Bureau. <http://www.cen sus.gov/population/www/documentation/twps0101/SWG_emigration_jensen. pdf>. [30/09/2014].

Lemaitre, G. (2005). "The Comparability of International Migration Statistics. Problems and Prospects". Statistics Brief, 9. [En línea]. París: OCDE. <http://www.oecd.org/ migration/mig/36064929.pdf>. [30/09/2014]. 
Ley 4/1996, de 10 de enero, por la que se modifica la Ley 7/1985, de 2 de abril, Reguladora de las Bases del Régimen Local en relación con el padrón municipal. Boletín Oficial del Estado, $n^{\circ} 11,12 / 01 / 1996$.

Marpsat, M y N. Razanfindratsima (2010). "Survey Methods for Hard-to-Reach Populations: Introduction to the Special Issue". Methodological Innovations Online, 5(2): 3-16. [En línea]. <http://www.pbs.plym.ac.uk/mi/pdf/05-08-10/2.\%20Marp sat\%20and\%20Razafindratsima\%20English2\%20(formatted).pdf>. [30/09/2014].

Martí Martí, X. (2011). "La actividad consular de España en el extranjero". Revista Electrónica de Estudios Internacionales, 21. [En línea]. <http://www.reei.org/index. php/revista/num21/notas/actividad-consular-espana-extranjero>. [30/09/2014].

Moscoso, D. y E. Moyano (dirs.) (2010). Condiciones de vida y expectativas de retorno de los andaluces en el extranjero. Sevilla: Consejería de Gobernación y Justicia-Junta de Andalucía.

Nowok, B. (2010). Harmonization by Simulation. A Contribution to Comparable International Migration Statistics in Europe. Dissertations - University of Groningen. Amsterdam: Rozenberg Publishers. [En línea]. <http://irs.ub.rug.nl/ppn/329320 742>. [30/09/2014].

OIM (2013). Informe sobre las migraciones en el mundo 2013. El bienestar de los migrantes y el desarrollo. Ginebra: Organización Internacional para las Migraciones.

Palazón Ferrando, S. (1995). Capital humano español y desarrollo latinoamericano. Evolución, causas y características del flujo migratorio (1882-1990). Alicante: Instituto de Cultura Juan Gil-Albert.

Pelaggi, S. (2011). L'altra Italia. Emigrazione storica e mobilità giovanile a confronto. Roma: Edizioni Nuova Cultura.

Perrin, N. y M. Poulain, M. (2006). "Belgium". En M. Poulain, N. Perrin y A. Singleton (eds.). THESIM. Towards Harmonised European Statistics on International Migration. Lovaina: UCL - Presses Universitaires de Louvain, 385-389.

Poulain, M. y N. Perrin (2011). Is the Measurement of International Migration Flows Improving in Europe. Joint UNECE-EUROSTAT Working Paper $\mathrm{n}^{\circ}$ 12. [En línea]. Ginebra, UNECE y EUROSTAT. <http://www.unece.org/fileadmin/DAM/stats/documents/2001/05/migration/12.e.pdf>. [30/09/2014].

Poulain, M. (2006). Key Issues for European Countries Regarding the Implementation of the UN Recommendations on International Migration Statistics. United Nations Expert Group Meeting on Measuring International Migration: Concepts and Methods, 47/12/2006. [En línea]. Nueva York: Naciones Unidas. <http://unstats.un.org/unsd/ demographic/meetings/egm/migrationegm06/DOC\%204\%20GeDAP.pdf>. [30/09/2014].

Poulain, M. y L. Dal (2008). Estimation of Flows within the Intra-EU Migration Matrix. Report for the MIMOSA Project. [En línea]. Lovaina: Universidad Católica de Lovaina. <http://mimosa.gedap.be/Documents/Poulain_2008.pdf>. [30/09/2014].

Prieto Rosas, V. (2008). ¿Dónde están y como son? Análisis territorial y demográfico de los españoles en el exterior 1997-2007. Máster en Estudios Territoriales y de la Población. 
Memoria de Investigación. [En línea]. Departamento de Geografía-Centro de Estudios Demográficos - Universidad Autónoma de Barcelona. <http://ddd.uab.cat /pub/trerecpro/2008/hdl_2072_41824/Treball_de_recerca.pdf>. [30/09/2014].

Raymer, J. y G. Abel (2008). The MIMOSA Model for Estimating International Migration Flows in the European Union. Joint UNECE/Eurostat Working Paper, 8. [En línea]. Ginebra: UNECE/Eurostat. <http://iussp2009.princeton.edu/papers/ 92501>. [30/09/2014].

Real Decreto 3425/2000 sobre inscripción de los españoles en los Registros de Matrícula de las Oficinas Consulares en el extranjero. Boletín Oficial del Estado, $n^{\circ} 3,03 / 01 / 2001$. Reglamento (CE) Bo 862/2007 del Parlamento Europeo y del Consejo de 11 de julio de 2007 sobre las estadísticas comunitarias en el ámbito de la migración y la protección internacional. Diario Oficial de la Unión Europea, 31/07/2007, L 199.

Rodenas, C. y M. Martí (2013). "La nueva Estadística de Migraciones: una buena elección por parte del INE". Revista Española de Investigaciones Sociológicas, 143: 113-120.

Recaño, J. y V. de Miguel (2009). La emigración andaluza: cuantificación y distribución. Seminario El Estado de la Investigación sobre la Emigración Andaluza. Ponencias. PN 10/09, 1-28. Sevilla: Centro de Estudios Andaluces-Consejería de la PresidenciaJunta de Andalucía.

Rinauro, S. (2010). "Le statistiche ufficiali dell'emigrazione italiana tra propaganda politica e inafferrabilità dei flussi". Quaderni Storici, 134: 393-417.

Romero Valiente, J. M. (dir.) (2012). La movilidad exterior de los españoles y las españolas en la actualidad. Informe Final. Huelva: Fundación Universidad de Huelva-Dirección General de Migraciones (Ministerio de Empleo y Seguridad Social), inédito.

Romero Valiente, J. M. (2013). "La migración española a Brasil (fines del siglo XIXactualidad): magnitudes y evolución". En J. M. Romero Valiente et al. (eds.). Migraciones iberoamericanas. Las migraciones España-Brasil. Huelva: Centro de Investigación en Migraciones (Universidad de Huelva) y LABIMI (Universidade de Río de Janeiro, 33-58.

Sanz Díaz, C. (2004). "Clandestinos”, "Ilegales”, "Espontáneos”... La emigración irregular de españoles a Alemania en el contexto de las relaciones hispano-alemanas, 19601973. Cuadernos de Historia de las Relaciones Internacionales, 4. Madrid: Comisión Española de Historia de las Relaciones Internacionales.

Sanz Lafuente, G. (2008). "Un balance de la estadísticas históricas del flujo migratorio exterior, 1956-1985”. En J. de la Torre y G. Sanz (eds.). Migraciones y coyuntura económica del Franquismo a la Democracia. Zaragoza: Prensas Universitarias de Zaragoza, 75-106.

Sanz Lafuente, G. (2009). "Estadísticas históricas de la emigración asistida e IEE, 1956-1985”. En L. M. Calvo Salgado et al. Historia del Instituto Español de Emigración. La política migratoria exterior de España y el IEE del Franquismo a la Transición. Madrid: Ministerio de Trabajo e Inmigración, 293-307. 
Thierry, X., A. Hermn, B. Kupiszewska y M. Poulain (2005). How the UN Recommendations and the Forthcoming EU Regulation on International Migration Statistics Are Fulfilled in the 25 EU Countries? XXV International Population Conference, Paper, Tours, 18-23/07/2005. [En línea]. <http://www.uclouvain.be/cps/

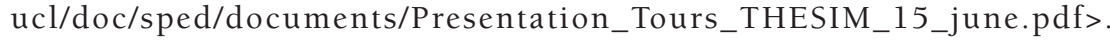
[30/09/2014].

UNECE (2009). Improving Migration Statistics by Exchange of Data between Countries. 95th DGINS Conference Migration Statistical Mainstreaming, Malta, 01/10/2009. [En línea]. <http://epp.eurostat.ec.europa.eu/portal/page/portal/conferences/docu ments/95th_dgins_conference/UNECE.pdf>. [30/09/2014].

UNECE (2010). Guidelines for Exchanging Data to Improve Emigration Statistics. [En línea]. Ginebra, United Nations Economic Commission for Europe, 2010. <http:// www.unece.org/fileadmin/DAM/stats/publications/Guidelines_improve_emigra tion_statistics.pdf>. [30/09/2014].

Naciones Unidas (1998). Recommendations on Statistics of International Migration. Revision 1. Statistical Papers Series M, no 58, Rev. 1. [En línea]. Nueva York: Naciones Unidas. <http://unstats.un.org/unsd/publication/SeriesM/SeriesM_58rev1E.pdf>. [30/09/2014].

Vilar, J. B. y M. J. Vilar (1999). La emigración española a Europa en el siglo XX. Madrid: Arco Libros.

Yáñez Gallardo, C. (1993). La emigración española a América (siglos XIX y XX). Dimensión y características cuantitativas. Gijón: Fundación Archivo de Indianos.

JUAN MANUEL ROMERO VALIENTE es licenciado en Geografía e Historia (1985) y Doctor en Geografía (1996) por la Universidad de Sevilla. Es Profesor Titular del Departamento de Historia II y Geografía de la Universidad de Huelva y miembro del Centro de Investigación en Migraciones (CIM) de la misma. Desarrolla una línea de investigación sobre migraciones internacionales con especial atención a las que se desarrollan entre España y Latinoamérica. Ha dirigido varios proyectos de investigación y publicados diversos trabajos sobre esta temática, entre ellos su propia tesis doctoral "Las migraciones exteriores de República Dominicana. Intercambios migratorios con España”. En su actividad reciente cabe destacar la dirección y redacción del "Estudio sobre la movilidad exterior de los españoles y las españolas en la actualidad" (MEySS, 2012).

ANTONIO LUIS HIDALGO-CAPITÁN es Doctor en Ciencias Económicas y Empresariales y Profesor Titular de Economía Aplicada en la Universidad de Huelva, donde imparte docencia de Economía Política Internacional y Economía Política del Desarrollo y forma parte del Centro de Investigación de las 
Migraciones de dicha universidad. Además, ha sido Subdirector de la Sede Iberoamericana Santa María de La Rábida de la Universidad Internacional de Andalucía, Secretario de la Revista de Economía Mundial, Experto Internacional Invitado del Sistema Económico Latinoamericano y, actualmente, es miembro de Consejo Académico de FLACSO-España.

Recibido: 18/11/2014

Aceptado: 12/12/2014 

CRÍTICA DE LIBROS BOOK REVIEWS 



\title{
HENRI LEFEBVRE LA PRODUCCIÓN DEL ESPACIO \\ MADRID: CAPITÁN SWING, 2013. INTRODUCCIÓN Y TRADUCCIÓN DE EMILIO MARTÍNEZ \\ ISBN: 978-84-941690-5-2
}

\author{
Eva Espinar Ruiz \\ Departamento de Sociología II. \\ Universidad de Alicante, España \\ eva.espinar@ua.es
}

Este libro representa la primera vez que se traduce al castellano la obra $\mathrm{La}$ Production de l'Espace del filósofo Henri Lefebvre (Hagetmau 1901-Navarrenx 1991). El texto fue originalmente publicado en francés en 1974 y constituye una de las obras clave del autor. Simplemente por ello, la presente edición de Capitán Swing será de especial interés para todos aquellos que quieran profundizar en el pensamiento del que ha sido considerado como uno de los filósofos más destacados del siglo XX.

Lefebvre, a través de numerosos libros, artículos y conferencias, llegó a tratar una amplia diversidad de temas, si bien destacan sus aportaciones al pensamiento marxista (de lectura especialmente recomendada es la obra Le matérialisme dialectique de 1939) y a la aplicación de éste al análisis de la sociedad contemporánea. Partiendo de este esquema, y entre las diferentes dimensiones que incorpora en el estudio de la realidad social, ocupa un lugar destacado el espacio urbano. De hecho, será este último uno de los campos de investigación en los que el autor ha ejercicio una mayor influencia, siendo clave en el desarrollo de la tradición crítica en el análisis de las relaciones entre espacio y sociedad.

En concreto, el interés urbano de Lefebvre se desarrolla, fundamentalmente, durante lo que ha venido calificándose como su momento o ciclo urbano, que 
recogería una serie de obras publicadas entre mediados de los años 60 hasta 1974. Es, precisamente, en este último año cuando se publica La producción del espacio, que puede calificarse como la obra cumbre de este periodo. Otros textos publicados durante esta escasa década e igualmente destacables son: $\mathrm{El}$ derecho a la ciudad (1968), De lo rural a lo urbano (1970), La revolución urbana (1970), El pensamiento marxista y la ciudad (1972) y Espacio y política (1973). En estas obras analiza el espacio como proceso social y todas ellas conforman un pensamiento coherente que se articula en torno a una serie de elementos básicos resumidos magníficamente por el traductor de la presente edición:

La ciudad como topos privilegiado de la cotidianidad, de su miseria y de su potencia creativa; la crítica de la racionalidad tecnocrática vehiculada por el funcionalismo de la Carta de Atenas; la significación social y política de la heterotopía y el habitar poético; la ciudad como escenario y objeto de la lucha de clases, objetivo del capital y del Estado, como se observa en esa urbanización "masiva y salvaje" que conquistaba el territorio, sin otra estrategia que no fuera la maximización de los beneficios, con sus implicaciones nocivas sobre la vida y las relaciones sociales (p. 35).

La producción del espacio, que, como comentábamos anteriormente, ha sido calificada como la mayor obra filosófica de Lefebvre y la culminación de su pensamiento urbano, tardó 17 años en ser traducida al inglés (no fue traducida hasta 1991) y la presente edición de Capitán Swing constituye la primera ocasión en que ha sido traducida al castellano. Por tanto, han pasado casi 40 años desde su publicación original en francés. En este sentido cabe destacar la excelente labor de traducción desarrollada por el profesor Emilio Martínez Gutiérrez, que ha sabido captar y conservar el estilo del autor, y su incisiva combinación de teoría y práctica. Igualmente, ha de señalarse la utilidad de los contenidos introductorios que se han incorporado a la obra original y que facilitan notablemente su lectura, contextualización y adecuada interpretación.

De alguna forma, esta última traducción de un texto de Lefebvre debe enmarcarse en un reciente y renovado interés por la figura del autor, que viene a demostrar la actualidad de buena parte de sus planteamientos. Así, en los últimos años se han reeditado algunos de sus principales textos, se han llevado a cabo estudios sobre su figura y pensamiento, así como diferentes publicaciones y congresos. En definitiva, el contexto socioeconómico actual parece haber favorecido la recuperación de los planteamientos del filósofo francés, quien ya encontró continuidad en la geografía crítica anglosajona, fundamentalmente a través de autores como Edward Soja (1989) o David Harvey (2013).

En los contenidos introductorios (tanto en el Prólogo como en la Introducción) se han incorporado algunas pinceladas biográficas sobre Henri 
Lefebvre. Esta información resulta especialmente útil a la hora de interpretar a un autor que siempre buscó unificar pensamiento y práctica, y cuya obra refleja una continua implicación política más allá del ámbito académico. Así, Lefebvre fue miembro durante unos 30 años del Partido Comunista Francés, inspirador de las movilizaciones de mayo del 68, crítico de las transformaciones y grandes proyectos urbanísticos de la Francia de los treinta años gloriosos, y estuvo ligado a diferentes movimientos sociales y luchas ciudadanas. Su obra refleja no sólo esta implicación sino también un talante que convierte sus escritos en textos especialmente sugerentes, heterodoxos y provocativos. Como resume Emilio Martínez en la Introducción "Henri Lefebvre pertenece a ese extraordinario tipo de intelectuales que, pensando el mundo, no olvidan vivir y actuar en él. Lo hizo cierta y radicalmente, con ese entusiasmo que caracterizó su empeño en saber y vivir" (p. 31).

La producción del espacio no es, definitivamente, una obra de lectura cómoda y fácil, como tampoco lo es la complejidad social que el autor pretende analizar. En ella se retoman, amplían y definen los elementos que conforman el pensamiento urbano de Lefebvre. Así, en el primer capítulo del libro, el autor introduce los planteamientos fundamentales, que irá recogiendo en los restantes seis apartados. El principal punto de partida es que la teorización sobre el espacio social no puede desarrollarse de forma independiente de la teorización sobre la sociedad, ya que ambos aspectos están estrechamente relacionados -"El espacio (social) es un producto (social)"- (p. 86). Con esta perspectiva, incorpora la dimensión espacial al materialismo histórico, estrategia que le permite elaborar la historia del espacio social ligada a los diferentes modos de producción.

En definitiva, los cambios desde un modo de producción a otro implican la configuración de un nuevo espacio, y, por tanto, los espacios urbanos modernos son un reflejo del modo de producción dominante en la actualidad. Dicho de otra forma, el espacio no se configura de manera natural, sino que es el producto de unas concretas relaciones políticas, económicas y sociales. Ahora bien, el espacio no únicamente es producto, sino que forma parte del proceso de producción. Es así como, para Lefebvre, existe un desarrollo paralelo entre la hegemonía del capitalismo y la producción del "espacio abstracto" (al que dedica una considerable parte del libro). Al igual que el espacio abstracto, el capitalismo crea homogenización, jerarquización y fragmentación social.

Lefebvre apuesta, decididamente, por el desarrollo de una teoría unitaria sobre el espacio, que incorpore tres momentos: el espacio percibido, el espacio concebido y el espacio vivido. Según el autor, la tendencia a fragmentar el 
espacio está asociada a las divisiones entre las especialidades que se han desarrollado para la explicación y control de la ciudad, y que definen elementos concretos de la misma como su objeto exclusivo de estudio y acción. Esta fragmentación implica barreras que han de ser superadas para la elaboración de una teoría unitaria del espacio que incluya a todos los actores implicados. Para ello apuesta por una tríada conceptual que incluiría: las prácticas espaciales (a las que corresponde el espacio percibido), las representaciones del espacio (relativo al espacio concebido) y los espacios de representación (espacio vivido). El primero es el espacio de la experiencia material; el segundo el de los expertos y planificadores; el tercero sería el espacio de la imaginación y lo simbólico.

Otro de los elementos clave es la diferenciación que el autor desarrolla entre aquellos espacios que son dominados y los que son apropiados. Así, por un lado, la producción del espacio está orientada por la razón industrial y la dominación; mientras que, por otro lado, la apropiación el espacio (el ámbito del habitar) está ligada a "una racionalidad urbana embrionaria que pugna por recuperar el sentido pleno de la obra, del valor de uso" (p. 42). Habitar es transformar el espacio (vivido) en lugar; es una actividad creativa libre. Este enfoque permite a Lefebvre situar, en la propia cotidianidad no alienada, las posibilidades de emancipación de los seres humanos: "¡Cambiar la vida! ¡Cambiar la sociedad! Nada significan estos anhelos sin la producción de un espacio apropiado" (p. 117).

\section{BIBLIOGRAFÍA}

Harvey, D. (2012). Rebel Cities. From the Right to the City to the Urban Revolution. Londres/Nueva York: Verso.

Lefebvre, H. (1939). Le matérialisme dialectique. París: Presse Universitaire de France [traducción castellana: El materialismo dialéctico, Buenos Aires: La Pleyade, 1974].

Lefebvre, H. (1968). Le Droit à la ville. París: Anthropos [traducción castellana: El derecho a la ciudad, Barcelona: Península, 1969].

Lefebvre, H. (1970). Du rural à l'urbain. París: Anthropos [traducción castellana: De lo rural a lo urbano, Barcelona: Península, 1991].

Lefebvre, H. (1970). La Révolution urbaine. París: Gallimard [traducción castellana: La revolución urbana, Madrid: Alianza, 1972].

Lefebvre, H. (1972). La Pensée marxiste et la ville. París/Tournai: Casterman [traducción castellana: El pensamiento marxista y la ciudad, México D.F: Extemporáneos, 1973].

Lefebvre, H. (1973). Espace et politique (Le droit à la ville, II). París: Anthropos [traducción castellana: Espacio y politica, Barcelona: Península, 1976].

Soja, E. (1989). Postmodern Geographies. The reassertion of space in critical social theory. Londres/Nueva York: Verso. 
EVA ESPINAR RUIZ es doctora en Sociología y profesora en el Departamento de Sociología II de la Universidad de Alicante. La mayor parte de su actividad docente e investigadora gira en torno a los Estudios de género, la Sociología urbana y la Sociología de la comunicación. Entre sus últimas publicaciones destacan: «Representaciones de género en la publicidad de alimentos: un análisis de contenido» en Revista Cuestiones de Género (2012); «Riesgos medioambientales en los espacios informativos: análisis cualitativo de la televisión española», en Estudios sobre el mensaje periodístico (2012); "El periodismo de paz como paradigma de comunicación para el cambio social: características, dimensiones y obstáculos» en CIC (2012).

Recibido: 20/09/2014

Aceptado: 28/11/2014 



\title{
EDITED BY JANE L. WOOD AND THERESA A. GANNON CRIME AND CRIME REDUCTION. THE IMPORTANCE OF GROUP PROCESSES
}

2013. EAST SUSSEX, ROUTLEDGE, PP. 206

ISBN 978-184872083-1

\author{
Maximiliano E. Korstanje \\ Department of Economics, \\ University of Palermo, Argentina
}

Over years, many studies have devoted effort in understanding the criminal mind alternating a set of interdisciplinary approaches. However, less attention was given to the influence of peers in criminal acts. The status, abiding rules and other social skills are of paramount importance to understand the attachment of people to crime. As this backdrop, Jane L Wood and Theresa A. Gannon compiled an intriguing book aimed at exploring the connection of social environs, family, social bonds and crime. To the biological basis of criminality proposed by Lombroso and colleagues followed the cultural-related theories, most of them coined in US, a country which was experiencing substantial demographic changes because of the mass-migration from Europe. Today, specialists are discussing that crime would be shaped in the free will of the subject, but would be determined by peer-pressure. Key factors such as selfesteem, status, retaliation and rule-reinforcement should be placed to the lens of scrutiny if social scientists want to expand the current understanding of criminality. Otherwise, Wood and Gannon add, the rich-empirical research as well as the efforts of Government to mitigate the local crime is backfired. This book exhibits a more pungent thesis; many criminals wish to be recognized by their peers. In so doing, crime seems to be in the only instrument to achieve their goals. The societies can be understood through the analysis of their criminals. 
The preliminary section contains four seminal chapters alluding to the needs of improving the conceptual framework whereby specialists give their diagnosis. G. Tendayi Viki \& D. Abrams open the discussion presenting a set of empirical-rich studies to find how group-affiliation needs and social identity may converge in criminal acts. Under some conditions, lay-people compare their own behavior with out-group members so that they adjust their own expectances to group-demands. What seems to be important to discuss is to what an extent these expectances may lead to commit a crime. Criminals look the approval of peers in their behavior beyond the ethic fields. To understand this it is necessary to examine how the rules of a group evolved. Further, it is clear how some devaluated-identities are prone to accept discourses that encourage the infra-humanization of others. These tactics not only alleviates the anxiety experienced after the crime, but also re-frames the prize/punishment system inside the group. What for ones is a moral disaster for others would be a prerequisite to gain further status or other underlying privileges. In this chapter, authors alert that two types of different des-humanization techniques surface, animalistic and mechanistic. While the former signals to the denial of human-based attributes in view of the potential punishments, the latter refers to views that presents human as machine-like. In some respects, these techniques are intended to reinforce the group-values.

Similarly to the previous discussed work, Wood J and Alleyne, in the second chapter, give an upshot on the gang-world and their ways of recruiting new members. Gangs are often moved by social skills, circumscribed to a specific soil. Steeped in the belief that gang-recruitment recognizes the need of teenagers to cause a good impression in other peers. Social determined by many factors, crimes are resulted from social learning and psychological needs for love. The sentiment of admiration some criminals exert over these youth not only bespeaks of the role played by emotions in crime, but also re-considers to what an extent gang-membership, encouraged by cultural entertainment industries as cinema, may become in a fertile source of research in next years. Violence and crime cannot be reduced, unless experts understand the complexity of the problem.

This argument begs an interesting question, what is the origin of violence?

Whenever any person, no matter the cultural environment, is exposed to unended episodes of violence in its childhood, once grown will develop hostile attitudes to others. This type of sympathy for violence is disposed by the subject when their ego is psychologically undermined. In respect to this, it is important not to loose the sight that psychological frustration not only engenders violence but also gang criminal-inclined activity. 
Any gang-membership offers certain degree of protection and social support combined by power enhancement and social recognition. In combination, both factors (power and recognition) facilitate the things for the advance of displaced-violence. This is exactly the point of research that E. Vasquez, B. Lickel and K Hennigan studied in their career. Displaced aggression is defined in terms of the acts of violence resulted from the fear of retaliation and ruminating, occurred when who initially provoked cannot re-direct their response to the source of the provocation. Now in US and England one of the most troubling aspects for inter-gang violence is posed by the displaced-aggression. Police should receive more psychological training in ruminating thinking to reduce the violence among gang-bangs.

The archetype of masculinity plays a pivotal role not only in the proliferation of violence but also in sexual offending. L. Harkins \& L. Dixon convincingly argues that sexual abuse unfortunately takes a common place in industrial societies. In UK for instance, $42 \%$ of rapes were acted by more than one person, or Gangs, preferably males in urban sprawl. This condition contrasts with those abuse committed by one person, which are contextualized in secrecy or in situations where police is absence.

The second section is based on the formation and functioning of terrorist network. The specialists who collaborate with this section are educated in terrorist-related research. In opposite to the thesis that points out terrorists suffer severe psychological disorders that leads to commit suicidal attacks against innocents, a theory originally portrayed by the media, Wilson, Bradford $\&$ Lemanski proposed a fresh interesting model why terrorists do what they often do. In Middle East, many teenagers accept to partake of radicalized groups following their friends or looking for social recognition. In other cases, their mothers and brothers earn a monetary income improving the existent conditions of life. Similarly to Gang-bang recruitments, terrorists join to fundamentalist networks in quest of approval and economic benefits.

Last but not least, the ultimate section places under the lens of scrutiny to what an extent a criminal may be or not socialized or rehabilitated. The recovery of criminals depends on the imaginary boundaries between the nature of law and criminal justice theory. Some inmates are subject to efficient psychological therapies to change the lines of their former behavior but without any result. The rate of reinsidency has risen in last years in almost all developed countries. The prison system not only is facing serious problems to recover criminals, but it encourages inmates to plan crimes. The efficiency in these psychological therapies seems to be determined by the degree of closing with the hermeneutical past. Jo, Thakker and W. Marshall give insight into de 
challenge and problems of the current criminal justice institutions in Europe and US. Because of time and space a full review of all chapters is almost impossible.

Of course, any book formed by chapters which have been written by diverse authors, face to the problems of readability. Alternating with a variety of styles and methods, it is very hard to orchestrate a main thesis to be discussed on the role played by social skills in crime-inclination behaviors. Quite aside from that, this book exhibits a new original response, recommended to studentships, scholars and practitioners, respecting to the crime-related issues. At a first glance, one idea anyway persists: group-membership should be seriously taken in mind in order for state-specialists may implement the necessary policies and plans in making streets safer.

MAXIMILIANO E. KORSTANJE es Sociólogo y especialista en el estudio del temor desde varias perspectivas académicas. En los últimos años, su interés estuvo abocado al estudio del 11 de septiembre y su impacto en el turismo, el mal, la movilidad, el cine, la tortura, violación a los derechos humanos, y la economía entre otros temas. Con más de 400 trabajos publicados en todo el mundo y 13 libros, el autor forma parte de la Philosophical Society of England, Newcastle y la International Society for Philosophers, Sheffield, Reino Unido. Trabaja como editor y miembro de comité editorial de muchas revistas dedicadas al estudio del riesgo y la violencia deportiva, entre las que se destacan International Journal of Disaster Resilience in the Built Environment (Universidad de Salford, Reino Unido) y Int. Journal of Emergency Service Information (Universidad de Nottingham Trent Reino Unido). En el 2012 gana el premio en calidad y excelencia por su labor como "outstanding reviewer" que otorga la cadena británica Emerald Publishing, Reino Unido.

Recibido: 15/12/2013

Aceptado: 07/04/2014 


\section{NORMAS EDITORIALES E INSTRUCCIONES PARA COLABORACIONES}

A continuación se ofrece un resumen de las normas editoriales e instrucciones para colaboraciones. Se recomienda consultar la última versión disponible en la dirección web.ua.es/revista-obets Instrucciones para el envío de originales

1. OBETS. Revista de Ciencias Sociales tiene como objetivo la difusión de estudios de naturaleza académica que permitan un mejor conocimiento de la sociedad contemporánea. En este sentido

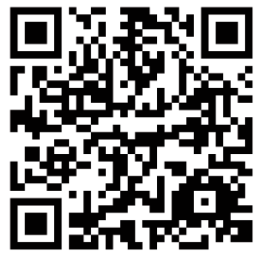
está abierta a la publicación de resultados de investigación empírica, metodológica o teórica de ámbito nacional e internacional, en un amplio abanico de temas inscritos en el ámbito de la Sociología y Ciencias Sociales, como estudios de opinión pública, metodología, demografía, estructura y cambio social, ciencia política, teoría sociológica, antropología o psicología social. Se dará prioridad a trabajos que comuniquen resultados de investigaciones académicas originales y que observen la estructura IMRyDC+B (introducción, metodología, resultados y discusión, conclusiones, y bibliografía actualizada).

2. Los trabajos, que podrán estar escritos en español, inglés, portugués o valenciano/ catalán deberán ser remitidos en formato digital, como archivo adjunto en formato .rtf o .doc a la dirección de correo electrónico: revistaobets@ua.es

3. Los meses de edición son julio y enero, y en cada edición se aceptan artículos que han sido positivamente evaluados al menos durante el mes anterior al de edición.

4. La extensión de los artículos que se remitan a la revista tendrán una extensión no superior a 25 páginas con el formato especificado en el punto 5 . Las notas de investigación (informe de hallazgos, aportaciones, etc.) tendrán una extensión máxima de 15 páginas en dicho formato. Las recensiones o críticas de libro no pueden superar las 5 páginas con el formato especificado en el punto 5 , y debe especificarse en ellas el autor, el título, la editorial, el lugar y la fecha de publicación de la obra recensionada, así como el nombre, los apellidos y la dirección de contacto del autor de la crítica. Sólo se aceptarán recensiones de libros publicados en los últimos 3 años.

5. Los trabajos se enviarán en el siguiente formato

1. Tipo de letra Times New Roman, tamaño 12. Espacio sencillo, tamaño de página DIN A4.

2. Los diferentes apartados irán en negrita, en mayúsculas sólo la primera letra y con el mismo tipo y tamaño de fuente que el cuerpo del texto.

3. Los párrafos irán sangrados en la primera línea.

4. Las palabras en idioma diferente al original del trabajo deben ir en cursiva.

5. Las citas textuales deben ir entrecomilladas cuando sean inferiores a tres líneas. Si tienen más de 3 líneas irán sin entrecomillar y sangradas por el margen izquierdo, indicando en todo caso entre paréntesis el apellido del autor o autores del texto, el año de publicación y la página. Por ejemplo: (Ramírez, 2009: 10). Si hay más de dos autores pero menos de seis, se citarán todos ellos la primera vez y las veces siguientes se usará la expresión "et al.". Si son más de seis autores, se usará "et al." desde la primera mención. 
6. Para la bibliografía, al final del trabajo, deberá utilizarse el estilo APA (American Psychological Association). A continuación se ofrecen algunos ejemplos de formato:

\section{Libros y capítulos:}

Anwar, M. (1979). The Myth of Return: Pakistanis in Great Britain. London: Heinemann.

Esser, H. (2003). "What substance is there to the term 'Leitkultur'?". En R. Cuperus, K. A. Duffek y J. Kandel (Eds.), The challenge of diversity. European social democracy facing migration, integration and multiculturalism. Innsbrück/Vienna: Studienverlag, 47-58.

\section{Revistas:}

Berry, J. W. (1970). "Marginality, stress, and ethnic identification in an acculturated Aboriginal community". Journal of Cross-Cultural Psychology, 1, 17-22.

Para documentos online, debe indicarse la fecha de consulta.

Cuando se incluyan varias referencias de un mismo autor/a, es necesario indicar el nombre del autor en cada título y no usar guiones/rayas.

7. Las imágenes y diagramas se incluirán en el texto. En función de la resolución y calidad de dichas imágenes, la redacción puede solicitar el envío posterior de los archivos de imagen originales como condición para su publicación.

6. Los artículos han de ser inéditos. Dicha condición debe indicarse en el envío (formato disponible en la web de la revista).

7. Las propuestas de contribuciones enviadas a la revista OBETS no pueden ser enviadas simultáneamente a ninguna otra publicación.

8. Todo original se somete al arbitraje por pares académicos. Con la finalidad de garantizar la imparcialidad en la selección de los artículos para publicar, se observa el anonimato tanto de autores como de evaluadores. Para proteger este anonimato, se respetará el siguiente formato en los trabajos enviados:

1. Una primera página en la que constará, únicamente, el título (en mayúsculas la primera letra y el resto en minúsculas), el nombre y apellidos de los autores, el centro de trabajo, dirección postal y correo electrónico, y teléfono y fax en su caso.

2. Una segunda página que contenga, nuevamente, el título, un resumen de no más de 100 palabras, y entre 4 y 8 palabras clave, separadas por punto y coma. Tanto el título como el resumen y las palabras clave deben aparecer en la lengua del trabajo y en inglés.

3. El texto del trabajo en la página tercera y siguientes.

Proceso de selección de originales

1. Las obras recibidas pasarán por el siguiente proceso en el que cada paso requiere la superación del anterior:

1. Notificación de acuse de recibo.

2. Clasificación temática del artículo (UNESCO). Al menos dos miembros del Consejo Editorial comprobarán que el trabajo cumpla los estándares editoria- 
les de un texto académico en el ámbito temático de la revista. Si hay al menos una valoración positiva, el trabajo pasará a la siguiente fase, y en caso contrario será notificado de manera justificada a los autores.

3. Revisión de aspectos formales y estilos, con notificación y devolución al autor en caso de existir errores.

4. Comprobación de la anonimización del artículo.

5. Revisión por dos personas evaluadoras externas, de acuerdo con criterios de calidad científica $^{1}$. En caso necesario por juicio dispar el equipo editorial solicita la contribución de un tercer evaluador/a. El formulario de evaluación está disponible en la web de la revista e incluye:

1. Evaluación de la originalidad y contribución científica.

2. Evaluación de la claridad y coherencia de objetivos, hipótesis, metodologías y conclusiones del trabajo.

3. Evaluación de la pertinencia y actualización de la bibliografía.

4. Evaluación de los aspectos formales (redacción, citas, organización del texto, tablas, gráficos, etc.).

5. Recomendación final sobre el trabajo y, en su caso, sugerencias de modificación o razones para no publicación.

6. Envío al autor del informe de revisión con la decisión correspondiente (aceptación, aceptación pendiente de rectificaciones, rechazo) de forma motivada en un plazo máximo de 6 meses desde la recepción del artículo.

2. En el caso de que un artículo sea aceptado para su publicación, se solicitará al autor/a la firma de un documento de cesión de derechos a fin de que sea publicado en la revista bajo licencia Creative Commons Reconocimiento 3.0 España (CC BY 3.0). De igual modo, las pruebas de imprenta serán enviadas al autor/a en formato PDF cuando estén disponibles y deberán ser devueltas a la secretaría de la revista en el plazo máximo de una semana, con las oportunas correcciones.

3. El proceso de evaluación suele tomar unos 4-6 meses. Al tratarse de una revista semestral, una vez aceptado un artículo la publicación final puede llevar por lo general hasta 6 meses más.

4. Para cualquier duda o aclaración, puede llamarse al teléfono 965909615 (Mª Carmen Albert), de $10 \mathrm{~h}$ a 14 h, de lunes a viernes, o bien mandar un correo electrónico a la siguiente dirección: revistaobets@ua.es

\section{Principios éticos de publicación}

La publicación de artículos en una revista con revisión por pares es un reflejo directo de la calidad del trabajo de sus autores, y del compromiso y cualificación de los investigadores que actúan como revisores. Por ello OBETS. Revista de Ciencias Sociales es una publicación comprometida con los principios éticos de la actividad científica en los siguientes términos:

\footnotetext{
${ }^{1}$ Centro de Información y Documentación Científica (CINDOC) CSIC. Madrid, 2001.
} 


\section{Publicación y autoría}

Todos los artículos deben incluir un listado de referencias, así como indicar si han recibido apoyo económico. Los trabajos deben estar libres de plagio o fraude científico, cuyos supuestos ${ }^{2}$ se enumeran de manera no exhaustiva a continuación:

- Plagio: copia literal sin entrecomillar y citar la fuente; copia sustancial (materiales de investigación, procesos, tablas...); parafrasear o reproducir ideas sin citar la fuente y/o cambiando el significado original; reutilizar y enviar textos propios ya publicados sin indicar la fuente y el parafraseo abusivo incluso citando la fuente.

- Fraude científico: no reconocimiento de todos los investigadores/as participantes en la elaboración del trabajo, el envío simultáneo a varias publicaciones, la división de un trabajo en partes diferentes que comparten las mismas hipótesis, población y métodos, así como la utilización de datos falsos o no probados. Finalmente, los autores/as deben declarar a la revista los potenciales conflictos de interés cuando envían un trabajo.

\section{Responsabilidad de los autores}

- El envío de trabajos a OBETS supone la lectura y aceptación de las normas editoriales y de publicación de la revista, incluida la participación en un proceso anónimo de evaluación por pares.

- Todos los autores que firman un trabajo deben haber contribuido de manera significativa a su elaboración y deben estar de acuerdo con el resultado final y con el envío del trabajo para su evaluación.

- Los trabajos deben reconocer a todos los autores que han participado en su elaboración.

- Los datos utilizados en el artículo deben ser reales y auténticos.

- Los autores asumen la obligación de corregir y/o retractarse ante posibles errores detectados posteriormente.

- Los artículos han de ser inéditos y no pueden ser enviados simultáneamente a ninguna otra publicación.

\section{Proceso de revisión}

Todos los artículos enviados a la revista se someten a un proceso de revisión por pares con las siguientes características:

- La selección de los revisores se realiza en función de normas y principios previos basados tanto en su cualificación como en la calidad de su producción científica.

- El proceso de revisión será totalmente anónimo tanto para los autores como para los revisores. Los artículos y sus revisiones serán tratados confidencialmente.

- Los revisores consideran, entre sus criterios de evaluación, el respeto a los principios éticos esenciales en la investigación científica.

- Los juicios expresados en las revisiones deben ser objetivos.

- Tanto autores como revisores deben revelar las relaciones y fuentes de financiación que puedan generar potenciales conflictos de intereses.

\footnotetext{
${ }^{2}$ Fuente: http://www.ethics.elsevier.com/
} 


\section{Responsabilidades de los editores}

- El equipo editorial tiene la responsabilidad y autoridad para aceptar o rechazar un artículo basándose en las revisiones.

- El equipo editorial revelará en su caso las relaciones o fuentes de financiación que puedan ser potencialmente consideradas como conflictos de intereses respecto a los artículos que rechaza o acepta.

- Sólo se aceptarán los artículos en los que existe una evidencia cierta sobre el cumplimiento de las normas editoriales

- El Consejo de Redacción de OBETS. Revista de Ciencias Sociales se reserva el derecho de retirar cualquier trabajo recibido, aceptado o ya publicado en caso de constatarse plagio, falsificación o publicación duplicada, así como los diversos supuestos de fraude científico anteriormente enumerados. Del mismo modo, promoverá la publicación de correcciones o retractaciones frente a errores detectados.

- El equipo editorial se compromete a preservar el anonimato de los revisores de manera que nunca puedan asociarse con los artículos revisados.

\section{Cuestiones éticas de publicación}

El equipo editorial se compromete a:

- Vigilar y preservar los principios éticos de publicación

- Mantener la integridad del expediente académico

- Evitar la publicación de material plagiado o elaborado de manera fraudulenta

- Estar abierto a la publicación de correcciones, clarificaciones, retractaciones y disculpas siempre que sea necesario

- Ofrecer apoyo en el proceso de retractación de artículos

- Realizar todas las acciones necesarias para cumplir los estándares de compromiso intelectual y ético

\section{Aviso legal}

A efectos de lo estipulado en los artículos 138-143 de la Ley de Propiedad Intelectual, la publicación de un trabajo que atente contra dichos derechos será responsabilidad del autor/a. El equipo editorial de OBETS. Revista de Ciencias Sociales no se hace responsable, en ningún caso, de la credibilidad y autenticidad de los trabajos. Del mismo modo, las opiniones y hechos expresados en cada artículo son de exclusiva responsabilidad de sus autores/as y OBETS. Revista de Ciencias Sociales no se identifica necesariamente con ellos. 



\section{EDITORIAL STANDARDS AND INSTRUCTIONS FOR CONTRIBUTORS}

Summary of guidelines for submitting manuscripts. Please check the latest version in http://web.ua.es/en/revista-obets

\section{Guidelines for submitting manuscripts}

1. The journal OBETS. Revista de Ciencias Sociales (OBETS. Journal of Social Sciences) aims at the dissemination of academic nature studies that allow a better understanding of contemporary society. In this sense it is open to the publication of results of empi-

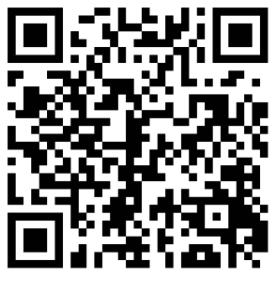
rical, methodological or theoretical research at national and international level, in a wide range of subjects enrolled in the field of sociology and social sciences, as public opinion surveys, methodology, demographics, structure and social change, political science, sociological theory, anthropology or social psychology. Priority will be given to works that communicate results of original academic research and to use the IMR\&DC+B structure (introduction, methods, results and discussion, conclusions, and updated bibliography).

2. Papers may be written in English, Italian, Portuguese, Spanish or Valencian/Catalan. They must be submitted in digital format as an attachment, in .Rtf or .Doc format to the email address: revistaobets@ua.es

3. The months of editing are July and January. For each edition are accepted only articles that have been positively evaluated at least during the month prior to the edit month.

4. The length of papers should not exceed 25 pages using the layout specified in point 5. The research notes (report on findings, contributions, etc.) should not exceed 15 pages in this layout. The book reviews cannot exceed 5 pages using the layout specified in point 5 , and should include the author, title, publisher, place and date of publication of the book. The full name and address of Contact of the author of the critique must also be included. We only accept reviews of books published in the last 3 years.

5. The works will be sent in the following format

1. Font Times New Roman, font size 12. Single space, page size A4.

2. Section headers in bold. Capitalize only the first letter, and with the same type and font size that the text body.

3. Paragraphs indented on the first line.

4. The words in a language other than the original work in italics.

5. Textual citations must be quoted if they are less than three lines. If you have more than three lines shall be indented by the left margin without quotation marks. In any case, indicate in parentheses the surname of the author or authors of the text, the year of publication and page. For example: (Ramírez, 2009: 10). If there are more than two authors but less than six, all of them will be cited the first time and the time following use the expression "et al.". If more than six authors, use "et al." from the first mention. 
6. The bibliography at the end of the work shall use APA style (American Psychological Association). Please find below some examples of format:

\section{Books and chapters:}

Anwar, M. (1979). The Myth of Return: Pakistanis in Great Britain. London: Heinemann.

Esser, H. (2003). "What Is There Substance to the term 'Leitkultur'?". In R. Cuperus, KA Duffek and J. Kandel (Eds.), The challenge of diversity. European Social Democracy Facing Migration, integration and multiculturalism. Innsbruck / Vienna: Studienverlag, 47-58.

\section{Journals:}

Berry, J. W. (1970). "Marginality, stress, and ethnic identification in an acculturated Aboriginal community". Journal of Cross-Cultural Psychology, 1, 17-22.

For documents online, you must indicate the accessed date.

When several references of a same author are included, it is necessary to indicate the name of the author in each title instead of using hyphens/dashes.

7. Pictures and diagrams should be included in the text. Depending on the resolution and quality of the images, the Journal can ask for the original image files as a condition for the publication.

6. Articles must be unpublished. That condition should be declared in the sending (template available on the website of the journal)

7. Proposals for contributions sent to the OBETS journal may not be sent simultaneously to any other publication.

8. All original is submitted to arbitration by academic peers. In order to ensure impartiality in the selection of articles to publish, the journal observes the anonymity of authors and evaluators. To protect the anonymity, please respect the following format in contributions:

1. A first page that contain only the title (capitalize the first letter and the rest in lower case), the name of the authors, the workplace, and email address, telephone and fax.

2. A second page containing, again, the title (but not the name of author/s), an abstract of no more than 100 words, and between 4 and 8 keywords, separated by semi-coma. Title, abstract and keywords should appear in the original language and in English.

3. The text of the work will follow in the third and following pages.

\section{Selection process of manuscripts}

1. The works received will go through the following process in which each step requires overcoming previous

\section{Acknowledgement Notice}

2. Subject classification of the article (UNESCO). At least two members of the Editorial Board will check the compliance of the article with editorial standards of an academic text in the subject area of the journal. If there is at 
least a positive assessment, the article proceeds to the next phase; otherwise it will be justifiably notified to authors.

3. Review of formal aspects and styles, with notice and return to the author in case of errors.

4. Verification of the anonymization of the article

5. Review by two external evaluators, according to scientific quality criteria ${ }^{1}$. The evaluation form (available on the website of the journal) includes:

1. Evaluation of the originality and scientific contribution.

2. Evaluation of the clarity and consistency of objectives, hypothesis, methodologies and conclusions.

3. Evaluation of the adequacy and updating of the bibliography.

4. Evaluation of the formal aspects (writing style, quotes, text organization, Tables, graphics, etc).

5. Final recommendation on the work and, where appropriate, suggestions for change or reasons for non-publication.

6. The author(s) will be notified with the relevant decision (acceptance, acceptance pending revisions, reject) on a reasoned way within a maximum period of 6 months.

2. When an article is accepted for publication, the author will be asked to sign a transfer of rights document in order to allow the journal to publish the article under a Creative Commons Attribution 3.0 Spain license (CC BY 3.0). Similarly, proofs will be sent to the author in PDF format when they are available and they must be returned to the secretariat of the journal within one week, with appropriate corrections.

3. The evaluation process is expected to last about 4-6 months. Since Obets Journal is semmianual, the final publication of the article once accepted usually can take up to 6 more months.

4. For any questions or doubts, please send an email to the following address: revistaobets@ua.es

\section{Publication ethics and malpractice statement}

The publication of articles in a peer-review journal is a direct reflection of the quality of the work of their authors, and the commitment and qualifications of the researchers who act as reviewers. Therefore OBETS. Revista de Ciencias Sociales is a publication committed to the ethical principles of scientific activity in the following terms:

\section{Publication and authorship}

All manuscripts must include a list of references, and indicate whether they have received financial support. Works must be free of plagiarism or scientific fraud. Illustrative cases ${ }^{2}$ of plagiarism and scientific fraud can be consulted in a non-exhaustive list below:

${ }^{1}$ Centre for Scientific Information and Documentation (CINDOC) CSIC. Madrid, 2001.

2 Source: http://www.ethics.elsevier.com/ 
- Plagiarism: literal copy without quoting and referencing the source; substantial copying (research materials, processes, tables...); paraphrasing or reproducing ideas without citing the source and/or changing the original meaning; text-recycling (reusing a published own text) without indicating the source, and abusive paraphrasing even quoting the source.

- Scientific fraud: no recognition of all the participating researchers in the study, simultaneous submission to several publications, the division of a work in different parts ('slices') that share the same hypotheses, population and methods, as well as the use of false or unproven data. Finally, the authors should disclose potential conflicts of interest to the journal when a manuscript is sent.

\section{Responsibility of the authors}

- The manuscripts submission to OBETS involves reading and acceptance of the journal publishing guidelines, including participation in an anonymous peerreview process.

- All authors signing a work must have contributed significantly to its development and must agree both with the end result and with the manuscript submission for evaluation.

- Manuscripts must acknowledge all authors who have participated in their elaboration.

- Data used in the article must be real and authentic

- The authors assume the obligation to retract/correct when possible errors are later detected.

- Articles must be original and cannot be sent simultaneously to any other publication.

\section{Review Process}

All articles submitted to the journal are subjected to a peer review process with the following characteristics:

- The selection of reviewers is done according to rules and principles based on both their qualification and the quality of their scientific production.

- The review process will be totally anonymous both for authors and for reviewers. Manuscripts and reviews will be treated confidentially.

- Reviewers will take into account for their evaluation criteria the respect for the ethical principles that are essential in scientific research.

- The judgments expressed in the reviews should be objective.

- Authors and reviewers should disclose all relationships and funding sources that could generate potential conflicts of interest.

\section{Responsibilities of Editors}

- The editorial board has the responsibility and authority to accept or reject a manuscript based on the peer reviews.

- The editorial board will reveal any relationships or funding sources that could potentially be considered conflicts of interest regarding the rejection or the acceptance of manuscripts.

- The journal only accepts manuscripts when reasonably certain of compliance with editorial standards. 
- The Editorial Team reserves the right to remove any received, accepted or already published work where plagiarism, falsification, duplicate publication or scientific fraud is found. Similarly, it will encourage the publication of retractions or corrections to errors detected.

- The editorial team is committed to preserve the anonymity of the reviewers so that they can never be associated with the reviewed manuscripts.

\section{Publishing ethical Issues}

The editorial board is committed to:

- Monitoring and maintaining the publishing ethics

- Maintaining the integrity of the academic record

- Avoid publishing plagiarized or fraudulently prepared material

- Be willing to publish corrections, clarifications, retractions and apologies when needed

- Provide support in the process of retracting articles

- Perform all actions required to meet the standards of intellectual and ethical commitment

\section{Disclaimer}

Regarding the provisions in articles 138-143 of the Spanish Law on Intellectual Property, the publication of a work prejudicial to those rights shall be the responsibility of the author. The editorial team of OBETS. Revista de Ciencias Sociales is not responsible, in any case, for the credibility and authenticity of the works. In the same way, the opinions and facts expressed in each article are the sole responsibility of the authors and OBETS. Revista de Ciencias Sociales does not necessarily agree with them. 
